\title{
Ulrike Kahlenborn
}

\section{Goethes Lyrik \\ in russischer Übersetzung}

\section{A. Žukovskij und F. I. Tjutčev als bedeutendste Goethe-Übersetzer der russischen Romantik}

Verlag Otto Sagner München · Berlin · Washington D.C.

Digitalisiert im Rahmen der Kooperation mit dem DFG-Projekt „Digi20“

der Bayerischen Staatsbibliothek, München. OCR-Bearbeitung und Erstellung des eBooks durch den Verlag Otto Sagner:

http://verlag.kubon-sagner.de

() bei Verlag Otto Sagner. Eine Verwertung oder Weitergabe der Texte und Abbildungen, insbesondere durch Vervielfältigung, ist ohne vorherige schriftliche Genehmigung des Verlages unzulässig. 


\title{
SLAVISTISCHE BEITRÄGE
}

\author{
BEGRÜNDET VON \\ ALOIS SCHMAUS \\ HERAUSGEGEBEN VON
}

JOHANNES HOLTHUSEN † - HEINRICH KUNSTMANN

PETER REHDER - JOSEF SCHRENK

REDAKTION

PETER REHDER

Band 185

\section{VERLAG OTTO SAGNER \\ MÜNCHEN}




\section{ULRIKE KAHLENBORN}

GOETHES LYRIK IN RUSSISCHER ÜBERSETZUNG V. A. Žukovskij und F. I. TjutCev als bedeutendste Goethe-Übersetzer der russischen Romantik

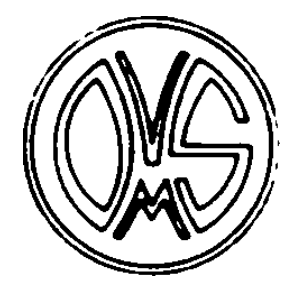

VERLAG OTTO SAGNER • MÜNCHEN 1985 

Murchen

ISBN 3-87690-312-2

(C) Verlag Otto Sagner, München 198: Abteilung der Firma Kubon \& Sagner, München Druck: D. Gräbner, Altendorf 
Vorwort

Die vorliegende Arbeit wurde im Herbst 1984 von der Philosophischen Fakultät der Westfälischen wilhelms-Universität Münster als Dissertation angenommen.

Sie basiert auf einer im Goethe-Jahr 1982 verfaßten Staatsexamensarbeit, zu der ich durch die Teilnahme an einem von Herrn Prof. Or. Hubert Rösel geleiteten Seminar uber "Goethe und die Welt der Slaven" angeregt wurde.

Die Fertigsteliung der Untersuchung wurde durch ein sechsmonatiges stipendium des DAAD gefördert, das mir den notwendigen forschungsaufenthalt in wien ermöglichte.

Mit großer Dankbarkeit denke ich an das wonlwollende Interesse und die großzügige finanzielle Unterstutzung durch Eltern und Verwandte. Onne inre Hilfe hätte ich diese Arbeit nicht schreiben können.

An dieser stelle sei auch Herrn Prof. Or. Friedrich Scholz für die Übernahme der Zweitkorrektur gedankt.

Besonders herzlich bedanke ich mich bei Herrn Prof. Or. Hubert Rösel für seine freundiche Unterstützung. An seine persönliche Betreuung und menschliche Anteilnahme während des studiums werde ich mich immer gern erinnern. 
res

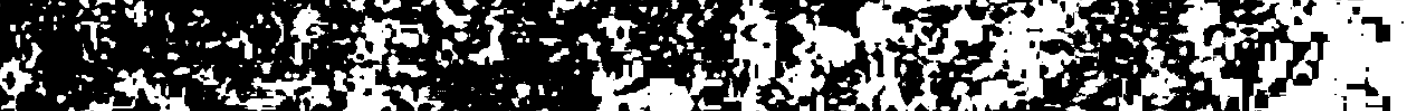
and

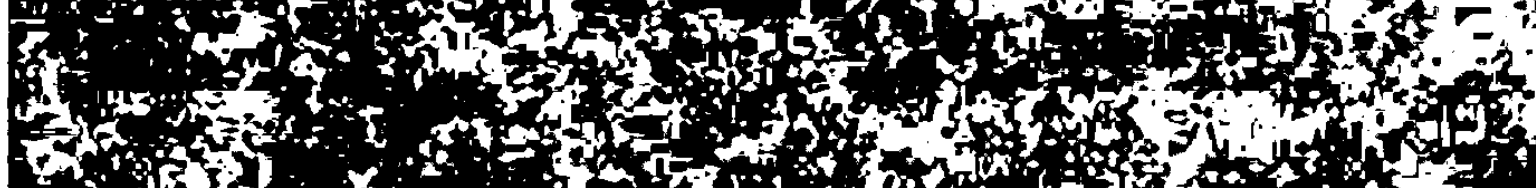

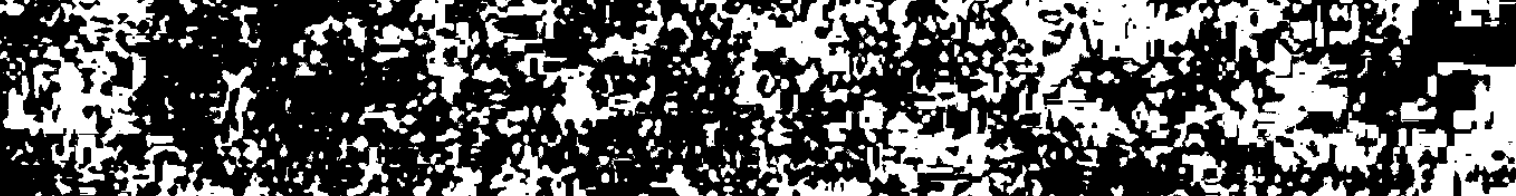

An i)

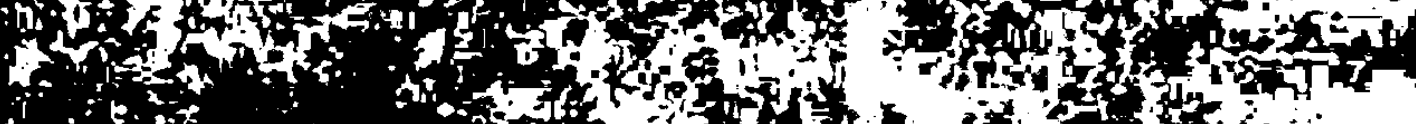
a

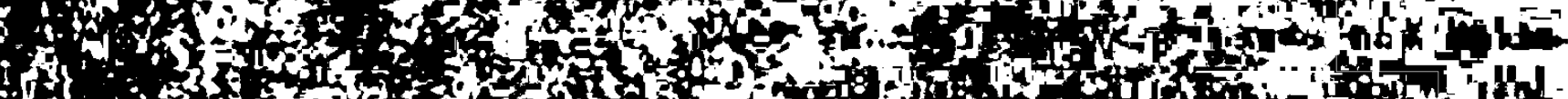

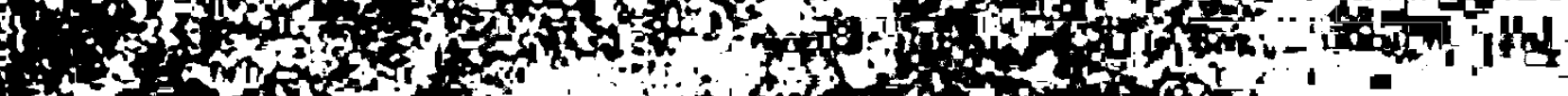
ton

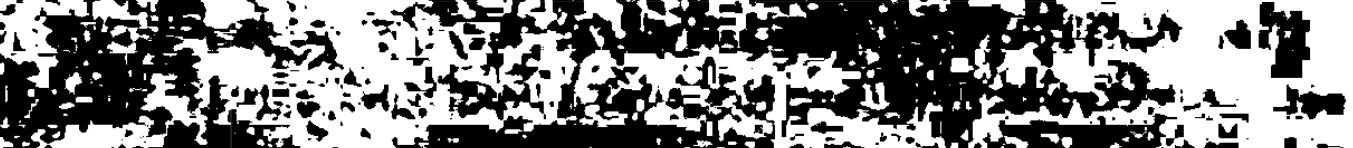

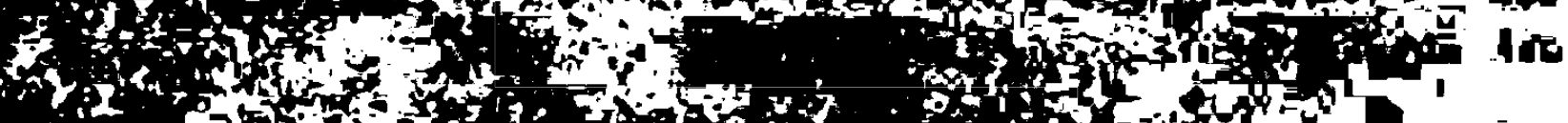

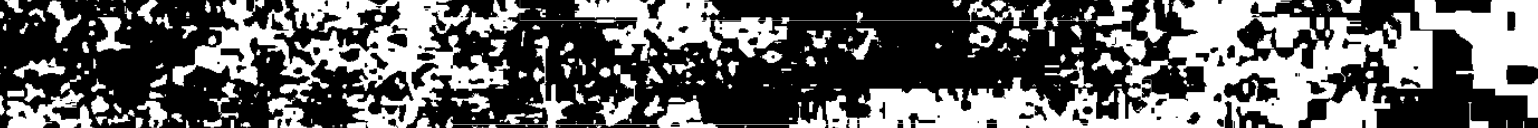
6. 2. 1 o

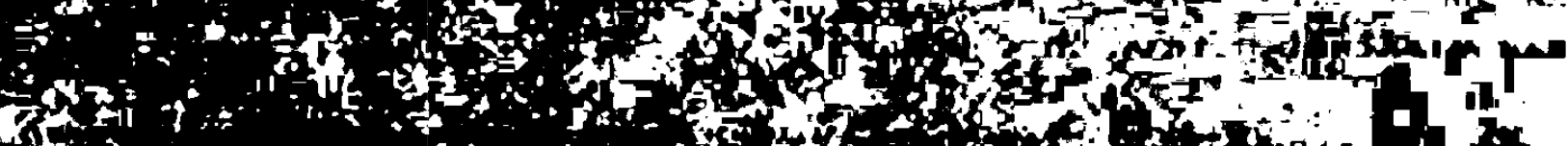
6.t.

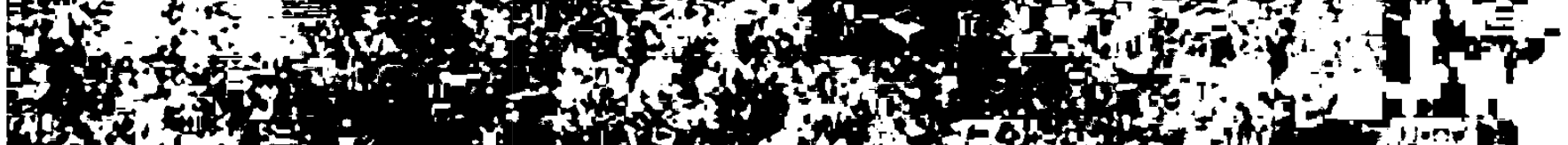

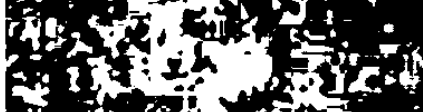

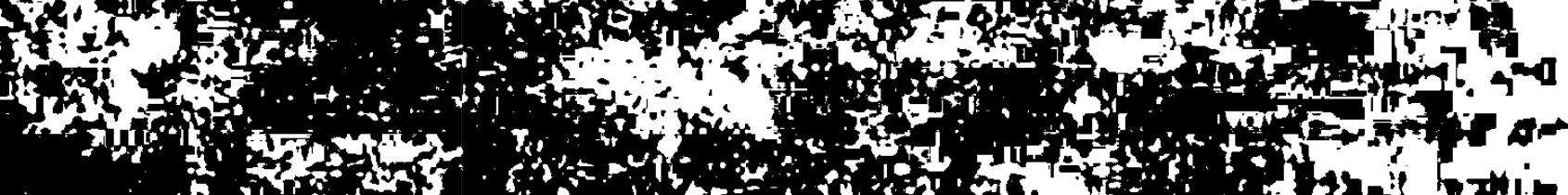

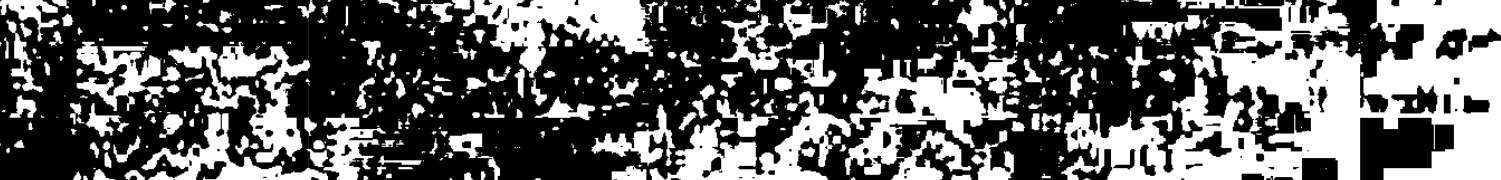
1

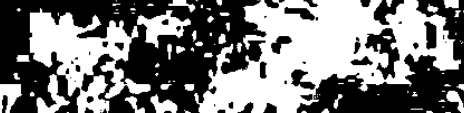

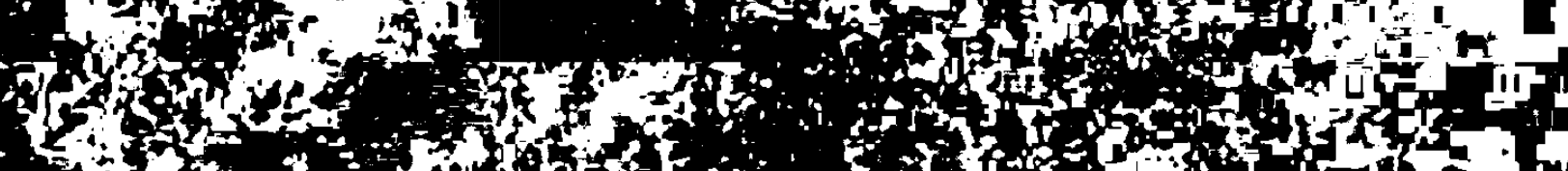

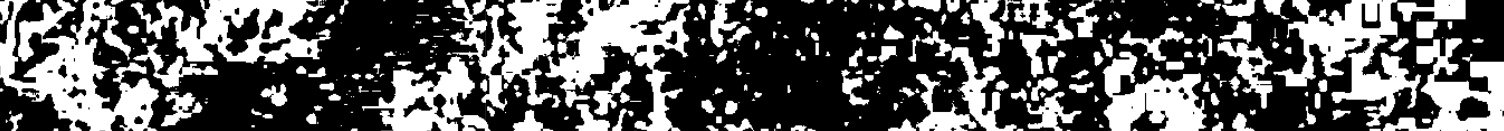

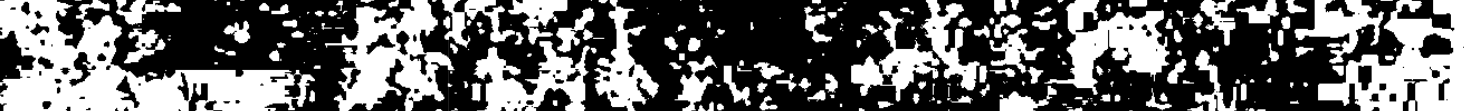
6 (2) (6)

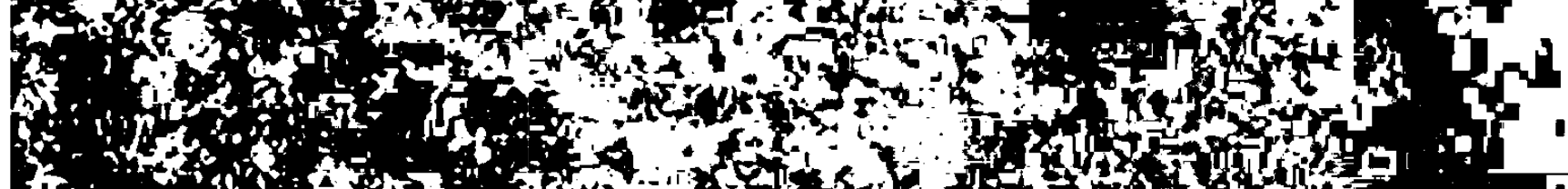
Afor 
1. Problemstellung und Abgrenzung

II. Žukovskij und TjutČev als bedeutendste Goethe-übersetzer der russischen Romantik

1. Grundsätzliches zur Romantik in RuBland 6

1.1. Neve Ansätze der Romantikforschung 6

1.2. Žukovakij und TjutZev als romantische Dichter 8

1.2.1. Zukovekij - ein Dichter an der Schwelle des romantischen Zeitalters

1.2.2. Tjutčev - der Romantiker zwischen Klassizismus und Symboliemus

2. Literarische Verbindungen zwischen RuBland und Deutschland

2.1. Goethe in RuBland des 19. Jahrhunderts

2.2. Beziehungen Žukovekijs und TjutŽevs zu Deutschland und zu Goethe

2.2.1. Zukovskijs Kontakte zur deutschen Kultur

2.2.1.1. Die "Dorpater Jahre" des Dichters 43

2.2.1.2. Žukovakijs Besuche bel Goethe 46

2.2.2. TJuť̌er und Deutschland

2.2.2.1. TjutCovs Leben in Deutechland. Ein biographischer AbriB

2.2.2.2. Zur geistigen Verwandtschaft zwischen Tjutcev und Goethe

66

2.2.2.3. 'Na dreve Čelovécestva vysokomn. TJutčevs Nachrufgedicht auf Goethe 
3. Fremdsprachige Dichtung in Übersetzung Zukovskijs und TjutZevs

3.1. Žukovskij, der wegbereiter westlicher Dichtung in Rußland

3.1.1. Übersetzungen als wesentlicher Bestandteil des dichterischen Werks

82

3.1.2. Zukovskijs Entwicklung als Goethe-übersetzer

85

3.1.2.1. Die Hinwendung zu Goethes Werken 85

3.1.2.2. Zukovskijs schöpferische Phase als Goethe-Übersetzer

88

3.1.2.3. Zunehmende Entfremoung von Goethe 90

3.2. TjutCev als Übersetzer $\quad 91$

3.2.1. TjutCevs Übersetzungen frendsprachiger Lyrik 91

3.2.2. Überblick über TjutCevs Goethe-Übersetzungen 93

III. Analyse der von Žukovskij und TjutŽev übersetzten Lyrik Goethes 95

1. Theoretische Ansätze zur Beurteilung der Qualität einer künstlerischen Übersetzung

95

2. Analyse der übersetzten Gedichte 98

2.1. Gedichte zur Beziehung Mensch und Unmelt 98

2.1.1. Künstler und Weltanschauung 98

2.1.1.1. Ubersetzungen Zukovskijs 98

2.1.1.1.1. "Weine Gbttin" 98

2.1.1.1.2. "Die Frouden" 106

2.1.1.1.3. "Der Wandrer" 110

2.1.1.1.4. "Der Adler und die Taube" 118

2.1.1.2. "Hegire" ("West-Östlicher Divan") in
Übersetzung Tjutčevs

2.1.2. Liebes- und Naturlyrik 135

2.1.2.1. Übersetzungen Žukovskijs 135

2.1.2.1.1. "Glïckliches Geheimis" 135

2.1.2.1.2. "Schäfers Klagelied" 138

2.1.2.1.3. "Kennst du das Land" 141

2.1.2.1.4. "An den Mond" 149

2.1.2.1.5. "Neue Liebe, neues Leben" 155

2.1.2.1.6. "Zueignung ("Der Morgen kam ...')"
und "Zueignung" zum "Faust" 
2.1.2.2. Übersetzungen TjutCevs 169

2.1.2.2.1. "Nachtgedanken" 169

2.1.2.2.2. "Kennst du das Land" 171

2.1.2.2.3. "Freudvoll und leidvoll" 176

2.1.3. Schicksal und Einsamkeit 177

2.1.3.1. Übersetzungen Žukovskijs 177

2.1.3.1.1. "Wer nie sein Brot mit Tränen aß" 177

2.1.3.1.2. "Trost in Tränen" 181

2.1.3.2. Übersetzungen Tjutčevs 184

2.1.3.2.1. "Wer sich der Einsamkeit ergibt" 184

2.1.3.2.2. "Wer nie sein Brot mit Tränen $a B^{\prime \prime} 189$

2.1.4. Zusarmenfassung 193

2.2. Besondere Gattungen 196

2.2.1. Bailaden 196

2.2.1.1. Die Ballade als Gattungsbegriff 196

2.2.1.2. Žukovskijs Übertragungen Goethescher Balladen 199

2.2.1.2.1. Žukovskijs Bedeutung für die Entwicklung der Balladendichtung in RuBland

199

2.2.1.2.2. Zur Auswahl der übersetzten
Goetho-Balladen

2.2.1.2.3. "Der Fischer" 215

2.2.1.2.4. "Erlkönig" 222

2.2.1.3. TjutČevs Übertragungen Goethescher Balladen 234

2.2.1.3.1. TjutCev als Übersetzer
Goethescher Bailaden

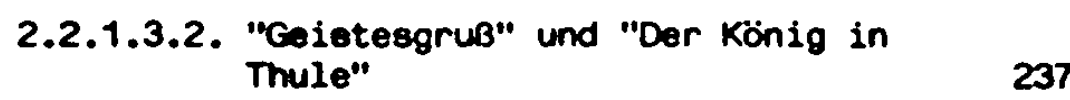

2.2 .1 .3 .3 . "Der Sänger" 246

2.2.2. Spruch und Epigramm 257

2.2.2.1. Lyrische Kleinformen in der deutschen und
russischen Literatur

2.2.2.2. Übersetzungen Žukovskijs 272

2.2.2.2.1. "Ländliches Glück" 272

2.2 .2 .2 .2 . Übersetzungen aus dem "Tasso" und
den "Zammen Xenien"

2.2.2.3. "Sakontala" in Übersetzung Tjutčevs 279

2.2.3. Zusarmenfassung 282 
3. Aus dramatischen Werken 
Abkïrzungsverzeichnis

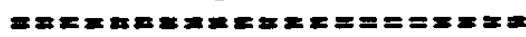

\section{A Periodica, Lexica, Reihen}

Corona

Deutsche Rundschau

Euphorion

FS

Germanoslavica

Krit Litt

Literaturnoe Nasledstvo

Monachium

Orbis litterarum

Put'

RA
Corona. Hrsg. M. Bodmer und H. Steiner. München - Berlin - Zürich 1930-1934.

Deutsche Rundschau. Gegründet von Julius Rodenberg. Ab 1919 weitergefunrt von Rudolf Pechel. Berlin bzw. Stuttgart - Bern - Wien 1874-1964.

Euphorion. Zeitschrift für Literaturgeschichte. Begründet von $A$. Saver. Hrsg. R. Gruenter und A. Henkel. Heidelberg ab 1894.

Forum Slavicum. Hrsg. D. Tschižewskij. München ab 1964.

Germanoslavica. Vierteljahreszeitschrift fur die Erforschung der germanisch-slavischen Kulturbeziehungen. Hrsg. J. Janko und F. Spina. Brunn - Prag - Leipzig - Wien 1931-1937.

Kritikon Litterarum. Internationale Rezensionszeitschrift für romanische, slavische, anglistische und amerikanische Sprach- und Literaturwissenschaft. Hrsg. K. Farrell, M. Franzbach, G. Giesemann, E. Jayne, R. Matthews, $M$. Putz. Frankfurt a.M. und Darmstadt ab 1972.

Literaturnoe Nasledstro. Zurnal'nogazetnoe ob'"edinenie. Moskau ab 1932.

Monachium. Beiträge zur Kirchen- und Kulturgeschichte Münchens und südbayerns anläblich der 800-Jahrfeier der Stadt München 1958. München.

Orbis litterarum. Revue internationale détudes littéraires. Hrsg. St. Steffensen und $H$. Sörensen. Kopenhagen ab 1943.

Put'. Organ russkoj religioznoj mysli. Hrsg. N.A. Berdjaev. Paris 1825-1940.

RusskiJ archiv. IzdavaemyJ Petrom Bartenevym. Moskau 1863-1913. 
RL

RLit

Russkaja Starina

SEER

Slavjanska

Filologija

SLOR

Vesy

VL

waSI

wiener

Slavistisches

Jahrouch

Slavische

Propyläen

ZfslPh

2fSI

ŽMNP

Zven'ja
Reallexikon der deutschen Literaturgeschichte. Begründet von P. Merker und W. Stammler. Hrsg. W. Kohlschmidt und w. Mohr. Berlin.

Russkaja Literatura. Istoriko-literaturnyj Zurnal. Leningrad ab 1958.

Russkaja Starina. St. Petersburg 18701914.

The Slavonic and East European Review. London ab 1922.

Slavjanska Filologija. Sofia ab 1963.

Slavia Orientalis. Warschau ab 1952.

Vesy. Naučno-literaturnyj i kritiko bibliografǐ̌eskij ežemesjačnik. Moskau 1904-1909.

Voprosy literatury. "Izvestija". Moskau ab 1957.

Die Welt der Slaven. Halbjahreszeitschrift für Slavistik. Wiesbaden 19561971. Köln - Wien 1972 - 1976. München ab 1977.

wiener Slavistisches Jahrbuch. Begr. von R. Jagoditsch. Hrsg. J. Hamm und G. Wytrzens. Wien ab 1950 .

Slavische Propyläen. Texte in Neuund Nachdrucken. München ab 1963.

Zeitschrift für slavische Philologie. Begr. von M. Vasmer. Hrsg. H. Bräuer und P. Brang. Leipzig 1927-1950. Heidelberg ab 1952.

Zeitschrift für Slawistik. Hrsg. H.H. Bielfeldt, R. Fischer, F. Liewehr, E. Winter. Berlin ab 1956.

Žurnal Ministerstva Narodnogo Prosvesčenija. St. Petersburg 18??-1914.

Zvenija. Sborniki materialov i dokumentov po istoril literatury, iskusstva 1 obšestuennoj mysli XIX veka. "Academia". Moskau - Leningrad 1932-1951. 
B Ausgaben, nach denen Goethes, Zukovskijs und TJutZevs Gedichte zitiert werden

HA

Goethes Werke in 14 Bänden. Hamburger Ausgabe. Hrsg. E. Trunz. 12., neubearb. Aufl. München 1981.

GOETHES GEDICHTE Goethes Gedichte in zeitlicher Folge. Hrsg. H. Nikolai. 2 Bde. Wiesbaden 1978.

ŽUKovskIJ V.A. Zukovskij, Sobranie sotinenij $\checkmark$ Zetyrech tomach. Moskau - Leningrad 1959.

TJUTČEV F.I. Tjuťev, Lirika. Hrsg. K. Pigarev. 2 Bde. Moskau 1965.

C Ausgaben der "Biblioteka potta, osnovana M. Gor'kim"

MBP

Malaja serija

BBP

Bol'šaja serija

D Sonstige Abküzungen
a.a.o.
am angefunrten Ort
Abt.
Abteilung
Art.
Artikel
Aufl.
Auflage
Bd. /Bde.
Band/Bände
Beil.
Beilage
begr.
begründet
bzw.
beziehungsweise
ders.
derselbe
Diss.
Dissertation
ebd.
ebenda
$f . / f f$.
folgende seite/folgende seiten
folkl.
folkloristisch 
Hrsg.

Izd.

ND

S.

Sp.

u.a.

vgl.

vyp.

$z$.

291 .
Herausgeber/in

Izdanie

Nachoruck

Seite

Spalte

unter anderem

vergleiche

vypusk

Zeile

zugleich 
I. EINLEITUNG

$m=x=m=z=x=x=$

\section{PROBLEMSTELLUNG UND ABGRENZUNG}

Trotz der immer wieder vertretenen Ansicht, daB Dichtung, vor allem Lyrik, eigentlich unübersetzbar sei, wurde zu allen zeiten der versuch unternommen, fremdsprachige Poesie in die jeweilige Muttersprache zu ubersetzen und damit den kulturellen Horizont des eigenen volkes zu erweitern. Erst übersetzungen ermöglichen eine umfassende gegenseitige Befruchtung des Geisteslebens; diese wiederum findet inren Niederschlag in dem eigenständigen geistigen Schaffen eines Kulturkreises.

Goethes EinfluB auf die russische Literatur- und Geistesgeschichte kommt eine nicht zu unterschätzende Bedeutung zu. Jede Zeit und jede literarische strömung nimmt sich das von Goethes Werk, was ihr zugänglich ist und deutet es unter mannigfaltigen, auch zeitbedingten Aspekten. Infolgedessen ist das, was in der literarischen Auffassung unterschiedlicher zeitlicher Perioden und kultureller Tradition mit dem Namen Goethes in Zusammenhang gebracht wird, keineswegs identisch.

Goethes wirken in RuBland ist folglich einer der zentralen Problemkreise der mit literarischen Bezienungen zwischen Völkern und Kulturen befaßten Literaturwissenschaft. In zahlreichen wissenschaftlichen Arbeiten wurde untersucht, inwieweit sich in dem verhältnis zu Goethe die ganze geistige und literarische Entwicklung RuBlands vom Sentimentalismus bis zum Symbolismus spiegelt.

Nur am Rande finden in den bisherigen Untersuchungen russische Ubersetzungen aus Goethes lyrischem Werk Beachtung. Während über russische Faust-ubertragungen eine 
umfassende Arbeit vorliegt, ${ }^{1}$ begnügen sich die verfasser thematisch weitgefaßter Arbeiten über Goethe in RuBland mit meist pauschal bleibenden Anmerkungen zu Gedichtwiedergaben, häufig beschränken sich diese Anmerkungen auf eine bloße Aufzählung der übersetzten Stücke.

Eine tiefgehende und selbständige Auseinandersetzung mit übersetzungen aus dem lyrischen werk Goethes fehlt bisher. Mit der vorliegenden Arbeit soll versucht werden, einen Teil aieser Lücke zu schließen.

Die Kunst des übersetzens hat in Rußland eine, z.B. im Vergleich zu Deutschland, lange Tradition. Zahlreiche der bedeutendsten Dichter ihrer Zeit beteiligten sich an der Aufgabe, fremasprachige Dichtung ins Russische zu übertragen und somit den eigenen Landsleuten zu erschließen.

Im Mittelpunkt der vorliegenden Arbeit stehen die Goethe-übersetzungen V.A. Zukovskijs und F.I. Tjutčevs.

Eine Beschränkung innerhalb der russischen Romantik auf diese beiden Dichter scheint dadurch gerechtfertigt, daß sowohl Žukovskij als auch Tjuť̌ev nicht nur umfangreiche Übertragungen Goethescher Lyrik lieferten, sondern auch vom Niveau inres Gesamtwerkes weit uber den Durchschnitt hinausragen. Im Gegensatz zu romantischen Dichtern wie A. Grigor'ev oder K. Aksakov, die ebenfalls zahlreiche Goethe-Gedichte ubersetzten, nehmen Žukovskij und Tjutčev einen zentralen Platz in der russischen Literaturgeschichte ein, bei ihnen fiel die Berührung und Auseinandersetzung mit Goethes Poesie somit gleichsam auf fruchtbaren Boden.

1 Vgl. W. POHL, Russische Faust-übersetzungen. Meisenheim am Glan 1962. Zugl. Diss. Minster (Slavisch-baltisches Seminar der Westfälischen Wilhelms-universität Minster. Veröffentlichung $\mathrm{Nr}$. 5); vgl. hierzu die Rezension: G. BIRKFELLNER. In: wiener Slavistisches Jahrbuch. Bd. 11 (1964). S. 208-211. 


\section{ZUM ABLAUF DER UNTERSUCHUNG}

Im Mittelpunkt der vorliegenden Arbeit steht die Analyse der von Žukovskij und TjutZev übersetzten Goethe-Gedichte. Um dem zentralen Gegenstand dieses Abschnitts, dem deutschen Gedicht und seiner russischen wiedergabe, möglichst gerecht werden zu können, geht die Analyse, abhängig vom jeweiligen Gedicht, von inhaltlichen oder von formalen Kriterien aus. Dies schlägt sich in der Zweiteilung des Abschnitts nieder. Eine thematisch orientierte Einteilung steht einer Gliederung nach bestimmten Gattungen gegenüber.

Der sich jeweils anschliebende vergleich zwischen den von Zukovskij und Tjutčev angefertigten Wiedergaben bezieht sich sowohl auf die Auswahl der übersetzten GoetheGedichte als auch auf besondere - möglicherweise für die Romantik signifikante - Merkmale des ubersetzungsstils. Dieser Vergleich soll weiterhin dazu beitragen, die Frage zu beantworten, ob und inwieweit sich Zukovskij und Tjutčev als eigenständige Dichter in ihren Goethe-ubersetzungen widerspiegeln.

Die Interpretation der deutschen Gedichte sowie die Analyse der russischen übersetzungen erfolgt nach möglichst umfassenden Gesichtspunkten.

Der zentrale Gegenstand ist das dichterische Werk selbst. Neben dieser von den russischen formalisten geforderten ausschließlich werkimmanenten Betrachtungsweise sollen jedoch auch auBerkünstlerische Methoden, wie die in älteren Untersuchungen bevorzugt angewandte biographisch-psychologisch orientierte Deutung sowie der rezeptionsästhetische Ansatz berücksichtigt werden. 
Um nicht Gefahr zu laufen, das dichterische werk aus seiner historischen Bedingtheit herauszulösen und somit in seiner Aussage völlig unverbindlich erscheinen zu lassen, müssen wir auch die Frage nach seiner Entstehung, dem Schaffensvorgang, der wirkung und den Einflussen, die es auf seine Leser ausiubte, seine Bedeutung für Epochen und literarische strömungen und vor allem die fragen, die uns zu seinem Dichter führen und sich mit inm beschäftigen, als einen weiteren Kreis von Problemen auffassen, die sich um den eigentlichen Gegenstand der 8etrachtung gruppieren.

Ein starres Interpretationsschema wurde für die Analyse der Übersetzungen vermieden. Abhängig vom konkreten Gedicht werden bestimmte Fragen schwerpunkmäßig behandelt, andere nur am Rande.

Zentrale Kriterien zur kritischen Untersuchung einer übersetzung sollen dabei sein: 1

1. Fragen zur eigentlichen übersetzerarbeit

wie verhält sich die übersetzung zum Original in folgenden Gesichtspunkten?

- äuBere Form (z.8. strophischer Aufbau, metrisches Schema, Reimschema)

- stilistisches Erfassen der Vorlage (2.B. Metapher, 8ild, Enjambement, Parallelismus, Zäsur, Alliteration)

- handwerkliches Erfassen der Vorlage (z.8. falsches Übersetzen von wörtern)

- inhaltiches Erfassen der Vorlage (z.8. Gedankengang, Zufügungen oder Auslassungen)

1 Diese Kriterien richten sich im wesentlichen nach dem von Karin Kijenzlen in ihrer Dissertation aufgestellten Fragenkatalog. Vgl. K. KUEENZLEN, Deutsche Übersetzer und deutsche übersetzungen Lermontovscher Gedichte von 1841 bis zur Gegenwart: Angaben uber das Leben und das literarische Wirken der Übersetzer und Versuch einer kritischen Beurteilung ihrer übertragungen. Diss. Tübingen 1980. S. $388-390$. 
2. Fragen nach dem Anteil des übersetzers an der übersetzung

- Wie sind seine sprachlichen fähigkeiten zu werten?

- Wie ist seine Einstellung zum Original?

- Hat er klare übersetzungsprinzipien?

- Ist eine übersetzertradition erkennbar?

- Tritt der übersetzer in Erscheinung?

Mit deri eigentlichen Thema der Arbeit nur lose verbunden sind die Übersetzungen Tjuttevs aus Goethes "Faust". Sie werden, der vollständigkeit halber, am Schluß der Arbeit überblicksmäßig behandelt.

Die Vorstellung der beiden übersetzer wird der Gedichtanalyse vorangestellt. Sie 8011 als Hinführung zum inhaltlichen Schwerpunkt dienen. Besondere Berücksichtigung finden dabel die Stellung Žukovskijs und Tjutčevs innerhalb oer russischen Literatur, ihre Bedeutung für die zunehmende verbreitung von Goethes Schaffen im RuBland des 19. Jahrhunderts, sowie biographische Ereignisse, die speziell geeignet sind, die Beziehung der Dichter zu Deutschland und zu Goethe zu erhellen. 
II. ŽUKOVSKIJ UND TJUTČV ALS BEDEUTENDSTE GOETHE-ÜBER-

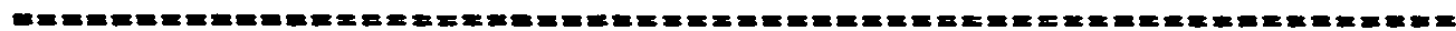
SETZER DER RUSSISCHEN ROMANTIK

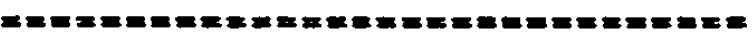

\section{GRUNDSÄTZLICHES ZUR ROMANTIK IN RUSSLAND}

1.1. Neue Ansätze der Romantikforschung

Zu Beginn unseres Jahrhunderts haben verschiedene Literaturwissenschaftler den versuch unternommen, die Romantik als kunst- und Geistesepoche in inrem wesen begrifflich zu bestimmen. 1 Dieser versuch muß jedoch als gescheitert betrachtet werden.

In neveren Untersuchungen setzt sich immer mehr die Erkenntnis durch, daB die Romantik sich einer umfassenden Definition entzient; inre vielfältigen und höchst unterschiedlichen Erscheinungsformen können nicht alle auf einen Nenner gebracht werden. ${ }^{2}$ Es gibt keine spezifischen Merkmale, die ein romantisches kunstwerk von vornherein als solches ausweisen.

1 Vgl. I.I. ZANOTIN, Romantizm dvadcatych godov XIX stoletija $v$ russkoj literature. 2 Bde. 2. Auf1. Petersburg-Moskau 1911-1913. Hier Bd. 2. S. 17: "Romantizm $v$ svoej suß̌čnosti jasno vyražennoe idealistiCeskoe mirovozzrenie ...."

Auch deutsche Literaturtheoretiker versuchten eine wesensbestimmung der Romantik zu formulieren. So z.B. J. PETERSEN, Di甘 Wesensbestimmung der deutschen Romantik. Eine Einführung in die moderne Literaturwissenschaft. Leipzig 1926, und $V$. KLEMPERER, Romantik und französische Romantik. In: Idealistische Neuphilologie, Festschrift für Karl vossler. Heidelberg 1922. S. 10-32. No in H. PRANG (Hrsg.), Begriffsbestimmung der Romantik. Darmstadt 1968 (wege der Forschung Bd. 150). S. 48-72. Hier S. 72. Für Klemperer ist das eigentliche Wesen der Romantik die "rastlose Qual und Lust des unersättlichen Ich-Strebens nach Erweiterung".

2 vgl. H. PRANG (Hrsg.), Romantik, a.a.O., S. 2; H.G. SCHENK, Geist der europäischen Romantik. Ein kulturhistorischer versuch. Frankfurt 1970. S. XVI. 
Eine klare Trennungslinie läßt sich weder zum Klassizismus ziehen, aus dem die Romantik hervorgegangen ist, noch zum Realismus, in den sie ubergeht. Dies gilt sowohl für die russische als auch europäische Romantik. Insofern dürfen Begriffe wie Klassizismus, Romantik und Realismus nicht als strikte Gegensätze verstanden werden, sondern als untereinander verknüpfte Entwicklungsphasen. 1

Die einzige Mögichkeit, sich dem zèitalter dér Romantik zu nähern, besteht in der Betrachtung seiner Phänomene und in der Beschreibung seiner unterschiedlichen Erscheinungsformen. Ein verbreitetes Merkmal dieser Epoche ist die Besinnung des Künstlers auf seine eigene Person, auf seine Sonderstellung unter den Menschen. ${ }^{2}$ Er thematisiert seine Visionen als Dichter-Prophet, ${ }^{3}$ seine Inspirationserlebnisse, Einsamkeit, Leid und Tod.

1 So hat R. Bach die Romantik mit gutem Grund als "offenes Zeitalter" bezeichnet. R. BACH, Deutsche Romantik. Ein geistesgoschichtlicher UmriB. Hamburg 1948. S. 9. Vgl. B. ZELINSKY, Russische Romantik. Köln - Wien 1975 (Slavistische Forschungen Bd. 15), S. 5; vgl. hierzu die Rezension: A.B. MacrLliN. In: SEER 55 (1977) Nr. 2. S. 237-240.

2 Die Auserwähltheit des Dichters ist auch ein immer wiederkehrendes Thema der russischen Romantik. Vgl. D. TSCHIŽEWSKIJ, Russische Literaturgeschichte des 19. Jahrhunderts. 2. Bde. Minchen 1977 und 1967. Hier 8d. 1. S. 150-151.

3 Bei der Herausbildung der Selbstreflexion des Künstlers nimmt Goethe eine zentrale Stellung ein. Er ist der erste bedeutende Dichter, der das Besondere einer Künstlerexistenz in seiner Dichtung thematisiert, und zwar in allen drei Gattungen. Näheres hierzu bei B. ZELINSKY, a.a.O., S. 7. 
Neben dieser Selbstreflexion des Künstlers entwickelt sich eine gesteigerte sensibilität, die in der Liebesund Naturlyrik ihren stärksten Ausdruck findet. Der romantische Dichter entdeckt das unbewuBte Leben der menschlichen Seele, Zustände wie der des Schlafes oder des Traumes, des wannsinns oder des Rausches ermöglichen es inm, den Sinn des Daseins zu erfassen.

\subsection{Zukovakij und TjutKev als romantische Dichter}

1.2.1. Zuukovskij - ein Dichter an der Schwelle des roman-

\section{tischen Zeitalters}

Die Frage nach Žukovskijs Bedeutung als Romantiker und seine Stellung innerhalb der europäischen Romantik ${ }^{1}$ ist bis heute Gegenstand der wissenschaftlichen Diskussion. Fest steht lediglich, daß Zukovskij, mit dem in RuBland eine neue Lyrikgesinnung anhebt, eine entscheidende Rolle bei der Entwicklung der russischen Romantik spielt und folglich mit gutem Grund als "Ahnherr" ("rodonacal'nik") aller bis einschlieblich Gogol' auf inn folgenden Dichter bezeichnet wird. 2

1 Dieser Themenkreis wird in einem von Vladimir I. Pokrovskij zusammengestellten Essayband von verschiedenen Seiten hec beleuchtet. Vgl.V.I. POKROVSKIJ (Hrsg.), Vasilij AndreeviC Zukovekij. Epo žizn' i sočinenija. Sbornik istoriko-literaturnych statej. Moskau 1912, Eine neuere Untersuchung liefert: S.E. SATALOV, Romantizm Zukovskogo. In: Istorija romantizma $v$ russkoj literature. Vozniknovenie i utverždenie romantizma $v$ russkoj literature (1790-1825). Moskau 1979. S. 110-144.

2 Vgl. S.P. SEMPEV, O znă̌enii Žukovskogo $v$ russkoj Žizni i poèzij. Moskau 1853,S. 35-36. Zukovskijs Tod im Jahre 1852 bot Sevyrev. dem einstigen wackeroder-Ubersetzer und Professor der Dichtkunst an der Moskauer Universität, den Anlaß, um auf die mit diesem Ereignis endgültig abgeschlossene Epoche als Ganzes zurückzuschaven. Vgl. B. ZELINSKY, a.a.0., S. 413. 
Noch zu Lebzeiten des Dichters werden unterschiedliche Ansichten über dessen konkrete verbindung zur Romantik geäußert.

Nach N.A. Polevojs Auffassung gelingt es Yukovskij kaum, sich das Wesen der neven Literaturbewegung anzueignen. 1 Für Belinskij ist der russische Dichter demgegenuber einer der Begründer der Romantik in RuBland. 2

In seiner berühmten Monographiej versucht Aleksandr N. VeselovskiJ zu beweisen, daß Zukovskij mit seiner Dichtung den Rahmen des Sentimentalismus nicht verlassen habe. Bei der Begründung seiner These stützt er sich im wesentlichen auf die vorstellung, die er sich von der Persönlichkeit Zukovskijs macht.

Veselovskijs Untersuchung liegt die Annahme zugrunde, Zukovskijs Lyrik sei ausschlieblich die Umschrift persönlicher Gefühle und Erlebnisse. Die wenig glückliche Kindheit, der frühe verlust seines freundes Andrej $I$. Turgenev und vor allem seine tragische Liebe zu Marija Andreevna Protasova werden als Determinanten seines künstlerischen Stils betrachtet.

1 Vgl. N.A. Polevoj, Očerki russkoj literatury. Bd. 1. St. Petersburg 1839, S. 119.

2 Vgl. Belinskijs Aufsätze über Puß̌kin. V.G. BELINSKIJ, Sočinenija Aleksandra Puškina. In: Ders., Polnoe sobranie sočinenij v 13-ti tomach. Moskau 1955-1959. Hier Bd. 7. S. 99-579, besonders die Auf sätze $\mathrm{Nr} .2$ (S. 132-222), Nr. 4 (S. 266-301), und $\mathrm{Nr} .5$ (5. 302-357).

3 Vgl. A.N. VESELOVSKIJ, V.A. Zutoovskij. Poezija Čurstra i "serdex̌nogo voobraženija". Petrograd 1918; vgl. hierzu die Rezension der 1. Auflage von 1904: V.S. In: Vesy 1/10 (1904). S. 71-72. 
Der Notwendigkeit einer Differenzierung zwischen der Person des Dichters und ihrer Projektion in seine Werke ist sich Veselovskij nicht bewuBt. Dem russischen Literaturwissenschaftler wird nicht klar, daB der "private Ton" in der Dichtung Zukovskijs nicht zuletzt epochenund genrestilistisch bedingt ist."

Überlegungen dieser Art werden zum ersten Mal von C.S. vol'pe ${ }^{2}$ und nach inm von G.A. Gukovskij ${ }^{3}$ angestellt. Beide verstenen ŽukovskiJ als tief romantischen Dichter.

In seiner Untersuchung "Pugkin i russkie romantiki" lehnt Gukovskij die Auswertung poetischer Werke als biographische Indizien ab; die Heranziehung biographischer Fakten zur Deutung der Dichtung betrachtet er jedoch als erforderlich.

Seine Differenzierung, das Leben des Dichters stehe nicht in seinen Versen sondern hinter diesen, 4 läßt jedoch immer noch auber acht, dab Zukovskijs werke, auch wenn sie als Selbstporträt gedacht waren, durch stilbewuBtsein und künstlerischen Formwillen geprägt sind. 5

1 Vgl. hierzu die Ausführungen von Gisela Schulz über biographische und psychologische Deutungsversuche von Zukovskijs Werk.G. SCHuLZ, Zur Balladen- und Märchendichtung V.A. Zukovskijs. Diss. Konstanz 1972. S. 2-8.

2 Vgl. C.S. Vol'pe in seiner Einleitung zur Werkausgabe: V.A. ZUKOVSKIJ, Stichotvorenija. Hrsg. C.S. Vol'pe. 2 Bde. BBP. Leningrad 1939-40. Hier Bd. 1. S. V-XLVIII; I.M. SEVENKO, Yizn' i poèzi ja Žukovskogo. Moskau 1975. S. 88; vgl. hierzu die Rezensionen: W. Busar. In: Zf8IPh 41 (1980). S. 230-234; L. SUCHANEK. In: Slor $3(1976)$. S. 411-413; J. Lerwaw. In: Krit Litt 1976/4. S. 291-293; P. STELLIFEROVSKIJ, "Ego stichov plenitel'naja sladost' ...". In: Vh 1977/1. S. 284-289.

3 Vgl. G.A. GuKovsKIJ, Pǚkin i russkie romantiki. Moskau 1965. S. 144.

4 Ebd. S. 141: "Žizn" Žukovskogo stoit $2 a$ ego stichami, chotja imenno tol'ko za nimi, a ne $\underline{v}$ nich." (Unterstrichene Stellen in original kursiv gedruckt).

5 vgl. G. sanlz, a.a.0., S. 5. 
Die Wurzeln von Kukovskijs poetischem Weltbild liegen ohne Zweifel im Sentimentalismus und in der schule Karamzins. Besonders deutlich zeigt sich dies in seiner frühen Lyrik, hier bedient sich der russische Dichter noch häufig sentimentalistischer Klischees.

Die traditionelle Figur des "unglücklichen Sängers". der unter Liebeskummer leidet und seinen vorzeitigen Tod vorausahnt (diese Figur ist einigen Karamzinschen Gestalten verwandt), finden wir in "Toska po milom" (1807) und anderen frühen Gedichten.

In den von Žukovskij übertragenen Ausschnitten aus "Don Quijote" (nicht nach $M$. de Cervantes sondern nach einer Umarbeitung Florians) gibt er das Liebes-Sonett im Geist einer sentimentalistischen Pastorale wieder.

Ах, нет! Либви твоея желать

Твоя пленник, Хлоя, не дерэает:

Любить и слезы проливать,

жестокая, и то блахенством он считает. 1

Auch im "Pevec" (1811) benutzt Žukovskij noch vorgefertigte thematische Klischees.

Он дружбу пел, дав другу нежну руку, -

но верны друг во цвете лет угас;

Он пел любовь - но был печален глас;

Увы! он знал либви одну лишь муку.

(ŽUKOVSKIJ I, S. 109-111)

Die Freundschaft und die Liebe besingen, oder "In der Blüte der Jahre verlöschen", dies sind typische Allgemeinplätze sentimentalistischer Poesie.

1 Abgedruckt in: I.M. SEMENKO, a.a.0., S. 93. 
Aber hinter diesen Versen steht bei Žukovskij der heftige schmerz über den Verlust eines nahen freundes und das Leiden an einer hoffnungslosen Liebe.

"Pevec", wie auch andere Gedichte dieser Art, ist jedoch so aufgebaut, daß das Bild des "Dichters" nicht mit dem Bild des Autors identisch ist; der Sänger, sein Grab, sowie sein äuberes und inneres Porträt ist ein von selbständigem Leben erfültes Bild. Der Autor zeichnet es von verschiedenen seiten:

В тени дерев, над чистьми водами Дерновыя холм вы видите ль, друзья?

Im "Pevec", wie auch in vielen anderen frühen Gedichten Žukovskijs, taucht der "lyrische Held" l"liričeskij geroj") 1 auf. Er verkörpert das verbindende Glied zwischen der inneren Welt des Dichters und ihrer künstlerischen Darstellung.

Die charakteristischen Eigenschaften dieser als Verbindung zwischen dem Autor und der handelnden Person gekennzeichneten Gestalt - Nachdenklichkeit und Melancholie - sind durch die Gattung der Elegie und ihres traditionellen sujets festgelegt; ebenso festgelegt wie das Schicksal des "lyrischen Helden", seine unglückliche Liebe und der frühe Tod.

Он сердцем прост, он нежен был душоп -

но в мире он минутныя странник кшл;

Едва расцвел - и жизнь уж разлюбил

и жиал кониа с волненьем и тоскою;

И рано встретил он конец,

Заснул желанным сном могиљы...

Твоя век был миг, но миг унилия,

Бедныя певец!

1 Hierzu ausführlicher I.M. SEMENKO, a.a.0., S. 94-96. 
Auch wenn der "lyrische Helo" bestimmte vorstellungen des Autors vom Leben personifiziert, ist in inm, wie in jeder handelnden Person, das objektive Element stärker als die subjektive Selbstaussage. 1

Allmählich beginnt sich Žukovskij von den klaren klischees des Sentimentalismus zu lösen. In seinen reifen Werken können sie nur als Anachronismus verstanden werden, als Merkmal eines längst überwundenen stils. Ist in "Sel'skoe kladbiłce" dieser stil noch organisch, dem Inhalt der Elegie gemäß, so scheint er in den Schlubzeilen von "veter" im vergleich zum stil des gesamten Gedichts bereits als veraltet.

Reine sentimentalistische Motive werden bei Zukovskij früh durch vorromantische und romantische Themen ergänzt. während im Sentimentalismus noch der Ton des subjektiven Gefunls, der traurig-resignierten stimmung im vordergrund steht, rücken in der Romantik immer mehr das Amt des Dichters, sein Inspirationserlebnis, Leiderfahrung und Leidtranszendenz, Einsamkeit und Tod, sowie die Tiefe sinnerfullter vergangenheit (besonders der mittelalterlichen vergangenheit) in den Mittelpunkt des Interesses.

Die Dichtung wird, was Inhalte und Formen betrifft, von klassizistischen stilzwängen befreit. Die einst so beliebten groben Hymnen an Gott oder feierlichen Oden zum Ruhme des Vaterlandes werden durch das schlichte, einfache wort verorängt. Die Poesie nähert sich dem Leben, der vertrauten, alltäglichen Umwelt.

1 So endet die Elegie "Sel'skoe kladbišče" mit der Darstellung des Grabes des Dichters, das jedoch von einem außenstehenden Zuschaver, einem Bavern, beschrieben wird. Ebenso wird in der Elegie "Večer" gegen Ende das Personalpronomen von dem Substantiv "Jüngling" ("junoša") verorängt. Der Dichter spricht auch hier von sich in der dritten Person. Vgl. I.M. SEMENKO, a.a.O.. S. 96 . 
Zukovskijs wegweisende Bedeutung liegt darin, daß er das Gefülserlebnis in die Dichtung eingebracht hat, nicht das sentimentale Gefühl Karamzins, sondern das schlichte, natürliche Gefühl.

Dem entspricht die Veränderung der angewandten Ausdrucksmittel. Neu sind die Lebendigkeit und Zartheit der Bilder, die Musikalität des Verses, das malerische Element des Wortes sowie die Schlichtheit des Stils. 1

Ein Hauptanliegen der russischen Romantik ist die Zerstörung der klassizistischen Tradition mit inren festgefügten und klar bestimmten formen. Das führt zu einer Bevorzugung never, dem Klassizismus unbekannter Gattungen. Mischgattungen wie die Ballade und das Poem werden beliebt.

So ist es kein Zufall, daB sich Zukovskij auch der Balladendichtung zuwendet und so die "Blütezeit der Ballade in RuBland" 2 einleitet. Besonders die "mittelalterlichen Balladen", wie z.B. Žukovskijs Originaldichtung "Ėolova arfa", sind eng mit der Entstehung der romantischen Bewegung in RuBland verbunden.

Nicht nur die von ŽukovskiJ eingeführten Ausdrucksmittel und Gattungen kennzeichnen ihn als frühen romantischen Dichter, sondern auch seine vorstellung vom ewigen geheimnisvollen wesen der welt tragen typisch romantische Züge. 3 Kennzeichnend für diese Umwelterfahrung ist der Glaube an die Zweigeteiltheit der Welt.

1 Vgl. S.P. Š SEMREV, a.a.O., S. 35-36; B. ZELINSKY, a.a.0., S. 414.

2 F.W. NEUMAN, Geschichte der russischen Ballade. Königsberg (Pr.) - Berlin 1937 (Schriften der Albertus-Universität Bd. 15). S. 51 .

3 Vgl. Dichtungen wie "Slavjanka" oder "Lalla Ruk". 
Diese von späteren Romantikern weiterentwickelte Vorstellung vom dualistischen wesen der welt manifestiert sich bei Zukovskij in der religiösen Gegenüberstellung von "Himmel" und "Erde"."

Auch wenn Tjuttevs romantisches verständnis der "Weltseele" weit entfernt ist von Zukovskijs schlichter vorstellung, so führt dennoch vom Bild der unter einer schale verborgenen seele eine direkte Linie zu Tjuttevs philosophischer Dichtung. 2

Als frühen Romantiker kennzeichnen Žukovskij weiterhin seine Vorstellungen von der Existenz des Dichters. Als erster russischer Dichter - Klopstock in Deutschland vergleichbar - lebt Žukovskij nur noch in seinem Dichtertum. 3

Während sich Lomonosov neben der Tätigkeit des Dichtens auch der wissenschaft zuwendet, Deržavin der Juristerei und Karamzin sich seinen historischen studien widmet, fallen bei Žukovskij Beruf und Berufung zusammen. Diese vorstellung charakterisiert zutreffend der vers "Žizn" i Poèzija odno" aus dem 1824 entstandenen Gedicht "Ja Muzu junuju, byvalo". 4

Kunst - bei Žukovskij leitmotivisch mit dem Moment des Leidens verbunden - wird in eine sakrale Sphäre gehoben, Dichtung gleichsam als Frucht gottgewollten Leidens, aber auch als Mittel der Leidtranszendenz, verstanden.

1 Diese Vorstellung Žukovskijs äußert sich nach "Slavjanka" besonders in den Gedichten des Jahres 1815, 2.B. "Rozy rascvetajut", "PtičkoJ peviceju", "K vostoku, vse k vostoku". Vgl. I.M. SEMENKO, a.a.0. S. 100 .

2 Vgl. I.M. SEMENKO, a.a.O., S. 101.

3 Vgl. S.P. ŠEYYREV, a.a.O., S. 19; B. ZELINSKY, a.a.O., S. 414.

4 Vgl. B. ZELINSKY, a.a.O., S. 414. 
Im Gegensatz zu Kjuchel'beker oder Lermontov nimmt die Erfahrung des Leids bei Zukovskij jedoch nie existenzbedrohende Ausmaße an. Fest verwurzelt in dem christlichen Glauben wird die verbindung des Religiösen mit dem Dichterischen bei Žukovskij nicht nur gedichtet, sondern auch gelebt. 1

Als Žukovskijs "poetisches Kredo" wird mit Recht seine russische Nachdichtung des Einakters "Camoens" von Friedrich Halm (Pseudonym für Eligius Freiherr von MünchBellinghausen) betrachtet. ${ }^{2}$ Diese "mystisch-romantische ars poetica" 3 faBt charakteristische Leitgedanken der Epoche zusammen.

Über ihre dichterische Funktion hinaus besitzt Žukovskijs Nachdichtung jedoch auch eine Bedeutung als Selbstaussage.

"Er [Zukovski] legte nier... in den Mund der beiden Dichter Kamoëns und $\mathrm{VascO}_{4}$ seine intimsten Uberzeugungen und Anschauungen."

1 Vgl. B. ZELINSKY, a.a.0., S. 414.

2 Im Jahre 1639 hatte Žukovskij im Wiener Burgtheater eine Aufführung dieses Dramas gesehen und begann unter dem Eindruck der Vorstellung spontan mit der übersetzung ins Russische. Diese ubbertraf schlioßlich das mittelmäßige Original an künstlerischem Gohalt pei weitem. So betrachtete die spätere Kritik den "Kamoéns" Zukovskijs auch als seine eigene schöpfung. Vgl. L. KOBILINSKIELLIS, W.A. Joukowski. Seine Persönlichkeit, sein Leben und sein Werk. Paderborn 1933. S. 233-234; vgl. hierzu die Rezension: K. Moă 'SKIJ. In: Put' 45 (1934). S. $79-80$.

Näheres zU dem Renaissance-Dichter Luis Vaz de Camoens, der bedeutendsten Erscheinung der portugiesischen Dichtung, und seinem Auftreten als gedichtete Gestalt in Deutschland bei B. ZELINSKY, a.a.0., S. 412 .

3 L. KOBILINSKI-ELLIS, a.a.0., S. 235. (Unterstrichene Stellen im Original kursiv gedruckt).

4 Ebd. (Unterstrichene Stellen im Original kursiv gedruckt). 
Die Reden der beiden Dichter enthalten die Leitgedanken der romantischen Kunstauffassung Zukovskijs. Der letzte vers dieser Dichtung, der die Rede des sterbenden Kamobns beschliebt: "Die Dichtung ist Gott in den heiligen Träumen der Erde" ("poezija est" bog v svjatych mečtach zemli") und der Ausruf Vaskos "Die Dichtung ist die irdische Schwester der himmlischen Religion" (poezija nebesnoj religii sestra zemnaja") fassen zentrale thesen der Poetik Žukovskijs zusammen.'

1 Vgl. I.M. SEMENKK, a.a.O., S. 70-71. Eine ausführliche Auseinandersetzung mit Zukovskijs "Kamoens" und ein vergleich mit Halms vorlage findet sich bei B. ZELINSKY, a.a.0., S. $412-423$. 


\subsubsection{TJuť̌ev - der Romantiker zwischen Klassizisans} und Symbolienus

Onne Zweifel gehört TjutZevs Lyrik der Epoche der Romantik an, auch wenn viele Gedichte erst nach deren Höhepunkt verfaBt wurden. 1

Typisch romantische Themenkreise, wie die Rückbesinnung des Dichters auf sich und seine Berufung, Liebe und Einsamkeit und das tiefe Erleben der Natur stehen im Mittelpunkt von Tjutčevs lyrischem Schaffen. Als romantischer Dichter entdeckt er das Traumhafte, begibt er sich in die unbewubten Sphären der menschlichen seele. 2

Neben dem Traum ist es vor allem die Nacht, die inm einen Zugang zu bisher unbekannten Tiefen des Seins ermöglicht. Nur in der Nacht ist der Mensch fähig, in die tiefsten Geheimnisse seines Bewubtseins einzudringen.

1 D. Tschižewskij bezeichnet Tjutčev gls den "echtesten Romantiker unter den Russen". Vgl. D. TSCHIZEWSKIJ, Literaturgeschichte, a.a.0., Bd. 1. S. 129 .

2 Alle diese Themenkreise lassen sich in Tjutčevs Lyrik wiederfinden:

Dichter-Gesellschaft: "Ty zrel ego v krugu bol'sogo sveta", "V tolpe 1 judej, v neskromom sume onja". Das Leiden des Künstlers an der Gesellschaft ist das gemeinseme Thema der beiden Godichte. Weiterhin wird das verständnis des Dichtertums durch zahlreiche Portraits bekannter Dichter, näher ausgeführt, 2.B. in "Na končinu Puškina" und "Panjati V.A. Žukovskogo".

Liebes- und Naturlyrik: Aus der groben Zahl von Gedichten zu diesem Thema seien zwei beispielhaft erwähnt: "Sej den', ja pornju, dl ja menja" und "Polden"".

Traumsymbolik: "Son na more", "Lebed". In diesen Gedichten entfaltet Tjutčev die verbindung von Traum und Meer. 
In den Abgründen der Seele entdeckt er das wesen aller Dinge. Selbsterkenntnis bildet die voraussetzung zum verständnis der Welt.

Besonders in TjutXevs Lyrik nimmt die Nacht eine herausragende stellung ein, nach Tschizewskij macht sie sogar "den Gehalt des bedeutendsten Teils seiner Dichtung" aus. 1

Auch wenn Tjutčevs Nachtlyrik ein ganz eigenes, unverwechselbares Wesen besitzt, so lassen sich doch besonders an inr beispielhaft die übergreifenden Merkmale der europäischen Romantik aufzeigen. 2

1 Vgl. D. Čyževśkyj = D. Techižewskij, Tjutčev und die deuteche Romantik. In: ZfsIPh 4 (1927). S. 299-323. Hier S. 305.

Das wesen von Tjutčevs Nachtmetaphorik kristalliaiert sich in einem Satz im Gedicht "Sumerki" heraus: "Vse vo me, i ja vo veem!" Aber auch Puškin und Gogol' verlegen die Handlung ihrer Werke - wie auch alle übrigen russischen Romantiker - häufig in die Nacht. Vgl. D. TSCHIĽLWKIJ, Literaturgeschichte, a.a.0., Bd. 1. S. 132.

2 In einem Vortrag über die deutsche und englische Romantik, gehalten im April 1963 an der Ohio State University, setzt René Wellek bereits voraus, daß die entscheidende Debatte über die europäische Romantik gewonnen sei: "Es gibt einen Zusammenhang romantischen Denkens und romantischer kunst in Europa." Anschließend wiederholt R. Wellek noch eimmal seine Argumentation aus dem Jahre 1949: "Wir finden in ganz Europa die gleichen Begriffe von Dichtung, von Wesen und Wirkung der dichterischen Imagination, den gleichen Begriff von Natur und ihrer Beziehung zum Menschen, und in Grunde den gleichen poetischen Stil mit einer Technik, Bilder, Symbole und Mythen zu verwenden, die allesamt vom Nooklassiziemus des achtzehnten Jahrhunderts deutlich unterschieden sind." R. WEUEK, Konfrontationen. Vergleichende Studien zur Romantik. Frankfurt an. M. 1964. S. 9-10.

Hans Georg Schenk untermavert Wolleks These durch eine unfangreiche Materialsammlung. Außerdem weist Schenk darauf hin, daß die romantische Bewegung nicht nur alle Teile Europas - mit Ausnahme der Türkei - erfaßt habe, sondern auch, wenn auch in geringerem Maße, den amerikanischen Doppelkontinent. Vgl. H.G. SOENK, a.a.O., S. XIII. 
Die Tradition der europäischen Nachtpoesie beginnt mit dem Hauptwerk des englischen Dichters Edward Youngs "Night Thoughts on Life, Death and Immortality" (1742 f), entwickelt sich weiter in Deutschland bei Klopstock und Herder, in RuBland bei Deržavin und Bobrov und teilt sich dann in zwei getrennte Richtungen: in die romantische Nachtphilosophie einerseits (H.G. Schubert und Schelling) und in die romantische Nachtlyrik andererseits (Novalis und Keats).

Erst Tjutčev gelingt es, diese beiden Richtungen, die philosophische und die lyrische, in einer "einzigartigen lyrisch-philosophischen synthese" zusammenzufassen."

Die Einordnung Tjutcevs in die Tradition der europäischen Romantik darf allerdings nicht dahingehend miBverstanden werden, die Lyrik des russischen Dichters als das Resultat gewisser philosophischer und lyrischer Einflüsse zu verstehen.

Es handelt sich bei TjutCevs Nachtlyrik auch nicht, bei aller gedanklichen Nähe zum deutschen Idealismus, um eine übertragung der philosophischen Gedanken Schellings in eine lyrische form. Tjutzev ist zwar von Schellingschen Gedankergängen befruchtet worden, letztlich legen diese aber nur die Grundlage fü die selbständige gedankliche Entwicklung des russischen Dichters. 2

Tjutčev steht jedoch nicht nur in einer europäischen, sondern gleichzeitig in einer spezifisch russischen literarischen Tradition.

1 B. ZELINSKY, a.a.0., S. 84. Vgl. L.V. PUMPJANSKIJ, Poezija Tjutčeva. In: Urani ja. T jutČevskij Al'manach 1803-1926. Leningrad 1926. S. 9-57. Hier S. 49-50. Bereits Pumpjariskij meist auf den gesamteuropäischen Zusammenhang der Nachtthematik hin.

2 Kirill Pigarev setzt sich ausführlich mit den unterschiedlichen Stellungnahmen zum Einfluß Schellings auf Tjutčev auseinander. vgl. K. PIGAREV, F.I. Tjutčev i ego vremja. Moskau 1978. S. 224 227. Zur Beziehung Tjutčevs zu Scholling vgl. auch $M$. BOČEA, Poézi ja Tjutčeva i tradicija romantizma. In: Slavjanska Filologija 13 (1973). S. 121-134. Hier S. 122. 
In seinem Werk spürt man gewisse Anklänge an die großen Formen des 16. Jahrhunderts. Diese Dichtung kannte Tjut Xev gut und besonders die Oden Derzavins haben eine deutliche Spur in seiner Dichtung ninterlassen. 1 Der Einflub des russischen Klassizismus auf Tjuttev darf aber nicht überbewertet werden. 2 Tjuttev nat nicht die Gattung der Ode weiterentwickelt, sondern die kleinformen der Lyrik in den Rang hoher Dichtung gehoben. 3

Neben Derzavin übt auch V.A. Žukovskij EinfluB auf TjutČrs Lyrik aus. 4 Am stil seiner Jugendgedichte spürt man diesen EinfluB besonders stark, aber auch in seinen späteren versen finden sich häufig wortverbindungen, die an Zukovskij erinnern. 5

1 2.8. die Ode Deržavins "Na emert" knjazja Meščerskogo". Die Einleitungszeile "Glagol vremen! metalla zvon!" ähnelt den Zeilen aus Tjutčevs "Bessonica": "Metalla golos pogrebal'nyj/Poroj aplakivaet nas!". Es gibt noch mehrere solcher Beispiele. Vgl. K. PIGAPEV, TjutZev, a.a.O., S. 286-289.

Auch in der bildhaften Beschreibung des Gewitters ist Deržavin der Vorläufer Tjutčevs. So erinnert Deržavins "Grom" deutlich an die zahlreichen Gedichte Tjutčevs zu diesem Thema. Nicht zuletzt macht sich Tjuť̌ev das von Deržavin häufig benutzte Epitheton "zlatoj/zolotoj" zu eigen. Vgl. K. PIGAREV, TjutZev, a.a.O., S. 289.

2 Diesen Fehler begeht Pumpjanskij. Vgl. L.V. PUMPJANSKIJ, a.a.O., S. 36-51.

3 Auch damit gab er A.A. Fet und den Symbolisten wichtige Anstöße. Zur europäischen Tradition der kleinen lyrischen Gedichte TJutčevs und ihrer Stilhaltungen vgl. A. SaluzE, Tjutčevs Kurzlyrik. Traditionszusarmenhänge und Interpretationen. Minchen 1968 (FS 25).

4 Seit 1617 waren die beiden Dichter miteinander befreundet. Tjutčevs Gedichte enthalten verschiedentlich Himweise auf inr freundschaftliches Verhältnis, 2.B. "Na rannej dnej moich zare" aus dem Jahre 1873.

5 Z.B. "očarovannaja mgla", "legkaja mečta" (aus dem Gedicht "Kak ni dyšit polden" znojnyj", 1850) oder "volsebnyj prizrak", "vozdušnyj ̌̌itel"" (aus dem Gedicht "Den" večereet, noł. bližka", 1651). Vgl. K. PIGAREV, T jutčev, a.a.0., S. 290; M. BOCEVA, a.a.o., S. 131 . 
Tjuttevs künstlerisches wirken ereignete sich weitgehend abseits der bedeutenden und einfluBreichen literarischen Gruppierungen seiner Zeit. ${ }^{1}$ Als Mensch wie als Dichter blieb er AuBenseiter. So kann man Tjuttev auch nicht zu den vertretern der "Reinen Kunst" zählen, wie es, besonders in populärwissenschaftlichen Darstellungen, näufig gemacht wird. Zwar stand er als konservativer Politiker den in den fünfiger und sechziger Jahren herrschenden sozialen und politischen Ideen fern, ${ }^{2}$ doch war er nie - im Gegensatz zu den Leitlinien der vertreter der "Reinen Kunst" - ein prinzipleller Gegner gesellschaftlicher Themen in der Literatur. 3

Intellektuell am nächsten stand Tjuť̌ev wohl den "Ljubomudry", die sich um Vladimir Odoevskij sammelten. In inrem Kreis wurde die Kenntnis der deutschen Philosophie und Dichtung vermittelt. Im Zentrum des Interesses stand neben Schelling auch Goethe. Erst später entwickelt sich Tjuttev zu einem verfechter slavophiler Ideen.

1 Vgl. M. BOČEVA, a.a.O., S. 127.

2 Tjutčevs politischen Anschauungen waren - besonders in seiner Jugend - vom Geiste des Sentimentalismus geprägt. Danach sind alle Menschen in dem Sinne gleich, daß sie imstande sind, Glück und Leid zu empfinden. Eine politische Dimension bekam diese Erkenntnis nur selten.

3 So machen nach Pigarev Gedichte mit gesellschaftlich-politischen Themen ungefähr den 4 . Teil des poetischen werks TjutCevs aus. vgl. K. PIGAREv, Tjutčev, a.a.O., S. 263. Besonders an seinen Epigrammen läßt sich ablesen, wie aufmerksam Tjutčev die Ummelt beobachtete. U.a. zu politischen und gesellschaftlichen vorgängen nimnt er hier - oft scharf - Stellung. Vgl. A. SOALZE, a.a.O., S. 80. Daneben verfaßte er noch einige politische Aufsätze. 
verwurzelt in der Geisteshaltung der Romantik führt Tjutלevs Lyrik direkt zur Welt der symbolisten. So waren es diese, die Tjuttevs Lyrik - nachdem sie fast in vergessenheit geraten war - neu für sich entdeckten. 1

Eingeleitet worden war diese neve Epoche in der Beurteilung TjutCevs in RuBland durch den Aufsatz "Poezija rjutteva" Vladimir Solov'evs, der 1895 im "vestnik Evropy" veröffentlicht wurde. 2 Die Dichter des fin de siècle empfanden TjutČevs Lyrik als innen innerlich nahestehend und erkoren ihn wegen seiner sprachbeherrschung und der Musikalität seiner Verse zu inrem Lehrer. 3

Nie zuvor hat die Lyrik TjutKevs eine solche wirkung auf seine Umgebung ausgeubt wie in den Jahren um die Jahrhundertwende. Tatsächlich erinnern Gedichte wie "Mal'aria", "Bezumie" und "Bliznecy"4 an die teilweise

1 Anfang des 20. Jahrhunderts murde TjutCev als Ahnherr des russischen Symbolismus verstanden. Vgl.V. IVANOV, Iskusstvo i Simvolizm. In: Ders.. Borozdy i Moži. Mookau 1916. ND Ilkley, Yorks. 1971. S. 119-232. Hier S. 132-133. VgI. V. OU FEU, Tiutcheff, premier symboliste russe. In: Langue et Littérature. Actes du vIII ${ }^{\text {p }}$ Congrè de la fédération Internationale des Langues et Littératures Modernes. Paris 1961. S. 330-331; vgl. B. ZELINSKY, a.a.0., S. 248 .

2 Die Bedeutung dieses Aufsatzes ist nicht zu unterschätzen. Solov'ev hat als erster Tjutčevs Lyrik auch als Ausdruck einer bestimnten Weltanschauung verstanden.

3 Vgl. V.Ja. BRJusov, F.I. TjutZev. Kritiko-biografiČeskij očerk. In: F.I. Tjutčev. Polnoe sobranie soX̌inenij. Hrsg. P.V. By̌̌kov. Izd. 7-e. St. Petersburg 1912. S. VII-XLVIII. Hier S. XLVI-XLVII.

4 In diesem Gedicht bildet die Liebe mit dem Selbstmord ein dämonisches Zwillingspaar. Pumpjanskij weist auf die Verwandtschaft, besonders der letzten Strophe des Gedichts, mit der Poesie Baudelaires und Brjusovs hin. Vgl. L.V. PUNPJANSKIJ, a.a.O., S. 34-35. 
übersteigerten Phantasien und Sehnsüchte der späteren Symbolisten. 1

Zu ihrem Leitspruch wählten sie den vers "Der ausgesprochene Gedanke ist Lüge" ("Mysl' izretennaja est" lož."), in dem TjutXevs "Silentium" gipfelt. Und 1910 macht Mandeliztam das Wort silentium zum Titelwort eines eigenen Gedichtes, in dem er - wie Tjuttev seinerzeit - uber die Sprache und damit uber das wesen des Menschen nachdenkt. 2

1 Kirill Pigarev hält jedoch ihr verständnis für die Lyrik Tjutčevs für oberflächlich; es erschöpfe sich weitgehend in der variierung unbedeutender Motive seiner Dichtung und in der Entlehnung bestimmter formen der künstlerischen Gestaltung. Innerlich nahe habe Tjutčev lediglich Aleksandr Blok gestanden. Vgl. K. PIGAPEV, TjutCev, a.a.0., S. 317. Tatsächlich sind in Bloks Dichtung verschiedene Tjutčevsche Themen und Bilder eingestreut, wie etwa die aus dem Jahre 1899 stammende Szene eines Gewitters ("Ty $\zeta_{i l}$ odin! Druzej ty ne iskal"). Vor allem in seinen "Gedichten über Rußland" ("Stichi O Rossii"), die 1915 erschienen, führt Blok die Tradition TjutZevs fort. In diesen Gedichten erblickt Blok in der Armut seines Heimatlandes das Unterpfand einer besonderen messianischen Sendung. Solche Gedanken erinnern an TJutČevs Gedicht "Éti bednye selen' Ja".

2 Zu Recht zieht Zelinsky den Schluß, daß die "Sprachkrise der Moderne", die sich vor allem an den Naren Hofmannsthals knupft, auch schon in der russischen Romantik vorliegt. Vgl. B. ZELINSKY, a.a.0., S. 250. Pigarev verengt die Aussage des TjutXevschen "Silentium" auf die für die Romantik typische Gegenuberstellung der feinempfindenden Persönlichkeit und der gleichgiultigen Gesellschaft. Die Sprachreflexion des Dichters kann jedoch nicht nur aus soziologischer Sicht gesehen werden. Im Zentrum des Gedichts steht das Wesen des Menschen, nicht nur seine gesellschaftliche Stellung. Vgl. K. PIGAREV, Tjutčev, a.a.0., S. 196-97; B. ZELINSKY, a.a.o., S. 241. 
TjutCevs beachtlicher EinfluB auf die Symbolisten läBt sich auch anhand der gebrauchten dichterischen figuren aufzeigen. Der "Abgrund" ist durch inn zu einer der "Modemetaphern der symbolistischen Literatur" geworden. 1

In TjutKevs "Svjataja not" na nebosklon vzołla" steht der Mensch, zurückgeworfen auf sich selbst, schaudernd vor dem unergründlichen Dunkel. Dennoch spürt er die verwandtschaft seiner Seele mit den Abgründen der Nacht. ${ }^{2}$

wie es in diesem Gedicht einen geheimen Zusammenhang zwischen der Welt der Seele und dem geheimnisvollen Dunkel gibt, so ist auch in "Sumerki" die vernichtung nicht Ziel sondern Durchgang $2 u$ einem neuen Leben." Das Finstere führt TjutZer nicht in die Leere des Nichts, sondern in den Raum der menschlichen Selbstfindung. Die Nacht setzt die schöpferischen Kräfte des Dichters frei, 4 jetzt wird er zum "helleuchtenden Gott". 5

1 H. SANEIDER, Der frühe Bal'mont. Untersuchungen 24 seiner Metaphorik. Minchen 1970 (FS 16). S. 56. A. BelyJ macht sich sogar schon über die allzu häufige verwendung dieser Metapher lustig. Ebd. S. 56-57.

2 Dies wird besonders in den beiden Abschlubzeilen des Gedichtes deutlich: "I $\vee$ Čuždom, nerazgadannom, nočnomvon uznaet nasled'e rodovoe". ("Und im Fremden, Unenträtselten, Nachtlichen/Erkennt er sein verhängnisvolles Erbe.") Vgl. S. FRANK, Das kosmische Gefühl in Tjutčevs Dichtung. In: Zfsiph 3 (1926). S. 20-58. Hier S. 26.

3 Vgl. B. ZELINSKY, a.a.0., S. 88.

4 Z.B. in Tjutčevs 1829 entstandenem Gedicht "Videnie" ("Est nekij čas, v noči i, vsemirnogo molčan' ja"l).

5 So in dem 1630 entstandenen Gedicht: "Ty zrel ego v krugu bol'šogo sveta". Die letzten beiden Zeilen lauten: "Nastala noč' - $i$, svetozarnyj bog,/Sijaet on nad usyplennoj roscej!". Zu deutsch: "Die Nacht ist angebrochen -, und er, ein helleuchtender Gott, $/$ Glänzt über dem eingeschläferten Hain." übersetzung nach B. ZELINSKY, a.a.o., S. 91. 
So bleibt Tjutלev ganz und gar "romantischer Symbolist". Für inn bedeuten Abgrund und Vernichtung, Nacht und Finsternis nicht Ende, sondern Beginn eines neven, schöpferischen Lebens. 1

1 Vgl. B. ZELINSKY, a.a.0., S. 91. Auch in Tjutčevs Naturlyrik schließt der Tod die Wiedergeburt zum Leben ein. Eine grundlegende Untersuchung über Tjutčevs Einfluß auf die Dichtung der Symbolisten lieferte der sowjetische Literaturwissenschaftler N.K. Gudzij. N.K. GUOZIJ, TJutčev v poètičeskoj kul'ture russkogo simvolizma. In: Izvestija Do russkomu jazyku i slovesnosti. Bd. 3, Buch 2. Leningrad 1930. S. 465-549. 

DEUTSCHLAND

\subsection{Goethe in RuBland des 19. Jahrhunderts}

Breiteren Leserschichten in RuBland ist Goethe bereits im ausgehenden 18. Jahrhundert bekannt geworden." 1780 erscheint das in Prosa abgefabte Jugenddrama "Clavigo" - im Original 1774 veröffentlicht - in der übersetzung oleg P. Kozodavlevs als erstes Goethe-Werk in russischer wiedergabe. Gebildeteren Kreisen, die deutsche Autoren im Original zu lesen vermochten, ist Goethe schon länger - vermutlich seit dem letzten Drittel des 18: Jahrnunderts - ein Begriff.

Weitaus gröBeren Anklang als der "Clavigo" findet jedoch in der Zeit des in RuBland aufkommenden Sentimentalismus Goethes Jugendroman "Die Leiden des jungen Werther". Je zwei Auflagen erleben die Übersetzung F. GalCenkovs (1761 und 1794) und Ivan Pogodins (1796 und 1616). Und 2 wischen 1799 und 1800 arbeiteten A.I. Turgenev und $v$. Merzljakov, beide Mitglieder des "Družeskoe Literaturnoe Obščestro", an einer weiteren übersetzung des Romans.

1 Einen bis heute grundlegenden Überblick ubber Goethes Wirken in Rußland und weiterführende Literaturhimweise finden sich in der Goethe gewidneten Jubiläumsausgabe voul "Literaturnoe Nasledstvo" 4-6, Moskau 1932, sowie bei V.M. ZIFMnNKIJ, Gete v russkoj literature. Leningrad 1981; vgl. hierzu die Rezension der 1. Aufl. von 1937: A. BEM. In: Zfslph 16 (1939). S. 430-434. Erwähnenswert sind auch folgende deutschsprachigen Untersuchungen: $M$. GORLIN, Goethe in RuBland. In: ZfslPh 9 (1932), S. 335-357, ZfslPh 10 (1933), S. 310-334; A. POCOOIN, Goethe in RuBland. In: Germanoslavica 1 (1931-1932). S. 333-347; B. KAISER, Über Beziehungen der deutschen und russischen Literatur. Berlin 1948. Eine umfassende Darstellung der literarischen Beziehungen zwischen Rußland und Westeuropa im 19. Jahrhundert liefert V.I. KULEŚSOV in seiner Arbeit "Literaturnye svjazi Rossii i zapadnoJ Evropy v XIX veke. Moskau 1965. 
Die allgemeine Begeisterung für Goethes "Werther" in der Epoche der Empfindsamkeit spiegelt sich weiternin in den zahlreichen Nachahmungen, Umarbeitungen und Iyrischen Weiterführungen, die am Ende des 18. Jahrhunderts entstanden sind. Unter den zahlreichen Nachahmungen jener Jahre kommt dem "Rossijskij Verter" Michail vladimir Suškovs (1792 verfaßt) besondere Bedeutung zu.

Gewisse thematische Anklänge an das Selbstmordmotiv in der Erzählung Werthers von einem im Stich gelassenen Mädchen - es nimmt sich das Leben durch Ertrinken - finden sich auch in Karamzins epochemachender Novelle "Bednaja Liza".

Goethes Lyrik bleibt zunächst - von wenigen Ausnahmen abgesehen - in RuBland weitgehend unbekannt. Zwar werden übersetzungen von Goethe-Gedichten in Zeitschriften veröffentlicht (2.B. Gavrill R. Derzavins übersetzung von "Mit einem goldnen Halskettchen" unter dem Titel "Cepołka", 1807, und Ivan I. Dmitrievs Wiedergabe der Hymne "Grenzen der Menschheit" unter "Na sluCaj groma", 1795), aber diese Übertragungen sind meist recht unbedeutend und insgesamt nicht sehr zahlreich. Berüht bleibt Goethe auch zu Beginn des 19. Jahrhunderts als verfasser des "Werther" und als Dramatiker.

Erst mit dem Ende des "Vaterländischen Krieges" 1812, das einen Meilenstein in der Entwicklung der deutschrussischen Literaturbeziehungen darstellt, beginnt in RuBland eine Epoche der intensiveren Bekanntschaft mit Goethes breitgefächertem Werk. Auch der deutsche Dichter selbst rückt immer mehr in den Mittelpunkt des Interesses. In den Jahren des Krieges und der darauf folgenden Zeit treffen K.N. Batjuškov, F.I. Glinka, N.I. Greč, 
V.A. Zukovskij, V.K. Kjuchel'beker und A.I. Turgenev in Deutschland mit Goethe zusammen. Etwas später folgen S.P. Sevyrev und N.M. Rozalin.

Besondere Bedeutung bei der verbreitung von Goethes lyrischem Werk kommt V.A. Žukovskij zu. Er ist es, der durch seine zahlreichen übersetzungen Goethes Gedichte in RuBland berühmt macht, die Balladen vom "Fischer" und "Erlkönig" entwickeln sich durch ihn zu einem festen Bestandteil der russischen Literatur.

Fortgesetzt wird dieser bedeutsame Anfang Žukovskijs Ende der zwanziger/Anfang der dreibiger Jahre durch F.I. TjutZev. Seine Übersetzungen Goethescher Lyrik tragen wesentlich dazu bei, dem russischen Leser ein umfassenderes und differenzierteres Bild von dem Lyriker Goethe zu vermitteln.

Puškin, der Deutsch nur sehr unvollkommen beherrscht und daher Goethe nicht im Original lesen kann, ist das lyrische Werk des deutschen Dichters noch weitgehend unbekannt. Lediglich an das berünte Lied Mignons "Kennst du das Land" finden sich Anklänge in zwei seiner Dichtungen.' Überhaupt lassen sich nur vereinzelt Spuren von Goethes Werk bei Puškin entdecken.

1823 entsteht das Gedicht "Der Dämon". Es ist der alles verspottende, alles verneinende Geist. In einem Kommentar zu diesem Werk bezieht sich Puškin auf Goethe und den von inm geschaffenen "Geist der Verneinung".

Im Jahre 1825 arbeitet Puškin an einem Gedicht - es sind Dialoge in Versen - über Fausts Besuch in der Hölle. Allerdings sind von diesem Poem nur Fragmente erhalten geblieben.

1 In "Želanie" (1821) und "Kto znaet kraj" (1627), das mit dem Epigraph "Könnst [sic!] du das Land ... Wilh. Meist." versehen jst. Die Handschrift dieses Gedichts ist abgebildet bei V.M. ZIPanNSKIJ, Literatura a.a.0., S. 107. 
Aus demselben Jahr stammt Pułkins "Szene aus dem Faust" ("Scena iz Fausta"). Dieses Kurzpoem entrält einige Motive, die auch im "Faust II" anzutreffen sind. Um eine Nachdichtung kann es sich allerdings nicht handeln, da Pußkins Werk einige Jahre vor der veröffentlichung des "Faust II" erschienen ist. Und so spricht Lew Kopelew hier von einer "kongenialen koinzidenz". 1

Die Frage, ob der russische Dichter Je Goethes "Faust", der bereits 1825 in der französischen übersetzung Albert Stapfers erschienen ist, vollständig gelesen hat, läßt sich nicht mehr eindeutig beantworten, Zweifel scheinen jedoch angebracht. Zum Bestand seiner Bibliothek zählte kein einziges Werk Goethes, weder im Original noch in übersetzung. Möglicherweise kannte Puškin lediglich die detaillierte Beschreibung des "Götz" und des "Faust", sowie einige Ausschnitte aus letzterem von der Lektüre Mme. de Stä̈ls vielgelesenem Werk "Deutschland" ("De l'Allemagne", 1810).

Dennoch taucht der Name Goethe - meist in Zusammenhang mit Shakespeare oder $w$. Scott - wiederholt in Puškins kritischen Aufsätzen und Briefen auf. Dies geschieht jedoch erst zu einem Zeitpunkt, als der russische Dichter Byrons prägenden EinfluB uberwunden und seine Abkehr von dessen Dichtung eingeleitet hat. Während jedoch Shakespeare und $w$. Scott tatsächlich einen bedeutenden Einfluß auf die schöpferische Entwicklung Puškins zu jener Zeit haben, ist Goethes Bedeutung für den russischen Dichter eher gering. Puškins ÄuBerungen über den deutschen Dichter und sein werk bleiben, von wenigen Ausnahmen abgesehen, vage und pauschal.

Ein interessantes Zeugnis über die Beziehung Puškins zu Goethe findet sich in einem Brief des russischen

1 L. KOPELEW, Faust in Rußland. In: Ders., Zwei Epochen deutschrussischer Literaturbeziehungen. Frankfurt a.M. 1973. S. 47-93. Hier S. 52. 
Dichters aus Odessa aus dem Jahre 1824. In Zusammenhang mit seiner Bibel-Lektüre berichtet er: "... svjatyj duch inogda mne po serdcu, no predpotitaju Gete i Škspira." 1 Die Erwähnung von Goethes Namen in diesem Kontext zeugt onne Zweifel von einem Gefühl der Verbundenheit, das Pułkin für den deutschen Dichter und sein Werk empfindet.

So ist es nicht überraschend, daB sich Pułkin für die verbreitung von Goethes Werk in RuBland engagiert. Er unternimmt mehrfach Versuche, die von der Zensur verbotene Veröffentlichung des "Egmont" in der übersetzung Aleksandr A. Siškovs aus dem Jahre 1831 doch noch zu ermöglichen. Weiterhin nimmt Puškin regen Anteil an der Arbeit E. Grubers, des ersten Faust-Ubersetzers. Veröffentlicht wird Grubers übersetzung allerdings erst ein Jahr nach Puškins Tod. 2

1 A.S. PǓ̌xin, Polnoe sobranie sočinenij $v$ desjati tomach. MoskaurLeningrad 1949. Hier Bo. 10. S. 86.

2 So ist es wesentlich Pułkin zu danken, daß sich Goethes "Faust" auch in Rußland immer größerer Beliebtheit erfreuen konnte. Besonders aus diesem Grunde wehrt sich Lew Kopelew in seinem Aufsatz "Faust in Rußland" gegen die Schablone, daß der russische Dichter sich nur für Byron und Shakespeare begeistert habe. Der russische Literaturwissenschaftler weist auf Puß̌kins großes Interesse für Goethe hin. Davon zeugen vor allem die zahlreichen Bearbeitungen des Faust-Themas in Puǧkins Arbeitsentwirfen.

Andererseits weist Kopelew aber auch die versuche zurick, in sehr vielen Werken Pư̌kins um jeden Preis Goethes EinfluB nachweisen zu wollen. vgl. L. KOPELEW, a.a.O., S. 50-56. 
Wie ein bedeutsamer EinfluB Goethes auf Pułkins Schaffen nicht festzustellen ist, entwickeln sich auch die meisten seiner Zeitgenossen völlig unabhängig von Goethe. Ein ernsthaftes Interesse am Werk des deutschen Dichters haben lediglich die den Dekabristen nahestehenden Dichter v. Kjuchelibeker - Tschižewskij bezeichnet inn als den "ersten russischen 'Goetheaner'"1 - und Aleksandr $S$. Griboedov.

Eine intensive Beschäftigung mit Goethe und seinem Werk setzt in der zweiten Hälfte der zwanziger Jahre ein. Diese philosophische wie poetische Nevorientierung entwickelt sich in engem Zusammenhang mit der zunehmenden Ausbreitung romantischen Gedankenguts in Rubland.

Besonderen EinfluB auf die wachsende Bedeutung Goethes nimmt eine Gruppe junger Leute, die sich um vladimir $F$. Odoevskij sammelt und deren Mitglieder sich kennzeichnenderweise als "Ljubomudry", als "Philosophen", bezeichnen. Zu ihnen gehören vor allem D.V. Venevitinov, N.M. Rožalin sowie S.P. Sevyrev und M.N. Pogodin. Zusammen mit Odoevskij bemühen sie sich um die Kenntnis der deutschen Philosophie und philosophischen Dichtung uberhaupt. Im Mittelpunkt ihres Interesses steht dabei die Philosophie Schellings sowie Denken und Dichtung von Goethe und Byron.

Goethe verehren die "Ljubomudry" besonders als verfasser des "Faust" und poetischen Denker. Neben zahlreichen kritischen Beurteilungen seiner Persönlichkeit und seines Werkes - hierbei tun sich besonders venevitinov und Ševyrev hervor, und sie vertreten keinesfalls immer identische Ansichten - verfassen die Mitglieder der

1 D. TSOHIŽLWSKIJ, Literaturgeschichte, a.a.0., 8d. 1. S. 74. 
Gruppe beachtliche Übersetzungen.

Venevitinov ubersetzt Abschnitte aus dem "Faust $I "$, zwei Szenen aus "Egmont", sowie die beiden thematisch eng verflochtenen Gedichte "Des Künstlers Erdewallen" ("Zemnaja ulast" chudoZnika") und "Künstlers Apotheose" ("Apofeoza chudoZnika").

Sevyrev wendet sich als erster russischer Dichter dem zweiten Teil des "Faust" zu, hieraus ubersetzt er Teile des Zwischenspiels ("Helena, Klassisch-romantische Phantasmagorie"). Weitere übertragungen liefern M.N. Pogodin (vom "Götz von Berlichingen") sowie N.M. Rozalin (vom "Werther"). Rožalins Übersetzung des "Egmont" ging verloren.

Ein Grobteil dieser Wiedergaben wird 1827 im "Moskovskij vestnik", dem bedeutendsten Organ der russischen "Goetheaner" veröffentlicht. Zwar hatte sich der Zirkel der "Ljubomudry" nach dem Dekabristenaufstand aufgelöst, jedoch widmet sich etwa derselbe Personenkreis nun der Herausgabe dieser Zeitschrift.

Deutscher Philosophie und Dichtung besonders verbunden fühlen sich neben den "Ljubomudry" auch die russischen "Hegelianer", die sich in den vierziger Jahren (gemeint ist die Zeit etwa zwischen 1835 und 1845) um Nikolaj $v$. Stankevič treffen. $Z u$ innen gehören neben Stankevič selbst U.a. Vissarion G. Belinskij, Michail A. Bakunin, Aleksandr I. Gercen (Herzen), Ivan S. Turgenev, Timofej N. Granovskij und Konstantin S. Aksakov.

Es beginnt die zeit der kritischen Auseinandersetzung mit Goethe. Durch die 1837/38 in Petersburg erschienene übersetzung der vielbeachteten Arbeit Wolfgang Menzels (1798-1673), in der er, nach mehreren polemischen Aufsätzen, zum Großangriff gegen Goethe übergeht, wird die 
Diskussion über den deutschen Dichter auch nach RuBland getragen.

Hier engagieren sich besonders lebhaft Gercen - dieser bezieht als erster Russe auch Goethes naturwissenschaftlichen Schriften mit ein - und Belinskij. Im Gegensatz zu Gercen, der seit Beginn seiner publizistischen Tätigkeit den romantischen Goethe-kult in RuBland kritisiert und den deutschen Dichter der politischen Indifferenz zeint, eignet sich Belinskij erst nach und nach eine kritisch-distanzierte Betrachtungsweise Goethes an. Vom enthusiastischen verehrer Goethes, der heftig gegen Menzel und die jungdeutschen Goethe-Gegner polemisiert, wandelt sich Belinskij zu einem kritiker des "egoistischen" und "nur auf die kunst beschränkten weimarer Olympiers".

Ende der vierziger Jahre schaltet sich auch der junge Turgenev in die Diskussion uber Goethes Werk und Weltanschauung ein. Im Mittelpunkt seiner Uberlegungen steht dabei der "Faust", den er als Ausdruck des aufgeklärten Humanismus auBerordentlich hoch schätzt. Gleichzeitig kritisiert Turgenev scharf die 1844 veröffentlichte Übersetzung $M$. Vrončenkos. Diesen bezichtigt er der beabsichtigten Entstellung der Goetheschen vorlage im sinne einer christlich orientierten Moral.

Nikolaj G. Černyševskij, neben Nikolaj A. Dobroljubov und Dmitrij I. Pisarev einer der maBgebenden Theoretiker des russischen Realismus, setzt die in den dreibiger und vierziger Jahren begonnene Auseinandersetzung mit Goethes werk fort.

Černyševskij trennt scharf seiner Überzeugung nach wirkliche Meisterwerke Goethes von eher schwachen stücken, zu denen er - wie auch Belinskij - "Hermann und Dorothea" zählt. Nur wo der deutsche Dichter in direkter 
Tradition Lessings stehe - diesen bewundert der russische Kritiker als bahnbrechenden Kunstkritiker der deutschen Aufklärung - zeigten sich die bedeutenden Seiten seines Werks. Als eine Weiterentwicklung der lessingschen Tradition sieht Cerny̧evskij u.a. Goethes "Faust", der folglich sein besonderes Interesse auf sich zieht.

überraschend hoch schätzt Cerny̧̌evskij auch Goethes Lyrik. Sowohl in seinem Tagebuch wie auch in dem 1863 in Nekrasovs "Sovremennik" (bis 1666 leitet Nekrasov die von Puškin gegründete Zeitschrift) veröffentlichten Roman "Čto delat"?" finden sich deutliche Anklänge an Goethes "Mailied". Nahe stehen inm weiterhin die Ballade von der "Braut von Korinth" - diese schätzt Cernyševskij wegen inrer Anklage der neven christlichen Religion mit ihrem gewissen Verschmähen der Geschlechtlichkeit - und das Gedicht der Sturm und Drang - Epoche "Auf dem See".

Grundsätzlich negativ beurteilen Goethe die beiden ebenfalls in der Belinskij-Tradition stehenden Kritiker und Mitarbeiter der radikalen Zeitschrift "Russkoe slovo" (diese wurde gleichzeitig mit Nekrasovs "Sovremennik" 1866 verboten) D.I. Pisarev und Varfolomej A. Zajcev.

Diese beiden radikalen vertreter des weltanschaulichen Materialismus, die sogar Puškin und Lermontov angreifen und verulken, halten Goethe für ein "gealtertes Götzenbild" und bezichtigen ihn der Servilität und Unaufrichtigkeit. Der Zugang zu Goethes werk bleibt Pisarev und Zajcev versperrt, beide betrachten literarische Schöpfungen ausschlieblich unter dem Aspekt der von ihnen im RuBland der fünfiger und sechziger Jahre der Literatur zugedachten sozial-revolutionären Aufgabe.

Solchen Ansichten fern stehen die vertreter des "l'art pour l'art", die - abseits des suzial-politischen Radi- 
kalismus jener zeit - von der politisch orientierten Literaturkritik scharf angegriffen werden. Die Theoretiker dieser auf das Ästhetische ausgerichteten Kunstauffassung, wie z.B. V.P. Botkin und A.V. Družinin, berufen sich neben Puškin auch auf Goethe. Ihrer überzeugung nach zeigt sich die Größe des deutschen Dichters darin, daß er seiner Gegenwart wenig Beachtung schenkte und statt dessen seinen Blick auf die unvergängliche Natur und die ewigen werte der menschlichen seele richtete.

Die aktive Auseinandersetzung der russischen Kritik mit Goethe entwickelt sich parallel zu einer wachsenden veroreitung seiner Dichtungen durch immer zahlreicher werdende übersetzungen. Besonders im verlaufe der dreiBiger und vierziger Jahre wird Goethe intensiv ubersetzt, veröffentlicht werden die Resultate in literarischen Zeitschriften oder sie erscheinen in seperaten Ausgaben.

1842 übernehmen I. Glazunov und I. Bočarov als erste den Versuch, Goethes werke gesammelt herauszugeben. Allerdings scheitert das Unternehmen, nach heftiger Kritik Belinskijs wird die Herausgabe nach der dritten Teillieferung bereits im folgenden Jahr wieder eingestellt.

Zu denjenigen russischen Dichtern, die sich besonders durch Übertragungen Goethes hervortun, gehören Apolion Grigor'ev - dieser setzt sich auch seit Beginn der füfziger Jahre als Kritiker theoretisch mit dem Werk des deutschen Dichters auseinander - und Konstantin Aksakov. Beide stehen sowohl als Dichter als auch als übersetzer in der Tradition der russischen Romantik.

Insgesamt nur 2 wei Mal wendet sich Lermontov Goethe zu. 1831 wird seine in Versen verfaßte übertragung des Abschiedsbriefes Werthers ("Zaveščanie") veröffentlicht, neun Jahre später folgt seine berünmte übersetzung von 
"Wandrers Nachtlied" ("Uber allen Gipfeln") unter dem Titel "Gornye veř̌iny".

Umfangreiche übersetzungen liefern die beiden Epigonen der Romantik A.A. Fet und A.K. Tolstoj. Fet, der iber seine Mutter der deutschen Kultur eng verbunden ist und hervorragend Deutsch beherrscht, ubersetzt zahlreiche Gedichte und den gesamten Faust (1882/83).

A. Tolstoj ist vor allem durch seine Wiedergabe der klassischen Balladen "Die Braut von Korinth" ("Korinfskaja nevesta", 1667) und "Der Gott und die Bajadere" ("Magadeva i Bajadera", 1867) in fast sämtlichen russischen GoetheAusgaben vertreten.

In der Tradition Nekrasovs steht der ebenfalls bedeutende Goethe- (und Heine-) Ubersetzer Michail L. Michajlov. Als erster russischer Dichter wendet er sich solchen Gedichten Goethes $z u$, denen im weitesten Sinn soziale Motive zugrunde liegen, wie z.B. den Gedichten "vor Gericht" ("Pered sudom") und "Die Spinnerin" ("Prjacha"). Interessanterweise steht bei beiden Gedichten der Typ der - obwohl in Bedrängnis geraten - klaren und selbstbewuBten Frau im Mittelpunkt.

In den frühen vierziger Jahren wenden sich zum ersten Mal auch professionelle Ubersetzer Goethes Werk zu. Auffällig ist dabei ein gewisses Absinken des Ubersetzungsniveaus. Die besondere Aufmerksamkeit gilt meist der Wiedergabe des Grundgedankens und der Absicht einer literarischen Schöpfung. In der Praxis führt dies jedoch - wie die Goethe-Ubersetzungen A. Strugov̌̌čikovs und F. Millers zeigen - leicht zu einer Loslösung des Inhalts von der Form, zu einer willkürlichen MiBachtung der metrischen Struktur des verses und einer stilistischen vereinfachung. 
In der zweiten Hälfte des 19. Jahrhunderts vollzieht sich eine deutliche Wandlung in der Beziehung der russischen Kritik zu Goethe. Der revolutionäre Schwung im RuBland der sechziger Jahre fördert in erster Linie solche literarische und publizistische schöpfungen, die offenkundig mit dem politischen Kampf der Intelligenz verbunden sind.

Dichtungen ausländischer Literaten werden $z u$ dieser Zeit nach neuen Gesichtspunkten beurteilt. Deutlich wächst das Interesse der Kritiker und übersetzer an der politisch relevanten Poesie Heines, Hugos und Bérangers. Das Problem Goethe scheint nun für die russische Literatur nicht mehr von so aktueller Bedeutung zu sein, wie noch zwanzig oder dreibig Jahre zuvor. Goethe wird zum großen Klassiker, mit dessen Werk sich uberwiegend Literaturwissenschaftler auseinandersetzen.

Gleichzeitig nimmt in RUBland die Zahl der literarisch interessierten Bürger ständig $2 u$, auch wenn sie im verhältnis zur Gesamtbevölkerung noch immer gering ist. So wächst auch der Leserkreis Goethes, neue Ausgaben seiner Werke, aber auch neue übersetzungen werden nötig.

Nach dem fehlgeschlagenen versuch Glazunovs und Bočarovs im Jahre 1842/43 erscheint zwischen 1865 und 1871 eine sechsbändige Goethe-Ausgabe, herausgegeben von P.l. vejnberg und kurz darauf, zwischen 1878 und 1880, kommt unter der Leitung N.V. Gerbel's die für das vorrevolutionäre RuBland bedeutendste Sammlung von Goethes Werken heraus. Diese zehn Bände umfassende Ausgabe enthält zahlreiche, bis dahin wenig bekannte Werke des deutschen Dichters, die größtenteils neu ubersetzt worden sind. Besondere Bedeutung für den wissenschaftler wie für den interessierten Laien haben die bibliographischen Anmerkungen Gerbel's, in denen die Geschichte der übersetzung jedes einzelnen Werkes zusammengefaBt ist. 
Von Goethes großen Schöpfungen erscheinen in der zweiten Hälfte des 19. Jahrhunderts viele in never ubersetzung, so "Götz von Berlichingen", "Die Leiden des jungen Werther", "Egmont", "Torquato Tasso", "Iphigenie in Tauris", die Romane von wilhelm Meister, sowie die Epen "Hermann und Dorothea" und "Reineke Fuchs". Von den zahlreichen übersetzungen des "Faust" verdienen diejenigen N. Cholodkovskijs (1878) und A. Fets (1882-83) besondere Erwähnung.

Das Begreifen Goethes als großen Klassiker, dessen Werk sich in einer zeitlichen Distanz zur damaligen Gegenwart befindet, schliebt somit nicht die aktive Aneignung seines dichterischen Schaffens aus.

Unter den Schriftstellern der zweiten Hälfte des 19. Jahrhunderts treten besonders I.S. Turgenev und Lev Tolstoj in ihrer Beziehung zu Goethe hervor. In inrer Einschätzung der literarischen Hinterlassenschaft des deutschen Dichters nehmen die beiden jedoch diametral entgegengesetzte Positionen ein.

Turgenev, der seit seiner frühen Jugend unter dem Einfluß deutscher Philosophie und Dichtung steht, bleibt zeit seines Lebens leidenschaftlicher "Goetheaner". Auch der in den vierziger Jahren einsetzende versuch einer Neubewertung des deutschen Dichters ändert seine vorstellung von Goethe als dem genialen Dichter, dem Verkünder fortschrittlicher Ideen, nicht mehr.

In vielen Romanen Turgenevs finden sich Reminiszenzen an Goethe. So steckt nach der Aussage eines Literaturwissenschaftlers in jedem literarischen Helden Turgenevs - von Rudin und Lavreckij bis Litvinov und Neždanov etwas von Goethes Faust. Sie alle sind gleichsam versessen 
auf die deutsche Tragödie, verehren sie leidenschaftlich. Manchen ist die innere verwanotschaft mit faust bewuBt, andere ahnen sie nur. 1

Turgenev versucht, auch Lev Tolstoj an Goethes Poesie heranzuführen. Er kann jedoch nicht verhindern, daß sich sein junger Schriftsteller-kollege im Laufe seines Lebens immer negativer und abwertender über Goethe äußert.

Tolstoj verlangt, von Rousseau beeinfluBt, nicht nur die Abkehr des Menschen von Wissenschaft und Technik, sondern lehnt in letzter Konsequenz auch Kultur überhaupt als eine den Menschen verderbende Kraft ab. Ästhetischer GenuB lenkt nach seiner Uberzeugung nur vom Dienst am Guten ab.

Das Aufbegehren Tostojs gegen Shakespeare und Goethe, seine leidenschaftliche Kampfansage an den Grobteil aller Kunst und Dichtung, versteht kopelew als "titanischen versuch, sein ganzes Leben von Grund auf umzugestalten", als den letzten Aufbruch eines alten Mannes aus dem "Studierzimmer". 2

So richtet sich Tolstojs Kritik an Goethes werk vor allem gegen die vermeintliche Eleganz der form, die dem volk fremo bleiben müsse. Interessanterweise schliebt der russische Dichter lediglich den "Werther" und "Hermann und Dorothea" - in beiden Werken wird das einfache Familienleben idealisiert - von diesem vorwurf aus.

1 vgl. D.S. GUTMAN, Turgenev i Gete. K. voprosu ob ocenke Turgenevym mirovozzrenija i tvorcestva Gete. In: Ucen. zap. Elabužskogo ped. in-ta. Bd. 5 (1959). S. 149-183. Hier S. 172.

2 Zu einem solchen Unternehmen gehört nach kopelew ein Mann, der wirklich faustisch ist, "zu alt, um zu spielen, zu jung, um ohne Wunsch zu sein." Vgl. L. KOPELEW, a.a.0., S. 64 . 
Weiterhin beschuldigt Tolstoj Goethe der Areligiositat, des Fehlens jeglicher religiöser Gefühle, was - nach seiner Uberzeugung - einen engen ZusammenschluB der Menschen verhindert. In einer Tagebucheintragung vom 30. Sept. 1896 bedauert der russische Dichter denn auch, daB Turgenev mit seiner Ehrfurcht vor dem "Faust" Goethes schädlichem EinfluB erlegen sei. 1

Tolstoj selbst ändert seine negativ gefärbte Einsteilung zu Goethe bis zu seinem Tod nicht mehr, obwohl seine verurteliung der von der großen Masse des volkes nicht verstandenen Ästhetik in seiner eigenen dichterischen Praxis, wie auch in seinem Privatleben, keinen Niederschlag findet.

Die Auseinandersetzung der wissenschaft mit Goethe wird eingeleitet durch Rezensionen uno Übersetzungen ausländischer Arbeiten. Ende des 19./Anfang des 20. Jahrhunderts erscheinen dann die ersten Abhandlungen russischer GoetheForscher. Beispielhaft erwännt seien hier die Namen A.A. Šachovs, D.N. Ovsjaniko-kulikorskijs und $S$. Bulgakors.

Besondere Aufmerksamkeit widmen Goethe die russischen Symbolisten, vor allem die der ersten Generation. Theoretiker dieser zu Beginn des 20. Jahrhunderts entstandenen Literaturrichtung wie A. Belyj, v. Ivanov, Ėllis (Pseudonym für Leo L. Kobylinskij) sehen in dem deutschen Dichter den Vorboten und Inspirator oer zeitgenössischen Asthetik.

Regelmäßig erscheinen in den bedeutendsten Organen des Symbolismus - in den Zeitschriften "vesy" und "Irudy i

1 Vgl. L.N. Tasta, Polnoe sobranie sočinenij v 90 tomach. Moskau 1934-53. Hier Bd. 55. S. 246. 
dni" - Aufsätze ibber das verhältnis der russischen symbolisten $z u$ Goethe. Konstantin Bal mont und $v$. Ivanov setzen sich - vom Kult des Individualismus geprägt - mit dem "Faust" kritisch auseinander. Das besondere Interesse gilt weiterhin Goethes später Lyrik, Gedichten wie "weltseele" und "Selige Sehnsucht" ("West-Östlicher Divan").

Die Auseinandersetzung mit dem Werk des deutschen Dichters findet allerdings nicht nur auf theoretischer Ebene statt. So beteiligt sich A. Blok, der innerhalb des russischen Symbolismus zur zweiten Generation zählt, maßgeblich an der Herausgabe des "Faust".

Die Zahl der übersetzungen ist jedoch im verhältnis zum umfangreichen Gesamtwerk der symbolisten eher gering. zu Beginn der neunziger Jahre ubersetzen den deutschen Dichter D. Merežkovskij (zwei Ausschnitte aus dem "Faust") und Bal'mont (Gedichte wie "Mailied", "Prometheus", "Grenzen der Menschheit". "Ein grauer trüber Morgen" u.a. sowie szenen aus dem "Faust"). Hinzu kommen einige übertragungen Goethescher Lyrik von V.Ja. Brjusov (2.B. "Willkommen und Abschied", "Wandrers Nachtlied", "Der König in Thule", "Talismane") und I.F. Annenskij (nur "Wandrers Nachtlied"). Viel Beachtung findet auch Brjusovs 1928 erschienene neue übersetzung des faust I.

Zu dieser Zeit hat bereits die Auseinandersetzung der marxistisch ausgerichteten Literaturkritik mit Goethes Werk begonnen. 
2.2. Beziehungen Žukovskijs und Tjuť̌evs zu Deutschland und zu Goethe

2.2.1. Žukovskijs Kontakte zur deutschen Kultur

2.2.1.1. Die "Dorpater Jahre" des Dichters

Die "Dorpater Jahre" (1815-1817) bilden ein selbständiges Kapitel in der Biographie des russischen Dichters.

Die Gründe für die Abreise des Dichters in die baltische Universitässtadt - seine tragische Liebe zu Marija Andreevna Protasova, der unbeugsame Widerstand ihrer Mutter Ekatarina Afanasievna Protasova, seiner Stiefschwester, gegen eine mögliche Heirat - sind bereits erschöpfend untersucht worden. 1

Das Leben in einer Stadt, die Begegnung und Zusammenwirken zweier Kulturen, der deutschen und der russischen, möglich machte, begründet Žukovskijs wachsende Zuneigung zur deutschen Romantik und zur Poesie des Mittelalters.

Hier hat Žukovskij zum ersten Mal direkten Kontakt zu deutschen Geisteswissenschaftlern und Dichtern. ${ }^{2}$ Am Leben der jungen Universität (gegründet 1802) nimmt er regen Anteil: ${ }^{3}$ Im August 1815 schließt Žukovskij auf einem Fuchskommers mit dem ehrwürdigen "Veteran unter den Professoren", 4 dem achtzigjährigen Theologieprofessor Lorenz

1 Wichtige Publikationen zu Žukovskijs Biographie: C. v. SEIDITZ, wasily Andrejewitsch Joukoffsky. Ein russisches Dichterleben. Mitau 1870. S. 63-100; A.N. VESELOVSKIJ, a.a.0., S. 171-202; B.K. ZAUCEV, Zukovskij. Paris 1951; M.Ja. BESSARAB, V.A. Zukovskij. Moskau 1975; vgl. hierzu die Rezension: P. STELLIFEROVSKIJ, "Ego stichor plenitel'naja sladost" ...". In: VL 1977/1 S. 284-289.

2 Vgl. L. KOBILINSKI-ELLIS, a.a.O., S. 141-142. Eine weiterführende Analyse der Kenntnisse Zukovskijs von der deutschen Philosophie und Literatur der Romantik liefert A. GIŽICKIJ, V.A. Žukovskij i rannie nemeckie romantiki. In: RLit 22 (1979) $\mathrm{Nr} .1$. S. $120-128$.

3 Näheres zur Gründung der Corpater Universität siehe: $c$. v. SEIOLITZ, a.a.0., S. 64.

4 Ebo. S. 68. 
Ewers, Froundschaft; ${ }^{1}$ im April 1616 erhält or in Anerkennung seiner Dichtung den Ehrendoktor der philosophischen Fakultät; ${ }^{2}$ ein halbes Jahr später stellt er sich schützend vor die Universität, deren Ruf und Existenz durch die nicht gerechtfertigte vergabe zweier juristischer Doktortitel gefährdet scheint; ${ }^{3}$ im Frühjahr 1617 nört er nistorische vorlesungen bei Professor Johann Philipp Gustav Ewers. 4 Mit Dorpater Literaten wie Carl Peterson, Martin Assmus, von der Borg und August H. von Weyrauch und Professoren wie Morgenstern und Moier pflegte Žukovskij regelmäßigen Umgang. 5

Carl von Seidlitz, ein langjähriger Bekannter Žukovskijs, berichtet:

"Auch Deutsche Lesezirkel existirten in denen Joukoffsky nicht fehlte, um dem meisterhaften vortrage des alten Assmus zuzuhören. Die Lectüre von Jean Paulischen, Hoffmann'schen, Tieck'schen Schriften war damals an der Tagesordnung; die nevesten Erzeugnisse der Deutschen Literatur brachte der s.g. "dicke Peterson", der Universitätsbibliothekar, zur kritischen Besprechung, ... In diesem Lesezirkel wurde Joukoffsky erst practisch mit Deutscher Sprache und Literatur bekannt." 6

1 Zwei Tage später dichtet Žukovskij die poetische Epistel "K Starcu Ėversu". Vgl. C. v. SEIOLITZ, a.a.0., S. 68.

2 In einem Brief vom 24.6.1816 teilt Žukovskij seinem Freund Aleksandr I. Turgenev die Verleihung der Ehrendoktorwürde mit: "Ja zabyl tebe napisat", čto uže mesjaca tri kak, ja polučil ot Derptgkogo universiteta doktorskoj diplom (početnyj)." PIS'MA V.A. ZuKOVSKOCO K A.I. Turgenevu. In: RA 1895 Beil. S. 160; vgl. A.N. VESELOVSKIJ, a.a.0., S. 200.

3 Vgl. PIS'MA V.A. ŽUKOVSKOGO k A.I. Turgenevu, a.a.O., S. 164-165 (Brief vom 21.10.1816) und $S .166-167$ (Brief vom 31.10.1616); C. v. SEIDIIZ, a.a.0., S. 96-100.

4 vgl. C. v. SEIOLITZ, a.a.o., S. 91.

5 Vgl. ebd. S. 65.

6 Ebd. S. $66-67$. 
In einem Brief vom September 1816 bekennt Žukovskij seinem Freund Aleksandr Turgenev sogar:

"F. здесь совсем огерманился." 1

Die Sprachkenntnisse dirften mit ein Grund dafür gewesen sein, daB bis etwa 1814 der Einflub französischer Literatur auf Žukovskij überwog. Während er Französisch seit seiner Schulzeit beherrschte, lernt er Deutsch wohl erst in Dorpat mühelos verstehen und offenbar nie fehlerlos frei schreiben und sprechen.?

Mit der Ubernahme einer festen Anstellung am Zarenhofe geht die eigentliche Dorpater Zeit des Dichters zu Ende; die neve Aufgabe als Russischlehrer der preuBischen Prinzessin Charlotte, der Verlobten Nikolaj Pavlovics (des zukinftigen Nikolaus I) und späteren Zarin Aleksandra Feodorovna, bindet ihn an die Hauptstadt. 3

1 PIS'MA V.A. Д̆KOVSKOCO k A.I. Turgenevu, a.a.O., S. 160 (Brief yom Septenber 1816). Vesolovekij kritisiert diesen Ausspruch Zukovgkijs: Vgl. A.N. VESELOVSKIJ, a.a.0., S. 200.

2 Ausführlicher über Žukovskijs Deutsch-kenntnisse siehe D. GEPALARDI, Aus deutschen Erimerungen an Zukovskij. In: Orbis Scriptus. Dnitrij Tschižewkij zun 70. Geburtstag. Minchen 1966. S. 245-313. Hier S. 285-266. Gerhandt weist darauf hin, daB Zukovskij auch nach seiner Heirat mit Elisabeth von Reutern und seiner endgültigen Ubersiedlung nach Deutschland Französisch bo vorzugte. Dies beweist U.a. seine Korrespondenz; 2.B. schrieb er seiner Frau, deren Muttersprache Deutsch war, auf französisch. Der Abechiedsbrief, den Zukovskij seiner Frau hinterließ, ist auf französisch abgefaßt: Vgl. C. v. SEIDITZ, a.a.0., S. 224.

3 Im Oktober 1817 traf Žukovskij seine Schillerin in Moskau und gab inr an 22.10.1817 die erste Russischlektion. Vgl. DNEWNIKI V.A. ZuKOVSKOCO. Hrsg. I.A. Byčkov. St. Petersburg 1903. S. 53. 


\subsubsection{2. Žukovskijs Besuche bel Goethe ${ }^{1}$}

ŽukovskiJ, der im Kreise Andrej I. Turgenevs (17841803) die deutsche Literatur kennengelernt hatte, entwickelte sich zu einem leidenschaftlichen Bewunderer Goethes.

Es gibt viele Zeugnisse von der groben Ehrfurcht, mit der Žukovskij seinem Lehrmeister Goethe begegnete. Ein Jahr vor seiner ersten Deutschlandreise schreibt er den vierzeiler "K Portretu Gete":

Свободу смелую приняв себе в эакон, Всезрямеи мыслию над мнром он носился.

И в мире все постигнул он -

и ничему не покорился.

(ŽUKOVSKIJ I, S. 333)

Am 3. Oktober 1820 wurde sein langgehegter Wunsch wirklichkelt: Er sollte Deutschland persönlich kennenlernen. Begeistert schreibt er A.P. Elagina einen Tag vor seiner Abreise:

".. буду видеть и шиллеровы и Гетевы трагедии..." 2

Seine geplante Reiseroute erklärt Žukovakij folgendermaßen:

"Из дрездена через Веямар (Гете) в Кассель, из Касселя во Франкфурт...."

Während seines kurzen Aufenthaltes in Berlin lernt er zahlreiche bedeutende deutsche Romantiker kennen, unter innen E.T.A. Hoffmann, Jean Paul, De la Motte-Fouqué

1 Als wichtigste Primïnquellen liegen den folgenden Ausfürungen zugrunde: DNEWIKI, Hrog. I.A. Byckov, a.a.O., GOETHES UNTERHALTN GEN MIT DEM KANZLER FRIEDRICH V. MULLER. Hrsg. C.A.H. Burkhardt. Stuttgart 1870. Die ausführlichste Sekundärliteratur zu diesem Thema ist zweifelsohne S. aRrIN, ZukovskiJ i Gete. In: Literaturnoe Nasledetvo 4-6. Moskau 1932. S. 324-373.

2 I.A. BY̌̌KoV, Neizdannye pis'ma Žukovskogo k A.P. Elaginoj i A.P. Zontag. St. Petersburg 1912. S. 5.

3 Ebo. S. 5 
und Bettina von Arnim. Weiterhin hat er Gelegenheit, einer Aufführung von Schillers "Jungfrau von Orléans" beizuwohnen, deren Ubersetzung er schon 1816 begonnen hatte und nach seiner Rückkehr nach RuBland beendete. 1

Am 5. Mai notierte Zukovskij in sein Tagebuch:

"Вечер у принц(ессы) Радзивил: Humboldt, M-e Humboldt. . . Рисунки Фауста. แЁлер. " 273

An diesem Abend dürfte mit Sicherheit über Goethe gesprochen worden sein. Wilhelm v. Humboldt (1767-1835), der berühmte Philologe, 4 war ein Freund Goethes, und der Hausherr Anton Heinrich von Radzivill (1775-1633) hatte die Musik zum "Faust" komponiert. Bei anderer Gelegenheit lernt Žukovskij in diesem Hause auch Alexander wolf (1762-1828), den begabten Schauspieler und ehemaligen Schuler Goethes am Weimarer Theater, und den Komponisten Friedrich Zelter (1758-1652) kennen.

Aber die begeisterndste Hinführung zu Goethe erhält ZukovskiJ von Sulpiz Boisserée (1765-1854), der von dem Interesse des jungen russischen Dichters an deutscher Kunst und Literatur ganz eingenommen ist. In seinem Empfehlungsschreiben an Goethe beschreibt Boisseré, der damals beste Kenner altdeutscher Kunst und Besitzer einer reichen Sammlung von Kunstschätzen, Žukovskij als begabten Dichter:

1 Vgl. R. JACOOITSOH, Goethe und seine russischen Zeitgenossen. In: Germanoslavica 1 (1931-1932) S. 347-361. Hier S. 375.

2 Reinhold otto Schöler (1772-1840), Diplomat, verbrachte 27 Jahre seines Lebens in RuBland. Vgl. S. DURYIN, a.a.O., S. 367, Anm.16.

3 DNEVNIKI, a.a.0., S. 116.

4 Engen Kontakt of legte Žukovakij auch zu Wilhelms jüngeren Bruder Alexander $v$. Humboldt (1769-1859). Wahrend seines vierzehntägigen Aufenthalts in Berlin 1636 in Gefolge des Zaren besucht der russische Dichter mehrfach den deutschen Naturforscher. Dieser macht inn auch auf die Bemihungen Varnhagen von Enses um die verbreitung russischer Literatur in Deutschland aufmerksam. Vgl. G. ZIEGEN GEIST, Varnhagen von Ense und V.A. ZukovskiJ. In: ZfSI 4 (1959). S. 1-14. 
"Stuttgart, 6. October 1621

... Ene ich schließe, muB ich Ihnen die Bekanntschaft eines Herrn $v$. Joukowsky aus dem Gefolge der GroBfürstin Alexandra, geb. Prinzessin von PreuBen rühmen. Dieser geistreiche Mann hat den regsten Sinn für kunst und Poesie, und namentlich für das, was die Deutschen darin geleistet haben. Er kennt Ihre und Schillers werke nicht nur, sondern er hat vieles davon ins Russische ibersetzt. Ehe er nach Petersburg zurückkehrt, will er noch die Rheinreise machen, und so wird er in etwa funf Wochen bei Ihnen eintreffen, wo er dann gar sehr wünscht, das Glück Ihrer persönlichen Unterhaltung zu genieBen. Sein Umgang ist mir so werth geworden, das ich es mir nicht versagen kann, Sie auf diesen Mann aufmerksam zu machen, um ihm eine freundliche Aufnahme zu bereiten, denn naben sie sich nur erst mit inm fingelassen, so wird's am Gefallen nicht fehlen ..."

Am 29. Oktober 1621 trifft Zukovskij in Weimar ein. Seine Tagebucheintragungen sind lediglich stichworte, die er vielleicht spater einmal ausarbeiten wollte. Trotz der Kürze geben die Notizen überraschend lebendig Žukovskijs Eindruck von Weimar wieder:

"штруве ${ }^{3}$... Дом Гете: лестница; бюсты и гипсы; Salve; длинная горница: Олитер Олимпияския и Ахилл; музеум. Бюсты шиллера, Гердера, Гёте; древних и новых. Сад. Внук Гете. Длинная гостиная; рисунки; софа; нап нею задернутая картина Les noces d'Aldobrandini; 4 Мадонна. Горница, где портфели и антики. ..."5

1 S. BOISSEREE, Briefwechsel/Tagebiicher. 2 Bde. Stuttgart 1862. ND Göttingen 1970. Hier Bd. 2. S. 321-322.

2 goisserée war seinerseits durch Caroline von Humboldt auf Zukovskij aufmerksam gemacht worden. Vgl. S. BOISSEREE, a.a.O., Bd. 1. S. 393-394.

3 Johann Struve (1763-1828), russischer Geschäftsträger in Weimar und häufiger Besucher Goethes.

4 Gemeint ist eine Kopie des Aldobrandini Freskos im Vatikan ( 1606 in Rom gefunden), angefertigt von Heinrich Meyer. Diese murde 1797 Goethe als Geschenk iberreicht.

5 ONEVNIKI, a.a.0., s. 166. 
Wir können dem russischen Dichter bei seinem Gang durch das Haus folgen: das Museum, der Garten, Treffen mit Goethes Enkel Wolfgang, wieder zurück ins Haus.

Da sich aber Goethe zur zeit gerade in Jena aufhält, läbt Marija Pavlovna, die Kaiserinmutter, Zukovskij in Begleitung Struves in ihrer eigenen kalesche nach Jena bringen. Spät abends kommen sie bei Goethe an. Diese erste Begegnung war, da Žukovskij schon am folgenden Tag wieder nach Dresden weiterreisen mubte, nur kurz und flüchtig. In Žukovskijs Tagebuch heiBt es:

"Гёте: Французскил язык; стол; план Рима; оост: ... Măhrçhen; Alles ist Vahrheit; Wahrheit und Dichtung. Karkas nomexa." 2

Glücklicherweise gibt es noch andere Zeugnisse, die es uns ermöglichen, mehr über Žukovskijs erstes Treffen mit Goethe zu erfahren. In einem Brief vom 1. (13.) November 1621 an Aleksandra Feodorovna schreibt Žukovskij:
"...но плавание по Реяну зыло не так удачно: пасмурная осенняя погода затуманила для меня красоту репнских оерегов. ...от спеху не мог проинть в Вегмаре более одного дня; там имел счастие представиться ея императорскиму внсо- честву великоя княгине Марии Павловне, которая приняла меня с очаровательноі милость!), и ел же милости обязан я свиданием с Гете; он находился в Иене, и, чтобы я имел время к нему съездить, ея высочеству угодно бшло прислать мне коляску, и я в тот пе день видел поэта. Но свидение мое С ним उыло похохе на плавание мое по Fеп̆ну; оно úыло туманное, хотя он принял меня с ласком." 3

1 So lautet der Titel von Goethes Autobiographie.

2 DNEWIKI, a.a.0., S. 167.

3 PIS'MA V.A. ŽKKOVSKOGO $k$ vel. kn. Aleksandre Feodorovne iz pervogo ego zagraničnogo putešestvija v 1821 g. Hrsg. I.A. Byčkov. In: Russkaja Starina 5 (1902). S. 357. 
Goethe hat die Unbeholfenheit bei Jer Begegnung mit dem russischen Dichter offensichtlich gespür. Fast entschuldigend schreibt er an Boisserée:

"...er [Žukovskij] kam mit dem russischen Geschäftsträger, Herrn $v$. Struve, bey mir an, eben da es Nacht werden wollte, unangemeldet, wo ich mit ganz anderen Dingen beschäftigt war. Nun faBt ich mich bald, Ihrer Empfehlung eingedenk, allein es geht doch immer eine Zeit hin, bis man sich nur gewahr wird, und so kann ich sagen, war mir der $A B-$ schied von inm schmerzlich; nach einer stunde fuhren sie wieder fort, und nach inrem Abscheiden kam mir ein, was ich hätte fragen und sagen sollen. Ich denke, inm ein gutes wort zu schreiben und einiges zu senden, auch die Einleitung zu treffen, dab wir manchmal voneinander hören, welches bey unseren Bezügen gar leicht ist." 1

Mitte November fuhrt Goethe seine Absicht aus und schreibt Žukovskij einen recht herzlichen Brief:

"Eu. Hochwohlgeboren haben gewiB bey'm Abschied von Jena gefült: daB es mir weh that, Ihren kurzen Aufenthalt nicht verlängert zu sehen. Wenn ein unerwartet hereintretender, schnell entwickelter neuer Freund sogleich sich wieder entfernt, uberdenken wir erst, was wir hätten sagen, wonach wir uns erkundigen, was mittheilen sollen. Das dieses doppelt und dreyfach der Fall gewesen, als Sie und Ihr werther Geleitsmann mich in der stillen nächtlichen Einsiedeley zurucklieben, darf ich nicht erst betheuren, indessen nehmen Sie gegenwärtiges Blatt als wiederholtes Willkommen und Lebewohl.

(...) treu ergeben

$$
\text { J.w. v. Goethe." } 2
$$

Dieser Brief ist von einer eleganten, kalligraphischen Handschrift geschrieben. Nur die Unterschrift ("treu ergeben ...") stammt von Goethe selbst.

Durch Žukovskijs verspätete Rückkehr nach st. Petersburg,

1 COETHES WERKE, hrsg. in Auftrag der Großherzogin SOphie von Sachsen. IV. Abt., Goethes Briefe, Bd. 35, Weimar 1906. S. 174175.

2 Ebd. S. 172-173. 
wo er erst am 16. Februar 1822 ankommt und Goethes Brief bereits vorfindet, verzögert sich sein Antwortschreiben.

"... Ce que vous y dites avec tant de bonté sur notre entrevue, je l'ai senti en votre présence et après vous avoir quitté. Cette entrevue si ardemment desirée et attendue, ne fût que d'un moment, mais ce moment fot riche en sensations vives; Je n'ai pû rien vous dire précisement, parcequili y avait trop à dire; mais je vous ai vu, et votre présence a été pour moi comme une récapitulation rapide des plus beaus temps de mon passé. Und manche liebe Schatten steigen auf! c'était cela! ... Recever donc, cher grand homme, ma reconnaissance et pour ce passé, qui a été si souvent embelli par l'influence de votré génie, et pour ce cours instant ou j'ai senti le bienfait de votre présence que vous avez terminé par un serrement de main si bienveillant et paternel, et pour cette lettre si touchante, ce wiederholtes willkommen und Lebewohl, qui sera conserve religieusemeqt, comme un don sacré d'une main
chérie...."

Im Frühjahr 1826 tritt Žukovskij seine zweite westeuropareise an. Zunächst, vom September 1826 bis April 1827, hält er sich in Dresden auf und verkehrt dort viel mit dem schöngeistig-pietistischen Kreis der Gräfin Elisabeth von der Recke. Von Dresden fährt er einige Monate nach Paris und unterzieht sich nach seiner Ruckkehr im Juli und August 1827 einer Kur in Bad Ems. Von dort aus nimmt er seinen weg uber Frankfurt, wo er in Beglei-

1 V.A. ŽxovSKIJ, Pis'mo Žukovskogo k Gete. In: RA 1870. Sp. 18171819, die russische ibersetzung des Briefes: Sp. 1820-1622. (Unterstrichene Stellen im Original kursiv gedruckt). 
tung Gerhardt von Reuterns ${ }^{1}$ Goethes Geburtshaus besucht.

Žukovskijs Tagebucheintragung rom 31. August lautet:

"дом Iете: герб 3 лиры, двор, колодез, манзарды, Гретген. Окрестности Франкфурта." 2

Seine Gedanken sind offensichtlich bei Goethe, als er durch dessen Geburtsstadt spaziert.

Auf seinem Weg nach Weimar beginnt Žukovskij Goethes "Helena" zu lesen, die gerade als "klassisch-romantische Phantasmagorie" erschienen ist. ${ }^{3}$ Am 3. September erreicht Zukovskij Weimar. Hier hat er nun an den drei folgenden Tagen Gelegenheit, Goethe zu sehen und zu sprechen. Zum 4. September steht in seinem Tagebuch:

"К Гёте. крыльно с повороток. Созака. Б прихожея: Юпитер du Capitole, Pallas de Velletri. B roctisноя Aldobrandini, јнсункн. Стол с гортфелян. Голова Юноны колоссальная. Барон ьвеяцер, 4 энук Вольфганг." 5

Einen Tag später besucht Žukovskij in Begleitung $v$. Reuterns wiederum Goethe. Kanzler von Müller beschreibt den Verlauf dieser Begegnung folgendermaßen:

1 Gerhardt von Reutern (1794-1865), Freund Žukovekijs. Als junger Mann studierte er in Dorpat Militärwissenschaften, nebenbei ging er seiner Liebhaberei, der Malerei, nach. Als 19-jähriger verlor er in der Völkerschlacht bei Leipzig seinen rechten Arm. Im FrühJahr 1814 lernte er zufälig in Heidelberg Goethe kennen und murde später von inm nach Weimar eingeladen. Vgl. G. von REUTERN, Ein Lebensbild, dargestellt von seinen Kindern. St. Petersburg 1894, S. $10,26,29$.

2 DNEWNIKI, a.a.0., S. 202.

3 vgl. ebd. S. 202, bes. Arm. 10.

4 Christian Wilhelm Schweizer (1781-1856), Jurist und Minister in Weimar.

5 DNEWNIKI, a.a.0., S. 203. 
"Mittwochs, 5. September,

Diesen Morgen war Goethe durch Schukowsky's und $v$. Reuters [5ic!] Besuch so freundlich bewegt, daB ich inn fast nie liebenswürdiger, milder und mittheilender gesehen. Was er diesen freunden nur irgend Angenehmes, Inniges, Förderndes an Urtheil, wink, Beifall, Liebe zuwenden konnte, holte er hervor oder sprach es aus.

... Froh, daß ich die werthen freunde zu längerem Hierbleiben beredet hatte, äußerte er: 'Meine Zeit ist so gingerichtet, daß für Freunde immer genug da ist...'

Begeistert berichtet Gerhardt $v$. Reutern in einem Brief an seine frau uber diesen Besuch bei Goethe:

"Der alte herrliche Mann war ganz offen, hingebend, mittheilend und ganz unbeschreiblich liebenswüdig, aber so, dass uns ordentlich dabei ein Beben uberkam, ob das Alles wahr und nicht ein Traum, oder wie wenn ein Höherer sich herabneigte, uns heranzuziehen in seine lichteren Regionen, und wir freudig staunen und in unbeschreiblicher, Spannung erfassen möchten, was wir sehen und hören!" 2

Nicht ohne Stolz gibt $v$. Reutern Goethes ÄuBerungen zu seinen Bildern wieder:

"Ich sehe in allen Ihren Zeichnungen Nichts, das Sie zu vermeiden hätten; in Allem ist klares Anschaven der Natur, wahres Gefuhl für dieselbe, Auffassung des Charakteristischen und Schönen. Durchgehends ein Gefühl für Zusammenstellung und Anordnung; und wo sie die Farben anwandten, sehe ich satte Farben und dass Sie sich nicht scheven, sie so kräftig zu nehmen, als die Natur sie uns zeigt. Sie sehen die Natur simmer als Bild; das finde ich in

1 KANZLER v. MILLER, a.a.0., S. 119.

2 G. V. REUTERN, a.a.0., S. 52.

3 Ebd. S. 52. Goethes Lob auf die Bilder v. Reuterns ist charakteristisch für seine Auffassung von Kunst. Besonders hebt Goethe $v$. Reuterns "Auffassung des Charakteristischen und Schönen" hervor: er lobt oie Fähigkeit des Malers, die Natur immer als "Bild" zu sehen. Dies erinnert sehr an Goethes Aufsatz: "Einfache Nachahroung der Natur, Manier, Stil". 
Er schließt seinen Bericht mit einem flüchtigen Blick auf Žukovskij.

"Joukovsky war ganz bewegt über die Anerkennung, welche meine Arbeiten bei Goethe fanden, und fülte mit mir das Glück, einen perartigen Richter und Zuspruch gefunden zu haben."

Am 6. September wird Žukovskij noch einmal von Goethe empfangen. Die auch diesmal knapp gehaltenen Tagebuchnotizen, die nur andeuten, wie interessant das Gespräch zwischen den beiden Dichtern gewesen sein muB, machen gespannt :

"К Гёте.Разговор о Елене, о Берроне [sic!] . Гёте ставит его подле Гомера и liекспира. Die Sonne; die Sterne bleiben doch echt; es sind keine Copien." 2

Das ist alles. Goethes Tagebuchaufzeichnungen zu diesem Treffen sind ebenfalls knapp: "Herr von Reutern und $w$. Joukoffsky, commentirendes
Gespräch über Helena."

Glücklicherweise ist der Bericht Kanzler von Mullers ausführlicher:

"Donnerstags, den 6. September.

Als Schukowsky, Reuter [sicl] und ich Goethen gegen Abend besuchten, fanden wir inn abgespannt, matt und leidend, so dab wir nicht lange verweilten. Doch äußerte er launig, als von der sucht mancher sein wollenden Kenner, alle Bilder für Copien zu erklären, gesprochen wurde: So haben sie uns ja auch manche alte Pergamente wie mit dem Besen ausgekehrt und weggefegt. Ich will immer lieber eine Copie für ein Original gelten lassen, als umgekehrt. Bilde ich mich doch in jenem Glauben an dem Bilde herauf.'

1 G. V. REUTERN, a.a.0., S. 52.

2 DNEVNIKI, a.a.0., S. 203-204.

3 GOETHES WERKE, hrsg. im Auftrag der GroBherzogin Sophie von Sachsen. III. Abt., Goethes Tagebiicher. Bd. 11. Weimar 1900. S. 106. 
Nun labt sie immerhin gewähren; Sonne, Mond und Sterne müssen sie uns doch lassen und können sie nicht zu Copien machen. Und daran haben wir im Nothfalle genug. Wer es ernst und fleibig treibt, wird daran genug finden. Man lasse sich nur nicht irren, suche vielmehr das eigene Urtbeil immer mehr zu bestätigen, in sich zu befestigen."

Zum 6. September heißt es in Žukovskijs Tagebuch weiter:

"Прогулка в саду Гёте; дом где он писал и сочинлт ифигенил. Домик герцога. 2 иесто, где сиживали он, инллер, Виланд, Якоби, Гердер. Река Иіьм." 3

Nach diesen Aufzeichnungen endet der Tag mit einem weiteren kurzen Besuch bei Goethe:

"К Гёте. Усталость и деятельность. Мн пробшли недолго." 4

Dies sollte Žukovskijs letzte Begegnung mit Goethe sein. Am folgenden Tag macht er sich auf die Heimreise nach RuBland. 5

Als Abschiedsgeschenk hinterläBt er ein Gemälde von Carl Gustar Carus. 6 Es zeigt einen gothischen Balkon mit einer gegen einen Stuhl gelehnten Harfe. Über diesem Stuhl liegt ein Mantel; es entsteht der Eindruck, daß jemand auf dem Balkon Harfe gespielt hat und dann fortgegangen ist. Nur der Mantel und die Harfe sind zurückgeblieben. Der Mond glänzt durch die Saiten der Harfe, im nebligen Hintergrund erheben sich die Türme einer gotischen

1 KAWLER v. MiLLER, a.a.0., S. 119-120.

2 Gemeint ist das kleine Schloß in Tierfurt a.d. Ilm.

3 ONEVNIKI, a.a.0., S. 204.

4 Ebd. S. 204.

5 Ebd. S. 204, Eintragung vom 7. November.

6 Nach R. Jagoditsch stellt dieses Bild eine Allegorie auf Byrons Tod dar. Vgl. R. JAGODITSCH, a.a.O., S. 380. 
Kathedrale. ${ }^{1}$ Goethe bemerkt zu diesem Bild:

"... ein merkwürdiges Bild von Carus drügkt die ganze Romantik dem bewundernden Blick aus ..."

Auf der Rückseite des Bildes schreibt Zukovskij folgende zeilen auf Russisch und auch auf Französisch:

\section{Приношение}

тому, кто арфою чудесныя мир творит,

Кт乞 таннства покров С создания снимает, Минувиее животворит

И Будушее предрекает!

\section{Offrande}

A celui, dont la lyre a crée un monde de prodiges, Qui a levé le volle mystérieux de la création, Qui anime Ie passe

Et prophétise l'avenir.

5 sept. $1827^{3}$

Dies sind nicht die einzigen Abschiedsworte Žukovskijs an Goethe. Am Morgen seiner Abreise hinterläBt er eine Ode an den großen deutschen Dichter, die von ihm selbst auch ins Deutsche ubertragen worden ist. Diese Prosafassung überreicht er seinem freund Kanzler $v$. Müller, der sie an Goethe weiterleitet und auch in seinen "Unterhaltungen" wiedergibt. Die deutsche version, die Kukovskij mit der Widmung "Dem guten großen Manne" versehen hat, lautet folgendermaken:

1 Das Original dieses Bildes hängt im Goethe- und Schillerarchiv in Weimar. Abgebildet ist es bei S. DURYLIN, a.a.0., S. 349.

2 GOETHES WERKE, hrsg. im Auftrag der Großherzogin SOphie von Sachsen. IV. Abt., Goethes Briefe. Bd. 43. Weimar 1908. S. 94.

3 Die Abbildung dieser Handschrift murde zum ersten Mal veröffentlicht bei: S. DURYIN, a.a.0., S. 347. 
Du Schöpfer groBer offenbarungen! treu werde ich in meiner Seele bewahren den Zauber dieser Augenblicke, die so glücklich in Deiner Nähe dahinschwanden.

Nicht vom Untergange spricht Deine herrlich flammende Abendsonne! Du bist ein Jüngling auf der Gottes-Erde und Dein Geist schaffet noch, wie er schaffte.

Ich trage in meinem Herzen die Hoffnung, Dir noch einmal hier zu begegnen! Noch lange wird Dein Genius sein der Erde bekanntes Gewand nicht ablegen.

In dem entfernten Norden verschönerte Deine Muse mir die Erde! Und mein Genius Goethe gab Leben meinem Leben!

- warum vergönnte mir nicht mein Schicksal, Dir in meinem Frühling $z u$ begegnen. Dann hätte meine Seele ihre Flamme auf der Deinigen entzündet!

Dann hätte eine ganz andere wunderherrliche welt sich um mich gestaltet; und dann vielleicht auch von mir wäre eine Kunde zu der Nachwelt gelangt: e $r$ a $r$ e i $n$ D c $n t e r$.

Schukoffsky, 7. Sept. $1827^{1}$

Žukovskijs Bemühen, seine Bewunderung und Dankbarkeit gegenüber dem großen deutschen Dichter auszudrücken, klingt ehrlich und hat eine persönliche Note. Er hebt Goethe in eine religiöse Sphäre. Seine Hoffnung, inm noch einmal zu begegnen, geht über eine höfliche Phrase hinaus.

Die abschließenden Strophen des Gedichtes zeigen Žukovskijs Erkenntnis, $d a B$ Goethes EinfluB, wäre er eher erfolgt, seinem Talent hätte eine andere Richtung geben können auf eine konkrete Welt hin, eine "ganz andere

1 KANZLER v. MÜLLER, a.a.0., S. 120.

Die russische Fassung dieses Gedichts murde mit dem Titel "K Gete" zum ersten Mal in: Pis'ma A.I. Turgeneva K N.I. Turgenevu, Leipzig 1872 veröffentlicht. Vgl. ZUKOVSKIJ I, S. 464. 
wunderherrliche welt". 1 Žukovskij wußte, daß die "flamme" seiner seele von Goethes "flamme" nicht entzündet worden war, daß sein poetischer Geist dem Goetheschen nicht verwandt war. 2

In seinen "Unterhaltungen" berichtet Kanzler von Müller von dem Eindruck, den dieses Gedicht auf Goethe gemacht nat.

"Viel zu kalt meiner Meinung nach, nahm Goethe Schukowsky's herrliches Abschiedsgedicht auf, wiewohl er etwas Orientalisches, Tiefes, Priesterliches darin anerkannte". 3

Nach von Milllers Bericht ließ sich Goethe anschließend im allgemeinen ablehnend über die melancholische Schwelgerei in Erinnerungen aus:

"... es sei gar nicht poetisch, die vergangenheit so tragisch zu behandeln, statt reinen Genusses und Anerkennung der Gegenwart, und jene erst todtzuschlagen, um sie besingen zu können. ... Weil die Menschen die Gegenwart nicht zu würdigen, zu beleben wüßten, schmachteten sie so nach einer besseren zukunft, coquettirten sie so mit der Vergangenheit. Auch Schukowsky hätte weit mehr aufs Objekt hingewiesen werden müssen". 4

In diesem Gespräch trifft Goethe den Kern von Zukovskijs Lyrik. Die sich in ihr äußernde stellung zur Vergangenheit lehnt Goethe entschieden ab. 5

1 In der russjischen Version spricht Žukovskij von "čudesno-pyšnyj svet". Vgl. ZuKOVSKIJ I, S. 374.

2 Ausführliche Informationen zur Entstehung dieser Paraphrase Zukovskijs auf ein von inm selbst verfaßtes russisches Gedicht sowie eine genaue Analyse der Übersetzung liefert: D. GERARDT, Eigene und übersetzte deutsche Gedichte Zukovskijs. In: Corski $V i j e n a c$. A garland of essays offered to Professor Elizabeth Mary Hill. Cambridge 1970. S. 118-154. Hier S. 123-130.

3 KANZLER v. MÜLLER, a.a.o., s. 120.

4 Ebd. S. 121.

5 Vgl. M. GORLIN, a.a.0., 9 (1932), s. 346. 
Es mag dem Kanzler bei seiner Verstimmung über Goethes Gleichgültigkeit gegenüber Žukovskijs Geschenk ein Trost gewesen sein, daB der russische Dichter nicht onne ein beachtliches Abschiedsgeschenk weimar verlassen hat. Es war eine Kopie der "Marienbader Elegie", mit einer eigenhändigen Widmung Goethes aus seinem "Tasso":

"Und wenn der Mensch in seiner Qual verstummt, Gab mir ein Gott zu sagen, wie ich leide". 1

(HA V, S. 166)

Auch Žukovskijs zweiter Besuch bei Goethe konnte inn nicht mehr zu bemerkenswerten Leistungen als übersetzer anregen. Vielleicht fülte er sich durch die Erkenntnis entmutigt, welch eine grobe Differenz zwischen seiner vorherrschend elegisch-subjektiven Muse und der Kunst Goethes zu überwinden sei.

Zukovskijs lebhaftes Interesse für Goethe bleibt jedoch wach. Unter dem Eindruck von der Nachricht von Goethes Tod wendet er sich mit neuer Energie dem Werk des von inm so bewunderten Dichters $2 \mathrm{u}$. In seinem Tagebuch finden sich zahlreiche Verweise auf Goethe, darunter eine treffende Charakterisierung von Goethes Stil; ein rückhaltloses Lob auf die Originalität seines Denkens:

"Ясность и живость. Нет ничего лишнего. О人о всем собственная мысль. Eigenthumlichkeit, Fasslichkeit und Bild - характер Гётева слога. Краткость и легкия порядок в иэложения; скрытая, но омутительная мысль." 2

Als Žukovskij am 22. August 1832 diese Tagebucheintragung schrieb, war er bereits wieder in Deutschland.

1 Diese Verse bilden gleichsam das Motto der "Marienbader Elegie", in der der alternde Goethe seinem tiefen Schmerz iber die hoffnungslose Liebe zu Ulrike $v$. Levetzow Ausoruck verleint.

2 ONEWIKI, a.a.0., s. 229. 
Die Erinnerung an Goethe läßt inn nicht los. In Frankfurt notiert er am 3. September:

"Поутру быт у югеля.1 разговор о Гете."2

Und am 8. September schreibt er:

"обедал с Реятерном. Разсматривали Фауста Гетева и Корнелиусова." $3 / 4$

In Heidelberg fühlt er sich an den "Götz von Berlichingen" erinnert:

"Старинныя дом с лестницея винтом, описаннып в Götz von Berlichingen. Прогулка на раэвалины. Реян в блеске; Туман, свечи в окнах; .... Месяи за горою. Гёте и разговор О назначения дуии." 5

Am 24. August kommt Žukovskij noch einmal nach weimar. Friedrich Theodor Kräuter, der persönliche Bibliothekar und Archivar Goethes, fuhrt inn zu Goethes Haus:

"Комната медалея: Медали Средних веков; бронзы, слепок с шиллерова черепа (история, как он наяден)." 6

Nachdem Kräuter erzählt hat, wle der Schädelabdruck Schillers entdeckt worden war, kommt man auf dessen Tod zu sprechen:

"Смерть Шиллера 1804 [sic!] погребение; в 1815;..."T

Anschließend besuchen Kräuter und Žukovskij auch noch Schillers Haus.

1 Karl Jügel (1783-1869), Buchhändler in Frankfurt.

2 DNEWIKI, a.a.0., S. 230.

3 Gemeint sind die bekannten Stiche zum "Faust" von Peter Cornelius (1787-1867).

4 ONEVIIKI, a.a.o., S. 232.

5 Ebd. S. 233.

6 Ebd. S. 310.

7 Ebd. S. 310. 
Den folgenden Morgen verbringt Zukovskij im Gespräch mit Kanzler von Müller über Goethes "Faust" und noch am gleichen Tag fährt er nach Berlin ab. 1

In den Jahren 1834-1836 natte Zukovskij keinen Kontakt zu Weimar. Am 14. Oktober 1837 unterbricht Kanzler von Mulller das lange Schweigen; er schreibt Žukovskij einen herzlichen Brief:

"Die Erinnerung an Sie, theuerster Mann! hat mich
in den langen Jahren, die seit Ihrem letzten Hierseyn
im Jahre 1833 verflossen, nie verlassen, obschon
kein sichtbares Zeichen wechselseitigen Andenkens
uns zukam. Während ich im stillen Weimarischen Kreise
meist nur in der vergangenheit lebte und den Blick
oft mit sehnsucht in die Ferne richtete, haben Sie,
im grosatigen [sic!] Berufe, reiche Saaten für
die Zukunft ausgestreut und noch jügst unermeBliche
Gebiete in zweyen welttheilen durchflogen, den
küftigen Herrscher in seine kunftige Bestimmung
einzuweihen ...
Und nun noch das herzlichste Lebewohl! Der Genius
allen Schonen und Guten sey fortwährend mit Innen!
Lassen Sie mich bald vernehmen, dab Sie meiner noch
freundlich gedenken. Der Inrigste

Im folgenden Jahr, 1838, kommt Žukovskij noch einmal nach Deutschland. Bereits in Berlin werden seine Erinnerungen an Goethe wachgerufen. Am 31. Mai hört er in der "Singacademie" die inm gut bekannten Kompositionen Anton Heinrich Radziwills zum "Faust". 3

In weimar, wo er am 6. September eintrifft, besucht er mehrmals Goethes Haus (am 8., 9. und 13. September). Sorgfältig beschreibt er jedes Detail:

1 Vgl. DNEWNIKI, a.a.0., S. 310, Eintragung vom 26. August.

2 BRIEFE OES KANZLERS FRIEDRIOH v. MÜLLER an Wasily Andre jewitsch Joukovsky, Hrsg. A. v. Schorn. In: Deutsche Rundschau 120 (1904) Nr. 3. S. 277-287. Hier S. 284.

3 Vgl. ONEWNIKI, a.a.0., s. 377. 
"В доме Гёте ... Разговор с Экерманом1 и креитером. Описание смерти Гете. Маленькие его комнаты. Эастоявинися воздух в горницах. Сулно. Прелестнып календарь в футляре. 22 марта.2 Бюст императрицы. Пирамида из папки: Sinnlichkeit зеленшя цвет, Verstand голубоя, Vernunft желтып, Fantasie красныn. Поэны и Tagebuch. Пролитые чернила. Гетевш рнсунки." 3

Am 14. September besucht Žukorskij das Grab Goethes.

Zum letzten Mal besucht Žukovskij Weimar im Jahre 1840. Engen und freundschaftlichen Kontakt pflegt der russische Dichter mit Kanzler von Müller. Am 26. März trägt er in sein Tagebuch ein:

"Пребывание в Веямаре ... К маллеру. К его невестке,

Einen Tag später besucht er wiederum Goethes Haus. Er bewundert verschiedene Gemälde wie auch die Totenmasken Schillers, Goethes, Napoleons, des Weimarer Herzogs Karl August und anderer. 5

Žukovskijs letzte Tagebucheintragung, die sich auf Goethe bezient, ist der immer wiederkehrende Hinweis

"в Гетев дом." "о

Dies ist Žukorskijs letzter Aufenthalt in weimar. In seinem Leben beginnt nun eine neve Epoche: Er heiratet die 18-jährige Tochter seines Freundes von Reutern und lebt abwechselnd in Düsseldorf, Sachsenheim (bei Frankfurt) und Baden-Baden. Mit Weimar bleibt er durch den Kanzler von Muller, mit dem er bis zu seinem Tod befreundet ist, in davernder verbindung.?

1 Johann Peter Eckermann (1791-1854), Schriftsteller, Verfasser der "Gespräche mit Goethe".

2 Das Datum des Kalenders war auf Goethes Todestag belassen worden.

3 DNEVNIKI, a.a.0., S. 409.

4 Ebd., S. 522.

5 vgl. ebd., S. 523.

6 Ebd., S. 523.

7 Vgl. R. JAGOOITSCH, a.a.O., S. 381. 


\subsubsection{IJutčev und Deutschland}

\subsubsection{TJutČevs Leben in Deutschland. Ein biographischer AbriB.}

Einen bedeutenden Teil seines Lebens verbrachte F.I. Tjuttev, Sohn einer alten Aristokratenfamilie, außerhalb RuBlands. Überwiegend weilte er in der stadt, die er ganz besonders schätzen lernte, in München.

Mit dem Geistesleben und der Literatur in Deutschland wurde Tjutלev bereits als junger Mensch von seinen Lehrern Semen E. RaiC ${ }^{1}$ (1792-1855) und Aleksej F. Merzljakov (1776-1830) vertraut gemacht. Beide waren hervorragende Kenner der deutschen Literatur, besonders der Werke Goethes und Schillers.

Nachdem er sein Studium an der Moskauer Universität beendet hatte, ${ }^{3}$ trat er zu Beginn des Jahres 1822 in den Dienst des AuBenministeriums in st. Petersburg ein. Im Sommer desselben Jahres begab er sich zur russischen Gesandtschaft in Müchen, wo er bis 1837 in relativ bescheidener stellung tätig war. TjutČev hatte also bereits als Achtzehnjähriger RuBland verlassen und erst im Alter von vierzig Jahren sollte er wieder in seine Heimat zuruckkehren.

Im Jahre 1826 heiratete Tjutčev die Deutsche Emilie Eleonore Peterson, geb. Gräfin Bothmer, Witwe des russischen Gesandten in Weimar. Gemeinsam mit ihr nahm er am gesellschaftlichen Leben in München teil.

1 Bekannt murde Raič vor allem durch seine versibertragung von Vergils "Georgica" und Torquato Tassos "Befreites Jerusalem".

2 Professor für Poetik an der Moskauer Universität. Besonders hervorgetreten ist Merzljakov als Ubersetzer antiker Dichtung und als verfasser von Volkslied-Nachahmungen.

3 Die Ubersicht Tjutčevs über die von inm besuchten Lehrveranstaltungen ist verlorengegangen. Der genaue Umfang seiner Studien ist daher nicht bekannt. vgl. K. PIGAREV, Tjutčev, a.a.0., S. 17-18. 
Zu seinen deutschen Freunden zählte er Heinrich Heine, aus dessen Werk er als erster ins Russische übersetzte, und Friedrich Schelling. Schelling lehrte zu dieser zeit an der neugegründeten Universität in München als Professor für Philosophie. Durch inn knüpfte Tjuťev persönliche Beziehungen zur Philosophie des nachkantischen deutschen Idealismus.

Eine persönliche Bekanntschaft Tjutčevs mit Goethe muB stark in Zweifel gezogen werden. In Weimar, wo Goethe bereits 1832 starb, ist der russische Dichter nie gewesen. 1

Tjutčevs Versetzung nach Turin, der Hauptstadt des sardischen Königreiches, beendete im Jahre 1837 die erste Münchener Lebensphase des Dichters. Bereits zwei Jahre später (1839) muBte er überraschend seine diplomatische Laufbahn aufgeben. In Verbindung mit seiner zweiten Eheschliebung hatte er eigenmächtig eine Reise in die Schweiz angetreten. 2

1 Vgl. K. PIGAREV, Tjutčev - perevodčik Gete. In: Uranija. Tjutčevskij Al 'manach 1803-1928. Leningrad 1928. S. 85-113. Hier S. 87-88. Pigarev zitiert die entscheidenden Sätze aus einem Brief von Tjutčevs Tochter Dar'ja Fedorovna an ihre Schwester aus dem Jahre 1873. Daraus geht hervor, daß alle Briefe des Grafen von Maltitz, eines engen Freundes Tjutčevs, verbrannt worden sind. Und Frau von Maltitz könne sich nicht erinnern, ob Tjutčev mit Goethe zusammengetroffen sgi. Zu diesem Aufsatz K. Pigarevs vgl. auch die Rezension von D. CyževśkyJ = D. TSOMIŽEWSKIJ. In: ZfsiPh 7 (1930) S. $459-467$.

2 Vgl. hierzu die Ausführungen von TjutČevs erstem Biographen A.S. AKSAKOV, Fedor Ivanovič TjutŽev. Biografičeskij Očerk. Moskau 1874. Sp. 32.

Kazanovič ergänzt noch, Tjutčev seien auf dieser Reise wichtige dienstliche Dokumente abhanden gekommen. Vgl. E.P. KAZANOVIC, Iz mjunchenskich vstrę F.I. Tjutčeva (1840-e 9g). In: Uranija. TjutZevskij Al'manach 1803-1928. Leningrad 1928. S. 125-171. Hier S. 132 . 
Auch TjutCevs zweite Frau, Ernestine von Dörnberg, geb. Baronesse von Pfeffel, die er im Juli 1839 heiratete, stammte aus Deutschland.' Mit inr lebte er bis 1844 als Privatmann in München. 2 Nach seiner Rückkehr nach $5 t$. Petersburg wurde TjutCev wieder ins AuBenministerium aufgenommen und leitete dort die Zensurbehörde für ausländische Literatur.

Entscheidende Jahre seines Lebens hatte TjutCev in München verbracht, der Kontakt mit dem geistigen Leben in Deutschland hinterlieb eine tiefe Spur in seinem weltbild. Dennoch blieb das Französische die Sprache seiner Aufsätze, Briefe und Gedanken, die Sprache seiner Poesie war Russisch.

Uber seine Beziehung zu RuBland soll Tjutčev einmal gesagt haben "Je $n$ 'ai pas le heimweh, mais le herausweh". 3 Trotzdem verband inn mit eben diesem Land ein tiefer Patriotismus, den er theoretisch in seinen politischen und kirchenpolitischen schriften untermaverte und der den konservativen Politiker die Ideen der Slavophilen übernehmen lieb.

1 Tjutčevs erste Frau war zehn Monate zuvor an den folgen einer Schiffskatastrophe, die sich auf der Reise von Petersburg nach Turin in der Ostsee ereignete und die auch Ivan S. Turgenev miterlebte, gestorben.

2 Ausführlich über Tjutčevs Leben und Schaffen in Muinchen: W. LETTENBAUER, Der russische Dichter Fjodor Tjutschev und Minchen. In: Monachium. Hrsg. A.W. Ziegler. Minchen 1958. S. $199-211$.

3 K. Pigarev zweifelt an der Autenzität dieses Ausspruchs. Vgl. K. PIGAREV, Tjutčev, a.a.0., S. 96. 
2.2.2.2. Zur geistigen Verwandtschaft zwischen Goethe und Tjutčev.

Zahlreiche Gedichte TjutXevs lassen in der Übernahme eines Bildes oder nur eines Gedankens sowohl den EinfluB Goethes als auch die innere Verwandtschaft beider Dichter erkennen. Valerij Brjusov zählt Goethe sogar zu den bedeutendsten Lehrern Tjutčevs. 1

Ein in diesem Zusammenhang immer wieder zitiertes Beispiel sind die beiden Zeilen aus "Pesok sypucij po koleni":

Ночь хмурая, как зверь стоокия,

Гляднт из кахдого куста!

(TJUTČEV I, S. 38)

Diese Verse spiegeln offensichtlich Goethes Zeilen aus "Willkommien und Abschied" wieder:

Wo Finsternis aus dem Gesträuche

Mit hundert schwarzen Augen sah. 2

Obwohl Tjutčev die vorstellung der Nacht als einer dem Menschen unheimlichen Macht von Goethe aufnimmt, unterscheiden sich beide Gedichte doch grundlegend voneinander: Im Gegensatz zu Goethe, bei dem das Bild vom "hundertäugigen Tier" metaphorisch verknüpft ist, wird es bei Tjutčev als vergleich angeschlossen. Die einzelnen vorstellungsbereiche bleiben getrennt.

1 "Gejne, Lenau, Ejchendorf, otčasti Šiller, i $v$ ǒen" sil'noj stepeni, car' i bog nemeckoj poézii, Gete, - vot ego glavnye učiteli." V.Ja. BRuSOV, a.a.0., S. XLIII.

2 Tschižewskij weist darauf hin, daß - obwohl nur zwei wesentliche Worte geändert sind - das, Bild in Tjutčevs Weltverständnis eingewoben wird. Vgl. D. TSCHIŽESKIJ, Tjutčev und die deutsche Romantik, a.a.0., s. 303 . 
Unterschiedlich ist auch die Darstellung der Natur. Während sie in "Willkommen und Abschied" die Empfindungen des Liebenden widerspiegelt, behält die Natur bei TjutCev ihr eigenes Dasein. Das lyrische Ich ist hier ein Beobachtendes, das Abstand zur Natur hält. 1

wiederholt analysiert worden ist auch die verbindung zwischen Goethes Freimaurer-Hymne "Symbolum" (HAI, S. 340-341) und Tjuť̌evs "Ova golosa" (TJUTČEV I, S. 129). ${ }^{2}$ Die Beziehung dieser Gedichte zueinander belegt vor allem die Gegenüberstellung folgender Zeilen. So heiBt es bei Goethe:

$$
\text { ... Stille }
$$

Ruhn oben die Sterne

Und unten die Gräber.

und bei Tjutčev:

$$
\begin{aligned}
& \text { Над вами светила молчат в вынине, } \\
& \text { Под вами могилы - молчат и оне. }
\end{aligned}
$$

In beiden Gedichten wird das Leben des Menschen als unaufhörliches streben charakterisiert, bei Tjutčev als Kampf, bei Goethe als ständiges üben "der Kräfte des Guten".

Im Gegensatz zu Goethes optimistischen versen, in denen die Stimmen "von drüben" den Menschen in seinem Streben ermutigen und inm am Schluß zurufen "Wir heiBen euch hoffen", äußert sich in Tjutčevs Gedicht eine eher pessimistische Stimmung. Die anspornenden Stimmen derer, die den sinnvollen Kampf bereits ausgefochten haben, ersetzt

1 vgl. A. SaHulzE, a.a.0., s. 40.

2 Zuletzt von A. v. GRONICKA, Fedor Iwanowitsch Tiutschew und Goethe. In: Literatur und Geistesgeschichte. Festgabe für Heinz Otto Burger. Hrsg. R. Grimm U. C. Wiedemann. Berlin 1966. S. 422-432. Hier S. 429-30. Gronicka verweist auch auf ältere Untersuchungen. 
er durch das Schweigen ferner Götter, die "mit neidischem Blick" von ihrer sorgenfreien olympischen Höhe auf den kämpfenden Menschen hinunterschauen:

Пуская олимпияці завистливьм оком

Глядят на оорьбу непреклонных сердец.

Für den fatalistischen Helden gibt es in seinem "ungleichen" und "hoffnungslosen" Kampf ${ }^{1}$ nur eine Erlösung durch den Tod. Die Tapferen jedoch, die "unbeugsamen Herzens" sind, vermögen die äußere Niederlage in einen Triumph zu verwandeln. Sie erwartet - wie auch Goethes Held, für den die inm im Kampfe Vorangegangenen eine Krone winden, - der Siegeskranz.

Diese zweite Stimme steht bei Tjutčev über der verzagtheit der ersten, die die Hoffnung auf den siegeskranz aufgegeben hat.

Obgleich die Verwandtschaft beider Gedichte offensichtlich ist, wurde doch deutlich, daB Tjutčev durch Goethes Gedicht lediglich inspiriert worden ist, Aufbau und Aussage beider Gedichte entsprechen sich nicht. 2

Als eine Paraphrase von Goethes Gedichten "Wandrers Nachtlied" ("Der du von dem Himmel bist", HA I, S. 142) und "Ein Gleiches" ("Über allen Gipfeln ist Ruh", HA I, S. 142) erscheint Tjutčevs "Tak, $v$ Žizni est" mgnovenija" (TJUTČEV I, S. 160). Die gemeinsamen Motive sind die Harmonie in der Natur

1 vgl. 1. Strophe, 2. Zeile: "Chot" boj i neraven, bor'ba beznadežna!"

2 A. von Gronickas Kritik, Goethes Gedicht habe bei Tjutčev Reichtum und fuille eingebüBt, ist unsinnig, da es sich um zwei unterschiedliche Gedichte mit unterschiedlicher Aussage handelt. Vgl. A. v. GRONICKA, Tiutschew und Goethe, a.a.0., S. 430. 
Uber allen Gipfeln

Ist Ruh,

In allen wipfeln

Spürest du

Kaum einen Hauch:

Die Vögelein schweigen im Walde.

Шумят верхи древесные

Высоко надо мноя,

И птиш лишь небесные

Беседуют со мноя.

und die innere Ruhe im Menschen:

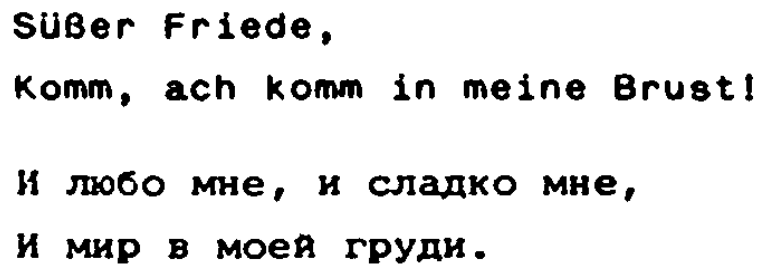

Bei Goethes Gedichten handelt es sich um schlichte Abendlieder, von denen das erstere Sehnsucht nach frieden, das zweite Erfüllung ausdrückt. TJutčevs Verse sind dagegen eher mystisch-erhaben. 1 Ihr Ende unterscheidet sich grundlegend von dem Goethes. Dessen lyrisches Ich sieht dem Tod gelassen entgegen, während es bei Tjuť̌ev aufbegehrt und noch um Zeit bittet: "O vremja, pogodil".

\footnotetext{
Neben dem Pan-Mythos, den sowohl Tjutčev als auch Goethe aufgreifen, 2 begegnet uns bei beiden Dichtern mehrfach
} die Mondmetapher.

1 Besonders die Zeilen 11 und 12: "Vse milo-nevozmožnoe/Tak blizko i legko." - "Alles Lieb-Ummögliche/Ist so nah und leicht."

2 Tjutčev hat vermutlich an Goethes neuen Mythos, der verschiedene alte Pan-Mythen zusammenfaßt, angeknüpft. Auf den möglichen Zusammenhang von Tjutčevs "Polden" mit dem Elfenchor aus dem 1. Aufzug des "Faust II" machte bereits $K$. Pigarev 1934 aufmerksam. Vgl. $K$. PIGAREV, Cto perevodil Tjutčev. (K voprosu o tvorčestve Tjutčeva-perevodčika). In: Zven'ja 3-4 (1934). S. 245-262. Hier S. 260-61. Vgl. A. SOHUZE, a.a.0., S. 37-36. 
In den beiden Achtzeilern "V tolpe ljudej, $v$ neskromnom šme dnja" und "Ty zrel ego v krugu bol'bogo sveta" symbolisiert der Mond die Existenz des Dichters. Der Tag trennt nicht nur die Menschen voneinander, 1 sondern er entfernt auch den Menschen von sich selbst. So wie der Mond tagsüber nur "neblig-weiB" zur Erscheinung gelangt, erst nachts sein wahres "helleuchtendes" Aussehen zurückgewinnt, so erwacht auch der Dichter in der Nacht zu neuem Leben, erst jetzt findet er sein eigentliches wesen. 2

Смотри, как днем туманисто-бело

Чуть брезжнт в небе месяц светозарныя, Наступит ночь - и в чистое стекло

Вольет елей душистыя и янтарныя!

Auch bei Goethe kommt dem Mond existentielle Bedeutung zu. In "An den Mond" (erste Fassung) wird der Blick des Mondes mit dem Auge der Liebsten verglichen. Dieses Auge blickt mild über sein Geschick, wie sich der Blick des Mondes lindernd uber sein Gefildebreitet.

Breitest uber mein Gefild

Lindernd deinen Blick

wie der Liebsten Auge, mild

Über mein Geschick.

(HA I, S. 128-129).

1 Dieses Thema behandelt auch Goethes Madrigal "Nähe".

Wie du mir oft, geliebtes Kind,

Ich weiß nicht wie, so frende bist!

Wenn wir im Schwarm der vielen Menschen sind,

Das schlägt mir alle Freude nieder.

Doch ja, wenn alles still und finster um uns ist,

Erkenn ich dich an deinen Küssen wieder.

In: GOETHES GEDIOHTE in zeitlicher Folge. Hrsg. Heinz Nikolai.

Bd. 1 und 2. Wiesbaden 1978. Hier Bd. 1. S. 232. Vgl. A. SCAULZE, a.a.0., S. 49 .

2 Vgl. B. ZELINSKY, a.a.0., S. 89-91. 
Oer Mond charakterisiert den Blick der Geliebten. Sein Schein ist das milde Leuchten ihres Auges. Es geht um ein Ausdeuten des einen durch das andere; vergleich und verglichenes vermischen sich zu einer Einheit. Der Mond ist die Liebste, die Liebste der Mond. 1

Jedoch nicht nur Goethesche Bilder und Motive haben Eingang in TjutZevs Lyrik gefunden. Auch bei der Entwicklung der Kurzlyrik, die Tjutלev in RuBland in den Rang hoher Dichtung hob, ${ }^{2}$ gaben deutsche Dichter, unter innen Goethe, wichtige AnstöBe.

Tjutčev verschmolz - wie Almut Schulze in ihrer Arbeit aufgezeigt hat - die Strukturen der antiken kleindichtung, die inm von Jugend an vertraut war, mit den neben Heine von Goethe entwickelten, für die deutsche Lyrik charakte-

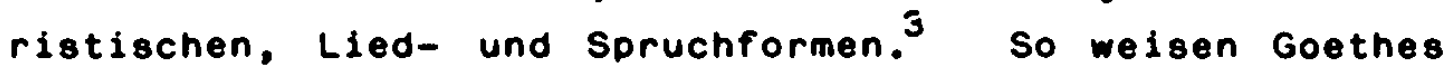
und Tjutlevs verse verschiedentlich eine ähnliche struktur auf, 4 auch erinnern einige Spruche des russichen Dichters in ihrer "kargen gnomischen form" an die Spruchdichtung des alten Goethe. 5

1 Vgl. H. ELEMA Zur Interpretation von Goethes "An den Mond". In: Ders., Imaginäres Zentrum. Studien zur deutschen Literatur. Assen (Niederlande) 1968. S. 124-145. Hier S. 134.

2 Kleinformen der Lyrik murden - obwohl sie so alt wie die Literatur selbst sind - lange in der Literaturtheorie nicht als vollwertig anerkannt. Vgl. A. SCHulZE, a.a.0., S. 17, 65.

3 Vgl. A. SOHULE, a.a.o.

4 Z.B. Goethes Epigrarm "Geweinter Platz" und Tjutčevs Kurzgedicht "Poeizija". Weiterhin gleichen Goothes Verse "An Lida" formal Tjutčevs Gedicht "Esče tomljus" toskoj Želanij". Vgl. A. SCHULZE, a.a.O., S. 56 .

5 Vgl. A. SCHULE, a.a.0., S. 64. 
Die Darstellung der Beziehungspunkte zwischen Tjutלevs und Goethes dichterischem Schaffen lieBe sich noch erweitern. Offensichtlich war TjutCev mit Goethes Werk bestens vertraut, auch beim verfassen eigener verse war es dem russischen Dichter gegenwärtig.

Diese enge Verbundenheit mit Goethes Dichtung erwächst aus einer inneren Verwandtschaft beider Dichter. Gemeinsam ist den beiden Dichtern die Fähigkeit, sich immer wieder, auch im fortgeschrittenen Alter, neu zu verlieben.

Ohne Rücksicht auf seine bestehende Ehe und auf gesellschaftliche konventionen knüpft der siebenundvierzigjährige Tjuttev eine leidenschaftliche Beziehung zu der gerade vierundzwanzigjährigen Elena Aleksandrovna Denis'eva. Drei kinder gehen aus diesem verhältnis hervor. Den Preis, den beide für diese Liebe zahlten, war hoch. Besonders E.A. Denis'eva mubte unter dem gesellschaftlichen Skandal, der in Petersburg durch inre verbindung zu Tjutkev ausgelöst wurde, leiden. Ihre Familie sagte sich von ihr los. 1

Als Culkov die Manuskripte Tjutčevs durchsah, fand er ein loses Blatt, auf dem der russische Dichter vier verse aus Goethes Gedicht "Rastlose Liebe" aufgezeichnet natte: ${ }^{2}$
Alle das Neigen
von Herzen zu Herzen
Ach wie so eigen
Schaffet das Schmerzen!

1 Die verschiedentlich vorgebrachte Behauptung, dieses illegitime Verhältnis habe Tjutčevs dienstlicher Laufbahn ein Ende gesetzt, ist nicht richtig. Vgl. K. PIGAREV, Tjutčev, a.a.O., S. 158.

2 Vgl. G.I. C̆LKov, Stichotvorenija, prislannye iz Germanii. K voprosu ob otnošenii Puškina $k$ Tjutčevu. In: Zven'ja 2 (1933). S. 255-267. Hier S. 262. 
Auch Goethe besaß die Fähigkeit, sich immer wieder leidenschaftlich zu verlieben. Erwähnt seien nur die Namen von Friederike Brion, Lotte Buff und Lili Schönemann. Aber auch er kann in seiner Beziehung zu fraven rücksichtslose Züge annehmen.

Als Zweiundsiebzigjähriger verliebt er sich in Marienbad in die siebzehnjährige Ulrike von Levetzow. Zwei Jahre später, 1823, trägt ein Freund die Werbung für den alten Goethe bei der Mutter des Mädchens vor. Goethe droht weniger ein gesellschaftlicher Skandal als die Lächerlichkeit. Dennoch kann er lange die Hoffnung auf ein wiedersehen mit Ulrike nicht aufgeben. Auch als alter Mann ist in ihm - noch wie einst - die volle Kraft des Erlebens. 1

Gemeinsam ist beiden Dichtern nicht nur die andauernde Lebendigkeit des Gefunls, sondern auch die Liebe zu Mittelmeerländern, die Sehnsucht nach dem sonnigen Italien.

Gegen Ende seiner "Italienischen Reise", 2 die Goethe unter das Motto "Auch ich in Arkadien" gestellt hatte, schreibt er:

1 Vgl. H. HEFELE, Geschichte und Gestalt. Leipzig 1940. S. 106.

2 Goethe selbst bezeichnete seine Zeit in Italien als seine "Italienische Reise". Es ist aber eher ein Leben in Italien, in Rom vor allem. Fast zwei Jahre weilte Goethe dort, vom September 1786 bis zum Juni 1788. Vgl. R. FRIEDENTHAL, Goethe. Sein Leben und seine Zeit. Frankfurt a.M. - Berlin - Wien 1978. S. 302. 
"In Rom hab' ich mich selbst zuerst gefunden, ich bin zuerst übereinstimmend mit mir selbst glücklich und vernüftig geworden. ... Ja, ich kann sagen, dab ich die höchste Zufriedenheit meines Lebens in diesen ... Wochen genossen habe und nun wenigstens einen äuBersten Punkt kenne, nach welchem ich das Thermometer meiner Existenz künftig abmessen kann ..."1

von Tjuť̌ev heiBt es, $\triangle a B$ seine vorfahren aus Italien abgewandert seien. Sein dringendes Lichtbediurfnis, wie es sich 2.B. in dem 1854 entstandenen Gedicht "Leto" äußert, weckte in inm eine unstillbare sehnsucht nach dem Süden Europas mit seinem wolkenlosen blaven Himmel und der Farbenpracht. Dem "glücklichen Süden" stellt Tjuttev in seinen Gedichten mehrfach den "verhängnisvollen Norden" gegenüber. 2

In "vnov" troi ja vižu ǒ̌i" rühmt er den süden als sein heimatliches Land, ein "gleichsam durch die schuld der väter für die Söhne verlorenes Paradies". 3

Und in "Gljadel ja, stoja nad Nevoj" sehnt sich TjutČev an den vereisten Ufern der Neva nach Sonne, nach dem harmonischen Leben des Südens. Beim Anblick des winterlichen Petersburg hat inn das Heimweh nach der Bucht von Genua uberwältigt. Die letzte Strophe dieses Gedichts lautet:

0 , если о мнмолетныя дух,

Во мгле вечернея тихо вея,

Меня унес скорея, скорее

туда, туда, на теплия Мг...

(TJUTČEV I, S. 101)

1 HA XI, S. 530, Zeile 3-5 und S. 526, Zeile 16-20.

2 Z.B. in den Gedichten "Davno 1 ', davno 1', O Jug blažennyj" (1837), "Gljadel ja, stoja nad Nevoj" (1844), "Vnov' tvoi ja vižu oči" (1850), "Na vozvratnom puti" (1859).

3 Slovno pradedor vinoju/Dlja synov pogibšij raj... (Schlußzeilen der ersten Strophe). 
Deutlich erinnert die Schlubzeile an den Refrain aus "Kennst ou das Land" (HA VII, S. 145) aus wilhelm Meister: Kennst du es wohl?

\section{Dahin! Dahin}

Möcht. ich mit dir, o mein Geliebter, ziehn!

In Tjutčevs "Ital'janskaja villa" enthüllt sich jedoch ein wesentlicher Unterschied in der vorstellung, die beide Dichter von dem Land ihrer Träume haben. Für Goethe bedeutet Italien einen Ort der Zuflucht, der wiedergeburt, der Lebensfreude. Hier findet Mignon Verständnis:

Und Marmorbilder stehn und sehn mich an:

Was hat man dir, du armes Kind, getan?

In Tjutčevs Gedicht dagegen ist dieses gelobte Land unerreichbar geworden. Als der Fremde die italienische villa mit inrem verzauberten Garten betritt, sind das universale EbenmaB und die Harmonie dieses Ortes dahin: Die Zweige der Zypresse fangen an zu zittern, die Springbrunnen verstummen plötzlich. Hier kann der Mensch aus dem Norden keinen Trost, keine Heilung finden.

И мы вошли....все было так спокояно!

так все от века мирно и темно!..

Фонтан журчал... Недвижимо и стропно

Соседния кипарис глядел в окно.

•. • • • • • • • • • • • • • • • •

Вдруг все смутнлось: судорожння трепет

По ветвям кипарисньм пробежал, -

Фонтан замолк - и некия чуднья лепет,

Как оы сквозь сон, невнятно пронептал.

(TJUTČEV I, S. 90-91) 
Die Wurzel der Wesensverwandtschaft dieser beiden Dichter liegt in ihrer gemeinsamen Art, die Natur zu erfahren. Beide erleben sie sie im Geist des Pantheismus. 1

Ausgehend von der Größe der Natur und dem inneren Gefühl des Eingeordnetseins in ein alles umfassendes Gesamtleben, steht für sie Geborgenheit, nicht Ungeborgenheit am Ende. Naturnähe und Naturverständnis ermöglichen ihnen ein Sich-Einfülen in die Natur.

In "Sumerki" beschreibt TJutZev das pantheistische Einswerden des Endlichen mit dem Unendichen. Der berühmte Schlubvers der ersten strophe lautet: "vse vo mne, i ja vo vsem" - "Alles ist in mir, und ich bin in allem". Und das Gedicht gipfelt in der Erkenntnis:

Дая вкусить уничтоженья,

С миром дремлияим смешал!

(TJUTČEV I, S. 75)

Während Goethe Jedoch die Natur als organische Einheit begreift, als Kosmos, durchdrungen von allumfassender Harmonie und Schönheit, ist für TJutčev das gesamte Universum von einer tiefen Dualität geprägt. Der russische Dichter sient die Natur als das Entzweite, im stetigen Streit Befindliche. Diese Dualitat durchoringt das ganze Sein, ihre Grundsymbole sind der Tag und die Nacht. 3

1 In der pantheistischen Lebensempfindung wird Gott zugleich als immanent und transzendent verstanden; er erschöpft sich niemals - wie es dem Pantheismus vorgeworfen murde - nur in der Natur. Pantheisten erfahren die Welt als Unauflösbarkeit von Außerem und Innerem, von Offenbarem und sich offenbarendem. Vgl. S. FRANK, Das kosmische Gefühl in TJutčevs Dichtung, a.a.0., S. 37.

2 Von diesem vers zejgt sich auch Lev Tolstoj besonders beeindruckt. Vgl. D. BLACO, Čitatel' Tjutčeva - Lev Tolstoj. In: Uranija. Tjutčevskij Al'manach 1803-1928. Leningrad 1928. S. 224-256. Hier. S. 246.

3 Vgl. S. FRANK, a.a.0., S. $40-42$. 
Unterschiedlich ist auch der gewählte weg der beiden Dichter zum Begreifen der Natur. Goethe betrachtet ihre Geheimnisse sowohl mit der Intuition des Dichters als auch mit dem wissenschaftlichen Interesse des Forschers.

TjutČevs Naturverständnis dagegen beruht allein auf der Erfahrung des Dichters. Nur ein Künstler vermag nach seiner überzeugung die geheimnisvolle Sprache der Natur zu enträtseln. 
2.2.2.3. "Na dreve Celoveל̌stva vysokom". TJutČevs Nachrufgedicht auf Goethe

Das Problem des Todes steht bei fast allen Romantikern mit im Zentrum ihres künstlerischen Schaffens. 1 Die Grunderkenntnis, daB jeder Mensch sterblich ist, fuhrt sie zu den unterschiedlichsten Bearbeitungen des Todesgedankens.

vor diesem Hintergrund müssen auch die verschiedenen Nachrufgedichte gesehen werden. Zwei Motivkreise heben sich besonders ab. Gedichte auf Goethes Tod (1832) stehen solchen auf den Tod Pułkins (1837) gegenüber. 2

Aus $A n l a B$ des Todes von Goethe verfaßte Tjutčev das Nachrufgedicht "Na dreve čelovečestva vysokom". 3 Zum hundertsten Todestag des deutschen Dichters übertrug es vjačeslav Ivanov, ein hervorragender kenner und verehrer Goethes, 4 zusammen mit Boratynskijs "Na smert" Gete" ins Deutsche:

1 Vgl. W. REHM, Der Todesgedanke in der deutschen Dichtung vom Mittelalter bis zur Romantik. Damstadt 1967. S. 368; B. ZELINSKY, a.a.0., S. 135 .

2 Vgl. Boratynskijs "Na smert" Gete" und Lemontovs "Smert" poèta".

3 Entstehungsgeschichtlich ist dieses Gedicht nicht mehr eindeutig bestimbar. Publiziert murde es erstmals 1879. Die russischen Verse lauten:

$\mathrm{Na}$ dreve čelovečestva vysokom

Ty lucsim byl ego listom, Vospitannyj ego čiste jšim sokom, Razvit čistejsim solnečnym lučom!

S ego velikoju dušoju

Sozvǔ̌nej vsech na nem ty trepetal!

Proröceski besedoval s grozoju

Il' veselo s zefirami igral!

Ne pozdnij virch', ne burnyj liven' letnij

Tebja sorval s rodinogo sucka:

Byl moogich kraše, monogich dolgoletnej,

I sam soboju pal, kak iz venka!

(TJUŤ̌EV I, S. 49)

4 Vgl. M. GORLIN, a.a.0., 10 (1933). S. 330-31. 
Am Baum der Menschheit prangtest du, gestadtet Zum schönsten Blatt durch Ero- und Sonnenkraft, vom lichtesten, vom reinsten Strahl entfaltet, Gesätigt mit des Baumes bestem Saft.

Einstimmig war dein Flüstern, lispelnd Zittern Mit seiner Seele leisestem Getön: Du rauschtest sibylinisch mit Gewittern Und spieltest mit dem Zephyrhauch der Hön'n. Kein Herbstwind war's, kein Sommerregenschaver, Der dich geraubt; du übertrafst an Glanz

Das grine Laub, an unverwelkter Daver Und fielst von selbst, gleichwie aus einem Kranz. 1

Die Geschlossenheit der verse berunt darauf, dab nur eine einzige Metapher entwickelt wird: Goethe als das schönste Blatt am Baum der Menschheit, genährt am besten Saft des Baumes, entfaltet vom reinsten Strahl der Sonne. von selbst, nicht etwa vom Herbststurm oder Sommerregen gewaltsam gelöst, ist dieses Blatt vom Ast gefallen.

Die Beurteilungen dieses Nachrufgedichts sind sehr unterschiedich. L. Pumpjanskij und nach inm M.P. Alekseev glauben, daB TJutčev Goethe entstellt betrachtet und - zusammen mit der ganzen Generation der russischen Schellingianer - im Sinne einer inspirierten Naturphilosophie falsch gedeutet habe. Tjutčev sei entgangen, dab der deutsche Dichter "ein unversöhnlicher Feind des vertauschens der Naturforschung mit der Naturdeutung war". 2 Diese falsche vorstellung ist nach Pumpjansklj und

1 Wiedergegeben in: $W$. Iwanow $=V$. IVANOV, Zwei Gedichte auf Goethes Tod. In: Corona 4 (1934). S. 697-703. Hier S. 703.

2 L.V. PUMPJANSKIJ, a.a.O., S. 23. Vgl. M.P. ALEKSEEV, Nochmals über Tjutčev und Goethe. In: Gemanoslavica 2 (1932-33). S. 64 69. Hier S. 66. 
Alekseev nicht als Resultat eines zufäligen Nichtverstehens zu betrachten, sondern als eine typisch romantische Verzeichnung der Gestalt Goethes. 1

Zu einem gegenteiligen Ergebnis kommen neuere Untersuchungen von F. Strich, A. von Gronicka und B. Zelinsky. Fritz Strich findet "nichts im ganzen Umkreis des europäischen Goethebildes", das dem "wahren und tiefsten Wesen Goethes" so nah gekommen ist wie diese Gedichte. 2 In seinem Aufsatz über TjutZev und Goethe wiederholt und bekräftigt A. von Gronicka diese Feststellung.j Bodo Zelinsky untermavert die These durch eine pointierte Analyse von TjutCevs Nachrufgedicht.

Danach entleint TJutčev von Goethe nicht nur das verfahren - es geht in dem Vergleich des deutschen Dichters mit einem Blatt am Baume der Menschheit um ein für Goethe typisches "Widerspiegeln des einen im anderen" - sondern auch die Metapher selbst. 4 Das Blatt ist für Goethe das Urphänomen der pflanze, in deren unaufhörlichen Wandlungen das ewige Gesetz allen Lebens deutlich wird.

In Tjutčevs Gedicht entspricht dem verhältnis des Blattes zum Baume das verhältnis des einzelnen Menschen zur Menschheit. 5 Gemeint ist jedoch nicht irgendein

1 Vgl. L.V. PUMPJANSKIJ, a.a.O., S. 23; M.P. ALEKSEEV, a.a.0., S. 66 .

2 F. STRIOH, Goethe und die Weltliteratur. Bern 1957. S. 315. Mit "diese Gedichte" sind TjutČevs "Na dreve čelovečestva vysokom" und Boratynskijs "Na smert" Gete" gemeint.

3 Vgl. A. v. GronICKA, Tiutschew und Goethe, a.a.O., S. 432.

4 Vgl. B. ZELINSKY, a.a.0., S. 150.

5 Vgl. V. IVANOV, a.a.0., S. 702. 
Blatt, sondern das schönste. Ebenso ist nichtvon irgendeinem Menschen die Rede, sondern von Goethe.

Tjutčev hat in diesem Nachrufgedicht von seiner eigenen Weltsicht Abstand genommen. Nicht die dualistische, entzweite Natur ist Gegenstand des Gedichts, sondern ein harmonisches, geeintes, gleichsam Goethesches Bild der Natur wird entwickelt.

- In diesen versen hat TjutCev Goethe offensichtlich nicht, der Tendenz der Zeit entsprechend, romantisch dargestellt. Zelinsky kommt überzeugend zu dem Ergebnis, daß Tjutčev es verstanden habe, Goethe "unter dem verzicht auf seine eigene Position" goethesch zu deuten."

1 Vgl. B. ZELINSKY, a.a.O., S. 150. 
3. FREMDSPRACHIGE DICHTUNG IN ÜBERSETZUNG ŽUKOVSKIJS UND TJUTČEVS

3.1. Zukovskij, der wegbereiter westlicher Dichtung in RuBland

3.1.1. Übersetzungen als wesentlicher Bestandteil des dichterischen Werks

Bei dem überwiegenden Teil von Žukovskijs Dichtungen handelt es sich entweder um Ubersetzungen oder Nachdichtungen meist fremdsprachiger Quellen. 1

Schon zu Beginn der schöpferischen Tätigkeit des russischen Dichters deutet sich der Verlauf seines weiteren poetischen weges an; 1802 schreibt Žukovskij das erste bemerkenswerte Gedicht ("Sel'skoe kladbi šce" ("Der Dorffriedhof")), das er selbst später an den Anfang der Gesamtausgabe stellt. Bei diesem Gedicht handelt es sich um die freie Nachdichtung einer Elegie des englischen Frühromantikers Thomas Gray. 2 Jedoch fällt es schwer, diese Nachahmung als übersetzung im eigentlichen sinn zu bezeichnen, da so viel von Žukovskijs eigenem Empfinden eingeflossen ist, daß etwas völlig Eigenes, Persönliches entstanden ist. Die englische vorlage liefert lediglich Stoff und Rahmen.

Žukovskij rechtfertigt diese vorgehensweise in dem Aufsatz "O basne i basnjach Krylova", den er 1809 für den "vestnik Evropy" verfaßte. 3 Die entscheidenden Passagen lauten:

1 Vgl. C.S. Va.PE, V.A. Žukovskij. In: Istorija russkoj literatury. Bd. 5. Moskau-Leningrad 1941. S. 355-391. Hier S. 356.

2 Vgl. hierzu E. REISSNER, Žukovskij und Gray. In: ZfSl 17 (1972) 4. S. 504-514.

3 Aus dieser Zeit stammen mehrere Aufsätze Žukovskijs, in denen er sich U.a. mit der gesellschaftlichen Rolle des Schriftstellers und mit der Problematik von Ubertragungen fremdsprachiger Vorlagen befaßt, 2.B. "Ob objazannost "Zurnalista", "Pisatel" v obščestve", "O nravstuennoJ Dol'ze Doezii". 


\begin{abstract}
"Не опасаясь никакого возражения, меs позволяем себе утверждать решительно, что подражательстихотворец может бить автором оригинальньм, хотя бы он не написал и ничего сосственного. Переводчик в прозе есть раб: переводчик в стихах - соперник. ...скажу более: подражатель, не будучи изобретателем в целом, долхен им быть непременно по частям; прекасное редко переходит из одного языка в другои, не утратив нисколько своего совершенства: что же обязан делать переводчик? Находить у себл в вообрахения такие красоты, которые бы могли служить заменол, следовательно производить собственное, равно и превосходное: не значит ли это быть творцом? И не потребно ли для того иметь дарование писателя оригинального?" 1
\end{abstract}

Das Problem der sprachlichen Gestaltung steht für Zukovskij im vordergrund, und im Hinblick darauf vertritt er die Meinung, originale Schöpfungen und Nachdichtungen seien als gleichrangig zu werten. Žukovskij ist davon uberzeugt, als übersetzer "Eigenes" hervorzubringen und in diesem Sinne selbst "Schöpfer" zu sein.

Die immer wieder vorgebrachte Kritik an seiner "wesentlich nachschaffenden Natur" 2 und seiner "eindeutig rezeptiven und reproduktiven dichterischen veranlagung" 3 verfehlt somit Žukovskijs künstlerische Bedeutung. Nicht mangelnde Fähigkeit, sondern Hochschätzung der Verarbeitung von Stoffen gegenüber der unabhängigen Erfindung

1 RUSSKIE PISATELI O PEREVOOE. Hrsg. Ju. Levin und A.V. Fedorov. Leningrad 1960. S. 86-87. (Unterstrichene Stellen im Original kursiv gedruckt).

Marcelle Ehrhard weist darauf hin, daß Žukovskij dieses Verständnis des Übersetzers, bei dem die Vermittlerrolle - im Gegensatz zur Dolmetscherfunktion - Vorrang hat, von La Harpe ubernahm. Aus dessen "Cours de littérature" übersetzte Zukovskij, ohne Angabe der Quelle, den Abschnitt, den er unter dem Titel "O perevodach voobł̌ce i o perevodach v stichach" in "Vestnik Evropy" veröffentlichte. Vgl. M. ERFARD, V.A. Joukovski et le préromantisme russe. Paris 1936. S. 229-236.

2 DEUTSOEE DICHTUNG in russischer Übertragung. Hrsg. M. Hellmann. Weimar 1948. S. 27.

3 F.W. NELMAN, a.a.O., S. 51. 
veranlast ihn, geeignetes Material von anderen Dichtern zu übernehmen. Fremde Dichtung gibt inm gleichsam oen AnstoB zu eigenem fruchtbaren schaffen.

Als alter Mann schreibt er Gogol' über das Wesen seines ralents:

"Я часто замечал, что у меня нанболее светльх мыслея тогда, как их надобно имлровизировать в выражение или в дополнение чухих мыслер. Мол ум - как огниво, которьм надобно ударить об кремень, чтоб из него выскочила искра. Это вообие характер моего авторского творчества; у менл почти все или чужое или по поводу чужого, и все однако мое."1

In diesem Schreiben betont Žukovskij seine enge, persönliche Beziehung zu den von inm ubersetzten Gedichten. wohl deshalb läBt er sich bei der Auswahl der Gedichte auch nicht von dem Gedanken leiten, den russischen Leser mit allgemein anerkannten, quasi mustergiltigen Gedichten der Weltliteratur bekanntzumachen. Er wählt stattdessen solche Gedichte aus, die seiner eigenen Gefühlswelt entsprechen oder zu entsprechen scheinen. 2

Žukovskij ubersetzte sehr viel, neben Goethe vor allem schiller, den er, nach einer Bemerkung F. Dostojevskijs, beinahe zu einem "russischen Dichter" machte, aber auch Unland und die englischen Romantiker. Seine übertragung der "Alemannischen Gedichte" J.P. Hebels hat bis heute nichts vor inrer Bedeutung verloren.

Später wendet sich Žukovskij sogar der orientalischen Dichtung zu (nach Rückert) und übersetzt nach der deutschen interlinearen Ubersetzung J.H. Voss' auch Homers

1 Zitiert nach: C.S. WOLPE, Istorija, a.a.O., S. 357. Der Brief stamnt vom 6./18. Februar 1847.

2 In der Zeit 2wischen 1808 und 1809 hatte sich Žukovskij zwar als Herausgeber des "Vestnik Evropy" mit dem Gedanken getragen, repräsentative Werke der westlichen, vor allem der deutschen, Dichtung ins Russische zu übersetzen; dieser Plan murde jedoch nicht realisiert. vgl. G. sanlZ, a.a.0., S. 5, Anm. 10. 
"Odyssee", die auf diese Weise in RuBland weite Popularität gewinnt.

\subsubsection{Zukovskils Entwicklung als Goethe-übersetzer}

\subsubsection{Die Hinwendung zu Goethes Werken}

Eingeführt in die Gedankenwelt der deutschen Romantik wurde Zukovskij von seinem früh verstorbenen Freund Andrej Ivanovic Turgenev. Andrej Turgenev, dessen Gedichte eine bedeutende dichterische Begabung verraten, 1 war ein leidenschaftlicher Verehrer Goethes, der in Rußland zunächst durch seinen "Werther" berühmt geworden war. 2

Der EInfluß des um ein Jahr Jüngeren freundes auf Žukovskij war beachtlich. ${ }^{3}$ Bereits 1799 schenkte A.I. Turgenev Žukovskij ein Exemplar des "Werther", mit einer von inm selbst verfabten Widmung, die eine Charakteristik Goethes beinhaltet. Bezeichnenderweise wird Goethe in diesem vierzeiler als ein Dichter gekennzeichnet, der sich ausschlieblich "den Gesetzen des Herzens" unterwerfe. 4

Um die Wende vom 18. zum 19. Jahrhundert trafen sich die begeistertsten Anhänger Goethes in der von Andrej I. Turgenev und seinem Bruder Aleksanor (1784-1845) ins Leben gerufenen "Družeskoe Literaturnoe Obščestro". Zu

1 Vgl. D. TSOHŽ̌EWSKIJ, Literaturgeschichte, a.a.0., Bd. 1. S. 29.

2 Vgl. V.M. ŽIPUNSKIJ, Literatura, a.a.O., S. 35-36.

3 Vgl. A.N. VESELOVSKIJ, a.a.O., S. 46.

4 Eine Abbildung der handschriftlichen Widiung Andrej Turgenevs ist abgebildet in dem Gethe gewiometen Samelband von "Literaturnoe Nasledstvo" 4-6. Moskau 1932. S. 291. 
diesem ersten "Goethe-Nest" 1 in RuBland gehörten U.a. der junge Žukovskij, Aleksej FedoroviZ Merzljakov (17781830) und Aleksandr Fedorovit voejkov (1779-1639). Aleksandr Turgenev beschreibt die literarischen Interessen des Kreises folgendermaßen:

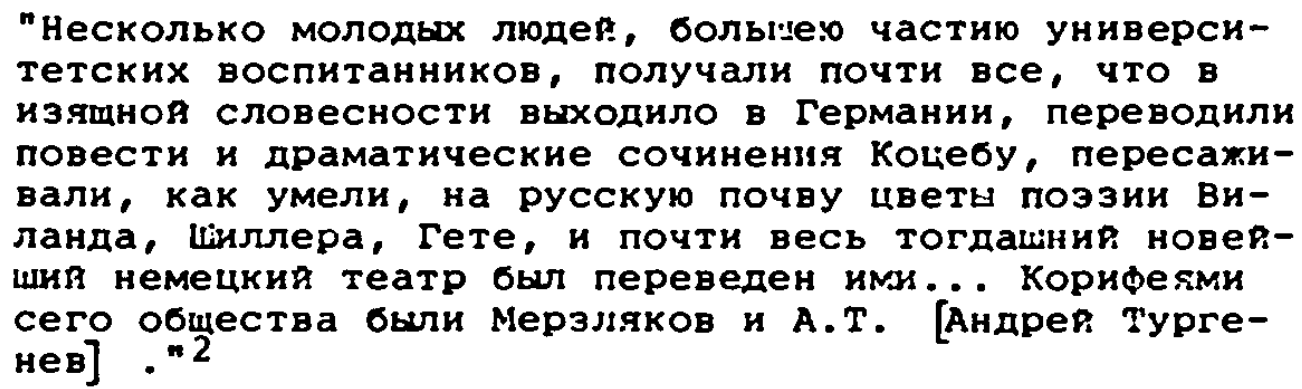

Gegenüber Aleksandr Turgenev bekannte Žukovskij sogar einmal, daß Schiller und Goethe inn erzogen hätten.'

Obwohl Žukovskij bereits als 19-jähriger lebhaften Anteil an der von Andrej Turgenev begonnenen Übersetzung des "Werther" genommen hatte, 4 konzentrierte sich sein Interesse als ubersetzer zunächst auf englische und französische Dichter wie Gray, Thompson und Lafontaine. Noch im Jahre 1605 gestand Žukovskij offen, oaß er die deutsche Literatur nur wenig kenne. 5

Eine entscheidende wende bringt das Jahr 1808: Žukovskij wird Herausgeber des "Vestnik Evropy". Diese bereits 1802 von Karamzin gegründete zeitschrift hatte es sich - wie der Titel schon andeutet - zur Aufgabe gemacht, regelmäßig Informationen über das politische und literarische

1 A. von GroNICKA, The Russian Image of Goethe. Goethe in Russian Literature of the First Half of the Nineteenth Century. Philadelphia 1968. S. 18.

2 K.M. ŽIRMUNSKIJ, Literatura, a.a.O., S. 61.

3 Vgl. ebd. S. 77.

4 vgl. S. DURYIN, a.a.0., S. 326.

5 Vgl. A.N. VESELOVSKIJ, a.a.O., S. 21. 
Geschehen in. übrigen Europa in RuBland $2 u$ verbreiten.' Entscheidend trägt der "Vestnik Evropy" auch zur Förderung des Goethe-kults in RuBland bei.

So ist auf dem Titelblatt der Nov./Dez.-Ausgabe des Jahres 1806 Goethes Porträt abgebildet, ${ }^{2}$ im Textteil befinden sich diverse Artikel uber den deutschen Dichter. Der Bericht "Gete, izobrakennyj Lafaterom" wird allgemein als Beginn des Goethe-kults in RuBland bezeichnet. 3 In diesem Umfeld müssen auch Žukovskijs erste Goethe-Ubertragungen "Moja Boginja" und "Motylek" gesehen werden."

1 Es murden hăfig Artikel aus ausländischen, meist französischsprachigen Zeitungen abgedruckt. Als deutsche Quelle benutzte Karamzin die in Leipzig erscheinende "Zeitung für die elegante Welt" und die von Garlieb Herwig Merkel herausgegebene Zeitschrift "Der Freimuithige". Näheres zu den benutzten Quellen bei: V.I. KULEŠV, a.a.0., S. 21-22.

2 Vgl. S. DURYIN, a.a.0., S. 326.

3 weitere Informationen zum "Vestnik Evropy": M. ERPHARD, a.a.O., S. 62-60; H. EICHSTÄDI, ŽukovskiJ als übersetzer. Drei Studien zu Übersetzungen V.A. Zukovskijs aus dem Deutschen und Französischen. Minchen 1970 (FS 29). S. 10-22, vgl. hierzu die Rezensionen W. Busat. In: ZfslPh 37 (1974). S. 196-201; S. HOLAEID. In: Wasl 1 (1972). S. 244-247; P. RIOHTER. In: Krit Litt 1972/1. S. 7677; M.V. JONES. In: SEER 121 (1972). S. 637-636.

4 vgl. v.1. KULEŠOv, a.a.0., S. 27. 
3.1.2.2. Žukovskijs schöpferische Phase als Goethe-Übersetzer

Die Mehrzahl der Goethe-übertragungen Zukovskijs stammt aus den Jahren 1816 bis 1818. Entscheidenden EinfluB auf die aktive Auseinandersetzung mit Goethes Werk hat der Aufenthalt des russischen Dichters in Dorpat. Fast zwei Jahre lang lebt und arbeitet Zukovskij in der baltischen Universitätsstadt, deren geistige Oberschicht überwiegend aus Deutschen besteht.

Doch so präzise wir auch über die äuBeren fakten von Žukovskijs Dorpater Jahren informiert sind, über seine zahlreichen Bekannten und Freunde, 1 mit so wenig Aufmerksamkeit wurde bisher den unmittelbaren Anregungen der neuen Umgebung auf Žukovskijs Dichtung nachgespürt. Im vordergrund stehen alle Hinweise, die Žukovskijs Beziehung zu Maša erhellen könnten; pauschal bleiben jedoch die Angaben der meisten Biographen zu Žukovskijs ausgiebiger Beschäftigung mit deutscher Literatur. Meist werden lediglich neue übersetzungen aus werken von Goethe, Schiller, Hebel und unland aufgezählt.

c. v. Seidlitz gibt einen wichtigen Hinweis:

"Andere Uebersetzungen entstanden, weil Weyrauch zu den Deutschen Originalen die Musik gemacht hatte und seine Lieder im Moier'schen Hause öfters vorgetragen wurden. Auf gleiche Weise ward er zu Uebertragungen Uhland'scher Balladen und Hebel'scher Gedichte veranlasst, weil sie dort gefielen." 2

Wohl zu Recht kritisiert Hildegard Eichstädt, daB die Kompositionen August Heinrich von Weyrauchs in den meisten Žukovskij-Blographien nur beiläufig erwähnt werden, obwohl

$\overline{1 \mathrm{Zu}}$ den Namen von Žukovskijs Dorpater Bekannten vgl. C. v. SEIDLITZ, a.a.O., PIS'MA V.A. ZUKOVSKOCO k A.I. Turgenevu, a.a.O..

2 C. v. SEIDLITZ, a.a.O., S. 91. 
sie es doch sind, die den Anstoß zu Žukovskijs übersetzungen gaben. 1

Eine eindeutige Trennung derjenigen Gedichte, die auf Anregung von Kukovskijs Dorpater Bekannten entstanden sind, von denen, die zur Auflockerung des Russischunterrichts der späteren Grobfüstin angefertigt wurden, ist kaum möglich. So dürfte auch die ubertragung von "Neue Liebe, neues Leben", die Žukovskij erst im Januar oder Februar 1818 in st. Petersburg verfabt hat, noch auf die vertonung seines in Dorpat wirkenden Freundes August H. v. Weyrauch zurückzuführen sein. ${ }^{2}$

In seiner schöpferischen Phase übersetzte Žukovskij insgesamt zehn Goethe-Gedichte, darunter zwei Lieder aus "Wilhelm Meister" ("Wer nie sein Brot mit Tränen ab" und "Kennst du das Land"), "Trost in Tränen", "An den Mond" sowie die beiden Balladen vom "fischer" und "Erlkönig".

Die Mehrzahl dieser übersetzungen wurde zum ersten Mal in den Privatdrucken "Für Wenige. Dlja nemnogich" veröffentlicht.

Die kleinen gelben Hefte, die in nur sehr geringer Auflage herauskamen, beinhalten neben Originalgedichten Žukovskijs vor allem übersetzungen deutscher Dichtung. Zu Unterrichtszwecken - seit dem Ende des Jahres 1817 unterrichtete Žukovskij die spätere GroBfürstin Aleksanora feodorovna (eigentlich Prinzessin Charlotte von Preußen) - hatte der russische Dichter eine Sammlung seiner Ubersetzungen zusammen mit den deutschen Originaltexten zusammengestellt.

1 Hildegard Eichstädt geht in inrer Arbeit ausführlich auf die Bedeutung von Weyrauchs Kompositionen zu deutschen Originalen, als Sammlung 1820 in Dorpat veröffentlicht, ein. Vgl. H. EICHSTÄDT, a.a.0., S. 39-54.

2 Vgl. H. EICASTADT, a.a.0., S. 52-5j.

3 Vgl. C. v. SEIDIIZ, a.a.0., S. 10j; I.M. SEMENKO, a.a.0., S.40. 


\subsubsection{Zunehmende Entfremdung von Goethe}

In den Jahren 1819-1833 übersetzte Zukovskij noch sechs weitere Dichtungen Goethes. Jedoch die persönliche Bekanntschaft mit dem deutschen Dichter konnte inn nicht mehr zu uberragenden Leistungen inspirieren.

Nach seinem letzten Besuch bei Goethe im Jahre 1827 ubersetzte Zukovskij lediglich noch drei Zeilen aus dem "Tasso" ("Die Stäte, die ein guter Mensch betrat..."), zwei Vierzeiler aus den "Zahmen xenien" ("wär nicht das Auge sonnenhaft" und "Liegt dir Gestern klar und offen") und die Versfabel "Der Adler und die Taube". Schlieblich versuchte Žukovskij 1848 noch eine Interpretation von zwei szenen aus Goethes "Faust". " Für eine Zeitspanne von fast zwei Jahrzehnten war dies keine überwältigende Leistung.

Žukovskijs Abschiedsgeschenk an Goethe, ein von inm selbst ins Deutsche UbertragenesGedicht, ${ }^{2}$ macht deutlich, daß Žukovskij bei seinen Gesprächen in weimar klar geworden sein muB, daB die Goethesche Welt eine ganz andere war als die seine.

Hierdurch läßt sich auch die einseitige Auswahl der ubersetzten Goethe-Gedichte erklären.

1 ŽukovskiJ deutet den "Faust" in seinem Aufsatz "Ove Sceny iz Fausta" religiös um. Vgl. M. GORLIN, a.a.O., 10 (1933). S. 321; D. GEPAARDT, Faust und die Folgen. V.A. Zukovskijs Aufsatz "Zwei Szenen aus Faust". In: Mnemozina. Studia litteraria Russica in honorem vsevolod Setchkarev. Hrsg. J.Th. Baer und N.W. Ingham. Minchen 1974 (Centrifuga 15). S. 130-152.

2 Vgl. bei uns Kapitel II, 2.2.1.2. "Žukovskijs Besuche bei Goethe". 


\subsection{TJutčev als Übersetzer}

\subsubsection{TJutČevs Übersetzungen Frendeprechiger Lyrik}

Tjutčev hat etwa fünfilg übertragungen fremdsprachiger Poesie hinterlassen. Sie machen annähernd den achten teil seines Iyrischen Gesamtwerks aus.

Die uberwiegende Anzahl der Ubersetzungen hat TjutCev während seiner Aufenthalte in München und Turin angefertigt. Nur wenige übertragungen stammen aus dem Petersburger Lebensabschnitt des Dichters.

Neben Goethe, dessen Werk Tjutלev am stärksten zu übersetzungen anregte, hat er sich vor allem Heine und Schiller zugewandt.

Aus Heines Werk überträgt Tjutčev unter anderem einen Prosa-Ausschnitt aus den "Reisebildern", den er in versen wiedergibt, und verschiedene Gedichte aus dem "Buch der Lieder". 1 Insgesamt existieren zehn Übertragungen und freie Wiedergaben des russischen Dichters aus Heines Werk.

Von Schiller übersetzt TJutčev fünf Gedichte, darunter so beruhmte wie das Lied "An die Freude" ("Pesn" radosti") und "Das Siegesfest" ("Pomniki").

Aus Shakespeares Märchenspiel "Ein Sommernachtstraum" wird von Tjutčev ein kleiner Ausschnitt von oreizehn Zeilen und ein Lied ubersetzt.

1 2.B. "Wie der Mond sich leuchtend dränget" ("Kak poroju svetlyj mesjac"), "Der Tod das ist die kühle Nacht ..." ("Esli smert" est' noč', esli Žizn" est" den'"), "Ein Fichtenbaum steht einsam" ("Na severe mračnom, na dikoj skale").

2 Diese Liedballade Schillers war bereits von Žukovskij im Jahre 1828 ins Russische Ubertragen worden. Hier lautet der Titel "Toržestvo pobeditelej". 
Weitgespannt ist der Bogen derjenigen Dichter, von denen Tjutčev jeweils nur eine Dichtung ins Russische überträgt. Zu ihnen gehören der römische Dichter Horaz, Lord Byron, Johann Gottfried von Herder, Joseph Christian von Zedlitz, Ludwig Uhland, Nikolaus Lenau, Alphonse de Lamartine, Jean Baptiste Racine, Victor Hugo, Pierre Jean de Béranger. Alessandro Manzoni und Michelangelo.

TjutČev übersetzte nur solche Gedichte, die inn vom Thema her ansprachen, die seine Aufmerksamkeit als Künstler zu wecken vermochten. Hieraus erklärt sich, daB die Übertragungen häufig Anklänge an Tjutčevs originale Dichtung aufweisen. In fremden Werken findet er gleichsam den Widerhall seiner eigenen Gedanken und Empfindungen. von allen übersetzungen fertigte Tjuťev nur eine, und zwar die Übertragung von Schillers "Das Glück und die weisheit" ("Fortuna i Mudrost"') auf Initiative von auben hin an. N.V. Gerbel', der eine Sammlung Schillerscher werke in russischer übersetzung vorbereitete, hatte TJutčev um die Übertragung dieses Gedichtes gebeten. 


\subsection{2. Überblick über TJutZevs Goethe-übersetzungen}

Insgesamt neun Goethe-Gedichte hat Tjutčev ins Russische ubersetzt, 1 dazu sind fünf Fragmente aus dem 1. Teil des "Faust" sowie das Lied Klärchens aus "Egmont" erhalten geblieben. Die übersetzung des ersten Aktes vom Faust II vernichtete TjutCer aus Unachtsamkeit selbst. 2

Die überwiegende Anzahl der übersetzungen stammt aus der ersten Münchener Lebensphase des russischen Dichters (1822-1837), insbesondere zwischen 1826 und 1832 beschäftigte er sich intensiv mit Goethes Werk. In seinen Jahren in Petersburg (ab 1644) überträgt Tjutčev lediglich noch "Kennst du das Land, wo die Zitronen blühn" aus "Wilhelm Meisters Lehrjahre" (vermutlich 1851) und das Lied Klärchens aus "Egmont" (1870).

Als erste Goethe-Übertragung erscheint "Sakontala" 1827 in der Zeitschrift "Severnaja lira". Drei Jahre später werden in "Galateja" ein Fragment aus dem "Faust" ("Začem gubit" v unynii pustom") und die Gedichte "Privetstrie ducha" und "Pevec" veroffentlicht. 1831 bringt die Zeitschrift "Sirotka" die Wiedergabe der beiden Harfner-Lieder aus "Wilhelm Meisters Lehrjahre" "Kto 8 chlebom slez svoich ne el" und "Kto chočet miru Čǔ̌dym byt"." Im Jahr darauf erscheint "Nočnye mysli", Tjutčevs übersetzung von Goethes "Nachtgedanken", in der Zeitschrift "Teleskop".

1 Die anonym veröffentlichte Übersetzung von Goethes Jugendgedicht "Wechsel" ("Auf Kieseln in Bache da lieg ich, wie hellel") mit dem russischen Titel "Peremena" ("Ležu ja $v$ potoke na kamnjach ... Kak rad ja!") murde in verschiedenen Werkausgaben Tjutcev zugeschrieben. Zahlreiche Anhaltspunkte weisen jedoch darauf hin, daß K. Aksakov der tatsächliche verfasser dieser Übersetzung sein dirfte. Vgl. V.M. ZIFMnSKIJ, Literatura, a.a.0., S. 165-66.

2 In einem Brief vom 7. August 1836 berichtet er seinem Freund I.S. Gagarin von dem Mißgeschick, das sich bereits im Jahre 1633 ereignet hatte. Vgl. ebd. S. 168. 
Erst nach zwanzig Jahren wird noch eine ubertragung Tjutčevs veröffentlicht. Es ist "Ty znaes. kraj, gde mirt i lavr rastet". Dieses Gedicht erscheint 1852 in dem Samimelband "Raut". Die verbleibenden sieben Goethe-Ubertragungen werden erst nach Tjutkevs Tod publiziert. 1

1 Vgl. V.M. ŽIPMNSKIJ, Literatura, a.a.0., S. 164-166. 
III. ANALYSE DER VON ŽUKOVSKIJ UND TJUTČEV ÜBERSETZTEN

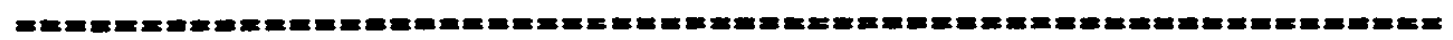
LYRIK GOETHES

$m=z=m=m=2=$

\section{THEORETISCHE ANSÄTZE ZUR BEURTEILUNG DER QUALITÄT EINER}

\section{KÜNSTLERISCHEN ÜBERSETZUNG}

Die Frage nach giltigen Kriterien fur eine Kritik von übersetzungen wird in der Theorie auf verschiedene Weise beantwortet. Hinter den vielfältigen Vorstellungen, die Theoretiker von einer "guten Übersetzung" haben, stehen unterschiedliche Auffassungen der Übersetzung als Kunstgattung.

während die einen Theoretiker des Übersetzens den philologischen, d.h. fachlichen Charakter dieser Tätigkeit betonen ldas übersetzen aus antiken und orientalischen Sprachen z.B. wird allgemein als wissenschaftliche Arbeit angesehen), steht bei anderen inr küstlerischer Charakter im Vordergrund (so werden Herders übersetzungen von Volksliedern zu seinem eigenen poetischen Schaffen gerechnet).

Wir schließen uns in unseren Überlegungen den Ausführungen Jiř́ Levýs, einem der fühenden Vertreter der Jüngeren Generation tschechischer Strukturalisten, an. 1

Grundlage jeder Übersetzungskritik ist danach die Vorstellung von dem, wie eine übersetzung beschaffen sein sollte. Diese Vorstellung ist durchaus veränderlich. Sie erwächst aus der - nicht zuletzt historisch bedingten Konzeption des übersetzers und seines Kritikers. Es können und sollen hier nicht die unterschiedlichen

1 J. LEV'́, Umění překladu. Prag 1963. Dieses Werk murde noch vom Verfasser selbst für die deutsche Übersetzung ungearbeitet. Die übersetzung Walter Schamschulas erschien 1969 im Athenäim Verlag, Frankfurt a.M. unter dem Titel "Die literarische Übersetzung. Theorie einer Kunstgattung". Weiterführende Ausführungen über textgattungsbezogene Übersetzungstheorien sowie über Ansätze, Entwicklungen und Stand der Übersetzungstheorie vgl. W. KOLER, Einführung in die Übersetzungswissenschaft. Heidelberg 1983 (UTB 819). 
Anschauungen davon, wie eine Übersetzung sein sollte, dargelegt werden.

Wir gehen davon aus, daß es nicht das Ziel der ubersetzerarbeit ist, ein neves werk zu schaffen, sondern das Originalwerk und seine Mitteilung zu erhalten, zu erfassen und $z u$ vermitteln. Dieses $z i e l$ ist reproduktiv, die ubersetzung als Werk somit eine eindeutige Reproduktion, auch wenn es sich beim Ubersetzen selbst um einen original-schöpferischen Prozeß handelt.

Aufgabe des übersetzers ist es, die semantischen und ästhetischen Werte des Kunstwerks für den Leser zu bewahren. Keinesfalls darf er sich auf die einfache Wiedergabe der sprachlichen Elemente und Strukturen des Originals, auf die mechanische Bewahrung der form beschränken.

Der ubersetzer soll die Mitteilungsfunktion der einzelnen sprachlichen Elemente erfassen und Mittel der eigenen Sprache finden, die einen Gegenwert mit gleicher funktionaler Eignung darstellen und somit die gleiche Funktion erfullen können. Dieser von der "Prager Schule" erarbeitete "funktionale Aspekt" stützt sich somit vor allem auf die Erkenntnis, daß die Gleichheit der künstlerischen Effekte wichtiger ist als die Gleichheit der Kunstmittel. 1

Als grundsätzliche Kriterien für die Analyse einer schöpferischen Reproduktion kommen nach Levy zwei Normen zur Geltung; erstens die Norm des Reproduzierens und zweitens die Norm des Künstlerischen. Bei der Übersetzerarbeit offenbart sich diese grundlegende ästhetische Antithese als der Gegensatz zwischen Ubersetzerischer Treue und Freiheit.

1 vgl. v. MATHESIUS, 0 problémech českéno prekladatelství. In: Prehled 11 (1913). S. 806. 
Dabei ist aus der Geschichte des übersetzens bekannt, daB sich der Begriff von der "Wahrheitstreve" einer übersetzung geändert hat. So verstand man im Humanismus unter einer "treuen übersetzung" das präzise verdolmetschen der Bedeutung, in der Romantik demgegenüber die Wiedergabe der nationalen und individuellen Eigenheiten. Ebenso änderte sich auch die Rangfolge der Normen.

Festzuhalten bleibt, daB beide Qualitäten unentbehrlich sind. Die übersetzung soll eine möglichst genaue wiedergabe des Originals sein, selbst aber ein nochwertiges sprachliches Werk. Der Wert einer künstlerischen übersetzung ist also an ihrem verhältnis zu beiden Normen zu messen. Schönheit und künstlerische vollkommenheit sowie Textreve durfen einander nicht ausschlieben.

Unmittelbar verbunden mit einer künstlerischen übersetzung ist die Person des übersetzers. Er stellt beim ProzeB des übersetzens einen individuellen faktor dar, der sowohl seinen Stil und seine Auffassung vom Original und dessen objektiver Idee, als auch den stil seiner Epoche mit in die übersetzung einbringt.

Eine Übersetzung kann also auch als Ausdruck der schöpferischen Individualität des verfassers verstanden werden; und zwar dann in besonderem MaBe, wenn es sich bei dem übersetzer gleichzeitig um einen eigenständigen Dichter handelt. 


\section{ANALYSE DER ÜBERSETZTEN GEDICHTE}

\subsection{Gedichte zur Beziehung Mensch und Umwelt}

\subsubsection{Kunstler und Weltanschauung}

\subsubsection{Ubersetzungen Zukovskijs}

\subsubsection{1. "Meine Göttin"}

Als erstes Gedicht Goethes übersetzte Kukovskij - vermutlich gegen Mitte des Jahres 1809 - "Meine Göttin" (HA I. S. 144-146) ins Russische. Bereits im September 1809 wurde diese Übertragung im "Vestnik Evropy" unter der uberschrift "Moja Boginja" (ŽukovskIJ I, S. 89-92), mit dem Untertitel "Podražanie Gete" veröffentlicht.

"Meine Göttin" gehört zu einer Reihe großer Hymnen, die Goethe in den Jahren 1779-1782, also in seiner Weimarer Periode, verfabt hat. Im Mittelpunkt stehen Goethes Ideen uber Sittlichkeit und Humanität: "Das Göttliche" geht vom Menschen aus, von seinem Innern. Er hat die Fähigkeit, sich künstlerisch zu biloen. Dieses Motiv wird zum Hauptthema von "Meine Göttin". Schöpferkraft unterscheidet den Menschen von allen anderen Lebewesen und macht ihn frei. 1
Alle die andern
Armen Geschlechter
Der kinderreichen
Lebendigen Erde
Wandeln und weiden
In dunklem Genub

1 Vgl. HA I, S. 547-546. 


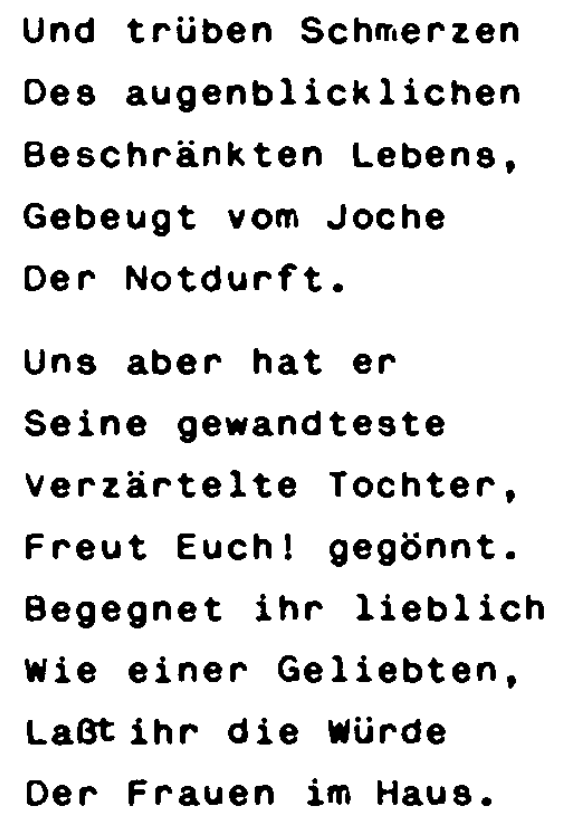

Goethe legt das soeben entstandene Gedicht im September 1870 einem Brief an Frau von Stein bei. "Meine Göttin" ist ein Hymnus des Künstlers, des Phantasiemenschen, auf den kostbarsten Besitz des Menschen, auf die Phantasie. 1 Sie ist es, die dem Menschen immer neue Möglichkeiten eröffnet.

Žukovskijs übertragung ist fast doppelt so lang wie das deutsche Original. Die ersten Zeilen des Goetheschen Gedichtes hat Žukovskij auf vierzenn Zeilen erweitert. Zur verdeutlichung der Unterschiede folgt eine Gegenüberstellung der deutschen und der russischen verse:

Welcher Unsterblichen

Soll der höchste Preis sein?

Mit niemand streit' ich,

Aber ich geb' inn

1 Wohl am Gegensatz war Goethe das wesen der Phantasie besonders deutlich geworden; er schrieb die Hymne in der Zeit seiner engagiertesten Beamtentätigkeit an Weimarer Hof. Vgl. HA I, S. 556. 


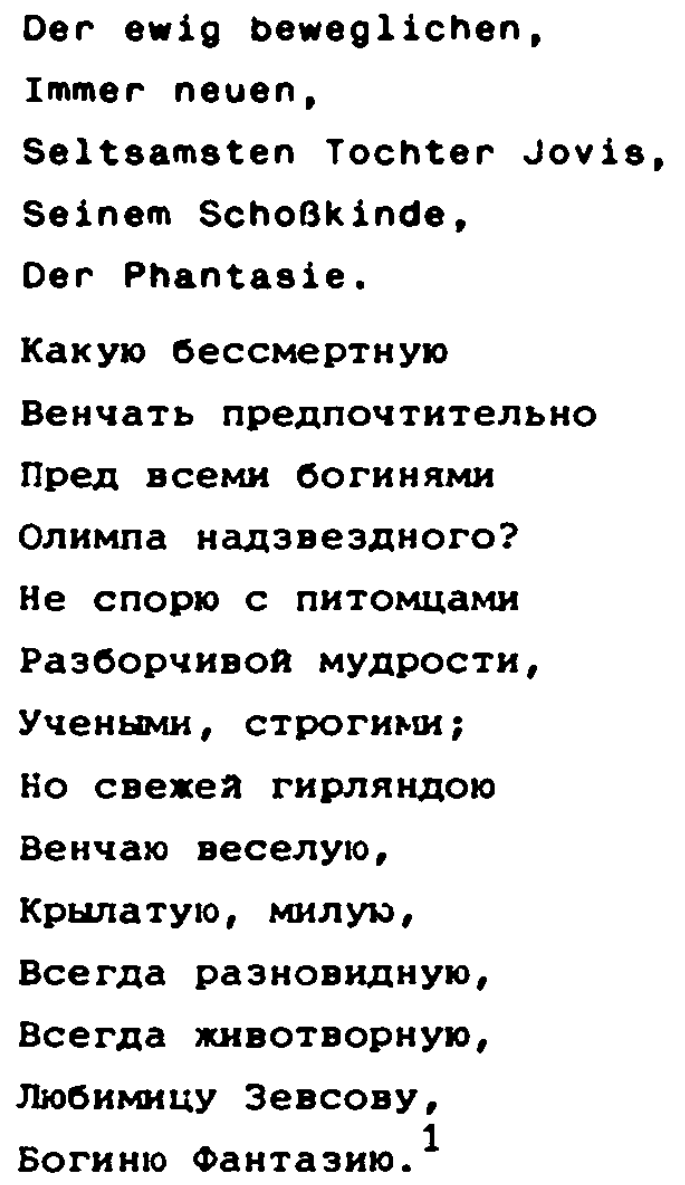

Zukovskij erhebt in seinen Zeilen die "Phantasie" uber alle anderen Göttinnen des Olymps; exakt beschreibt er uns den Preis, einen Kranz aus Blumen. Er schmückt Zeus' Tochter - im Gegensatz zu Goethe, dem drei Adjektive genügen (beweglich, neu, seltsam) - mit insgesamt fünf Adjektiven (veselyj, krylatyj, milyj, vsegda raznovionyj,

1 Welche Unsterbliche/Soll man mit Vorrang bekränzen/vor allen Göttinnen/Des Olymps über den Sternen?/Ich streit nicht mit den Zöglingen/Der wählerischen Weisheit,Mit den Gelehrten, den Gostrengen;/Doch mit frischer Girlande/Bekränz ich die fröhliche,/ Beflugelte, liebliche,/Stets andersgeartete,/Stets erquickende/ Lieblingstochter des Zeus', /Die Göttin Phantasie.

(Falls es nicht anders vermerkt ist, stamen die ubersetzungen von der Verfasserin selbst. Wegen des unterschiedlichen Satzbaus im Russischen und im Deutschen deckt sich die in der Prosaibersetzung durch einen Schrägstrich angezeigte Länge einer verszeile nicht immer mit der entsprechenden Zeile des Originals. Das idiomatische deutsche Sprachgefühl verbot es, Wort- und Satzteile pedantisch in jedem Fall zu reproduzieren.) 
Životvornyj). Die treffendste Charakterisierung der Göttin als Zeus" "Schoßkind" übersetzt Zukovskij jedoch nicht."

Zukovskijs Erweiterungen sollen vielleicht die allgemeine verständlichkeit der Zeilen erhöhen, doch die mit wenig worten erreichte Klarheit und der Charme des Originals drohen dabei verloren zu gehen.

Noch stärker als die einleitenden Zeilen inspirieren die beiden uberwiegend beschreibenden strophen, die mit den Zeilen "Sie mag rosenbekränzt" bzw. "Oder sie mag/ Mit fliegendem Haar" anheben, zu kühnen Variationen des ursprünglichen Themas. Die insgesamt 17 Zeilen der beiden strophen hat Žukovskij auf 66 Zeilen erweitert (Zeile 26-91).

Zeus" "Schoßkind" nimmt bei inm die unterschiedlichsten Gestalten an: Es fliegt als Rotkehlchen durch ein duftendes ral und über grasbedeckte Hügel (Zeile 31-34); als kleine Biene läßt es sich auf Maiglöckchen, Lilien und anderen glumen nieder und saugt mit Bienenlippen den Honigtau (Zeile 35-41). - Die Anhäufung von Adjektiven (lilejnyj, nežnyj, dušistyj, muravčatyj, utrennij, dubravnyj, pčelinyj, medvjanyj) und der Gebrauch von Deminutiva wie "travka" statt "trava", "pčelka" statt "pčela". "listiki" statt "list'ja" geben den russischen zeilen eine zarte, fast sübliche färbung, die Goethes versen in keiner weise entspricht.

1 Ebenso ersetzt Žukovskij die Kennzeichnung der Göttin als "Törin" (Zeile 16) durch das vergleichqueise blasse Kompositum "boginjaradost" (Zeile 25). Vgl. V.M. ZIPMNSKIJ, Gete v russkoj poézii. In: Literaturnoe Nasledstvo 4-6. Moskau 1932. S. 505-650. Hier S. $539-540$. 
In dem folgenden beschreibenden Abschnitt (Zeile 4291) verwandelt sich Žukovskijs Göttin - bedingt durch den Stimmungswechsel im Original - in ein nachoenkliches, melancholisches Wesen. vieles erinnert an die weltschmerzlich-erhabenen Naturschilderungen Ossians.

Žukovskijs zeilen vermitteln etwa folgende szene: Die Göttin "Phantasie" sitzt auf einem steilen felsen, inre Locken wehen lässig im wind und ihr Haupt ist geneigt. In ihrem Blick liegt Schwermut. In Gedanken verioren schaut sie auf das trostlose Meer. Sie liebt es, den Wellen zu lauschen, die gegen das ufer schlagen (Zeile 4252 ).

Während Zukovskijs Göttin ruhig auf einem Felsen sitzt und ihren Gedanken nachgeht, ist Goethes Göttin die Personifizierung der Bewegung:
Oder sie mag
Mit fliegendem Haar
Und dusterm Blicke
Im winde sausen
Um Felsenwände

1 Der schottische Dichter James Macpherson (1736-1796) ubte mit seinen Ossian-Dichtungen, die or als Uborsetzungen aus dem Gälischen ausgab - sie sollten aus dem 3. Jahrhundert stamen - entscheidenden Einflus somohl auf die deutsche wie auch auf die rugsische Romantik aus. An der Echtheit dieser Dichtungen wurde zunächst nicht gezweifelt. Dies bezougt der Aufsatz Johann Gottfried Herders: "Auszuige aus einem Briefwechsel uber Ossian und die Lieder alter Völker", 1771. Der Einflue dieses Aufsatzes auf die Entwicklung der russischen Literatur war nicht geringer als der Ossians selbst. Vgl. G. Schulz, a.a.0., S. 37, 64-66. 


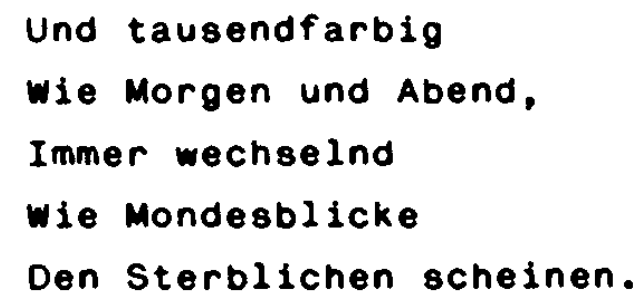

Die "Mondesblicke" lösen bei Zukovskij eine ganz andere vorstellung aus. Er kreiert eine Szene, die einem Traumbild ähnlich ist: Zeus' Tochter spielt in einem kleinen Wald, der vom Mond angestrahlt wird, mit Najaden auf der Wasseroberfläche eines Waldbaches oder mit Zephiren uber träumenden Lilien, Maiglöckchen und anderen Blumen (Zeile 59-78).

Nach diesen Flügen in die Welt der Phantasie hält sich Zukovskij wieder enger an die vorlage. Vergleichsweise genau ubersetzt er Goethes Zeilen:

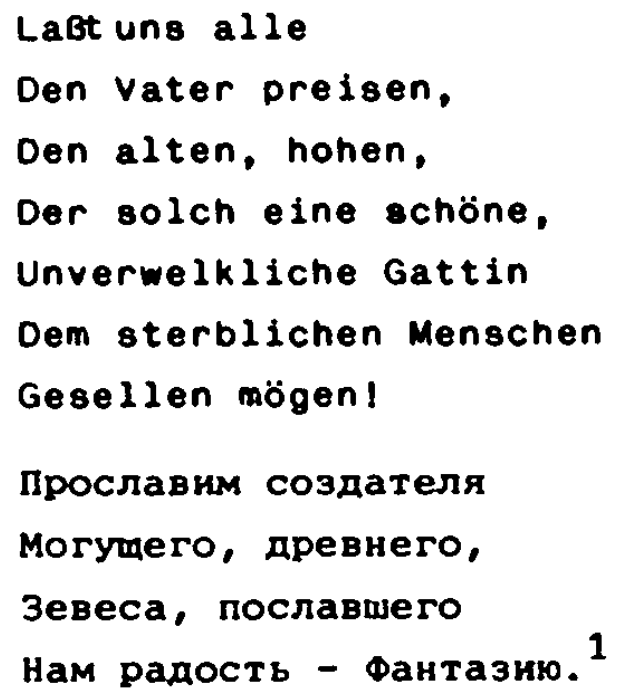

Es folgt Zeus' Befehl an seine Tochter. Während Goethe dieses Gebot mit leichter Hand als indirekte Rede einfügt, formt ŽukovskiJ es in eine schwerfällige, direkte Rede um. 2

1 Laßst uns den Schöpfer loben,/Den mächtigen, alten/Zeus, der uns gesandt hat/Die Freude-Phantasie.

2 Vgl. A. v. GRONICKA, The Russian Image of Goethe, a.a.0., S. 50. 
Und inr geboten,

In Freud' und Elend

Als treve Gattin

Nicht zu entweichen.

"Да будешь, - сказал он ер., -

и в счастье и в горести

им вернал спутница,

утеха, прибежние." 1

Diese Schwerfäligkeit wird durch das gleichbleibende daktylische versmaß noch betont. Das Tempo ist insgesamt verlangsamt, so daB sich eine schwermitige stimmung auf die russischen Zeilen legt. 2

Demgegenuber verwendet Goethe freie Rhythmen, 3 die die zentrale Aussage dieser Ode an die Schöpferkraft, die Phantasie des Menschen, klanglich untermalen. Die Monotonie der regelmäßigen Daktylen, in die Žukovskij seine verse zwängt, kann dem Inhalt des Gedichtes nicht gerecht werden.

Nach der Phantasie preist Goethe am SchluB des Gedichtes inre Schwester:

Doch kenn' ich ihre schwester, Die ältere, gesetztere,

Meine stille Freundin:

o dab die erst

Mit dem Lichte des Lebens

sich von mir wende.

1 "Ou wirst, - sagte er ihr -/In Glïck und Kummer/Ihm eine treve Gefährtin,/Freude und Zuflucht sein."

2 Vgl. A.N. VESELOVSKIJ, a.a.O., S. 304.

3 Vgl. I. BRAAK, Poetik in Sticmmorten. Kiel 1974. S. 61. 
Die edle Treiberin,

Trösterin, Hoffnung!

Für Žukovskij ist sie:

Причина всех добрнх дел,

Источник великого,

Нам твердость, и мужество,

и силу даюмая,

надежда отрадная!... 1

Im Gegensatz zu Goethe hebt Žukovskij deutlich den moralischen wert der Hoffnung hervor, dem er größeres Gewicht beizumessen scheint. - Es gelingt Zukovskij, die Spannung der Goetheschen Verse, die erst in der letzten zeile preisgeben, wer die ältere Schwester der "Phantasie" nun eigentlich ist, dem russischen Leser zu erhalten.

Die Motive der wiederholten Abschweifungen Žukovskijs (Zephire, Najaden, ein kleiner, vom Mondschein erhellter Wald) entstammen uberwiegend dem Inventar der Empfindsamkeit bzw. der Frühformen der Romantik. Diese Erweiterungen und Ausarbeitungen lassen vermuten, daß es nicht seine Absicht war, eine exakte Übersetzung des Goethe-Gedichtes zu erstellen. Žukovskij muß auch gespürt naben, daß er Goethes Gedicht eine Geziertheit und Zartheit gab, die diesem ziemlich fremd ist. 2

1 Die Ursache aller guten Werke,/Die Quelle des Großen,/Die uns Standhaftigkeit und Mut/Und Kraft gibt,/Hoffnung, tröstliche!.....

2 Die Thematik des Gedichtes hat Žukovskij offensichtlich gereizt. In einem in versen verfaßten Brief an K.N. Batjuškov aus dem Jahre 1812 taucht wieder die Göttin "Phantasie" auf. Ihre Mutter, die Natur, läßt sie sorglos spielen. Doch die Freiheit ist nur Illusion, weil die älteren Brider, der "Geist" ("genij"), das "Wissen" ("nauka") und der "Geschmack" ("vkus") sie beaufsichtigen sollen. Vgl. V.A. ZuKOVSKIJ, Polnoe sobranie soX̌inenij v 12-ti tomach. Hrsg. A.S. Archangel'skij. St. Petersburg 1902. Hier Bd. 1. S. 98-105. 


\subsubsection{2. "Die Freuden"}

Es vergehen mehrere Jahre, bis sich Žukovskij an der übersetzung eines weiteren Goethe-Gedichtes versucht. Im Jahre 1814 ahmt er Goethes Jugendgedicht "Die Freuden" (HA I, S. 19) aus dessen Leipziger Zeit (1765-1766) unter dem bemerkenswerten Titel "Motylek"1 nach.

Genau wie bei Žukovskijs erster Goethe-wiedergabe ist auch hier die russische version fast doppelt so lang wie die deutsche vorlage. Goethes 14 Zeilen hat Zukovskij in ein sechsstrophiges Gedicht umgeformt.

Das russische Gedicht zeichnet sich durch formale Gleichmäßigkeit aus: Zeilen mit vier und orei Hebungen wechseln sich regelmäBig ab. Obwohl Žukovskij das jambische versmaß des Originals beibehält, läßt er doch dessen formale UnregelmäBigkeiten, die sich in der ungewönnlichen zeileneinteilung und in der nicht immer regelmäßig wechselnden Zahl der Hebungen pro Zeile manifestieren, unberlicksichtigt. Wie bereits bei der übertragung von "Meine Göttin", legt ZukovskiJ auch hier größeren wert auf formale Einheitlichkeit als Goethe.

Der Aussage der ersten Strophe des deutschen Gedichtes entsprechen die ersten beiden strophen der russischen wiedergabe:

1 Abgedruckt in: V.A. ŽKKOVSKIJ, Sočinenija v 6-ti tomach. Hrsg. P.A. Efremov. Izd. 7-e. St. Petersburg 1878. Hier Bd. 1. S. 434 435. Veröffentlicht murde diese übersetzung im "Russkij Archiv", 1864, Nr. 10. "Wotylek" gehört zu den sog. "Dolbinischen Gedichten" Zukovskijs, die er zwischen 1814 und 1815 in Dolbino verfaßt hatte. Hier lebte Zukovskij einige Zeit bis zur übersiedlung nach St. Petersburg im Mai 1615. Vgl. ebd. S. 432. 
Da flattert um die Quelle

Die wechselnde Libelle,

Der Wasserpapilion,

Bald dunkel und bald helle

wie ein Chamäleon;

Bald rot und blau, bald blau und grün,

O daB ich in der Nähe

Doch seine Farben sähe!

Goethes Libelle verwandelt Zukovskij in einen SchmetterIing:

Вчера я долго веселился,

Смотря, как мотылек

Мелькал на солньшке, носился

С иветочка на цветок.

И милья цвет его менялся

Всечасно предо мноя,

То алоя тенью отливался,

то нежнов голубоя. 1

Bei Žukovskijs version handelt es sich wohl weniger um eine übersetzung im eigentlichen Sinn als um eine Nacherzählung des Inhalts. Durch den Gebrauch von Deminutiva wie "solnyško" und "cretoček" und süBlich-blassen Adjektiven wie "milyj" und "nežnyj" schleicht sich auch nier ein sentimentaler ton ein, der die frischen, lebensvollen Zeilen Goethes verfälscht.

1 Gestern habe ich mich lange vergnügt,/Als ich gesehen habe, wie ein Schmetterling/In der Sonne [Deminutiv] schimmerte/(Und) eilte/von Blume [Deminutiv] zu Blume. Und seine anmutige Farbe veränderte sich/vor mir stiundich,/Bald schimmerte er als purpurrote Silhowette,/Bald als zarte himmelblave. 
Die folgenden vier Zeilen des Originals dehnt Zukovskij auf orei strophen aus. Wortreich erzählt er von seiner Jagd nach dem Schmetterling und beklagt schlieblich den verlust von dessen einzigartiger schönheit, gerade in dem Moment, als der Schmetterling in seine Gewalt gerät.

Da fliegt der kleine vor mir hin

Und setzt sich auf die stillen weiden.

Da hab' ich ihn, da hab' ich inn!

Und nun betracht' ich ihn genau

Und seh' ein traurig dunkles Blau.

Žukovskijs wiedergabe dieser strophe wirkt im vergleich zur vorlage naiv und in der Beschreibung der Ereignisse uberdeutlich. Die vorletzte Strophe soll dies exemplarisch verdeutlichen:

Увы! коснувшись к ним перстами,

я стёр их нежныя цвет;

И мотылек ... Он все с крыламн, но красоты уж нет. 1

Goethes einzigartige verbindung von lebhafter Schilderung und Nachdenken hat Zuukovskij in ein langatmiges sentimental-beschreibendes Stück mit moralisierendem Ende umgearbeitet. Goethes geschickten didaktischen verstob in der letzten zeile:

So geht es dir, Zergliedrer deiner Freuden!

dehnt Žukovskij auf eine ganze strophe aus.

1 Ach! Als ich sie [die Flügel] mit den Fingern berïhrte,/Habe ich inre zarte Farbe abgerieben;/Der schmetterling hat zwar noch seine flügel,/Aber die Schönheit ist dahin. 
"Так наслахненье изменяет!"

Вздохнувшия, я сказал,

"Пока не тронуто - блистает:

дотронься - блеск пропал!"1

Trotz dieser Ausweitung kommt der typisch Goethesche Gedanke, der sich in dem Begriff "Zergliederer" 2 trifft, in der russischen wiedergabe nicht zum Ausdruck.

Nach Goethe werden Lebewesen und Gefühle, die der Mensch in besitzergreifender Neugier zerlegt, zerstört, und übrig bleiben fade, tote Einzelteile. Zukovskij übersieht Goethes Einsicht, daB nur der ProzeB eines dynamischen Verständnisses und lebendiger Anschauung die Geheimnisse des organischen Lebens enthüllt und die Freude des persönlichen Kontaktes mit inm schenkt. 3 Goethes Gedicht lehrt, den Augenblick zu genieBen, während Žukovskijs Verse mit einem elegischen Seufzer über die Vergänglichkeit jeglichen Genusses schlieben. 4

Der abstrakte Gedanke steht bei Žukovskijs Gedicht im Hintergrund, der Schwerpunkt der Aussage liegt beim konkreten Beispiel. Insofern entspricht der von Zuukovskij abweichend vom Original gewählte Titel "Motylek" gut dem im rein Konkreten verhafteten Inhalt.

1 "So verändert der Genuß [den Schmetterling] !"/Sagte ich mit einem Seufzer,/"Solange man inn nicht berihrt, glänzt er:/Berihre inn (und) der Glanz ist fort!"

2 Gemeint ist derjenige Mensch, der seine Gefühle genaw analysiert.

3 Vgl. A. v. GRONICKA, The Russian Image of Goethe, a.a.0., S. 51.

4 Vgl. V.M. ŽIRanNKIJ, Poézija, a.a.o., S. 540. 


\subsubsection{3. "Der Wandrer"}

Im November 1819 übersetzt Kukovskij Goethes berühmtes Gedicht "Der wandrer" (HA I, S. 36-42) ins Russische. Unter dem ritel "Putě̌stvennik i Poseljanka" (ŽukovskIJ I, S. 338-344) erscheint diese übersetzung zum ersten Mal im Jahre 1623 in der Zeitschrift "Syn Oteלestra".

Die Bezauberung, die das deutsche Gedicht auf Zukovskij ausgeübt hat, läßt sich leicht erklären. Diese Idylle entspricht dem Geschmack der Menschen des ausgehenden 16./beginnenden 19. Jahrhunderts: eine schlichte Bäuerin mit ihrem Kind zwischen Tempelruinen, umgeben von Bäumen, eine Quelle. 1

Goethes Gedicht ist fest geformt und gerundet: mit dem Eintreffen des Wanderers beginnt es, mit seinem Abschied endet es. Wie die antiken Idyllen besteht "Der Wandrer" aus Wechselreden, in denen sowohl die Landschaft - eine romantisch unbestimmbare Gegend Italiens - als auch die jeweilige Haltung und Bewegung der Personen anschaulich gezeichnet werden. In dieser bildhaften Klarheit vollzieht sich eine einfache Handlung: BegrüBung, gemeinsamer Weg, Wasser schöpfen, Trunk, Abschied - also natürliche, zeitlose Motive. Symbolisiert der Dialog mit der Bäuerin dieses zeitlose Element, so stellen die eingefügten Monologe des Wanderers, eines empfindsam-reflektierenden Menschen, in dem sich eine seeliche Entwicklung voll-

1 Vgl. M. EHRHARD, a.a.0., S. 304. 
zieht, das moderne Element dar. 1

Der erste Monolog findet angesichts des verfallenen Tempels statt. Der Wanderer richtet vorwurfe gegen die Natur, da sie ihres "Meisterstücks Meisterstück" (Zeile 79) zerstöre.

Die abschließenden verse des Monologs lauten bei Goethe:

Schätzest du so, Natur,

Deines Meisterstücks Meisterstück?

Unempfindlich zertrümmerst

Du dein Heiligtum,

Sä'st Disteln drein.

Žukovskij gibt diese Verse genau wieder:

Как мало дорохииъ, природа,

Ты лучшего созданья своего

Прекраснеяинм созданьем!

Сама святилиме свое

Бесчувственно ты раздросила

и терн посеяла на нем. 2

1 Vgl. HA I, S. $479-480$.

M. Ehrhard glaubt, in dem Wanderer Goethe selbst wiedererkennen zu können und in der Gestalt der jungen Fraw dessen Jugendliebe Friederike von Sesenheim: "En mậme temps il [Goethe] relève cette ceuvre qui aurait pu n'être qu'une pastorale .... en y ajoutant un élément d'émotion personelle, car le voyageur, c'est lui, et la jeune ferme a les traits de Frédérique, et il a parfois rêve de vivre avec elle dans la paix de la nature." M. Ehrowaro, a.a.0., S. 304 .

2 Wie wenig schätzt du, Natur,/Du deines besten Werkes/Schönstes Werk!/Du selbst hast dein eigenes Heiligtum/Gefühllos zerstört/Und hast auf itm Schlehdorn gesät. 
Es gelingt Zukovskij, das Polyptoton" 1 "Meisterstücks Meisterstück" ins Russische zu übertragen, 2 wobei er die Nachformung auf zwei Zeilen ausdehnt.

Den zweiten Monolog (Zeilen 90-104) führt der Wanderer vor dem schlafenden Kind der Bäuerin:

SüB ist deine Ruh!

Wie's in himmlischer Gesundheit schwimmend,

Runig atmet I

Du, geboren uber Resten

Heiliger Vergangenheit,

Run' inr Geist auf dir!

Welchen der umschwebt,

wird in Götterselbstgefühl

Jedes Tages genießen.

Žukovskij gelingt es nicht, das vielsagende Kompositum "Götterselbstgefühl" 3 umfassend wiederzugeben:

Прекрасен твор покоя...

Как тихо дылит Он,

Исполненныя небесного здоровья.

ты, на святых остатках

Мннувшего рожденныя,

О, будь с тобоя его великия Гения;

Кого присвонт он,

Тот в сладком чувстве бътия

Земную жизнь вкушает. 4

1 Vgl. I. BRAAK, a.a.O., S. 50.

2 Žukovskij wiederholt "sozdan' $e$ " in verschiedenen Beugungsformen.

3 Gereint ist ein kraftroll-gesundes, sich in seiner form erfüllendes Leben. Vgl. HA I, S. 480.

4 Wunderbar ist deine Stille ... Wie ruhig er atmet,/Erfüllt von himmlischer Gesundheit./Du, auf heiligen Resten/Des Vergangenen geboren, $/ 0$, sei mit dir sein großer Genius;/Wen er in Besitz nimmit,/Der geniebt das irdische Leben/Im angenehmen Gefühl des Daseins. 
Der dritte Monolog (Zeile 127-142) - angesichts der Mutter mit dem Kind, nachdem sie inm ihre Lebensgeschichte berichtet hat - beginnt mit einem Lob auf das müterliche Wesen der Natur:

Natur, du ewig keimende!

Schaffst jeden zum GenuB des Lebens;

Deine Kinder all

Hast mütterlich mit einem

Erbteil ausgestattet.

Einer Hütte.

Und endet mit den worten:

Leb wohl, du glücklich Weib!

Einfühlsam übersetzt Žukovskij diese verse ins Russische:

О вечныя сеятель, природа,

даруешь всем ти сладостную хизнь;

Всех чад своих, любя, ты наделила

Наследством хижины приотноя.

Прости, младая поселянка. 1

Der vierte, das Gedicht abschliebende Monolog des wanderers (Zeile 154-168), ist zeitlich nach dem Abschied von der jungen frau einzuordnen.

10 ewiger Sämann, Natur,/Du schenkst allen ein siBes Leben;/Alle deine Kinder hast du, liebend, ausgestattet/Mit dem Erbe einer obdachbietenden Huitte. ... Lebe wohl, junge Bäuerin. 


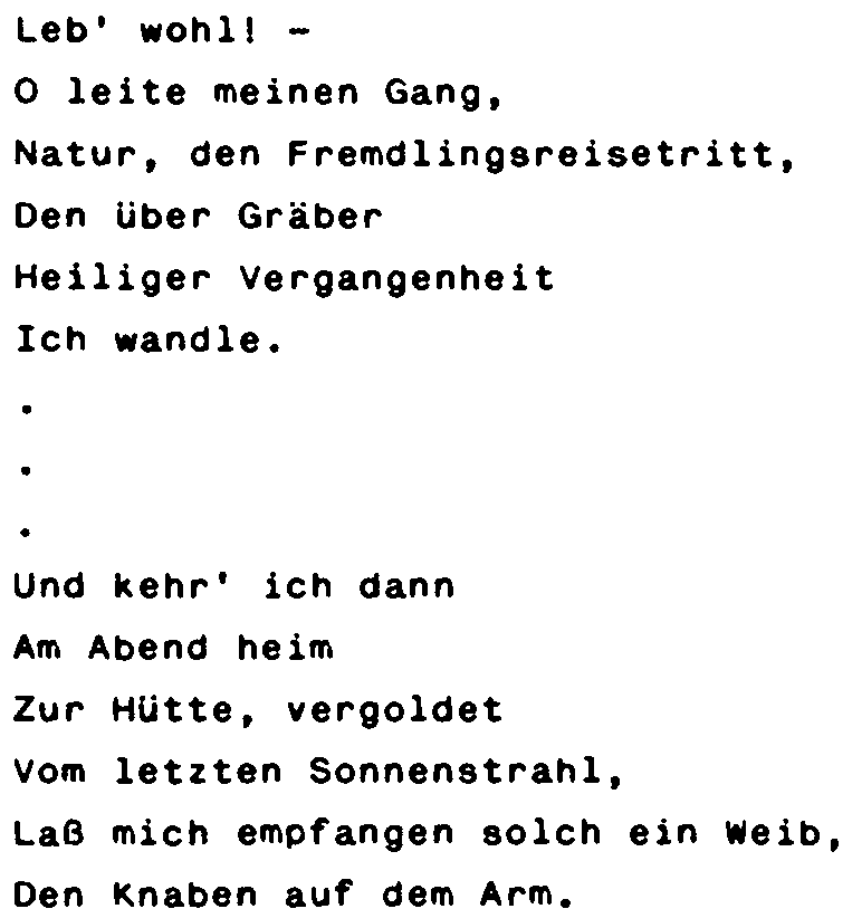

Der Wanderer will diese Urform des Lebens nicht nur betrachten, sondern sie in seinem eigenen Leben verwirklichen. 1

Das auffälige Kompositum "Fremdingsreisetritt", das in diesem Zusammenhang besagen soll, daß die Natur den Weg des fremden leiten soll, gibt Žukovskij durch eine sinngemäße Umschreibung wieder.

Прости!

0, будь моим вождем, природа:

Направь моя странническия путь;

Здесь, над гробами

Священноя древности, скитаюсь; 2

1 Vgl. HA I, S. 480.

2 Lebe wohl!/0, sei mein Führer, Natur;/Lenke meinen Wanderweg;/Hier über Gräbern/Geheiligter Vergangenheit streife ich umher; ... 
Когда ж в вечерния час,

Усталыл, возврамусь

Под кров домашния,

Лучом заката позламенния,

Чтоб на порог мокх дверея

Ко мне навстречу вьшла

Подобно милая подруга

С младенцем на руках. 1

Die Frau spricht nur dann, wenn sie den Wanderer oder das Kind anredet. Žukovskij neigt dazu, ihre natürlichspontane Sprache in Phrasen umzuformen. So verwandelt er das originelle "Du Schelm" (Zeile 126), womit die junge Frau das Baby in inrem Arm anspricht, in das gängige, süBlich klingende "O milyj". Insgesamt sind ihre Erwiderungen knapp gehalten, sie beschränken sich meist auf Mitteilungen einer bestimmten Information.

Der Wanderer monologisiert in einer völlig anderen Sprache. Seine Rede ist geprägt durch neologistische Komposita wie "Götterselbstgefinl", "Fremdingsreisetritt", "Blütenhülle" und außergewöhnliche Metaphorik. Seine Sprache wirkt empfindsam und gefühlvoll: ${ }^{2}$

1 Wenn ich zur abendlichen Stunde,/Emijdet, zurückkehre/Unter das häusliche Dach,/Vergoldet durch den Lichtstrahl des Abendrots, / (In Erwartung) daß auf der Schwelle meiner Tür [Plural] Mir entgegenkorme/Eine ähnlich liebe Freundin,/Mit einem Kind in den Armen.

2 Vgl. HA I. S. 480. 
Voller keim, blin' auf.

Lieblich dämmernden Lenzes Schmuck,

Scheinend vor deinen Gesellen!

ind welkt die 8 littenhille weg,

Dann steig aus deinem Busen

Die volle Frucht, und reif' der Sonn' entgegen.

Die russische wiedergabe erscheint dagegen blaß und kraftlos; Wortverbindungen wie "voller Keim", "lieblich dämmernd", "aus dem 8usen steigen" und auch "8lütenhülle" werden nicht ebenbirtig ibersetzt: ${ }^{1}$

lвети $x$ надеждоя,

Весенния цвет прекраснья;

Korдa же отиветешb.

Созрея на солнце благодатном

и дая богатья плод. 2

Dem insgesamt gehobenen Sprachstil des Wanderers verversucht Žukovskij dadurch gerecht zu werden, daß er zahlreiche worte verwendet, die im modernen Russisch nicht mehr benutzt werden und heute teilweise einer poetischgehobenen stilebene angehören. ${ }^{3}$

1 Weitere Beispiele dafür, daß es Zukovskij nicht immer gelingt, Goethes unverwechselbare Art des Ausdrucks angemessen wiederzugeben: Anstelle des neologistischen "weggewandelt" (Zeile 39) findet Zukovskij nichts Geeigneteres als den Allgemeinplatz "weggegangen" ("udalilos""); für den erfinderischen Ausdruck im Original "Und hohes Gras wankt darüber hin" (Zeile 77 ) steht bei Zukovskij das konventionelle "Und der Wind bewegt das Gras über innen [den Ruinen]"("I veter travoj nad nimi sevelit").

2 Erblühe durch die Hoffnung,/Die Frühlingsblüte ist wunderbar;/ (Und) wenn du verblühst,/Schau auf die wohltätige Sonne/Und gib reiche Frucht.

3 Wie 2.8. "se jatel"", "čado", "mladoj", "posel janka", "darovat"", "prosti" [im Sinne von "lebe wohl"], "chlad", "pozlatit". 
In seiner Interpretation von Goethes Gedicht charakterisiert walter silz es sowohl als naiv und sentimental, wie auch als klassisch und romantisch. Mit hervorragendem Einblick fügt er hinzu:

"It [the poem] conveys the mood of the young Goethe's Sturm und Drang and it foreshadows the older Goethe's Classicism at its best, that is, where he represents a blending of the cultural heritage, from antiquity with the persistent naturalness of Goethe's mind, his native 'Naturhaftigkeit"'. 1

Bei seinem ersten Erscheinen im Jahr 1774 im "Göttinger Musenalmanach" wurde die ganze Originalität von Goethes komplexer Leistung keineswegs begriffen. Das Gedicht wurde Uberwiegend ausschlieblich als Hirtenidylle im Geist Rousseaus verstanden, die die Schönheit eines schlichten Lebens in der Natur preist und in der der Dichter einen sentimentalen Blick auf die vergänglichkeit der menschlichen Werke wirft. Diese Sichtweise des Gedichtes hat Žukovskij vermutlich geteilt. ${ }^{2}$

Dennoch gluckt es inm in seiner Ubersetzung, etwas von Goethes lakonischer, strenger Einfachheit, von seinem "klassischen Geist" auszudrücken. Und obwohl das deutsche Gedicht eine sentimentale Lesart herauszufordern scheint, gelingt es Žukovskij, ein Abgleiten in oie Sentimentalität zu vermeiden.

Trotz einiger Schwächen ist Žukovskijs Übersetzung gelungen. Die aufgezählten Abweichungen - besonders bel der Wiedergabe der Komposita - schärfen unser Bewußtsein für die enormen Probleme, vor die sich der übersetzer eines Goethe-Gedichtes gestellt sieht.

1 W. SILZ, Goethe: 'Der Wandrer'. In: Stoffe, Formen und Strukturen. Hans Heinrich Borcherdt 2um 75. Geburtstag. Minchen 1962. S. 139150. Hier S. 139.

2 vgl. A. v. GRONICKA, The Russian Image of Goethe, a.a.0., S. 56. 


\subsubsection{4. "Der Adler und die Taube"}

Die Wiedergabe von Goethes versfabel "Der Adler und die Taube" (HA I, S. 57-56), die Zukovskij im Jahre 1833 verfaßte, 1 wertet André von Gronicka als Anzeichen dafür, daß sich Zukovskij mehr und mehr vom Zentrum der Goetheschen welt entfernte. Von der fulle der poetischen Kostbarkeiten, die Goethe in seinem bereits vollendeten Lebenswerk offenbarte, habe ŽukovskiJ die relativ unbedeutenden werke ausgewählt. ${ }^{2}$

"Der Adler und die Taube", eine Fabel von unrealistischem Wesen, stellt den gestürzten Adler mit seiner unstillbaren Sehnsucht nach freiheit den erdgebundenen genügsamen Tauben gegenüber.

Vielleicht reizte Žukovskij die scheinbar eindeutige Botschaft der Fabel - Genügsamkeit als die einzige form wahren Glücks -, vielleicht ihre idyllische Komposition mit den gurrenden Täubchen und dem pathetisch wirkenden verwundeteten "Adlerjüngling".

Am Ende der Fabel belehrt die Taube den verletzten Adler:

- Freund, das wahre Glück ist die Genügsamkeit, Und die Genügsamkeit hat überall genug!

Žukovskij dehnt diese beiden verse auf vier zeilen aus:

1 Zukovskijs Ubersetzung, die den Titel "Drel i Golubka" trägt, ist abgedruckt in: ZuKovsKIJ I, S. 386-387. Diese Fabel murde zuT. ersten $\mathrm{Mal}$ veröffentlicht in: Stichotvorenija $v$. Žukovskogo. 80. 6. St. Petersburg 1836. Vgl. ebd. S. 466.

2 vgl. A. v. GRONICKA, The Russian Image of Goethe, a.a.0., S. 57. 
О друг! поверь,

Умеренность прямое счастье;

С умеренностью мы

Везде и всем довольны. 1

Zukovskij war unfähig, den zeitweise ironischen Unterton des Originals zu bemerken; die Botschaft von der Wonne an taubengleicher Zufriedenheit wird zur zentralen Aussage der russischen übersetzung. 2

2.1.1.2. "Hegire" ("West-Östlicher Divan") in Ubersetzung Ijutêva

Mit diesem Gedicht läßt Goethe seinen "West-Östlichen Divan" beginnen.

"Divan" kommt aus dem Persischen und bedeutet soviel wie "Versammlung", hier wohl besonders "Lieder- oder Gedichtsammiung". Der dritte und letzte der groben lyrischen Zyklen wurde ausgelöst durch die Begegnung mit dem persischen Lyriker Hafis (14. Jahrhundert), dessen Werk in Übersetzung von Josef von Hammer-Purgstalls Goethe 1614 in die Hände fiel. Der tiefere Grund jedoch war, dab Goethe die Kulturen des Vorderen Orients seit seiner Jugend interessierten. In innen glaubte er die Naturformen

1 O Freund! Glaube,/Die Genijgsamkeit ist das wahre Gluick;/Mit Genijgsamkeit sind wir/iberall und mit allem zufrieden.

2 Ehrhard erkennt in der Gestalt der Taube Žukovskijs Wesen wieder: "... en face de l'aigle, Joukovski a été le pigion qui sans effort accepte la vie paisible, limitée dans ses besoins et ses ambitions, remplie par les joies du coeur." M. EHPAAPD, a.a.O., S. 304 . 
des menschlichen Daseins erhalten. 1

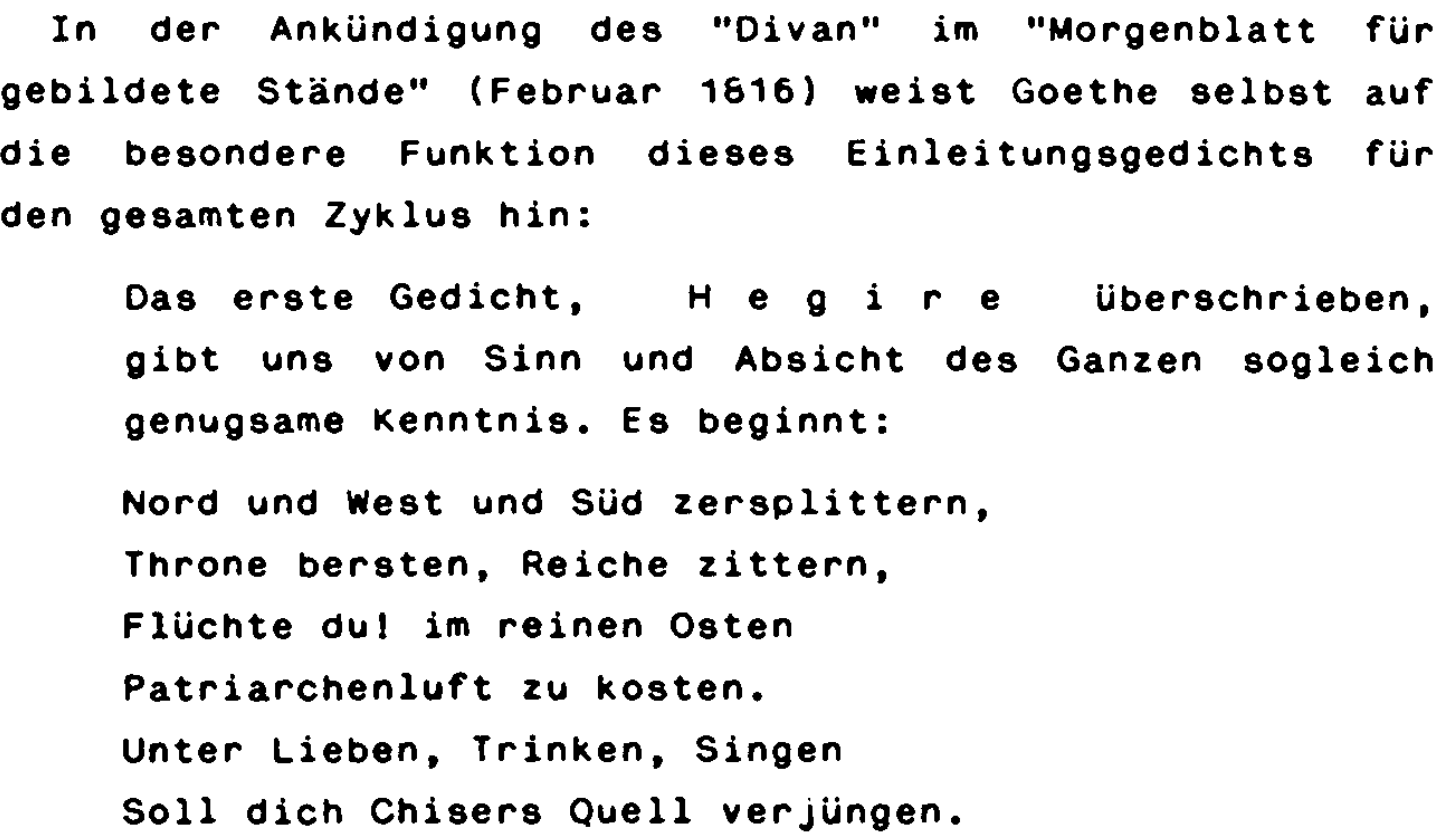

(HA II, S. 268)

1 Vgl. M. RYONER, Antworten. Aufsätze zur Literatur. Zürich 1961. S. 66-67. Der "West-Östliche Divan", der durch thematische verflechtung von Grundmotiven eine in sich geschlossene Einheit bildet, wird häufig mit den "Römischen Elegien" verglichen. Beiden Zyklen geht die Entdeckung einer newen geistigen welt voraus, das eine $\mathrm{Mal}$ war das Rom, das andere Mal der Orient. Während jedoch die Reise der "Römischen Elegien" eine wirklich gereiste Reise war, hat Goethe die "Reise", die das erste Gedicht des "Divan" als Absicht ankïndigt, nicht wirklich unternommen. Diese Reise ist nur erdichtet. Mit ihr eröffnete Goethe dem deutschen Leser die bis dahin wenig beachteten oder unbekannten kulturen des Ostens.

Im Gegensatz zu Italien und besonders Rom, die ganze Völker faszinierten, waren persische und arabische Lyrik selbst im Wissen der Gebildeten kaum vorhanden. So ist es nicht vermunderlich, daß der "Divan", als er 1819 erschien, wenig beachtet und kaum verstanden murde. Vgl. HA II, S. 550-570; M. KOMMERELL, Gedanken über Gedichte. Frankfurt a.M. 1943. S. 249-253; H.J. WEITZ (Hrsg.), Johann Wolfgang Goethe, West-Ostlicher Divan. Mit Essays zum "Divan" von Hugo v. Hofmannsthal, Oskar Loerke und Karl krolow. Mit Erläuterungen versehen von HansuJ. Weitz. Frankfurt 1974. S. 296-297. 
Ohne die Bedeutung dieser verse für den gesamten Zyklus weiter zu verfolgen, wollen wir in unserer Analyse das Gedicht selbst und seine russische wiedergabe in den Mittelpunkt unserer Betrachtungen stellen.

Entgegen der immer wieder aufgestellten Behauptung, daß "diese Gedichte nicht einzeln, sondern in ihrer gegenseitigen Bedingtheit" 1 ausgelegt werden müssen, hat Edith Ihekweazu in ihrer Untersuchung zur Komposition des "West-Östlichen Divans" deutlich gemacht, daß, ehe textüberschreitende Untersuchungsmethoden überhaupt vorgenommen werden können, die Interpretation aller Einzelgedichte soweit wie möglich voranzutreiben sei. Bedenken meldet die verfasserin gegen solche Interpretationsverfahren an, die die Eigenständigkeit jedes einzelnen Gedichts vernachlässigen. Nach ihrer Auffassung ist ein lyrischer Zyklus ein "aus autonomen Gedichten komponiertes Ganzes, in dem das einzelne Gedicht für sich, in der Sukzession der Anordnung und in bezug auf die Simultaneität des Ganzen zu untersuchen ist." 2

Nach dieser Definition ist die textimmanente Betrachtungsweise - und damit auch die übersetzung - eines Einzelgedichts eines lyrischen zyklus' sinnvoll und notwendig, auch wenn zweifellos vorhandene und intendierte Bezüge des Gedichts zum Gesamtzusammenhang nicht berücksichtigt werden können.

1 E. BEUTLER, vorwort. In: J.W. Goethe, West-Östlicher Divan. Wiesbaden 1945. S. IX-XIV. Hier S. XI. Vgl. St. ATKINS, Zum besseren Verstänonis einiger Godichte des "West-Östlichen Divan". In: Euphorion 59 (1965). S. 178-206. Hier S. 178.

2 E. IHEKWEAZU, Goethes West-Ostlicher Divan. Untersuchungen zur Struktur des lyrischen Zyklus. Hamburg 1971. S. 32. 
Der Titel "Hegire" setzt ein gewisses Sachwissen des Lesers über das Leben des Propheten Mohammed und die Bedeutung der Hedschra für den Islam voraus. ${ }^{1}$ Tjutとev läßt diesen Titel unübersetzt. Dadurch erscheint die Aussage der ersten beiden verse des Gedichts - diese begründen die "Hegire" des Dichters - dem russischen Leser eher unvermittelt.

Nord und west und süd zersplittern, Throne bersten, Reiche zittern ${ }^{2}$

(HA II, S. 7-6)

Запад, Норд и Ог в крушенье,

троны, царства в разрушенье ${ }^{3}$

(TJUTCEV II, S. 67-68)

Aus dem Raum, der geprägt ist von politischen wirren und kriegerischen Auseinandersetzungen, erfolgt die Flucht in den "reinen Osten":

Flüchte du, im reinen Osten

Patriarchenluft zu kosten

Die Qualität "rein", die erste Charakterisierung des Ostens, ersetzt Tjutčev durch die geographische Bestimmung "fern":

На Восток укрояся дальныя,

Воздух пить патриархальның!..4

1 "Hegire" ist die französische form für arabisch "Hedschra". Oogleich "Hegire" metaphorisch aufzufassen ist, geht der religiöse Aspekt nicht völlig verloren. Es wird eine Beziehung zwischen Prophet und Dichter hergestellt, von religiösem und dichterischem Bereich. Vgl. E. IHEKWEAZU, a.a.0., S. 46-49. - Der Begriff "Hegire" taucht bei Goethe öfter auf, 2.B. in Zusamenhang mit seiner "Italienischen Reise". Zum Problem des Zusammenspiels von Biographie und Dichtung vgl. ebd. S. 46-47.

2 Dies ist eine Anspielung auf die politischen Ereignisse der Jahre 1806-1614. Vgl. HA II, S. 573.

3 Westen, Norden und Siiden (stürzen) in die Katastrophe/Throne, Reiche (stürzen) in die Vernichtung.

4 Verstecke dich im Fernen Osten/Patriarchenluft zu trinken. 
Wörtlich iberträgt Tjuťev das Kompositum "Patriarchenluft", das an die biblische Frühzeit des Alten Testaments erinnert ${ }^{1}$ und dem Raum des Ostens einen religiösen Akzent verleint.

Die abschliebenden verse der ersten strophe beschreiben die weltiche komponente des angestrebten Ziels:

Unter Lieben. Trinken, Singen

Soll dich Chisers Quell verjüngen

Heiterer LebensgenuB ist im Osten somit ebenso anzutreffen wie religiöser Ernst. In dieser Umgebung kann der Dichter verjüngung erfahren.

В играх, песнях, пированье

обнови существованье!..2

Goethes Anspielung auf "Chisers Quell" soll deutlich machen, daB nur dem Dichter eine solche verjüngung zuteil werden kann; gleichzeitig legt sie einen vergleich dieses Dichters mit Hafis, der ebenfalls dieses Geschenk von Chiser erhalten hatte, nahe. 3 Diese Anspielung kann allerdings nur verstehen, wer mit östlicher Literatur vertraut ist und wem somit die Sagengestalt Chiser, der als Hüter des Lebens in verschiedenen Dichtungen des Ostens auftaucht, ein Begriff ist.

1 Vgl. H.J. WEITZ (Hrsg.), a.a.O., S. 301

2 Bei Spielen, Liedern, beim Zechen/Ernevere das Leben.

3 Vgl. Hammer-Purgstalls Vorrede zu seiner Hafis-übersetzung: "Am nächsten Morgen ... erschien Hafisen ein ehrwürdiger Greis, in grïnen Mantel gehillt, mit einem Becher in der Hand. Es war Chiser, der Hiter des Quells des Lebens, der Hafisen davon zu trinken vergönnte, und ihm unsterblichen Ruhm verhieß. So gelangte er zur Weihe des Dichters." J. v. HANER-PURGSTALL, Der Diwan von Mohammed Schemsed-dintlafis. Aus dem Persischen zum ersten $\mathrm{Mal}$ ganz ubersetzt von Josef von Hamer. 2 Bde. Stuttgart und Tübingen 1812-1813. Hier Bd. 1. S. XXIII. 
Tjutčev erwähnt Chiser in seiner ubersetzung nicht möglicherweise aus Rücksichtnahme auf die Mehrzahl der russischen Leser, denen die Kultur des Ostens wenig vertraut war.

Das religiöse Bild des Ostens, welches in der ersten Strophe mit dem Begriff "Patriarchenluft" angedeutet wird, entfalten ausfürlich die folgenden beiden strophen.

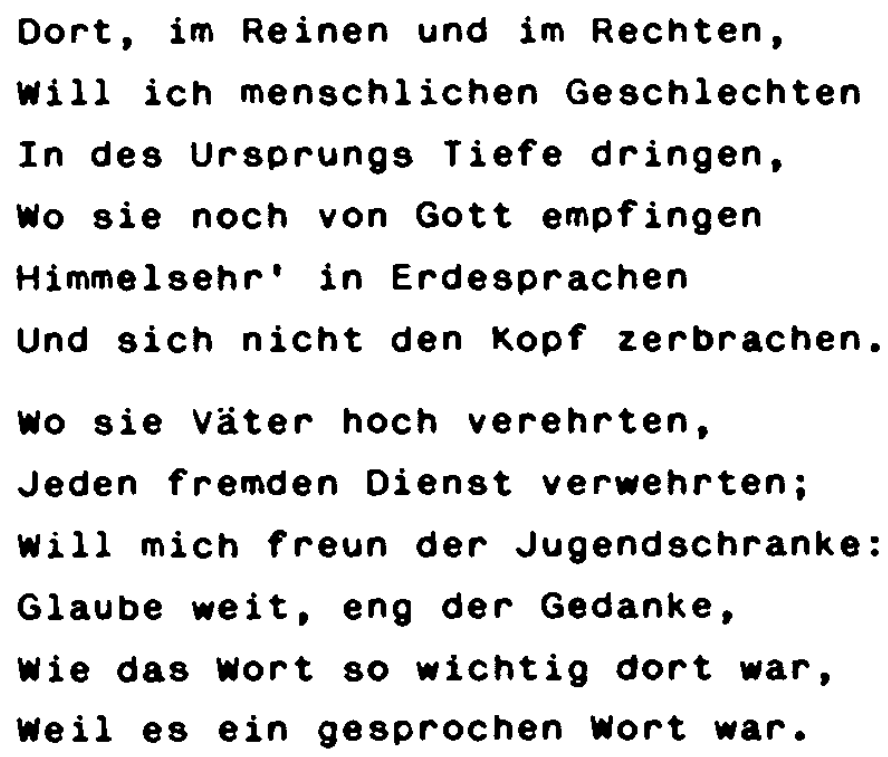

Der Aufbruch in den Osten soll in des "Ursprungs Tiefe" führen. Charakteristisch für diesen Ursprung ist, daß Religion und Poesie nicht voneinander getrennt sind ("Himmelsehr" in Erdesprachen"), sie bilden hier eine Einheit im gesprochenen Wort. ${ }^{1}$ Der so dargestellte Urzustand der Menschheit, in dem die Tradition der Väter noch bewahrt wird, erscheint als positives Gegenbild zur welt des Umsturzes und des Chaos'.

1 Vgl. E. IHEKWEAZU, a.a.0., S. 52-53.

2 vgl. ebo. 
Auch die russischen verse beschreiben das besondere verhälthis der Menschen zum Wort und zur Sprache. Auch hier als hervorstechendes Merkmal die Abwesenheit von übertriebener Reflexion.

Там проникну, в сокровенных,

До истоков потаенних

Первородных поколения,

гласу бохиих веления

Непосредственно внимавиих

и ума не надрывавиих, 1

Память праотцев святивиих,

Иноземию претивин,

Где во всем хранилась мера,

мысль - тесна, пространна вера,

Слово - в силе и почтенье,

Как живое откровенье!..2

Besonders gelungen ist Tjutčev die übersetzung der prägnanten formulierung

Glaube weit, eng der Gedanke

мысль - тесна, пространна вера

Einfühlsam, wenn auch nicht wörtlich, die Wiedergabe der folgenden beiden zeilen. Der Dichter wünscht sich in einen Bereich zurückzukehren, wo das Wort durch seine Lebendigkeit besonderes Gewicht hatte.

1 Die wörtliche Ubertragung der Redewendung lautet in Russischen: "I sebe golovy ne lomali (lomavšich)". Vgl. die Variante der Ubersetzung in TUUTEVV II, S. 285. Da sich diese Formulierung jedoch nicht ins trochäische versmaß einfügt, hat $T$ jutčev wohl auf die ungewöhnliche Formulierung "ne nadryvat' uma" zuriuckgegriffen, die sinngemäß auch richtig ist. Vgl. R.F. BRANDT, Materialy dlja issledovanija "Fedor Ivanovič Tjutčer i ego poèzija". In: Izvestija otd. russk. jaz. i slovesn. Imp. Akad. Nauk. St. Petersburg 1911. Bd. 16, 2. Buch, S. 136-232; 3. Buch, S. 1-65. Hier 3. Buch, S. 12.

2 Dort vertiefe ich mich in die verborgenen/Bis zu den Anfängen geheimen/Erstgeborenen Geschlechter,/Die der Stime der göttlichen Gebote/Umittelbar lauschten/Und die Köpfe nicht überanstrengten.

Die das Andenken der Vorväter weihten/Und das Frende ablehnten, /wo in allem Maß gewahrt wurde,/Der Gedanke ist eng, weit der Glaube,/ Das Wort ist stark und geachtet,/Als eine lebendige offenbarung! 
Wie das Wort so wichtig dort war.

Weil es ein gesprochen wort war

Слово - в силе и почтенье,

Как живое откровенье!..

MiBverstanden hat Tjuťev das Kompositum "Jugendschranke" in der Zeile:

Will mich freun oer Jugendschranke.

Der Dichter drückt hier seine positive Einschätzung der Begrenztheit der jungen völker mit ihrer jungen kultur aus. Worin diese Beschränkung besteht, erläutern die folgenden zeilen.

Tjutčev demgegenüber liefert ein weiteres konkretes Beispiel sinnvoller Lebenseinstellung des orientalischen Menschen:

Где во всем хранилась мера

Während in der zweiten und dritten Strophe die Beschreibung des religiösen Bereichs des Orients überwiegt, entfaltet sich in den folgenden drei strophen ein weltlicheres Bild des Orients. Der Dichter begegnet uns als Kaufmann, der mit "Schal, Kaffee und Moschus" handelt.

will mich unter Hirten mischen,

An Oasen mich erfrischen,

Wenn mit Karawanen wandle,

Schal, Kaffee und Moschus handle;

Jeden Pfad will ich betreten

von der Wuiste zu den Städten.

Auch dem russischen Leser eröffnet sich in dieser strophe die lebendige welt des orients. Wie in der Goetheschen vorlage werden zur veranschaulichung der welt des Orients beispielhaft Hirten, Oasen, Karawanen und die wüste erwähnt. 
То у пастыреи под кушеи,

то в оазисе иветупеи

С караваном отдохну 8 ,

Ароматами торгуя:

Из пустыни в поселенья

исслежу все направленья. 1

In solcher Umgebung lebt die Dichtung des Hafis im Munde des volkes weiter.

$$
\begin{aligned}
& \text { Bösen Felsweg auf und nieder } \\
& \text { Trösten, Hafis, deine Lieder, } \\
& \text { Wenn der führer mit Entzücken } \\
& \text { Von des Maultiers hohem Rücken } \\
& \text { Singt, die Sterne zu erwecken } \\
& \text { Und die Räuber zu erschrecken. }
\end{aligned}
$$

Die Bedeutung von Hafis ${ }^{\circ}$ Liedern geht über das rein Nützliche hinaus. Sie vertreiben nicht nur Räuber, sondern dringen auch bis in nimmlische Sphären vor. 2

Auch bei Tjutčev - trotz freler Bildwahl - diese doppelte Wirkungsweise von Hafis' Liedern:
Песни Гафица святые
Усладят стези крутые:
Их вожатың голосистыя,
Распевая в тверди чистоя,
В позднем небе звезды будит
и шаги верблюдов нуднт. ${ }^{3}$

1 Bald bei Hirten unter Zelten,/Bald in blühender Oase,/Ruhe ich mit einer Karawane, /nd handle mit Whlgerichen:/Von der Wiste zu den Siedlungen/Hinterlasse ich Spuren auf allen Wegen.

2 Vgl. bei Goethe in der zweiten Strophe die Zeile: "Himelsehr' in Erdesprachen".

3 Die heiligen Lieder des Mafis/Erquicken die steilen Pfade:/Ihr Führer mit klangvoller Stime,/Am wolkenlosen Fimament singend,/ Weckt an späten Himel die Sterne/Und treibt die Schritte der Kamele an. 
Besonders kraß treffen in den folgenden beiden strophen Himmlisches und Irdisches, Frömmigkeit und Lebensgenuß, aufeinander.

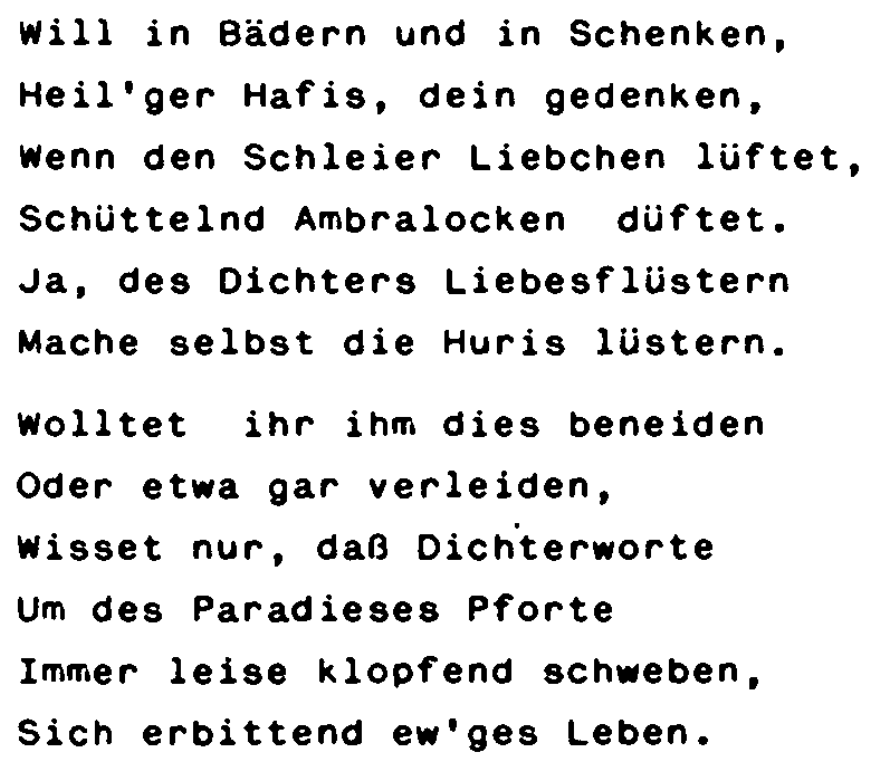

Will in Bädern und in Schenken, Heil'ger Hafis, dein gedenken,

Hafis - als einem Dichter von Liebes- und Trinkliedern - kann auch an den stätten sinnlichen vergnügens gedacht werden. Hier ist seine Lyrik ebenso beheimatet wie in himmlischen Sphären. Deutlich erinnern die Schlußzeilen an Worte aus der Bergpredigt Jesu: "Bittet, so wird euch gegeben; ... klopfet an, so wird euch aufge$\tan " 1$

Felativ genau ist Tjutčevs Ubersetzung dieser beiden Strophen. Huris, die ewig jungfräulichen Schönen des Paradieses, übersetzt Tjutčev umschreibend mit "nimmlische Jungfrauen" ("rajskie devy").

То упьюся в банях ленью,

Верен Гафица ученью:

дева-друг фату бросает,

Амвру с кудрея отрясает, -

и поэта сладкопевность

В девах раяских будит ревность!..2

1 Matthäus 7,7 (Lutherbibel).

2 Bald ergötze ich mich an der Trägheit in den Bädern,/Getreu der Lehre des Hafis:/Madchen-freund wirft den Schleier fort,/Schuittelt mit den Locken das Ambra ab,-/Und der suiße Gesang des Dichters/ weckt in den himmlischen Jungfrauen die Eifersucht. 
и сие высокомерье

не вменяяте в суеверье;

Знаите: все слова поэта

Легким роем, жадным света,

У двереи стучатся рая,

дар бессмертья вьмоляя!... 1

Die Bitte des Dichters um ewiges Leben, bei Goethe bereits in der ersten Strophe im Motiv des Chiser-Quells angedeutet, wird zur wesentlichen Schlußaussage des Gedichts.

Jedoch nur eine Dichtung, die vom volke gesungen wird und auch in "Bädern und schenken" beheimatet ist, und gleichzeitig bis in himmlische Bereiche vororingt, wo sogar die Huris auf sie hören, kann Zugang zum Paradies finden.

Eine endgiltige Zuoranung zu einem der beiden Bereiche erfolgt jedoch nicht. Die Eigenart der Unsterblichkeit dieser Dichtung ist "die permanente vermittlung zwischen oben und unten." 2

Das zugrunde liegende Motiv der Reise des Dichters in den orient spiegelt sich in der formalen struktur von "Hegire" wider: Die zahlreichen, meist gleichartig anhebenden Sätze ("will ...") mit futurischer und imperativischer Bedeutung teilen auch in der versgestalt - lebhaft pulsierende vierhebige Trochäen, durchweg weibliche, oft auf -en auslautende Reime - die energische Unruhe des Aufbruchs mit.

1 Und diesen Hochmut/Haltet nicht für Aberglauben; Wisset: Alle Dichterworte klopfen/Als leichtfliegender Schwarm, begierig nach Licht,/An die Türen des Paradieses,/Und erbitten das Geschenk der Unsterblichkeit.

2 E. IHEKWEAZU, a.a.0., S. 55. 
vierhebige Trochäen mit weiblichem versschluß auch bei TjutXev. ${ }^{1}$ Die Wendungen futurischen Charakters ubersetzt er meist mit der Praesensform vollendeter verben oder - wie in den ersten beiden Beispielen - mit einem Imperativ:

Flüchte du, im reinen Osten

На Восток укрояся дальныя

Soll dich Chisers Quell verjüngen

Обнови суиествованье

Dort im Reinen und im Rechten

Will ich menschlichen Geschlechten

In des Ursprungs Tiefe dringen

там проникну, в сокровенних,

до истоков потаенных

Jeden Pfad will ich betreten

исслежу все направленья

Will in Bädern und in Schenken

Heil'ger Hafis, dein gedenken

то упьюся в банях ленью,

Верен Гафнца ученью

Solche in die Zukunft weisenden formulierungen wechseln mit sätzen im Tempus der vergangenheit oder Gegenwart, die sachliche Aussagen uber das Ziel der Reise entnalten.

1 Der Konsonant " $n$ " taucht auch häufig bei den Reimen im Russischen auf: krǔ̧en'e-razruł̌en'e; dal'nyj-patriarchal'nyj. Während bei Goethe jedoch" "-en" immer an Ende des wortes steht, finden wir es bei Tjuttev auch in anderen Silben. Vgl. K. PIGAREV, TjutZer - perevodčik Gete, a.a.0., S. 94. 


\begin{abstract}
Wo sie väter hoch verehrten, Jeden fremden Dienst verwehrten

Память праотиев святивших,
\end{abstract}

иноземню претивших

Tjutčev hält sich bei seiner Ubersetzung von "Hegire" inhaltlich eng an die vorlage, auch wenn er häufig in Bildwahl und Formulierung von Goethe abweicht. Durch Weglassen oder Umschreiben von Begriffen wie "Hegire" und "Moschus", von Gestalten wie "Chiser" und den "Huris", deren Sinn nur derjenige verstehen kann, der mit der Kultur und Religion des Orients vertraut ist, erleichtert TjutZev dem russischen Leser das Verständnis dieser verse.

Eine wesentliche Schwäche seiner wiedergabe liegt jedoch darin, daB der Begriff des Reinen, der zu Beginn des deutschen Gedichts zunächst als Adjektiv, in der Formulierung "im reinen Osten" und dann als Abstraktum in der verbindung "im Reinen und im Rechten" erscheint, nicht ubersetzt wird.

Die Qualität "rein" ist die erste umfassende Charakterisierung des Ostens bei Goethe. Sie steht in Opposition zur Qualität des Ortes, von dem die Reise des Dichters seinen Ausgang nahm: Der Osten ist "rein" von den politischen Wirren einer von Zerstörung gezeichneten welt, hier herrscht somit noch "Ganzheit, Geschlossenheit, Ruhe". "In den folgenden Strophen entfaltet sich die konkret-inhaltliche Bedeutung des Begriffs des Reinen weiter.

1 E. IHEKWEAZU, a.a.0., S. 49. 
Als weitere Leitbegriffe ziehen sich "Sprache" und "wort" durch alle Strophen von "Hegire". Der Dichter sehnt sich nach einem Zustand, in dem Gottes wort - und auch das Wort des Dichters - noch unmittelbar verständich war.

Ein solches "Verstehen-können" hat sich im Orient offensichtlich bis in Hafis Zeit hinein erhalten. Hier sind die Lieder des Dichters in aller Munde, die Menschen leben mit ihnen. Eine solche lebendige kommunikation ist in der anfangs beschriebenen welt nicht mehr möglich. Das wort hat seine unmittelbare Wirkung verloren.

Diese Welt, in der eine Verständigung mit worten nicht mehr möglich ist, beschreibt Tjutčev in seinem 1830 entstandenen Gedicht "Silentium".

Как сердиу высказать себя?

Другому как понять тебя?

Поямет ли он, чем ты живешь?

Мысль изреченная есть ложь. 1

(TJUTČEV I, S. 46)

Gedanken und Gefühle können sprachlich nicht mehr offenbart werden, jeder versuch gerät zur verstellung, zur verbergung der Wahrheit. Das Wesentliche, das Innerste des Menschen, entzient sich der Sprachwerdung. 2

1 Wie kann das Herz sich offenbaren?/Wie kann ein anderer dich verstehen?/Begreift er, wodurch du lebst?/Der ausgesprochene Gedanke ist Lüge.

2 Nach Zelinsky liefert TjutZev mit "Silentium" den "ersten gültigen Ausdruck für die Not sprachlicher Gestaltung und das versagen der Sprache selber." Seit TjutZev sei in RuBland "das Vertrauen in das Wort erschuittert." Vgl. B. ZELINSKY, a.a.O., S. 249. 
Aus dieser welt der Sprachlosigkeit tritt der Dichter seine Reise in den Osten an, wo ewig Gültiges noch verstehbar und folglich auch in Worte fabbar ist. Die Reise des Dichters ist also nicht nur räumlich und zeitlich zu verstehen. Bei diesem Motiv handelt es sich auch um "eine verbildichung des geistigen Aufbruchs des Dichters in neve poetische Gefilde". 1

Tjutlev ist der einzige Dichter von Rang, der eine wiedergabe von "Hegire" versuchte. Dies ist nicht verwunderlich, da es auch in Deutschland lange brauchte, bis Leser und Literaturwissenschaftler einen Zugang zu den Gedichten des "Divan" fanden. So ist auch die DivanLiteratur - im vergleich z.B. zur nahezu unübersehbaren Anzahl von Arbeiten über die Faust-Tragödie - wenig umfangreich. 2

Im Gegensatz zu anderen Gedichten des Zyklus, die sich insofern einer besonderen vorliebe erfreuten, als sie die Aufmerksamkeit der Interpreten immer wieder anzogen, '3 brauchte "Hegire" - trotz seiner exponierten Stellung als Einleitungsgedicht des gesamten Buches - über 150 Jahre, bis sich eine Germanistin fand, die sowohl eine umfassende textimmanente Interpretation lieferte,

1 E. IHEKWEAZU, a.a.0., S. 103.

2 Noch zu Boginn des Ersten Weltkrieges lagen die Divan-Exemplare der ersten cottaischen Ausgabe unverkauft in den Regalen. $\mathrm{Vgl}$. E. BEUTLER, Vorwort, a.a.O., S. XII.

3 "Selige Sehnsucht" ist das an häufigsten interpretierte Gedicht des "West-Östlichen Divan", es folgen "Volk und knecht", "Wiederfinden", "Geheimstes", "Die Jahre nahmen dir" und "Hobheres und Höchstes". Vgl. E. LOWNER, Einleitung. In: Ders. (Hrsg.), Interpretationen zum West-Östlichen Divan Goethes. Darmstadt 1973 (Wege der Forschung, Bd. 288). S. VII-XVII. Hier S. VIII. 
als auch seine kompositionelle Funktion für den Zyklus überzeugend darlegte. 1

TjutZevs Hinwendung zum Einleitungsgedicht des "WestÖstlichen Divan" ist somit durchaus überraschend. Der russische Dichter suchte - und fand - einen Zugang zu dieser gedanklich reflektierten Alterslyrik Goethes, die bis heute, abgesehen von wenigen Ausnahmen, nicht ins Bewußtsein des deutschen Lesers dringen konnte.

Tjutčev verstand die Flucht des Dichters aus der abendländischen Erdbebenzone in den Osten, in des "Ursprungs Tiefe", wo Gottes Wort noch unmittelbar verständich war und das wort des Dichters sowohl Zugang zum einfachen volk fand, als auch die Fähigkeit besab, bis zu den sternen vorzudringen.

Tjutyev sehnte sich mit Goethe in einen neven Bereich dichterischen Sprechens, in einen Bereich, wo das wort noch als eine "lebendige offenbarung" verstanden wurde.

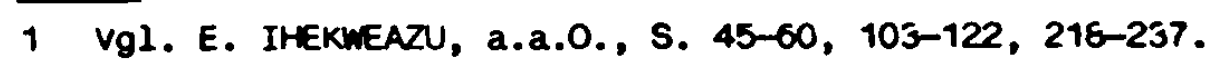

2 vgl. H. HEFELE, a.a.O., S. 95. 
2.1.2. Llebes- und Naturlyrik

\subsubsection{1. Übersetzungen Žukovakijs}

\subsubsection{1. "Gluckliches Geheimnis"}

1911 veröffentlichte I.A. ByCkov mit anderen bis dahin ungedruckten Werken Žukovskijs das Gedicht "Persidskaja pesnja", "dem ebenfalls ein Goethe-Gedicht zugrunde liegt.

Er hatte die Kopie des russischen Gedichts im Album der Dorpaterin Marija Nikolaevna Dirina neben zwei bekannten Liedern des Dichters entdeckt. ${ }^{2}$ Zur zeitlichen Einordnung schreibt Bytkov:

\footnotetext{
"Вероятно, и печатаемые ныне два стихотворения относятся $к$ тоя ке эпохе, ко времени жизни Хуковского в Дерпте, до выхода М.А. Протасовоя замуж за и.Ф. Мояера." 3
}

Durch die Nachbarschaft der bereits publizierten Lieder war das neventdeckte Gedicht also leicht einzuordnen. Der Herausgeber wubte allerdings nicht, daß "Persidskaja pesnja" eine übersetzung ist, deren Original weyrauch vertonte. Wiederum ist ŽukovskiJ wohl durch die Vertonung Weyrauchs auf das Goethe-Gedicht aufmerksam geworden. 4

Heute steht das dreistrophige Gedicht im "Buch der Liebe" des "West-östlichen Divan" unter dem Titel "Geheimes" (HA II, S. 32-33). Weyrauchs Uberschrift und eine wortänderung in der vierten Zeile der ersten strophe (statt "allein" - später "recht gut") legen nahe, daß der Komponist eine andere vorlage benutzt hat. Goethes Gedicht, Ende August 1814 in wiesbaden geschrieben,

1 I.A. BYčxov, Iz neizdannych stichotvorenij N.M. Jazykova 1 V.A. Zukovskogo. St. Petersburg 1911. S. 33.

2 Die erwähnten bekannten Lieder Žukovskijs sind: "Gde fialka, moj cretok?" und "Ptičkoj peviceju".

3 I.A. Bř̆̌xoV, Iz neizdannych stichotvorenij, a.a.o., S. 32.

4 Vgl. H. EICHSTÄT, a.a.O., S. 46. 
wurde zunächst im "Taschenbuch für Damen auf das Jahr 1817" als "Glückliches GeheimniB" veröffentlicht." Diese Fassung des Goethe-Gedichts hat Weyrauch seiner Komposition zugrunde gelegt, und diese Fassung hat Žukovskij somit ins Russische übertragen.

Formal und inhaltlich hält sich Žukovskij genau an seine Vorlage. Bei Goethe bilden je zwei Zeilen einen Satz; nur die Satzenden sind durch einen weiblichen Reim verbunden:

Über meines Liebchens Äugeln

Stehn verwundert alle Leute;

Ich, der Wissende, dagegen

Weis allein, was das bedeute.

Auch die regelmäßigen vierfüBigen Trochäen des Originals behält Žukovskij bei:

Все глядят и все дивятся:

что в глазах ее сверкает!

я молчу, но молча знауо

то, что блеск их выражает. 2

Den stil der deutschen Verse verändert Žukovskij jedoch grundlegend. Die ungewöhnliche Vokabel "Äugeln" übersetzt er durch eine eher gängige wendung ("glaza"). Gegenüber den originellen und beschwingten Anfangszeilen der dritten strophe

Ja, mit ungeheuren Mächten

Blicket sie wohl in die Runde

wirkt Žukovskijs Wiedergabe übertrieben pathetisch:

1 Vgl. COETHES WERKE, hrsg. in Auftrag der GroBherzogin SOphie von Sachsen. I. Abt., [Goethes Werke in engeren Sinne] . Bd. 6. Weimar 1888. S. 383; H. EICHSTÄDT, a.a.O., S. 48.

2 Alle schaven und alle wundern sich,/Was in ihren Augen funkelt!// Ich schweige, aber schweigend kenne ich/Das, was ihr Glanz ausdrijckt. 
Скажешь: пламенные духи!

Видя глаз её сверканье. 1

Das anmutige, ja fast neckische Geständnis Goethes

Denn es heiBt: ich liebe diesen

und nicht etwa den und jenen

verwandelt Žukovskij in ein schablonenhaftes Bekenntnis:

Ясно, ясно говорит он:

"Одного люблю я страстно!" 2

Nur in den beiden letzten, das Gedicht abschlieBenden Zeilen gelingt es Zukovskij, den leichten, scherzhaften Ton des Originals zu treffen:

Doch sie sucht nur zu verkünden

Ihm die nächste süBe stunde

Diese Verse lauten bei Zukovskij:

Нет! Они лишь обемают

другу таяное свиданье! ${ }^{3}$

Es dirfte deutlich geworden sein, welche groben Anforderungen die Wiedergabe dieses Gedichts an einen ubersetzer stellt. Auch wenn Žukovskij dazu neigt, den scherzhaft-koketten Ton, in dem schlieblich der Reiz des Originals liegt, eher schwerfällig wiederzugeben, so bleibt diese übersetzung doch eine mutige leistung des russischen Dichters.

1 Du sagst: flammende Geister,/Wenn du das Funkeln ihrer Augen siehst.

2 Deutlich, deutlich sagt er [der Glanz] :/"Einen liebe ich leidenschaftlich!"

j Nein! Sie versprechen nur/Dem freund die heimliche Zusammenkunft! 


\subsubsection{2. "Schäfers Klagelied"}

Das Thema dieses Goethe-Gedichts, die Erinnerung an eine verlorene Liebe, steht Zukovskijs Gefülswelt sehr nahe, in dieser Facette von Goethes lyrischem Schaffen fült er sich gedanklich zu Hause.

Žukovskijs übersetzung "Žaloba Pastucha" (ŽukovskIJ I, S. 288) hält sich formal wie inhaltich sehr eng an das Original. 1

Da droben auf jenem Berge

Da steh ich tausendmal,

An meinem Stab gebogen,

Und schave hinab in das Tal.

(GOETHES GEDICHTE I, S. 528-529)

Diese Strophe übersetzt Žukovskij fast wörtlich ins Russische:

Ha ту знакомую ropy

Сто раз я в день прихожу;

Стою, склоняся на посох,

и в дол с веринне гляжу. 2

Auch die vierte strophe

Und Regen, Sturm und Gewitter

verpab ich unter dem Baum.

Die Türe dort bleibet verschlossen;

Denn alles ist leider ein Traum.

ubersetzt Žukovskij feinfühlig ins Russische:

1 Selbst Marcelle Ehrhard, der im allgemeinen Žukovskijs Ubersetzungen sehr kritisch beurteilt, weist ausdrücklich auf die Exaktheit dieser Wiedergabe hin. Vgl. M. EHPHARD, a.a.O., S. 299.

2 Auf jenen vertrauten Berg/Kom' ich hundert $\mathrm{Mal}$ an Tag;/ICh stehe, gebeugt an. Stab,/Und schaue vom Gipfel ins Tal. 
Здесь часто в дождик и в грозу

Стон, $к$ земле пригвожден;

Все жду, чтоб дверь отворилась...

Но то обманчивия сон. ${ }^{1}$

Die Gefunle des Schäfers, der von weitem ein Haus sieht, dessen Tür immer verschlossen ist, da die Geliebte weggezogen ist. "vielleicht gar über die See", waren Žukovs$k i j$ offensichtlich nicht fremd. 2

Dennoch gelingt es Žukovskij nicht immer, den schlichten, volkstumlichen Ton Goethes zu treffen. Aus der einfachen Beschreibung

Da stehet von schönen Blumen

Die ganze wiese so voll

wird in der russischen Version:

Весь луг по-прежнему полон

младоя цветов красоты ${ }^{3}$

Statt der modernen Polnoglasie-Form "molodoj" benutzt Žukovskij das altertümliche "mladoj". Diese literarische sprache paßt nicht zu dem einfachen Ton des originals.

Die gedrückte Stimmung des Schäfers malt Žukovskijanschaulich aus. Die erste Zeile der zweiten strophe

Dann folg ich der weidenden Herde

lautet in der russischen wiederagabe:

Вздохнув, медлительньм шагом

иду вослед я овцам ${ }^{4}$

1 Im Regen [Deminutiv] und Gewitter/Stehe ich oft nier wie angewurzelt;/Immer (noch) warte ich, daß die Tür sich öffnet ... Aber dies ist ein trügerischer Traum.

2 Vgl. M. ERPAAD, a.a.O.. S. 299.

3 Die ganze Wiese ist wie immer voll von/Der jungen Schönheit der Blumen.

4 Seufzend geh ich langsamen Schrittes/Hinter den Schafen her. 
Auch in der fünften strophe ist Kukovskijs vorliebe für ausgearbeitete romantische Bilder deutlich zu spüren. Aus den deutschen versen

$$
\begin{aligned}
& \text { Es stehet ein Regenbogen } \\
& \text { Wohl über jenem Haus }
\end{aligned}
$$

macht Zukovskij:

$$
\begin{aligned}
& \text { Над милоя хижинкоя светит, } \\
& \text { Видау, радуга мне... }
\end{aligned}
$$

Bemerkenswert ist das Metrum der russischen verse: Žukovskij verbindet innerhalb einer zeile zwei Versmaße (Jambus und Anapäst) miteinander. Die Anzahl der Hebungen bleibt dabei unverändert. Während Goethe Jamben und Anapäste frei mischt, bestehen die russischen verse durchgehend zunächst aus zwei Jamben und nachfolgend einem Anapäst, der somit immer am Ende der Zeile steht.

"Žaloba Pastucha" ist das einzige Gedicht Žukovskijs, das er im "dol'nik" verfaßt hat. 2

Она все дале! все дале!

и скоро слух замолчит!

Бегите $\%$, овиы, бегите!

здесь горе душу томит! $!^{3}$

Genau wie bei Goethe sind auch hier jeweils die zweiten und vierten verse ourch einen männlichen Reim verbunden.

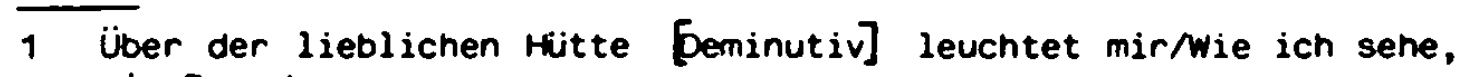
ein Regenbogen ....

2 Näheres zum "dol'nik" vgl. KRATKIJ SLOVAR' literaturovedčeskich terminov. Hrsg. L.I. Timofeev und S.V. Turaev. Moskau 1978. S. 39-40. Erst von den Symbolisten murde dieses versmaß häufiger angewandt.

3 Sie geht [wörtlich: ist] immer weiter, immer weiter fort!/Und bald wird die Nachricht (von ihr) verstumen!/Lauft doch Schafe, lauft!/Hier quält der Kummer die Seele! 
Žukovskij hat in seiner Wiedergabe diese beiden versmaBe derart sorgfältig miteinander verbunden, daB dieser - für den russischen Dichter auBergewöhnliche - versfuB als gelungen bezeichnet werden kann. 1

\subsubsection{3. "Kennst du das Land"}

Die Wiedergabe des berühmten Liedes der Mignon "Kennst du das Land, wo die Zitronen blühn" (HA VII, S. 145) aus dem Roman "Wilhelm Meisters Lehrjahre" stellt Zukovskij unter die Überschrift "Mina" (ZukovskIJ I, S. 289).

Goethes "Mignon" gehört $2 u$ einer Gruppe von Gedichten, die während der ersten Jahre in Weimar entstanden ist: "Jägers Abendlied" (1775), "An den Mond" (1778) und die beiden Gedichte mit dem gleichlautenden Titel "Wandrers Nachtlied" (1776 und 1780).2

In Žukovskijs Wiedergabe sind die Abweichungen vom Original zahlreich. So hat er den sich in jeder strophe wandelnden Refrain grundlegend umgeformt. Anstelle der verschiedenen Anreden - Geliebter, Beschützer, Vater die dem Original Spannung und Farbe verleinen, wiederholt Žukovskij monoton den "Freund".

Kennst du es wohl?

\section{Dahin! Dahin}

Möcht' ich mit dir, o mein Geliebter, ziehn! -

Kennst du es wohl?

Dahin! Dahin

Möcht' ich mit dir, o mein Beschützer, ziehn!

1 Vgl. M. EHPHARD, a.a.O., S. 402.

2 Vgl. V.M. ŽIPAMNSKIJ, Sravnitel'noe literaturovedenie. Leningrad 1979. S. 413. 
Zukovskij beachtet die im Original vorhandenen Nuancen nicht. Bei inm lautet der Refrain der ersten und zweiten Strophe völlig gleich:

Там счастье, друг! туда! туда

мечта зовет! Там сердием я всегда! 1

Goethes Sehnsucht nach Italien kommt in diesen sich wiederholenden Zeilen besonders deutlich zum Ausdruck. Der Refrain der letzten Strophe lautet bei Goethe:

Kennst du es wohl?

\section{Dahin! Dahin}

Geht unser Weg; O Vater, laB uns ziehn!

Der zweimalige Aufruf "Dahin! Dahin" erhält eine besondere Iyrische Note durch die Versüberschreitung, durch die Unterbrechung sowohl des Satzes als auch des Gedankens. Dieses Enjambement führt zu einer Steigerung des Intonationsbogens mit einer senkung in der letzten silbe des Satzes. 3

Das Ubergreifen des Satzes in den nächsten vers behält Zukovskij bei, jedoch läbt er einen Hauch von Hoffnungslosigkeit einflieben, die man bei Goethe nicht herausnören kann:

\section{О друг, поядем! туда! туда}

Мечта зовет!.. Но бшть ли там когда? ${ }^{4}$

Eine schwerwiegende Schwäche der Ujbersetzung liegt im Übergehen der Frageformen, mit denen Goethe jede der drei Strophen einleitet: "Kennst ou das Land"/"Kennst du das Haus"/"Kennst du den Berg"; diese anaphorischen Strophenanfänge sind es, die dem Gedicht sein Gepräge geben und

1 Dort ist das Glick, Freund! Dahin! Dahin/Ruft der Traum! Mit dem Herzen bin ich immer dort!

2 Vgl. R. FRIEDENTHAL, a.a.O., S. 301.

3 Vgl. V.M. ŽIPMNSKIJ, Literaturovedenie, a.a.O., S. 415.

4 O Freund, laß uns gehen! Dahin! Dahin/Ruft der Traum! ... Aber werden wir je eimal dort sein? 
den Versen ihre einprägsame Melodie.

Eine Analyse des Metrums macht deutlich, das "Kennst". jeweils am Anfang jeder ersten und füften zeile, immer den schweren Eingangstakt fült; alle ubrigen zeilen pausieren die erste Hebung:

Kénnst dú das Lánd, $\bigwedge$ wo díe Zitrónen blứnn, $\bigwedge$ Nim dúnkeln Láub $\bigwedge$ die Góldorángen glứhn, $\wedge$ Ein sánfter wína $\Lambda$ vom bláuen Hímmel wént, $\Lambda$ Noie Mýrte stíll $\bigwedge$ und hóch der Lórbeer stént, $\bigwedge$

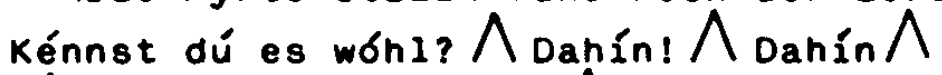

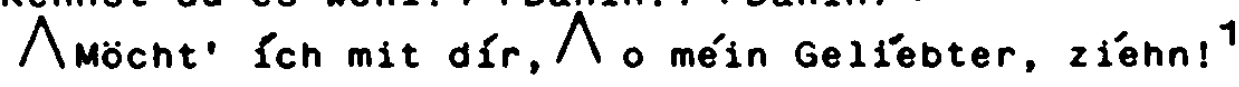

Es ist offensichtlich, daß es sich hier um achttaktige Langzeilen handelt, ein füffübiger Jambus kann dem Rhythmus der verse nicht gerecht werden. Dies wird bei der funften Zeile besonders deutlich. ${ }^{2}$ Im allgemeinen gelingt es Žukovskij, den Rhythmus der Goetheschen verse nachzubilden:

\Das Máultier súcht $\bigwedge$ im Nébel seínen Wég $\bigwedge$

$\bigwedge$ в тума́нах му́л $\bigwedge$ там пу́ть нахо́дит сво́я $\bigwedge^{3}$

Rhythmisch exakt ist auch die wiedergabe des Refrains:

$$
\text { Там счастье, друг! туда! туда }
$$

Мечта зовет! Там сердием я всегда! 4

1 Vgl. A. HEUSLER, Goethes Verskunst. In: Kleine Schriften. Bd. 1. Berlin 1943. ND Berlin 1969. S. 462-482. Hier S. 478. Die von Heusler vorgenormene Differenzierung der Hebungen murde nicht beachtet.

2 Sie bekäme die Form: "Kennst dú es wóhl? Dahín! Dahín". Aber dieses dichte Zusammenstehen der beiden "Dahin" wäre sinnwidrig. Vgl. ebd. S. 478.

3 In Nebel [Plural] findet das Maultier seinen Weg.

4 Dort ist das Glück, Freund! Dahin! Dahin/Ruft der Traum! Mit dem Herzen bin ich immer dort. 
Im Gegensatz zum Original liegt der betonte Eingangstakt bei Žukovskij auf unterschiedlichen worten (ja, tam, 0 ). Dadurch geht die Geschlossenheit des Goethe-Gedichts verloren, und ein rhythmischer vortrag wird erschwert, zumal die betonten worte an anderer stelle auch in unbetonter Position stehen.

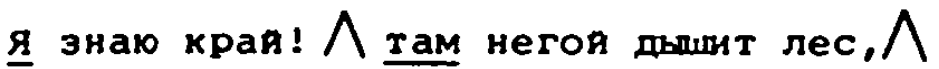

$\bigwedge$ златоя лимон $\Lambda$ горит во мгле древес, $\wedge$

$\bigwedge и$ ветерок $\bigwedge$ хар неба холодит, $\bigwedge$

$\bigwedge$ и тихо мирт $\bigwedge$ и гордо лавр стонт... $\bigwedge$

там счастье, друг! $\bigwedge$ туда! $\bigwedge$ туда $\bigwedge$

$\bigwedge$ мечта эовет! $\bigwedge$ там сердцем я всегда! 1

An dieser stelle bietet sich ein Vergleich mit der übersetzung F.I. Tjutčevs aus dem Jahre 1851 an. Hier liegt der betonte Eingangstakt immer auf "ty". Gleichzeitig gelingt es Tjutčev, die Frageformen des Originals beizubehalten:

Ть знаешь края, где мирт и лавр растет,

Глубок и чист лазурнья неба свод,

Цветет лимон, и апельсин элатон

Как жар горит под зеленью густоя?..

ть бшл ли там? Туда, туда с тобоя

Хотела 6 я укрыться, милыя мон. 2

(TJUTČEV II, S. 133).

1 Ich kenn' ein Land, dort atmet der Wald vor Zufriedenheit,/Die goldene Zitrone glüht in Dunkel der Bäume,/Und ein linder Wind [Deminutiv] kunlt die Glut des Himels, /Und ruhig die Myrte und stolz der Lorbeer steht .../Dort ist das Glück, Freund! Dahin! Dahin/Ruft der Traum! Mit dem Herzen bin ich immer dort!

2 Kennst du das Land, wo Myrte und Lorbeer wächst,/Das blaue Himmelsgewölbe tief und $k$ lar ist,/Die Zitrone wächst, und die goldene Apfelsine/Wie feuer unter dem dichten Grün leuchtet? ... Warst du schon dort? Dahin! Dahin mit dir/würde ich mich gern zurickziehen, mein Geliebter. 
Die erste strophe des deutschen Gedichts enthält die lyrische Beschreibung einer reizvolien Landschaft. Diese Beschreibung vermittelt jedoch nicht ein konkretes Bild von der Natur, begrenzt durch Raum und zeit, sondern eine zeitlose, verallgemeinerte Aufzählung ihrer Schönheiten: Das ist das Land, wo die Zitronen blühen und Orangen in dunklem Laub leuchten, wo ein sanfter wind vom blauen Himmel weht, und wo Myrte und Lorbeer wachsen.

Diese beschreibende Aufzählung geht auf die Tradition der Landschaftsbeschreibung in der antiken Poesie, sowohl der griechischen als auch der lateinischen, zurück und wurde durch die Dichter der Renaissance wieder aufgegriffen. 1

Bei Goethe wird jede der aufgezählten Schönheiten von einem Epitheton, in der grammatischen form eines Adjektivs (dunkel, sanft, blau), eines Adverbs (still, hoch) oder als erster Teil eines Kompositums (Gold-orangen), begleitet. Es handelt sich eindeutig um "schmückende Beiwörter" ("epitheton ornans"), da diese nicht die Bedeutung des zu beschreibenden Begriffs durch ein individuelles Merkmal einengen oder konkretisieren, 2 sondern ein allgemeines, typisches und vollkommenes Kennzeichen des Gegenstandes geben: das dunkle Laub, ${ }^{3}$ Goldorangen, ein sanfter Wind, 4 der blave Himmel, 5 die still stehende Myrte und der hoch stehende Lorbeer.

1 Vgl. V.M. ŽIPunsKIJ, Literaturovedenie, a.a.0., S. 414.

2 In diesem Fall wirde es sich um ein "Individualisierendes Beiwort" (franz. "épithète rare") handeln.

3 Zitronen und Apfelsinen sind immergrüne Gewächse.

4 Der sog. "Zephir" ist gemeint.

5 Die Rede ist eindeutig vom südlichen Himmel. 
Getrennt durch eine Zäsur stehen sich jeweils zwei Epitheta in einer Zeile gegenüber. Das kompositorische Gleichgewicht der verse bleibt so gewahrt. Nach ihrer Bedeutung sind sie parallel oder kontrastiv:

Im dunkeln Laub die Goldorangen glühn (kontrastiv)

Ein sanfter Wind vom blaven Himmel weht (parallel)

Die Myrte still und hoch der Lorbeer steht (kontrastiv)

In der übersetzung der ersten strophe finden sich nur drei Epitheta (zlatoj, ticho, gordo). Nur in der vierten Zeile gelingt es Žukovskij, die gleichgewichtigen Halbverse, in diesem Fall mit kontrastiver Bedeutung, genau nachzubilden:

И тихо мнрт и гордо лавр стонт ${ }^{1}$

Die zweite strophe gibt das räumlich begrenzte Bild eines Hauses wieder. Auch nier tragen Elemente des Bildes einen typischen, nicht individuellen Charakter. Beschrieben wiro eine Renaissance-Villa mit Säulen, glänzenden Sälen, schimmernden Gemächern und Marmorstatuen.

In der zweiten zeile wird der gedankliche Gleichlauf der beiden Halbverse noch durch den syntaktischen Parallelismus und die Wiederholung der einleitenden worte (Anapher) bekräftigt:

Es glänzt der Saal, es schimmert das Gemach

Žukovskij behält in seiner Übersetzung zwar die Zäsur bei, die parallele Gegenüberstellung der beiden Halbverse fehlt jedoch. Ein Enjambement verbindet die zweite Zeile mit der vorangehenden:

1 Und runig die Myrte und stolz der Lorbeer steht. 
Там светлыр дом! на мраморных столбах Поставлен свод; чертог горит в лучах 1

Die dritte strophe steht völliy im Zeichen des subjektiven Gefunls, der inneren Erregung des lyrischen Ich. Typisch für sie ist die Anhäufung metaphorischer und märchenhafter Bilder; statt statischer Beschreibung dynamische Bewegung, die alles mit sich fortreiBt und alle Hindernisse uberwindet: Der Wolkensteg, der durch das Gebirge führt, 2 das Maultier, das im Nebel seinen Weg sucht, das märchenhafte Bild "der Drachen alte Brut", die dem Relsenden aus einer Felsenhöhle droht, der Wasserfall, der vom Felsen niederstürzt.

In dieser Zeile wird die Parallelität der beiden Halbverse durch die Alliteration zweier betonter worte besonders hervorgehoben:

Es stürzt der Fels und Uber inn die flut

Das Kompositum "Wolkensteg" ist ein poetischer Neologismus Goethes. Žukovskij übersetzt ihn mit "zaoblačnaja tropa" wörtlich ins Russische.

Die Metapher "es stürzt der Fels" uberträgt die Dynamik der Bewegung des von inm herabsturzenden Wasserfalls, der flut, auf den leblosen Stein. Žukovskijs Übertragung dieser einzigartigen Metapher ist dem Original ebenbürtig. Die Alliteration in den deutschen versen gibt er als Polyptoton ${ }^{4}$ wieder:

1 Dort ist ein helles Haus! Auf Marmorsäulen/Ist das Gewölbe gestellt; Das Prunkgemach funkelt in den (Sonnen-) Strahlen.

2 Gemeint ist der Weg uber den St. Gotthard.

3 Vgl. V.M. ŽIPanNSKIJ, Literaturovedenie, a.a.O., S. 417.

4 Wiederholung desselben wortes in einem Satz in verschiedenen Beugungsformen. Vgl. I. BRAAK, a.a.O., S. 50. 
Летит скала и воды на скалу!..'

Auch wenn Zukovskij der letzten Strophe durch die Änderung des Refrains eine pessimistischere stimmung verleint, so bleibt es dennoch im ganzen eine gelungene übersetzung. Žukovskij hält sich inhaltlich eng an die deutsche Vorlage; gleichzeitig gelingt es ihm, die lebendige Dynamik dieser Strophe, die mannigfaltigen stilmittel genau ins Russische zu übertragen.

Der übersetzung Žukovskijs folgen im Laufe des 19. Jahrhunderts acht weitere, unter anderem je eine von Mej, Majkov und Tjutčev. "Mignon" wurde zum populärsten Gedicht Goethes in RuBland.

Žukovskijs Verdienst bleibt es, den AnstoB zur übernahme eines neven Motivs in die russische Literatur gegeben zu haben. Die Popularität "Mignons" rief zahlreiche Nachahmungen hervor, poetische Schilderungen einer schönen Landschaft, die mit einem "Kto znaet kraj" oder "Ty znaeš" kraj" anheben. 2 selbst Puלkkin greift in zwei seiner Dichtungen auf dieses Motiv zurück.

$\overline{1}$ Es fliegt der fels und Wasser [Plural] auf den Felsenl... 2 Vgl. M. GORLIN, a.a.O., 9 (1932). S. 347. 


\subsubsection{4. "An den Mond"}

Zukovskijs wiedergabe "K mesjacu" ${ }^{1}$ (ŽukovskIJ I, S. 289-290) stützt sich auf Goethes spätere, neunstrophige Fassung von "An den Mond"2 (HA I, S. 129-130). wann diese verfaBt wurde, ist unbekannt; vielleicht am Ende der ersten weimarer zeit, wahrscheinlich aber nach der Italienreise Goethes. 3

"An den Mond" gehört zu den "Versen an Lida", 4 die ganz auf das Du gestimmt sind und aus dem Bewubtsein gegenseitigen Verstehens leben. 5 sie haben nicht nur in der Sprache, sondern auch in der Liebe ihren eigenen Stil, bestimmt durch den Gedanken der Entsagung und der Reinneit. 6

1 Die erste Veröffentlichung dieser Übersetzung im Heft $\mathrm{Nr} .2$ (1818) "Für Wenige. Dlja nemnogich" enthält noch eine Strophe, die Zukovekij in den folgenden Nachdrucken verwarf:

Cto $v$ polnočnyj tichij cas

Slyð̧ imo ducoj,

ocarovyvaet nas

Tajnoju močtoj.

vgl. ŽKovsKIJ I, S. 450.

2 Die erste Fassung ist Uberliefert zwischen Goethes Briefen an Frau $v$. Stein, ohne Datum. Sie besteht aus nur sechs Strophen. Vgl. HA I, S. 544.

3 Vgl. ebd. S. 523. Goethes sog. "Italienreise" dawerte von September 1786 bis Juni 1788.

4 Erst in den Jahren 1848-1851 murde durch die veröffentlichung der Briefe Goethes an Fraw $v$. Stein aus dem Steinschen Familienbesitz Klar, wer "Lida" war, nämlich Frau $v$. Stein selbst. Vgl. HA I, S. 537.

5 Vgl. "Rastlose Liebe", "Für Ewig", "Jägers Nachtlied" und "An Lida".

6 Vgl. HA I, S. 537-538. 
Goethes "An den Mond" stellt für Zukovskij eine Herausforderung dar, der er nicht gewachsen ist. Es gelingt inm nicht, die emotionale Spannweite des Originals wiederzugeben. Žukovskij hat in diesem Gedicht nur das äußere Geschehen erkannt: einen Spaziergang im Mondschein an einem Bach entlang und die Erinnungen an längst vergangene Tage.

Fullest wieder Busch und Tal

Still mit Nebelglanz,

Lobsest endich auch einmal

Meine Seele ganz;

Jeden Nachklang fühlt mein Herz

Froh- und truber zeit,

wandle zwischen Freud' und Schmerz

In der Einsamkeit.

Goethe erzählt in diesen Versen vom Abschiednehmen, von der Vergangenheit und der Trauer uber inre Unwiederbringlichkeit. Žukovskij demgegenüber belebt das Vergangene, die Traver uber den verlust wird dadurch noch intensiver erfahrbar:

Снова лес и дол покрыл

Блеск туманныя твоя:

Он мне душу растворил

Сладкоя тнинноя.

-

$\cdot$

Скорбь и радость давних лет

Отозвались мне,

И минувшего привет

сльшу в тишине. 1

1 Wieder uberzog Wald und Tal/Dein matter Glanz:/Er öffnete mir die Seele/Mit süßer Stille. Kummer und Freude vergangener Jahre/Haben mir geantwortet,/Und den Gruß des Voribbergegangenen/Höre ich in der stille. 
Die zentralen Begriffe dieser beiden Strophen - duša, (sladkaja) tifina, skorb', radost' - sind typisch für die poetische Lexik des russischen Dichters. Auch in seinen eigenständigen Dichtungen kommt ihnen grundlegende Bedeutung zu.

Die siebte strophe, die mit den dramatischen zeilen Wenn du in der Winternacht Wutend überschwillst

beginnt, läßt Žukovskij in seiner übersetzung einfach weg; sie pabt in ihrem leidenschaftlichen Ton nicht zu seiner bevorzugt elegischen Ausdruckweise. Zukovskij hat nicht bemerkt, daB er nicht nur die Beschreibung eines wildbaches in einer winternacht und die "frülingspracht junger Knospen" wegläbt, sondern auch die emotionale vielfalt der Goetheschen Verse verlorengeht.

Bei Goethe bereitet die vorausgehende strophe diesen Gefunlsausbruch vor:

Rausche, fluB, das Tal entlang.

Ohne Rast und Ruh,

Rausche, flustre meinem Sang

Melodien zu

Žukovskij schwächt diese strophe ab, verlegt sie in eine 'Molltonart':

Леяся, леяся, моя ручея,

и журчанье струя

С одинокою моея Лироя согласуя. 1

1 Fließe, fließe, (du) mein Flus,/Und das Rauschen der Strömung [Plural] /Stimme mit meiner einsamen/Lyra überein. 
Das konventionelle Bild der Lyra, dem Lieblingsinstrument der russischen sentimentalen Dichtung, ist bei Goethe nicht zu finden. Die veränderte lautliche Instrumentierung unterstreicht die elegische verträumtheit der russischen verse. 1

Der sinn von Goethes letzten beiden strophen entgeht Žukovskij völlig.

Selig, wer sich vor der welt

Ohne $H a B$ verschlieBt,

Einen Freund am Busen hält

Und mit dem geniebt

Er hat nicht verstanden, daB "sich ohne $H a B$ vor der welt verschlieben" für Goethe keineswegs bedeutet, "die Welt zu verlassen und zu vergessen", sondern Ruhe zu finden vor ihrem seelenlosen Getriebe.

Счастлив, кто от хлада лет

Сердце охранил,

Кто без ненависти свет

Бросил и забыл 2

In der übersetzung von Goethes letzter Strophe

Was, von Menschen nicht gewußt

oder nicht bedacht,

Durch das Labyrinth der Brust

Wandelt in der Nacht

gibt es keine Beziehung zum Innersten der menschlichen seele, dem "Labyrinth der Brust", durch das das Geheimnis in der Nacht wandelt. Žukovskij besingt lediglich

1 Besonders das in der sechsten Strophe massierte Auftreten der hellklingenden Diphthonge ' $\mathrm{Jj}$ ' $(6 \mathrm{mal})$, 'OJ' (2 mal), 'uj' $(2 \mathrm{mal})$.

2 Glücklich, wer sich vor der Kälte der Jahre/Das Herz bewahrte, Ner ohne Haß die welt/Verlassen und vergessen hat. 
die Freuden, die vom Teilen mit einer verwandten seele kommen, in Abgeschiedenheit, von den ubrigen Menschen verachtet.

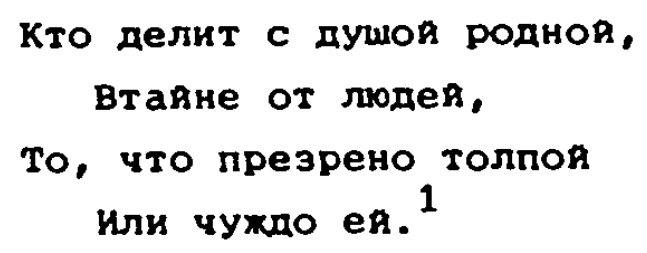

Goethes Schlußstrophe führt zur Anfangsstrophe zurück. Der geheimnisvolle Zusammenhang von Landschaft und Mensch wird deutlich: einerseits wirkt inre Kraft in den Menschen hinein, andererseits wird die Landschaft durch seine Innerlichkeit belebt. Zum SchluB findet sich wieder die gleiche Offenheit für das Geheimnis der Nacht wie zu Beginn des Gedichts. 2

Die zentrale Aussage der letzten strophe, die den Sinn des Ganzen abrundet, hat Žukovskij nicht erfaßt. Übrig bleibt eine farblose Huldigung an die Freundschaft.

Goethe läBt uns die Natur in inrer grobartigen vielfalt, in allen ihren Variationen erleben. Er beschreibt in seinem Gedicht das geheimnisvolle Wechselspiel zwischen Mensch und Natur.

Obwohl es Žukovskij durchaus verstanden hat, die abwechselnd vier- und dreifübigen Trochäen des Originals nachzubilden und vom Rhythmus her den gleichen Eindruck wiederzugeben, der auch bei den Goetheschen versen zu

1 Wer mit einer verwandten Seele teilt,/Heimlich vor den Menschen,/ Das, was von der Menge verachtet wird/Oder was ihr frend ist.

2 Vgl. HA I. S. 545. 
finden ist, kann dies doch nicht über die verflachung der Aussage hinwegtäuschen. 1

Anklänge an die Thematik von "An den Mond" finden sich auch in einer eigenständigen Dichtung Žukovskijs aus dem Jahre 1824, in "Motylek i Crety" (ŽuKovSKIJ I, S. 369370). In ihr besingt Žukovskij die Erinnerung und die Hoffnung als die einzig wahren Güter der Erde. ${ }^{2}$ Besonders die letzten verse erinnern deutlich an die vorletzte Strophe von Goethes "An den Mond" und sie entsprechen der Interpretation, die Žukovskij innen gegeben hat:

Блахен, кто вас среди губямего

Волненья хизни сохранил

И С вами низость настоямего

и пренебрег и позабыл. 3

1 Hierzu Ehrhard: "Une des oeuvres oi la puissance évocatrice de la pósie a atteint son plus émouvant degré est reduite à la banalité de l'élégie; la musique du vers ne suffit pas pour excuser un tel crime." M. EHPARO, a.a.O., S. 302.

2 Diesen beiden Begriffen kormt auch bei Goethe eine entscheidende Bedeutung zu: In der dritten Strophe wird aus der Gegenwart Rijckschau, die Gegenwart ist "Nachklang" und aus dieser Riickschau wird an Ende wieder Gegermart und Vorschau. Das Motiv der Freundschaft bezeichnet Moglichkeit und Hoffnung, nicht Gegenwart und Besitz. Vgl. HA I, S. 545.

3 Selig, wer euch imitten der ins Verderben stürzenden/Unruhe des Lebens schuitzte/Und mit euch die Niedertracht der Gegenwart/Verachtete und vergaß. 


\subsubsection{5. "Neue Liebe, neves Leben"}

"Neve Liebe, neves Leben" (HA I, S. 96) gehört zU Goethes Liebeslyrik um Lili Schönemann. 1 Diese Gruppe von Gedichten ist - ganz im Gegensatz zur Lida-Lyrik eher monologisch. In ihr spricht ein nicht mehr ganz junger Mensch, der bereits die Liebe erfahren hat und von inrer Tragik weib. 2

Žukovskijs Wiedergabe "Novaja Ljubov" - Novaja Žizn"" (ŽUKovskIJ I, S. 298) entspricht nur in Form und Titel der Vorlage, inhaltlich ist das Gedicht völlig ungestaltet und die Idee in ihr genaves Gegentell verkehrt.

Es ist bemerkenswert zu vergleichen, was aus Goethes einleitenden Zeilen

Herz, mein Herz, was soll das geben,

Was bedränget dich so sehr?

geworden ist. Anstatt sich auf die schlichten fragen zu beschränken, mit denen das Gedicht in stürmischem Tempo einsetzt, bauscht Žukovskij sie in seiner wiedergabe auf:

Что с тобоя вдруг, сердце, стало?

Что ты ноешь? Что опять

Закипело, защшлало? 3

1 Richard Friedenthal beschreibt in seiner Goethe-Biographie ausfürlich, wie sehr sich Goethe in der Liebe zu Lili Schönemann (1758-1817) gefangen fühlte: "Hier aber, zum ersten und auch zum einzigen Male, hat er sich gefangen gefült, 'in Sack', wie er in Leipzig angstvoll geträumt hatte. Der Vergleich ist etwas zu grob. Es waren Seidenfäden. Aber sie scrmerzten." R. FRIEDEN THAL, a.a.0., S. 193.

2 Vgl. HA I, S. 523.

3 Was ist mit dir, (mein) Herz, plötzlich geschehen? Was presst du dich zusammen? Was hast du wieder angefangen/(Vor Erregung) zu brodeln, aufzuflamen? 
Goethes konstatierenden Aussagen sind durchgehend durch sentimentale formeln ersetzt. Die Veränderungen zu seinem bisherigen Leben beschreibt der Liebende so:

Weg ist alles, was du liebtest, Weg, worum du dich betrubtest, Weg dein fleis und deine Ruh -

Žukovskij macht daraus:

Все исчезло, чем ты жило,

Чем так сладостно грустило!

Где беспечность? где покоя?.. 1

Er fugt der Traurigkeit einen Hauch sentimentaler Lieblichkeit an. Die leere Formelhaftigkeit wird durch ein scheinbar selbstverständliches Nebeneinander von "sladostno grustilo" und "bespečnost" offenkundig."

Völlig verändert hat Žukovskij Goethes Mädchenfigur. seine "Jugendblute". Statt ihrer "lieblichen Gestalt" schätzt Žukovskij besonders "Gespräche voller seele". von der bemerkenswerten Charakteristik "dieser Blick voll Treu und Güte" bleibt bel Žukovskij nur die flache Formel von der "leidenschaftlichen Süe des Blickes." 3

1 Alles ist verschmunden, wovon du lebtest, wodurch du so angenerm traurig warst!/Wo ist die Sorglosigkeit? Wo die Ruhe? ...

2 Vgl. H. EIOASTÄDT, a.a.0., S. 53-54.

3 Vgl. ebd. S. 54. 
Goethes Gedicht stellt den Versuch einer selbstbesinnung dar. Der Dichter befindet sich in einem inneren Zwiespalt: im "Zauberkreis" seines Mädchens fühlt er sich zugleich gücklich und "wider Willen" festgehalten. Er versucht, sich ihr zu entziehen, aber es gelingt inm nicht. Sein weg führt immer wieder zu inr zurück.

Fesselt dich die Jugendblüte,

Diese liebliche Gestalt,

Dieser Blick voll Treu und Güte

Mit unendlicher Gewalt?

will ich rasch mich inr entziehen,

Mich ermannen, ihr entfliehen,

Führet mich im Augenblick

- Ach - mein weg zu ihr zurück.

Von diesem Inneren Kampf Goethes, der sich auch in der strophenform widerspiegelt, ${ }^{1}$ ist bei Žukovskij wenig zu spüren. Während Goethe bemüht ist, die schwächenden Fessein der Liebe abzustreifen, "sich zu ermannen", sehnt sich ZukovskiJ danach, seiner Geliebten "einen schmachtenden Blick zuzuwerfen"; bereitwillig gibt er sich seiner Liebessehnsucht hin:

1 Die erste Strophenhälfte ist durch Kreuzreime verbunden, mit Wechsel von weiblichem und männlichem Reim, die zweite Strophenhälfte ist in Paarreimen gehalten, erst in weiblichen, dann in männlichen. Vgl. J. KLEIN, Geschichte der deutschen Lyrik. Von Luther bis zum Ausgang des Zweiten Weltkrieges. Wiesbaden 1957. S. 314. 
Расиветаюиая ль младость,

Речи ль, полнье дуиіо,

Взора ль пламенная сладость

Овладели так тобоя?

Захочу ли ободриться,

Оторваться, удалиться -

Бросить томныя, томныя взгляд!

Aх! я $к$ нея лечу назад! 1

Bezieht man die völlig gewandelten AbschluBverse Žukovskijs mit ein, so wirkt Žukovskijs oben geäußerter Wunsch, sich loszureiBen, unglaubwirdig.

и бежать очарованья

Нет ни силы, ни желанья!

Рад тоске! хочу любить!..

Видно, сердце, так и бить! ${ }^{2}$

Žukovskij ist bereit, sich seiner Leidenschaft hinzugeben, er will lieben. Goethe dagegen leistet lebhaften widerstand:

MUB in inrem Zauberkreise

Leben nun auf ihre weise;

Die Verändrung, ach, wie grob!

Liebe, Liebe, lab mich los!

An die Stelle des Eingeständnisses der unendichen Schwäche tritt bei Žukovokij eine Atmosphäre, uberladen

1 Die aufblühende Jugend,/Gespräche, voller Seele,/Die leidenschaftliche SïBe des Blicks/Haben sie dich so ergriffen?/Ich will Mut fassen, Mich losreißen, mich entfernen -/Einen schmachtenden, schmachtenden Blick werfen!/Ach! Ich flieg zu ihr zurijck!

2 Und dem Zauber zu entfliehen/Habe ich weder die Kraft, noch das Verlangen!/Ich bin froh über die Sehnsucht! Ich will lieben! .... Das Herz tritt zutage, so muß es sein! 
mit künstlich wirkender Emotionalität, die nie den warmen Klang echter Empfindung erreicht. 1

Eine wirklich befriedigende übersetzung dieses GoetheGedichts scheint es nicht zu geben. Der vorlage am nächsten kommt Vil'gel'm Levik, der in seiner übertragung mehrere Redewendungen A.A. Fets ubernommen hat. 2

1 Vgl. H. EIOASTÄDT, a.a.O., S. 54.

André $v$. Gronicka bemerkt zu Zukovskijs Wiedergabe: 'No better example could be found of Zhukoveki's tendency to recast Goethe's work to approximate his awn prevalently sentimental mood in the Karamzin tradition wich extolled the sweet sorrows of a heart in hopeless love." A. v. GRONICKA, The Russian Image of Goethe, a.a.O., S. 55.

Ehrhard beurteilt die Verse ähnlich: "Le titre seul de Nouvel amour, nouvelle vie est étrange sous sa plume. ... Joukovski ne peut se rendre compte de ce qu'avait pu signifier pour le jeune Goethe le frémissement d'une nouvelle passion; à côté de la spontanité, de la jeunesse des vers de Goethe, les siens sont appliqués, conventionnels." M. EHPAARD, a.a.0., S. 300. (Unterstrichene Stelle im Original kursiv gedruckt).

2 Die Übersetzung Vil'gel'm Leviks ist abgedruckt in: V. LEVIK, Izbrannye perevody. Bd. 1. Moskau 1977. S. 58. 
2.1.2.1.6. "Zueignung ('Der Morgen $k a m \ldots)^{\prime \prime}$ und "Zueignung" zum "Faust"

Von Goethes insgesamt vierzehnstrophiger "Zueignung" (HA I, S. 149-152), die mit den Versen "Der Morgen Kam; es scheuchten seine Tritte" anhebt, übersetzt Zukovskij lediglich die ersten beiden strophen ins Russische (ŽUKOVSKIJ I, S. 338). 1

In diesen beiden Strophen beschreibt Goethe das Erleben der Natur auf einer morgendichen Wanderung. Die zentrale Gestalt des Gedichts, das "göttlich Weib", das inm erscheint und den "Schleier der Dichtung" überreicht, taucht erst in der vierten strophe auf. Žukovskijs Wiedergabe bleibt somit bei der Beschreibung des Naturerlebnisses stehen, der inhaltich tragende Teil der Dichtung bleibt unbeachtet.

Es gelingt Žukovskij durchaus, die Atmosphäre der ersten beiden Strophen wiederzugeben, auch wenn er die deutschen Verse nicht immer wörtlich ins Russische uberträgt.

Und wie ich stieg, zog von dem Flub der wiesen

Ein Nebel sich in Streifen sacht hervor

Die Verse lauten in der übersetzung:

Я восходил; вдруг тихо закурился

Туманныя дым в долине над рекоя ${ }^{2}$

Žukovskij bemüht sich um eine Nachbildung der Goetheschen Klangfiguren:

1 Žukovskij verfaßte diese Übersetzung an 27. November 1819. Veröfentlicht wurde sie zum ersten Mal in "Russkij Archiv" des Jahres 1837 unter der Überschrift "Utro na gore". Diese Überschrift jst jedoch nicht auf Zukovskij zurückzuführen. Vgl. V.A. ZUKOVSKIJ, Stichotvorenija, a.a.0., Bd. 2. S. 527-528.

2 Ich stieg hinauf; plötzlich beginnt ruhig/Der neblige Rauch über dem Fluß im Tal zu dampfen. 
Und alles warerquickt, mich zu erquicken

и жизнью все живому сердиу бшло 1

Die Alliteration in den Zeilen

Er wich und wechselte, mich zu umflieben,

Und wuchs geflügelt mir ums Haupt empor

verwandelt Zukovskij in einen Zäsurreim:

Густел, редел, тянулся, и клубился,

и вдруг взлетел, крылатыя, надо мноя ${ }^{2}$

Das deutsche Gedicht gilt als eines der gelungensten Beispiele für Stanzen. In den Anmerkungen der Hamburger Goethe-Ausgabe heiBt es:

"... man sieht der vollendeten Gestalt nicht mehr an, dab er [Goethe] darum gerungen hat. Er liebte diese anspruchsvolle Form, wo es galt, Meisterschaft zu zeigen." 3

In seiner Übersetzung beläßt ŽukovskiJ die Zäsur gleichmäßig nach der zweiten Hebung:

Взошла эаря. / дыханием приятным

Сманила сон / с монх она очен ${ }^{4}$

Goethe dagegen setzt die zäsur auch nach der fünften Silbe:

Der neven Blume, / die voll Tropfen hing

Und wuchs geflügelt / mir ums Haupt empor

und sogar nach der sechsten Silbe, wobei er ihren Akzent mildert und so einen daktylischen Effekt erreicht:

1 Und durch das Leben war alles dem lebendigen Herzen.

2 Er [der neblige Rauch] murde dichter, lichtete sich, breitete sich aus und stieg in Schwaden auf, /Und plötzlich flog er, beflïgelt, hoch über mir auf.

3 HA I, S. 549. Vgl. I. BRAAK, a.a.O., S. 105.

4 Das Morgenrot ist emporgestiegen. Mit angenehmem Oden/Hat es den Schlaf aus meinen Augen vertrieben. 


\begin{abstract}
Und alles war erquickt, / mich zu erquicken
Er wich und wechselte, / mich zu umfließen

Die Gegend deckte mir / ein trüber flor
\end{abstract}

Tatsächlich bietet sich ein Vergleich mit Žukovskijs wiedergabe der ebenfalls in stanzen verfaßten "Zueignung" zum "Faust" (HA III, S. 9) an."

Diese Übersetzung erschien zum ersten Mal 1817 in der Zeitschrift "Syn Otelestva" unter dem bezeichnenden Titel "Mečta. Podražanie Gete" und im gleichen Jahr - ohne Hinweis auf die Quelle - als Einleitung zu Zukovskijs Poem "Dvenadcat" spjał̌̌ich dev" (ŽukovskIJ II, S. 84-85). Das Poem stellt eine überarbeitung des Romans "Die zwölf schlafenden Jungfrauen, eine Geistergeschichte" des deutschen Vorromantikers Christian Heinrich Spiess (17551799), dar. 2

Mit der Wiedergabe der "Zueignung" zum "Faust" führt Žukovskij die achtzeilige stanze als neue strophenform in die russische Lyrik ein. Nicht nur Anregungen inhaltlicher Art, ${ }^{3}$ sondern auch formale Neuerungen innerhalb der russischen Literatur lassen sich also auf Goethe zurückführen.

1 Obwohl diese "Zueignung" nach dem Willen des Dichters zum "Faust" gehört, steht sie doch außerhalb des Werks. Vgl. G. STORZ, Goethevigilien. Stuttgart 1953. S. 150.

2 Spiess bearbeitet in diesem Roman Legenden über einen Menschen, der seine Seele dem Teufel ubergibt, beschreiby dessen Verdammung und schließlich die Sühne durch den Glauben. Zukovskij überträgt die Handlung in das RuBland des 11. - 12. Jahrhunderts. Vgl. ZuKOVSKIJ II, S. 460 .

3 Wie 2.B. die Übernahme eines Motivs in die russische Literatur. Vgl. bei uns das Kapitel III, 2.1.2.1.3. "Kennst du das Land". 
Die russische Stanze ist genau der Goetheschen nachgebildet: sie hat dieselbe Reihenfolge weiblicher und männlicher Reime, die für jede stanze die gleiche bleibt. 1 Das Grundschema jeder strophe sieht folgendermaßen aus: $a b$ ab ab $c c$, wobei b einen männlichen versschluß bezeichnet, alle anderen suchstaben einen weiblichen.

In seiner genauen Betrachtung der von Zukovskij angewandten Versmaße weist Ehrhard darauf hin, daß es dennoch einen Unterschied zwischen den beiden Stanzen gibt: Goethes Vers, der vom elfsilbigen italienischen ottava rima ausgeht, zeigt - obwohl er in der Mehrzahl der Zeilen eine Zäsur nach der zweiten Hebung aufweist eine gewisse Tendenz zu einer weiblichen zäsur nach der füften oder siebten silbe. In zeilen mit weiblichem versschluß ist diese Neigung besonders ausgeprägt. ${ }^{2}$

Inr naht euch wieder, / schwankende Gestalten

Ein Schaver faßt mich, / Träne folgt den Tränen

was ich besitze, / seh' ich wie im weiten

Und manche liebe Schatten / steigen auf

Zukovskij hingegen bleibt der französischen Tradition treu. Seine verse haben die Zäsur nach der vierten Silbe ${ }^{3}$ - diese entspricht der zweiten Hebung -, wodurch der zweite Halbvers dem des Alexandriners ähnlich wird. 4

1 Später flihrt Puŏkin eine andere Form der Stanze ein, bei der die Reihenfolge der weiblichen und männlichen Reime bei jeder Stanze wechselt. Vgl. M. GORLIN, a.a.0., 9 (1932). S. 347, Anm. 1.

2 Vgl. M. EFPARD, a.a.0., S. 390.

3 Ausnamen bilden die erste Zeile der dritten Strophe (Zäsur nach der sechsten Silbe), die erste, zweite (Zäsur nach der dritten Silbe) und sechste (Zïsur nach der vierten Silbe) Zeile der vierten Strophe.

4 Der Alexandriner ist ein jambischer Reimvers von zwölf (männlicher Ausgang) oder dreizehn Silben (weiblicher Ausgang) mit deutlicher Diärese nach der dritten Hebung; vgl. I. BRAAK, a.a.0., S. $92-93$. 
Проснулась Скорбь, / и жалоба зовет

Сопутников, / с пути сошедших прежде

и здесь вотще / поверивших надежде. 1

Nur in der zweiten zeile der zweiten strophe setzt Žukovskij die Zäsur - genau wie Goethe - nach der siebten silbe:

и много милых тенея / восстает 2

Inhaltich sind Goethes Verse nicht sehr genau ubersetzt, die Veränderungen sind zahlreich. Dennoch gelingt es Y̌ukovskij, den im Gedicht ausgedrückten seelenzustand genau wiederzugeben. Vielleicht dachte Zukovskij an seine Freunde, die früher in seiner Nähe waren; nun, da sie gestorben oder weit weg sind, bleibt nur die Erinnerung.

Häufig zitiert Zukovskij in seinen Briefen die zeile Goethes, die inm sehr nahe gegangen sein muB:

Und manche liebe Schatten steigen auf

Und obwohl seine übersetzung

и много мнлих тенея восстает ${ }^{2}$

als vollkommen erscheint, zitiert er doch immer das deutsche original. 3 .

1 Es erwachte die Traver, und die Klage ruft/Die Gefährten, die friher vom Weg abgewichen sind/Und die hier vergeblich der Hoffnung vertraut haben.

2 Und viele liebe Schatten stehen auf.

$3 \mathrm{Vgl}$. Žukovskijs 8rief an Goethe vorn 25. Februar (9. Marz) 1822: "... mais je vous ai vu, et votre présence a été pour moi corme une récapitulation rapide des plus beaus temps de mon passé. Und manche liebe Schatten steigen auf! c'était cela! ..."v.A. ZuKovSKIJ, Pis'mo k Gete, a.a.0., Sp. 1817-1819. IUnterstrichene Stellen im Original kursiv gedruckt). 
Auch die beiden letzten Verse der "Zueignung", die Goethes wesen so poetisch beschreiben, luberträgt Zukovskij treffend ins Russische.

Was ich besitze, seh' ich wie im weiten,

Und was verschwand, wird mir zu Wirklichkeiten

Diese abschließenden Verse lauten bei Zukovskij:

Все близкое мне зрится отдаленным,

отжившее, как прежде, оживленньм ${ }^{1}$

Einen grundlegenden Unterschied - er bezieht sich auf die Entstehungsumstände - gibt es dennoch zwischen den beiden Gedichten: Goethes Gedicht ist in einer konkreten Situation entstanden; der Dichter widmet seine schöpferische Energie wieder einer schon lange ruhenden Aufgabe, der Fertigstellung des "Faust".

Den nachdenklichen Rückblick in den ersten beiden Strophen setzt er durch die Aussicht auf erneute Aktivität fort. Die "schwankenden Gestalten", wie z.8. Faust und Mephisto, lassen Goethe keine Ruhe, er will sie "festhalten", sie zu ihrem Ziel füren.

Žukovskij hat wohl niemals einen ähnlichen Ruf vernommen, er kann den Gestalten seiner Phantasie nicht genug von seinem eigenen Leben geben, so daß sie sich emporheben und ihre Rechte fordern könnten. 2 Das, was Žukovskij anspricht, ist die Poesie, der "segensreiche Geist", das ist der Traum "mit einer Vielzahl vertrauter Erscheinungen" und das sind die "Erinnerungen":

1 Alles Nahe scheint mir entfernt,/Das Erstorbene, wie einst, (scheint mir) wieder belebt.

2 Vgl. M. ERPAARD, a.a.0., S. 301. 
Опять ты здесь, моп благодатнын Гекия,

Воздушная подруга юных днел;

Опять с толпоя энакомых приведения

Теснишься ты, Мечта, к душе моея...

Приди $*$, о друг! дая прежних вдохновения,

Минувшею мне жизнию повея,

Побудь со мноя, продли очарованья,

дая сладкого вкусить воспоминанья. 1

Žukovskij neigt dazu, seine Nachahmung dem populären Genre der Elegie anzupassen. Er fügt frei den unvermeidlichen Schmuck dieser Gattung ein: die "nachdenkliche Lyra", "süBe Erinnerungen", das "träumerische Herz", in dem "das streben nach jener geheimnisvollen welt" wieder auflebt und "die sehnsucht nach dem Gluck vergangener Jahre".

Bezeichnend ist Žukovskijs übertragung der einleitenden zeilen der dritten strophe:

Sie hören nicht die folgenden Gesänge,

Die Seelen, denen ich die ersten sang

Goethe spricht von folgenden, also zukünftigen Gesängen; Zukovskij ubersetzt sie charakteristischerweise mit "das letzte Lied", dessen Klänge den Freund nicht mehr erreichen:

К ним не доядут последнея песни эвуки;

Рассеян круг, где первую в пел ${ }^{2}$

1 Wieder bist du hier, mein segensreicher Genius,/Ou beschwingte Freundin jugendlicher Tage;/Wieder mit einer Vielzahl vertrauter Erscheinungen/Drängst du dich, Traum, an meine Seele .../Korm doch, o Freund! Gib die vergangenen Inspirationen,/Und winde (sie) mir wie ein vergangenes Leben,/Sei mit mir, verlängere die Zauber,/Gib von der sußßen Erinnerung zu kosten.

2 Zu itm gelangen nicht die Klänge des letzten Liedes;/Zerstreut ist der Kreis, wo ich das erste sang. 
Der Rückblick inspiriert Goethe zu never schöpferischer Tätigkeit, während Žukovskij dazu neigt, bei süßen Erinnerungen zu verweilen, und der Gedanke neuer schöpferischer Aktivität in den Hintergrund tritt. 1

Insgesamt ist Zukovskijs Wiedergabe von Goethes "Zueignung" eine bemerkenswerte Leistung, was auch Ehrhard durchaus erkennt:

"... nulle part, le vers et la strophe russes ne se sont aussi parfaitement moulés sur les formes allemandes que dans ces octaves, et celles diune autre Dédicace d'après Goethe: celle des poésies lyriques, que Joukovski a malheureusement abandonnée à la seconde strophe." 2

Die beiden in Stanzen verfaßten zueignungen Goethes nehmen auch EinfluB auf das eigenständige Werk Žukovskijs. In Stanzen schreibt er bald darauf zwei Originalgedichte: die Elegie "Na konCinu ee velitestva korolevy Virtembergskoj" (1819) und "Cvet Zaveta" (1819), in dem sich auch inhaltlich gewisse Anklänge an die "Zueignung" zum "Faust" finden lassen. 3

1 Žirmunskij hält es für möglich, daß Žukovskij wegen der zahlreichen Abwandlungen die Wiedergabe der "Zuejgnung" später ohne Quellenangabe veröffentlichte. Vgl. V.M. ZIPaLNSKIJ, Poézija, a.a.0., S. 545 .

2 M. EHARD, a.a.0., S. 301. (Unterstrichene Stelle im Original kursiv gedruckt).

3 Hierzy Žirmuskij: "Poslednee stichotvorenie [Cvet Zaveta] i v soderžanil svoem obnaruživaet celyj rjad sovpadenij so stichotvoreniem Gete, tak čto mestami kažetsja ne to vol'nym pereskazom, ne to variaciej na tu Že élegileskuju temu serdečnogo vospominanija." V.M. ŻIRMunsKIJ, Poézija, a.a.O., S. 545. 


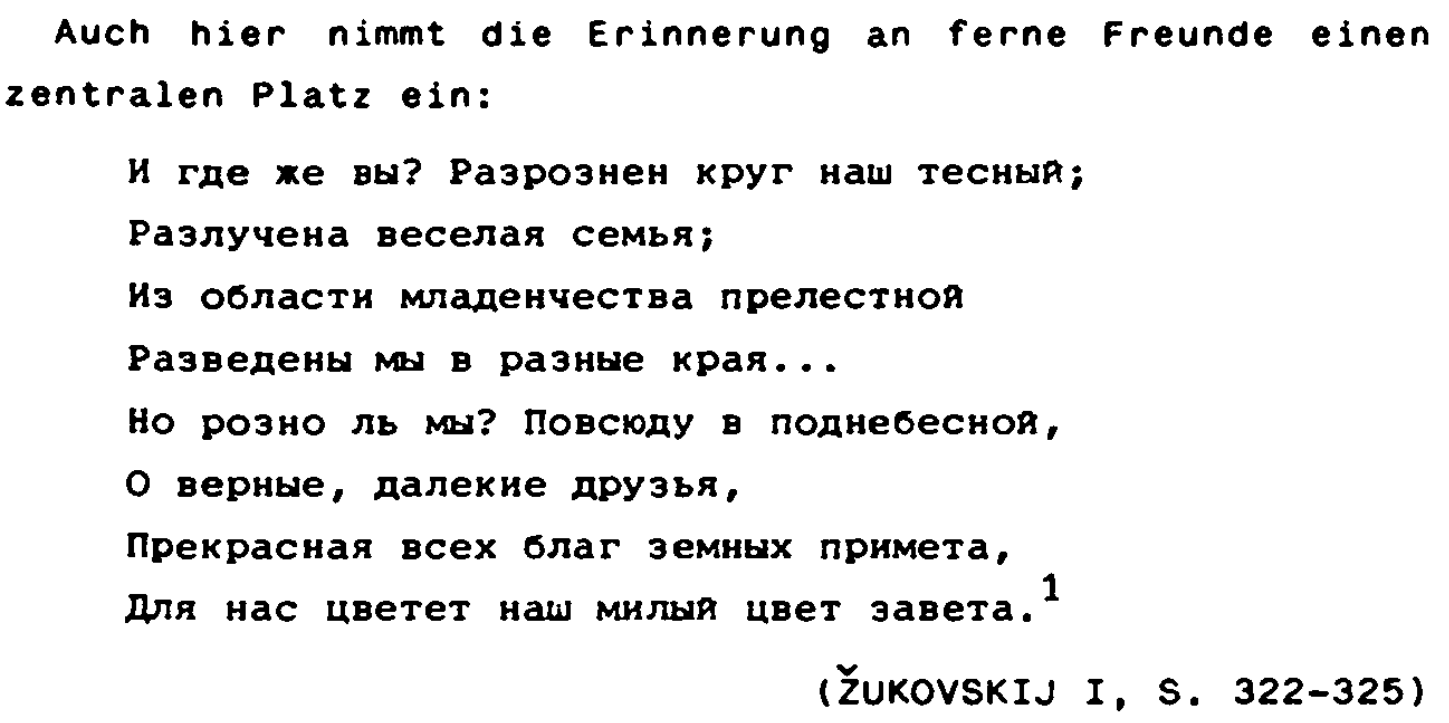

1 Aber wo seid ihr? ... Unser enger Kreis ist zerstreut;/Getrennt ist die fröhliche Familie;/Aus der anmutigen Sphäre der Kindheit/ wurden wir in verschiedene Gegenden auseinander geführt ....Aber sind wir getrennt? Überall unter dem ganzen Himmelszelt, 10 treue, ferne Freunde,/Wunderbares Kennzeichen allen irdischen Heils, Blüht für uns unsere liebliche Blüte des Vermächtnisses. 


\subsubsection{2. Übersetzungen Tjuttevs}

\subsubsection{1. "Nachtgedanken"}

Die in diesem Gedicht zum Ausdruck gebrachten Empfindungen, vielleicht auch zunächst nur der Titel "Nachtgedanken", sowie die kurze, knappe form - solche Kleinformen sind es, die der russische Dichter zeit seines Lebens bevorzugt - haben Tjuttev wohl zur Übersetzung dieser Verse angeregt.

Euch bedaur ich, unglückselge Sterne, Die ihr schön seid und so herrlich scheinet, Dem bedrängten Schiffer gerne leuchtet, Unbelohnt von Göttern und von Menschen: Denn ihr liebt nicht, kanntet nie die Liebe! Unaufhaltsam führen ewge Stunden

Eure Reihen durch den weiten Himmel. Welche Reise habt ihr schon vollendet!

Seit ich weilend in dem Arm der Liebsten

Ever und der Mitternacht vergessen.

(GOETHES GEDICHTE I, S. 244)

Einfühlsam gibt Tjutčev diese worte eines nächtlichen Verliebten, gerichtet an die Sterne des Himmels, 1 wieder. Auch in den russischen Versen projiziert das lyrische Ich seine Empfindungen in die Natur, auch hier die einfühlende Personifizierung der himmlischen Gestirne:

1 Das Bild der "reinen" Sterne, die die Liebe nie kennengelernt haben und die "mit keuschen Strahlen" den sterblichen Blicken Antwort geben, taucht auch in Tjutčevs un 1850 entstandenem Gedicht "Končen pir, umolkli chory" auf. 
Вы мне жалки, звезды-горемжки!

Так прекрасны, так светло горите,

мореходиу светите охотно,

Без возмездья от богов и смертных!

Вы не знаете любви - и ввек не знали!

Неудержно вас уводят оры

Сквозь ночную беспредельность неба.

O! какоя вы путь уже свершили

С тоя поры, хак я в ооъятьях милоя

Вас и полночь сладко забываю! 1

$$
\text { ("Nočnye mysli", TJUTČEV II, S. 103) }
$$

Die feierliche Sprache des Goetheschen Gedichts unterstreicht Tjutčev durch in diesem Zusammenhang gewählt wirkende worte wie "goremyki" (für "unglückselge") und "Ory" ("Horen", für "Stunden"). 2

Mit "NoČnye mysli" liefert Tjutčev eine adäquate Übersetzung: Nur wenige seiner Übertragungen geben ein solch' gelungenes Spiegelbild eines Goethe-Gedichts wie diese zehn Zeilen.

1 Inr tut mir leid, Sterne-Unglückliche!/So schön (seid ihr), so strahlend leuchtet inr,/Gern leuchtet ihr dem Seefahrer,/Ohne Lohn von Göttern und von Sterblichen!/Ihr kennt nicht die Liebe und habt sie niemals kennengelernt!/Unaufhaltsam führen euch die Horen fort/Durch die nächtliche Unendlichkeit des Himmels.10, welchen weg habt ihr schon vollendet/Seit der Zeit, als ich in den Armen der Geliebten/Euch und Mitternacht angenelm vergesse!

2 Vgl. A. v. GRONICKA, The Russian Image of Goethe, a.a.O., S. 159. 


\subsubsection{2. "Kennst du das Land?"}

Erst relativ spät, vermutlich nicht vor 1850 , entschließt sich Tjutčev, auch das "Italienlied" aus "Wilhelm Meister" ins Russische zu übersetzen. Er tut dies zu einem Zeitpunkt, als er schon seit uber füf Jahren in Petersburg lebt, inm die sehnsucht nach der fremde aber keine Ruhe läßt. Nach einer Bemerkung seiner Frau in einem Brief aus dieser zeit spielt er sogar mit dem Gedanken, seine Heimat endgültig zu verlassen. 1

Vertraut war Tjutčev das Lied Mignons mit Sicherheit schon lange, 2 er zögerte jedoch, eine eigene übertragung des Gedichts neben die bereits zahlreich vorhandenen Fassungen anderer Dichter und übersetzer zu stellen." Aber schlieblich muBte er doch zugeben, dab dieses Gedicht gerade wegen seiner Beliebtheit der Prufstein

1 Vgl. K. PIGAREV, Čto perevodil Tjutčev, a.a.0., s. 253.

2 Besonders deutlich sind die Anklänge an das "Italienlied" Goethes in TJutčevs "Gljadel Ja, stoja nad Nevoj" aus dem Jahre 1844. Zahlreich sind auch diejenigen Gedichte TjutZevs, in denen er seine Sehnsucht nach dem Sijden thematisiert, 2.8. in "Vnov' tvoi ja vǐ̌u ơ̌i" (1848-1849) und "Davno l', davno l', O Jug blažennyj" (1837). Vgl. bei uns das Kapitel II, 2.2.2.2. "Zur geistigen Verwandtschaft zwischen Tjutčev und Goethe".

3 Das Lied Mignons war bereits von V.A. Zuukovskij, P. Obodovskij, A. Strugovscikov, $P$. Skljarevskij und V. Zotov übersetzt worden. Nach Tjutčev übersetzten es U.a. noch L. Mej, N. Gerbel', M. Michajlov, M. Sempervero, A. Majkov, S.O. Rokin, S. Servinskij und B. Pasternak. 
für jeden Übersetzer sei. 1

Charakteristisch für Tjutčevs Wiedergabe des "Italienliedes" ist zunächst die Umkehrung der Reihenfolge der zwejten und dritten strophe. Während bei Goethe in den ersten beiden Strophen das Ziel der Sehnsucht - Italien beschrieben wird und schlieblich in der dritten strophe der weg dorthin - der AlpenpaB - erscheint, empfindet Tjuťev, die Wanderung Mignons zum Land ihrer Träume müsse, nach überschreiten des Alpenpasses, in dem "glänzenden Saal" eines Hauses enden.

Vielleicht wollte Tjutčev durch die Umstellung der strophen auch einen "in sich geschlossenen Geschehensverlauf in chronologischer Progression"2 gestalten, um

1 Im Wortlaut sagte TjutZev: "Romans iz Gete neskol'ko raz pereveden byl u nas, - no tak kak èta p'esa iz Zisla tech, kotorye počti obratilis' $v$ literaturnuju pogovorku, to ona navsegda ostanetsja probnym kamem dlja ochotnikov." Abgedruckt in: TJUTCEV II, S. 364-365.

Bemerkenswerterweise bezeichnet TjutČev das Lied Mignons als "Romanze" und rïckt es damit - nach damaligem Sprachgebrauch in die Naihe der Ballade. Auch Goethe steht ganz im Banne seiner Zeit, als er dieses Gedicht in seiner Gedichtsermlung von 1815 an die Spitze der Gruppe "Balladen" stellt. - Nach heutigem Gattungsgefühl kann das Lied Mignons jedoch nicht als Ballade gelten, da in monologischer Rede drei Phantasiebilder entwickelt werden, die nicht durch eine reale Handlung miteinander verbunden sind. Sowohl in RuBland als auch in Deutschland fehlte somit ein fester Gattungsbegriff. Vgl. W. KAYSER, Geschichte der deutschen Ballade. Berlin 1936. S. 141-142; H. MEYER, Mignons Italienlied und das wesen der Verseinlagen im "Wilhelm Meister". Versuch einer gegenständlichen Polemik. In: Euphorion 46 (1952). S. 149-169. Hier S. 156-157; G. SOHULz, a.a.0., S. 34-37.

2 H. MEYER, a.a.O., S. 156. 
so die balladen- bzw. romanzenhaften Züge des Gedichts zu betonen.

Neben der Umstellung der Strophen weicht Tjuťev noch in weiteren Punkten von Goethe ab. Das Kompositum "Wolkensteg", gemeint ist ein wolkenumhüllter Gebirgssteg, übersetzt er frei mit "weg entlang von Abhängen".

Die markante Metapher "Es stürzt der Fels und über inn die Flut" lautet bei TjutZev: "Es donnert die Lawine und der Wasserfall tost". Statt der gewaltigen Dynamik der Bewegung steht hier die Geräuschkulisse im Mittelpunkt der Beschreibung.

Von der Goetheschen Dreiheit "Geliebter - Beschüzer Vater" im Refrain der Strophen, ersetzt TjutCev ohne ersichtlichen Grund den "Beschützer" durch einen "Gebieter" ("vlastitel"").

Diese und noch zahlreiche weitere Änderungen und inhaltliche Ungenauigkeiten legen die Vermutung nahe, daB eine exakte wiedergabe des Inhalts gar nicht TjutČevs Hauptanliegen war. Vielmehr reizten ihn Metrum und Rhythmus der deutschen Verse.

Sorgfältig gibt Tjutčev die achttaktigen Langzeilen ${ }^{1}$ wieder. Das einsilbige "ty" jeweils am Anfang der ersten und funften Zeile fült immer den schweren Eingangstakt, 2 alle ubrigen Zeilen pausieren die erste Hebung. Gleichzeitig gelingt es TjutCev, die Frageformen des Originals beizubehalten.

1 Vgl. A. HEUSLER, a.a.0., S. 478; vgl. bei uns das Kapitel III, 2.1.2.1.3. "Kennst du das Land".

2 Es entspricht dem einsilbigen "Kennst" zu Beginn der jeweils ersten und fünften Zeile bei Goethe. 
Tw знаешь края, $\bigwedge$ где мирт и лавр растет, $\bigwedge$

\Глубок и чист $\bigwedge$ лазурныя неба свод, $\bigwedge$

$\bigwedge$ щветет лимон, $\bigwedge$ и апельсин златог $\bigwedge$

$\bigwedge$ как жар горит $\bigwedge$ под зеленью густоя?.. $\Lambda$

ты был ли там? \туда, туда с тобор $\bigwedge$

$\bigwedge$ хотела $о$ я укреться, $\bigwedge$ мильр моя. ${ }^{1}$

(TJUTČEV II, S. 133)

Auch bei den folgenden beiden strophen achtet Tjutčev auf eine rhythmisch exakte Wiedergabe der Goetheschen Verse.

Ты знаешь высь с стезея по крутизнам?
Јошак бредет в тумане по снегам,
В ушельях гор отродье змея живет,
Гремит обвал и водопад ревет...
Ты был ли там? Туда, туда с тобоя
лехит наш путь - уядем, властитель
моя. $^{2}$

1 Kennst du das Land, wo Myrte und Lorbeer wächst, /Das blave Hinmelsgewölbe tief und klar ist,/Die Zitrone wächst, und die goldene Apfelsine/Wie Fever unter dem dichten Grin leuchtet? .... Warst du schon dort? Dahin, dahin mit dir/Wirde ich mich gern zurickziehen, mein Geliebter.

2 Kennst du die Höhe mit Wegen entlang von Abhängen?/Der Maulesel geht mihsam im Nebel durch die Schneemassen,/In den Schluchten der Berge lebt der Drache Ausgeburt,/Es donnert die Lawine und der Wasserfall tost ...l

Warst du schon dort? Dahin, dahin mit dir/führt unser weg - laß uns gehen, mein Gebieter. 
Tы знаешь дом на мраморных столпах?

Сияет зал и купол весь в лучах;

Глядят кумиры, молча и грустя:

"Что, что с тобою, бедное дитя?.."

Tw был ли там? туда, туда с тобоя

уядем скорея, ундем, родитель моя. 1

Die Bedeutung dieser übersetzung liegt somit nicht in inrer inhaltlichen Genauigkeit, sondern in dem Feingefunl, mit dem Tjutčev Metrum und Rhythmus des deutschen Gedichts ins Russische uberträgt.

1 Kennst du das Haus auf Marmorsäulen?/Es glänzt der Saal und die Kuppel ist ganz in Strahlen;/Es schauen die heidnischen Statuen, schweigend und traurig:/"Was, was ist mit dir, armes Kind? ..."/ Warst du schon dort? Dahin, dahin mit dir/Laß uns schneller gehen, laß uns gehen, mein vater. 
2.1.2.2.3. "Freudvoll und leidvoll"

Das Lied Klärchens aus dem dritten Aufzug des "Egmont" stellt eine selbständige lyrische Einheit dar. Dieses Lied mit seinen berühmten Schlubversen zeichnet sich im Ausdruck durch klare Einfachheit und gleichzeitig knappe Gedrängtheit aus. Der Rhythmus ist beschwingt-liedhaft.

Freudvoll

Und leidvoll,

Gedankenvoll sein,

Langen

Und bangen

In schwebender pein,

Himmelhoch Jauchzend,

Zum Tode betrübt;

Glücklich allein

Ist die Seele, die liebt.

(HA IV, S. 410-411)

TJutZevs Wiedergabe ist hauptsächlich durch übernahme des Grundgedankens mit Goethe verbunden. Die Ausgestaltung des Themas erfolgte dann weitgehend unabhängig.

Радость и горе в живом упоенье,

думы и сердие в вечном волненье,

В небе ликуя, томясь на земли,

Страстно ликуюея,

Страстно тоскуюеея,

Жизни блаженство в одноя лишь любви... 1

(TJUTČEV II, S. 219).

1 Freude und Kummer in lebendiger Begeisterung,/Die Gedanken und das Herz in ewiger Unruhe,/Im Hirmel Jubilieren sie, auf der Erde schmachten sie,/Des leidenschaftlich jubilierenden,/Des leidenschaftlich sich sehnenden,/Lebens Glückseligkeit (liegt) in nur einer Liebe. 
2.1.3. Schicksal und Einsamkeit

2.1.3.1. Übersetzungen Zukovski js

2.1.3.1.1. "wer nie sein Brot mit Tränen $a B^{\prime \prime}$

Žukovskijs Goethe-wiedergabe "Kto slez na chleb svoj ne ronjal" (ŽukovskiJ I, S. 269), die er zu Beginn des Jahres 1816 verfaßt hatte, erschien zum ersten Mal im zweiten Heft der Privatorucke "Für Wenige. Dlja nemnogich". 1 Das Lied des Harfners eröffnet eine Reine von zwölf weiteren Goethe-Übertragungen.

Die beiden vierzeiligen strophen bestehen je aus einem einzigen Aussagesatz, die Syntax beider sätze ist sich sehr ähnlich: je zweimal setzt ein einleitender Vordersatz mit jeweils wortgleichem Anfang (Anapher) an und erweckt einige spannung. 2

$$
\begin{aligned}
& \text { Wer nie sein Brot mit Tränen ab, } \\
& \text { Wer nie die kummervollen Nächte } \\
& \text { Ihr führt ins Leben uns hinein, } \\
& \text { Ihr labt den Armen schuldig werden }
\end{aligned}
$$

(HA VII, S. 136)

Nur in der ersten strophe gelingt es Žukovskij, diese Spannung zu erhalten:

Кто слез на хлеб своя не ронял,

Кто близ одра, как близ могиль ${ }^{3}$

$\overline{1 V g 1}$. bi uns Kapitel II, 3.1.2.2. "Žukovskijs schöpferische Phase als Goetho-Ubersetzer".

2 Vgl. G. STORz, a.a.O., S. 119.

3 Wer (noch) nicht Tränen auf sein Brot fließen ließ,/Wer an dem Bette wie an einem Grab. 
Die Frage nach dem Metrum des deutschen Gedichts läßt sich nur scheinbar leicht beantworten. In seinem Basler Vortrag von 1925 weist Andreas Heusler ausdrücklich darauf hin, daß diese verse über die scheinbaren jambischen Viertakter hinausgehen; ${ }^{1}$ Heusler erkennt hier eine tripodische form, in die sich auch die letzte zeile jeder strophe einfügt. ${ }^{2}$

Im allgemeinen wird man die Verse jedoch als vierfüßige Jamben gelten lassen können, auch wenn diese Lösung bei sinngemäßer Betonung durchaus problematisch erscheint.

Jeweils die letzte zeile jeder strophe durchbricht das alternierende Schema offensichtlich: "himmlischen" ist ein Daktylus und bei "Denn alle schuld rächt sich auf Erden" stoben zwei Ikten ohne ein Polster von Senkung aufeinander. 3 Die pointierte Aussage der SchluBzeilen spiegelt sich im Metrum wider; die form fügt sich dem Inhalt.

1 Vgl. A. HEUSLER, a.a.0., S. $480-481$.

2 Graphisch stellt Heusler diese Form folgendermaßen dar:

wer nie sein // brót mit trấnen // áß, $\Lambda$

Wer nie die // kúmèrvòllen // nấchtè

Auf sèinem // béttè wéinend // sáß, $\Lambda$

Der kénnt euch // nicht, ihr hímmlischen // mächtè.

Inr führt ins // lébèn ùns hin- $/ /$ éin, $\Lambda$

Inr làßt den // ármèn schúldig // wèrdèn,

Dann über- // láßt inr inn der // péin; $\Lambda$

Denn álle // schúld rä́cht sich auf // érdèn.

Die zeitliche Grundeinheit ist das Viertel;

$\wedge$ entspricht einem pausierten Viertel,

- entspricht dem Hauptton,

- entspricht dem Nebenton.

Vgl. I. BRAAK, a.a.0., S. 87.

3 Vgl. G. STORZ, a.a.0., s. 120. 
Mit deutlichen Worten erhebt der Harfner seine bittere Anklage. In den ersten Zeilen beschreibt er bildich sein Elend; in zielstrebigem Schritt steigt die erste strophe an zu den dem Glücklichen unbekannten Himmelsmächten. Die Anrede "ihr himmlischen Mächte" schliebt den Satz und leitet zur Aussage der folgenden strophe über. Eine längere Pause zwischen beiden Strophen ist nicht denkbar.

Nun steigert der Harfner seine Anklage zur allgemeingültigen Aussage, die in der Sentenz "Denn alle Schuld rächt sich auf Erden" ihren Höhepunkt findet. Diese Zeile schließt den Gedankengang des Gedichts und unterstreicht rhythmisch den Ausklang. Inhaltlich wie formal bilden diese beiden vierzeiler eine vollendete, in sich geschlossene Einheit. 1

Auch die betonten Eingangstakte, mit denen jede Zeile der zweiten strophe beginnt, fügen sich nicht in das jambische Versmaß. In jeder zeile ist das erste, stets einsilbige wort mit solcher sinnbetonung beschwert, daß der Sprecher vor der sofort folgenden Hebung eine leichte Zäsur eintreten lassen muB:

Ihr/führt ins Leben uns hinein,

Ihr/labt den Armen schuldig werden,

Dann/uberlaßt ihr ihn der Pein,

Denn/alle Schuld rächt sich auf Erden.

Solcher Zusammenprall weist auf eine merkwürdige Gewalt des Sprechers hin. Die Aussage des Harfners ist durch eine klare Härte gekennzeichnet, hinter der man jedoch eine tiefe innere Erregung vermuten kann. 2

1 Vgl. H. EICASTÄDT, a.a.o., S. 47.

2 Vgl. G. STORz, a.a.0., S. 120. 
In seiner Übertragung gibt Žukovskij alle acht Verse der deutschen Vorlage in vierfüigen Jamben wieder; es werden weder die jeweils letzten verse rhythmisch von den übrigen abgehoben, wodurch die Geschlossenheit der Goetheschen Verse verlorengeht, noch heben betonte Eingangstakte die bittere Anklage des Harfners rhythmisch hervor.

на хизнь мы брошены от вас!

И вы *, дав знаться нам с виною,

Страданью выдаете нас,

Вину преследуете мздою. 1

Trotz dieser Schwächen bleibt Žukovskijs wiedergabe des Harfnerliedes eine bemerkenswerte Dichtung, bei der er sich - im Vergleich zu seinen vorangegangenen Goetheübertragungen - um mehr übereinstimmung mit dem deutschen Original bemüht. Es ist Žukovskij ohne Zweifel gelungen, dem russischen Leser die Stimmung des Goetheschen Gedichts zu vermitteln.
Wer nie sein Brot mit Tränen aB,
Wer nie die kummervollen Nächte
Auf seinem Bette weinend $s a B$,
Der kennt euch nicht, ihr himmlischen Mächte.

Die übertragung dieser strophe macht Žukovskijs Anstrengungen besonders deutlich:

Кто слез на хлеб своя не ронял,

Кто близ одра, как близ могилы,

В ночи, бессонныя, не рыдал, -

Тот вас не знает, вынни силы! ${ }^{2}$

1 Ins Leben murden wir von euch geworfen!/Und gerade ihr ließt uns mit Schuld bekannt werden/Und übergebt uns der Pein,/Ihr verfolgt die Schuld durch Lohn.

2 Wer (noch) nicht Tränen auf sein Brot fließen ließ, Wer an dem Bette wie an einem Grab/In der Nacht, schlaflos (noch) nicht schluchzte,/Der kennt euch nicht, höchste Mächte! 


\subsubsection{2. "Trost in Tränen"}

Die Wiedergabe von "Trost in Tränen" (GOETHES GEDICHTE I. S. 547-548) ist ein gelungenes Beispiel für Zukovskijs schöpferisches Talent. Mit "Utešenie $v$ slezach" (ŽUKOVSKIJ I, S. 287-288) schafft er ein der vorlage in Gehalt und Form gleichwertiges Gedicht.

Der Grundgedanke, daB bei hoffnungsloser Liebe Trost nur in Tränen $z u$ finden ist, daß nur sie die ersehnte Erleichterung bringen können, entspricht völlig Žukovskijs eigenen Anschauungen und gehört mit zu den charakteristischen Themen seiner Dichtung. 1

Goethes Gedicht, 2 dessen ersten bejden strophen einem bekannten Volkslied nachgebildet sind, ${ }^{3}$ stellt im Dialog zweier Freunde Lebensbejahung und Resignation gegeneinander.

In den Reden des Trostsuchenden

"Ach nein, erwerben kann ichs nicht,

Es steht mir gar zu fern.

Es weilt so hoch, es blinkt so schön,

wie droben jener stern."

und

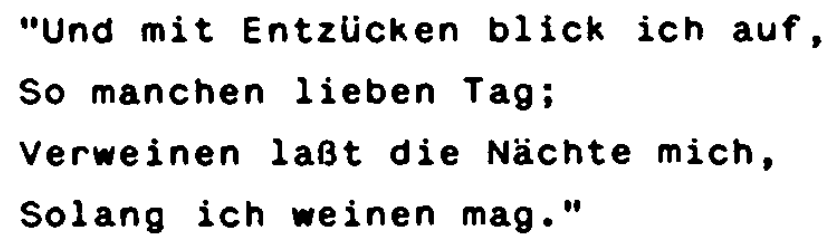

1 Vgl. "Teon $i$ Ėschin" und "Vospominanie".

2 Auch dieses Gedicht Goethes murde von weyrauch vertont. Vgl. C. v. SEIDLITZ, a.a.0., S. 100.

3 "Der rechte Trost". Abgedruckt in: L. ERK, Deutscher Liederhort. Neubearb. U. fortges. V. F.M. Böhme. Bd. 2. Leipzig 1893. S. 357, $\mathrm{Nr} .531$ a. 
glaubt Ehrhard sogar Zukovskijs Wesen wiedererkennen zu können:

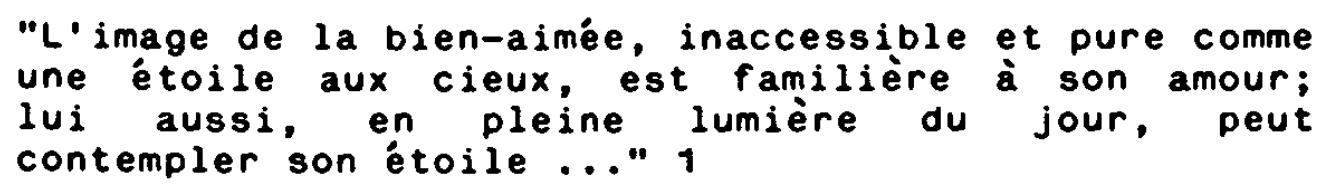

Ansätze zu einer übertriebenen sentimentalität lassen sich jedoch auch bei dieser übersetzung erkennen. Durch eingefügte Ausrufe und Wortwiederholungen erhalten die Erwiderungen des Trauernden eine stärkere emotionale Färbung. 2

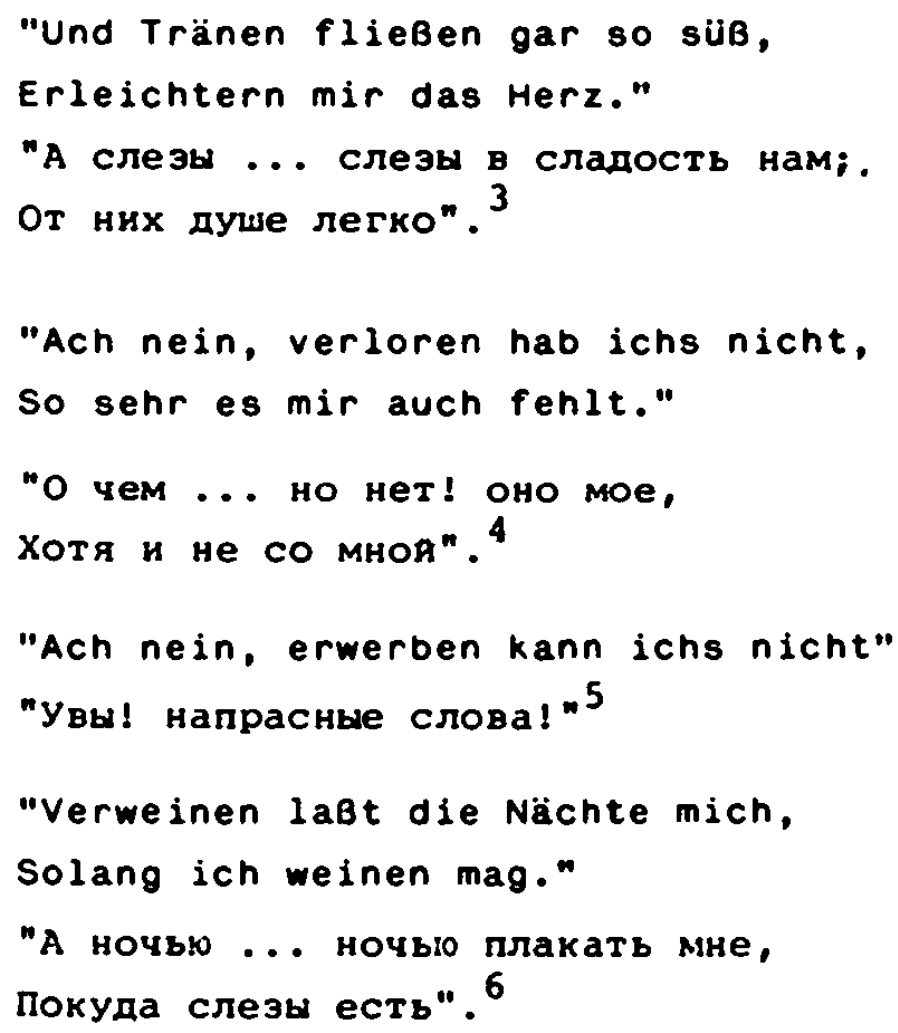

1 M. EHPHARD, a.a.O., S. 299.

2 Vgl. H. EICASTÄDT, a.a.0., s. 50.

3 "Aber Tränen ... Tränen sind uns zur Wonne,/Von ihnen wird der Seele leicht."

4 über was (ich travere) ... aber nein! Es ist mein/Obwohl es nicht bei mir ist."

5 "O weh! Vergebliche Worte!"

6 "Aber nachts ... nachts muß ich weinen,/Solange es Tränen gibt." 
Ansonsten gelingt es Žukovskij, den Kontrast zwischen den beiden gegensätzlichen Freunden wirkungsvoll zum Ausdruck zu bringen. Die straffe Dialogführung vermeidet ein Abgleiten in allzu empfindsame Gefühlsseligkeit, die das Thema des Gedichts - Tränen als einzig mögliche Linderung des schmerzes - geradezu herauszufordern scheint.

Aber auch hier trifft Žukovskij im großen und ganzen den adäquaten Ton, auch wenn an einigen stellen die Neigung des russischen Dichters zu gesteigerter Emotionalität offensichtlich wird:

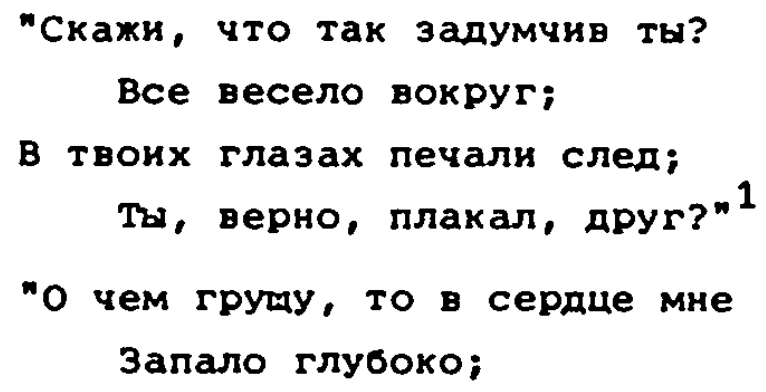

1 "Sag, was bist du so nachdenklich?/Alles ist fröhlich ringsum./In deinen Augen ist die Spur des Kummers;/Du hast wohl geweint, Freund?"

2 woruber ich traurig bin, das hat sich mir ins Herz/Tief eingeprägt;/Aber Tränen sind uns zur Wonne,/Von ihnen wird der Seele leicht."

3 "Dich umsorgen die Freunde zärtlich,/Scheue dich nicht vor ihrem zärtlichen Trost;/Und was du immer verloren haben magst,/Teile den verlust (mit uns)." 
Žukovskij gibt sowohl die form als auch die stimmung der Goetheschen Verse mit bewundernswerter Genauigkeit wieder. Völlig zu recht wird diese übersetzung zu Žukovskijs gelungensten Goethe-Interpretationen gezählt. ${ }^{1}$

\subsubsection{2. Übersetzungen TJuť̌evs}

\subsubsection{1. "wer sich der Einsankeit ergibt"}

Im Gegensatz zur Übersetzung des vorangehenden Harfnerliedes "Wer nie sein Brot mit Tränen $a B^{\prime}$ ist Tjutčevs wiedergabe von "wer sich oer Einsamkeit ergibt" wenig gelungen.

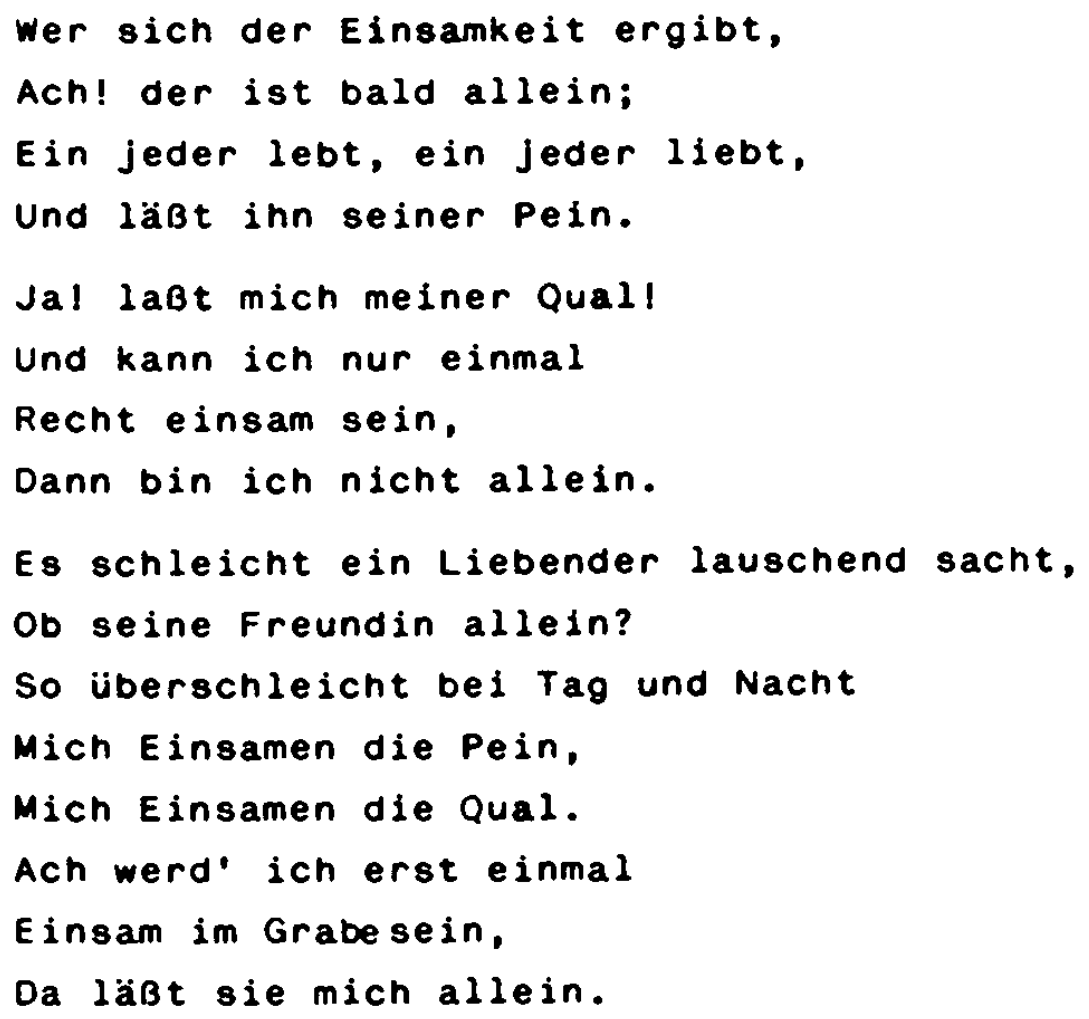

(HA VII, S. 137-138)

1 André von Gronicka bemerkt hierzu: "This rendering must be judged among the most successful of Zhukovski's faithful interpretations of Goethe." Vgl. A. v. GRONICKA, The Russian Image of Goethe, a.a.O., S. 53; M. Ehrhard schreibt: "... c'est une des ceuvres ou Joukovski a le mieux rendu le lyrisme de Goethe." M. EHPARD, a.a.0., S. 299 . 
Das deutsche Gedicht mit seiner einfachen, fast banalen 'Syntax, der schlichten Wortwahl und der eigentumlich verschränkten Reimstellung ${ }^{1}$ lautet in Tjutčevs wiedergabe:

$$
\begin{aligned}
& \text { Кто хочет миру чухдым быть, } \\
& \text { Тот скоро будет чужд, - } \\
& \text { Ах, людям есть кого лобить, } \\
& \text { Что им до наших нужд! } \\
& \text { так! что вам до меня? } \\
& \text { Что вам беда моя? } \\
& \text { Она лишь про меня, - } \\
& \text { С нея не расстанусь я! }
\end{aligned}
$$

Как крадется к милоя любовник таяком:

"Откликнись, друг мншы, одна ль?"

так бродит ночио и днем

кругом меня тоска,

Кругом меня печаль!..

Ах, разве лишь в гробу

От них укрыться мне -

В гробу, в земле сыроя -

там бросят и оне! 4

1 Vgl. G. STORZ, a.a.O., s. 155.

2 Wer der Welt frend sein möchte,/Der wird balo fremd sein,-/Ach, die Leute haben jemanden zu lieben, Was liegt innen an unseren Nöten!

3 So! Was liegt euch an mir? Was bedeutet euch (liegt euch) an meinem Unglück?/Es ist nur für mich,-/Von itm trenne ich mich nicht!

4 Wie schleicht ein Verliebter heimlich zur Geliebten:/"Antworte, teurer Freund, bist ou allein?"/So gährt nachts und tags/um mich herum die Schwermut, / m mich herum die Traurigkeit! .../Ach, wie wäre es nur im Sarg/Um mich vor innen zu schützen -/Im Sarg, in feuchter Erde-/Dort werden auch sie (von mir) ablassen. 
Auffällig ist zunächst die Erweiterung der bei Goethe achtzeiligen AbschluBstrophe um einen Vers auf neun Zeilen. Bei näherem Vergleich ergeben sich dazu noch zahlreiche Abweichungen, auch in den beiden vorangehenden strophen.

Dabei weist die wiedergabe der ersten strophe noch relativ deutliche Bezüge zum Original auf. Trotz der freien Wortwahl, trotz des übergehens formaler Besonderheiten wie der Entsprechung des "liebt" zum vorangehenden "lebt" in der zweigeteilten dritten Verszeile, können wir eine gewisse Kongruenz zwischen beiden Fassungen feststellen.

Demgegenüber ist Tjutčevs Wiedergabe der folgenden vierzeiligen strophe kaum mehr mit Goethes Zeilen verbunden.

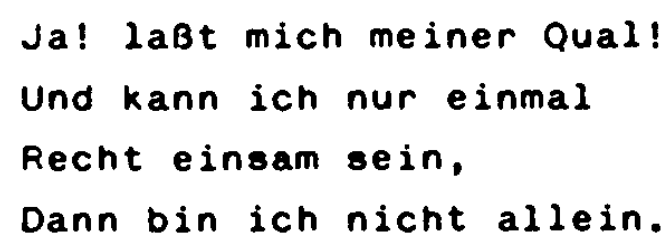

Diese Zeilen haben Tjutčev zwar inspiriert, aber deutlich empfinden wir die russischen Zeilen als seine eigene Schöpfung, als Widerspiegelung seiner persönlichen Gefühle und Empfindungen.

Так! что вам до меня?

что вам беда моя?

Она лишь про меня, -

С нея не расстанусь я! 1

Eine Weiterführung dieser Gedanken zur menschlichen Einsamkeit finden wir in Tjutčevs "Silentium". Dieses Gedicht ist in dem gleichen Zeitraum entstanden wie die übersetzung des Harfnerliedes. ${ }^{2}$

1 So! Was liegt euch an mir?/Was bedeutet euch (liegt euch) an meinem Unglück?/Es ist nur für mich,-/Von ilm trenne ich mich nicht!

2 Beide Gedichte entstanden wohl un 1830. 
Молчи, скрываяся и тан

И чувства и мечты свон -

Пуская в душевноя глубине

Встают и заходят оне

Безмолвно, как звезды в ночи, -

Любуяся ими - и молчи. 1

Лишь жить в себе самом умея -

Есть целыя мнр в душе твоея

Таянственно-волшебных дум;

Их оглушит наружныя шум,

Дневные раэгонят лучи, -

Внимая их пенью - н молчи!..2

(TJUTČEV I, S. 46)

Goethes oritte Strophe setzt - nach merklicher Pause mit einem anderen Ton und einer anderen Bewegung ganz neu ein. Völlig auBerhalb des Zusammenhangs schleicht unversehens ein Liebender zu seiner Geliebten. Beschwingt-daktylische Takte verleihen den beiden ersten zeilen einen uberraschend heiteren Charakter.

wiederum unerwartet folgt ein plötzlicher Umschlag von Stimmung und Rhythmus in der folgenden zeile. Nun wird die Tragik des Llebenden deutlich. Sein füchterliches Verhängnis läßt inm scheinbar keinen Ausweg. 3

1 Schweige, verbirg dich und halte/deine Gefüle und Träume geheim,/laB sie in der Tiefe deiner Seele/lautlos auf- und untergehen/wie Sterne in der Nacht;/erfreue dich an ihnen - und schweige.

2 Verstehe, nur in dir selbst zu leben:/es gibt in deiner seele eine ganze Welt/geheimnisvoll-zauberhafter Gedanken;/sie betäubt der äußere Lärm,/die Strahlen des Tages vertreiben sie;/lausche inren Gesang - und schweige! ...

Übersetzung nach: RUSSISCFE LYRIK. Von den Anfängen bis zur Gegenwart. Russisch/Deutsch. Hrsg. Kay Borowsky und Ludolf Miller. Stuttgart 1983. S. 157 und 159. Zur Verbindung dieser beiden Gedichte miteinander vgl. $K$. PIGAREV, Cto perevodil Tjutčev, a.a.0., S. 250.

3 Vgl. G. STORz, a.a.O., S. 116. 
Es gelingt Tjutčev nicht, den zweimaligen stimmungsumschwung rhythmisch zu untermalen. Die Dopplung "Mich Einsamen die Pein,/Mich Einsamen die Qual", in der sich die Hoffnungslosigkeit des Sängers manifestiert, gibt Tjutłer mit "Krugom menja toska,/Krugom menja pečal". wieder.

Das Thema des Goethe-Gedichts - die angstrolle Einsamkeit des Sängers, der sich der Erinnerung an die Vergangenheit nicht erwehren kann, wobei die tiefere Ursache seiner Qual jedoch nicht deutlich wird ${ }^{1}$ - hat Tjutčev offensichtlich zur übersetzung gereizt.

Schwerwiegend sind jedoch die Schwächen der russischen Fassung. Es gelingt Tjutלer nicht, die Goetheschen Reime, die sich "wie Ausbrüche der Verzweiflung" 2 folgen, adäquat wiederzugeben. Immer männlich, einsilbig auf der Hebung reimend, sammelt sich noch einmal im Reimausklang die ganze Kraft der Verszeile, zweimal in "Pein", zweimal in "Qual" und viermal in "allein".

Zwar bemüht sich Tjutčev um die Nachbildung des freien Rhythmus, 4 der - zusammen mit der unregelmäßigen strophenform - dem Lied seinen improvisierten Charakter verleiht. Aber der Versuch des russischen Dichters, das Gesetz der RegelmäBigkeit in Reim, Rhythmus und VersmaB zu durchbrechen - dieses Gesetz ist noch während der ersten Hälfte des 19. Jahrhunderts in der russischen Lyrik nach dem Kanon inrer Prosodie unantastbar ${ }^{5}$ - scheint insgesamt wenig erfolgreich.

1 Vgl. HA VII, S. 731.

2 G. STORZ, a.a.0., S. 116.

3 Vgl. ebd.

4 Im Gegensatz zu Andreas Heusler, der den Versen eine tripodische Form zugrunde legt, geht Gerhard Storz davon aus, daß es sich nicht um ein kompliziertes Taktschema handelt, sondern daß die Auf lockerung des freien Gefüges als rhythmische Prosa zu verstehen ist. Vgl. A. HEUSLER, a.a.0., S. 481; G. STORZ, a.a.0., S. 115.

$5 \mathrm{Vgl.} \mathrm{A.} \mathrm{V.} \mathrm{GRONICKA,} \mathrm{The} \mathrm{Russian} \mathrm{Image} \mathrm{of} \mathrm{Goethe,} \mathrm{a.a.0.,} \mathrm{S.} 158$. 


\subsubsection{2. "Wer nie sein Brot mit Trünen as"}

Mit "Kto s chlebom slez svoich ne el" liefert Tjutčev eine bemerkenswerte ujbersetzung des Harfnerliedes aus "Wilhelm Meister" "wer nie sein Brot mit Tränen aß" (HA VII, S. 136 ).

Gegenüber Žukovskijs übertragung aus dem Jahre 1816 trifft diese Fassung in der Wortwahl Goethes lakonischen, epigrammatischen stil besser. Dabei geht TJutčev sehr genau vor, ubersetzt teilweise wörtlich ins Russische: ${ }^{1}$

кто с хлеоом слез свонх не ел,

Кто в жизни цельми ночами

на ложе, плача, не сидел,

Тот незнаком с небесньми властями. 2

Они нас в бытие манят -

Заводят слабость в преступленья,

и после муками казнят:

нет на эемли проступка беэ отмиенья! ${ }^{3}$

(TJUTČEV II, S. 65).

1 Im Gegensatz dazu weicht Žukovskij in seiner übersetzung von Goethes Versen ab. So hat der Vergleich in der zweiten Gedichtzeile "Kto bliz odra, kak bliz mogily" keine Entsprechung in der deutschen Vorlage.

2 Wer (noch) nicht mit Brot (auch) seine Tränen aB, Wer im Leben ganze Nächte hindurch/(NoCh) nicht auf dem Bett weinend saß,/Der kennt nicht die himmlischen Mächte.

3 Sie locken uns ins Dasein,/Sie führen die Schwäche zu Verbrechen,/ Und racther strafen sie mit Qualen:/Es gibt auf der Erde kein Vergehen ohne Rache! 
Darüberhinaus spiegelt Tjutčevs wiedergabe die metrischen Nuancen bewundernswert exakt wider. In der letzten Zeile jeder strophe wird das regelmäßige Metrum der übrigen Verse unterbrochen. Der deutschen Vorlage entsprechend beginnen diese AbschluBverse mit einem starken Auftakt, der - wegen der unmittelbar folgenden Hebung - zu einer Verzögerung beim sprechen führt. 1

Тот/незнаком с небесными властями

Der/kennt euch nicht, ihr himmlischen Mächte

Нет/на земли проступка без отмиенья

Denn/alle Schuld rächt sich auf Erden

Der Harfner scheut sich gleichsam, seine ungeheuerlichen Anklagen auszusprechen, er zögert, formuliert seine für sich - und auch für alle übrigen Menschen - als guiltig erkannte Wahrheit nur stockend. Aber gerade dadurch wecken seine Worte die besondere Aufmerksamkeit der Hörer.

Die bei Goethe folgenden Daktylen jeweils in der zweiten Zeilenhälfte ("himmlischen" und "rächt sich auf") gibt Tjutčev durch tonschwache Jamben wieder ("nebesnymi" und "prostupka bez").

Durch diese Abweichungen vom alternierenden VersmaB bleibt die Geschlossenheit der Verse auch im Russischen gewahrt; gleichzeitig wird die pointierte Aussage der Schlubverse unterstrichen.

Trotz der bemerkenswerten Sorgfalt, mit der Tjutčev die deutschen Verse übersetzt hat, trotz der Gedankentreue und formalen Genauigkeit seiner wiedergabe,

1 Bei dem Metrum der russischen Verse handelt es sich nach $K$. Pigarev um fünffüßige Jamben. Er übersieht bei seiner Analyse jedoch, daß rhythmische Sinnbetonung und metrische Gliederung im Widerspruch zueinander stehen. Vgl. K. PIGAREV, Tjutčev perevodčik Gete, a.a.0., S. 96. 
können wir uns André von Gronickas uneingeschränkt positivem Urteil nicht bedingungslos anschlieben. 1

So ist gleich in der ersten Gedichtzeile die semantische Unkorrektheit bei der wiedergabe der biblisch klingenden Formulierung "sein Brot mit Tränen essen" ${ }^{2}$ irritierend. Diese Wendung, die soviel bedeutet wie "sein Brot weinend essen", ubersetzt Tjutłev mit der befremdich wirkenden Ausdrucksweise "mit Brot seine Tränen essen".

Die voller Erregung ausgerufene Anklage des Harfners am SchluB der ersten Strophe

Der kennt euch nicht, ihr himmlischen Mächte

formuliert als direkte Anrede, verwandelt TjutČev in einen Bericht über die himmlischen Mächte:

Tот неэнаком с небесньми властями

Die Figur der Anklage setzt sich bei Goethe in den folgenden zeilen fort. Vorwurf türmt sich auf Vorwurf. Einsilbige Worte wie "ihr" und "dann" werden gegen das Metrum in die Hebungsstufe genommen. Die dadurch beim Sprechen eintretenden Zäsuren verlangsamen insgesamt das Sprechtempo und unterstreichen so die Empörung des Harfners.

1 A. von Gronicka lobt nicht nur die Gedankentreue und Gefühlstiefe von Tjutčevs Wiedergabe, sondern für inn sind die russischen Verse auch ein kleines Meisterwerk an Stimmigkeit in allen formalen Einzelheiten des Originals. Vgl. A. V. GRONICKA, The Russian Image of Goethe, a.a.0., S. 158.

2 Vgl. Lutherbibel Psalm 6,7: "Ich bin so muide vom Seufzen;/ich schwerme mein Bett die ganze Nacht/und netze mit meinen Tränen mein Lager." Und Psalm 80,6: "Ou speisest sie mit Tränenbrot/und tränkest sie mit einem großen Krug voll Tränen." Hierzu auch: DEUTSOHES WÖRTERBUCH. Von JakOb Grimm und wilnelm Grimm. 16 Bde. und 1 Quellenverzeichnis. Leipzig 1854-1971. Hier Bd. 11, Abt. 1,1. Sp. 414 . 
Auch hier schwächt Tjuttev die Spontanität oer Beschuldigungen $a b$, wiederum tritt an die stelle der direkten Rede die Erzählung über das unerforschliche spiel der gnadenlosen Himmel smächte. ${ }^{1}$

Они нас в бытие манят -

Заводят слабость в преступленья,

и после муками казнят:

Нет на земли проступка без отмиенья! ${ }^{2}$

Trotz der aufgezählten Schwächen hinterläßt Tjutčevs übersetzung einen überwiegend positiven Gesamteindruck. Mit "Kto s chlebom slez svoich ne el" liefert Tjutzev eine Goethe-Wiedergabe, bei der er sich eng an die vorlage hält und - im Gegensatz zu vielen anderen seiner Goethe-Übersetzungen - keine eigenen Bilder und Gedanken einfließen läßt. Insofern kann man diese wiedergabe mit gutem Grund als ein "russisches Spiegelbild des deutschen Gedichts" ${ }^{3}$ bezeichnen.

1 Hier bietet sich ein Vergleich mit der Übersetzung Marina Cvetaevas aus dem Jahre 1941 an. Inr gelingt es besser, die unmittelbare Empörung des Harfners auszudricken. Die entscheidenden Strophen lauten:

Kto s plačen chleba ne vkušal,

Kto, placen provodiv svetilo,

Ego slezami ne vstrečal,

Tot vas ne znal, nebesnye sily!

Vy zavlekaete nas $v$ sad, Gde obol' Cenija i Cary:

Zatem vvergaete nas $v$ ad:

Net pregresenija bez kary!

Abgedruckt in: M. CVETAEVA, Stichi zarubežnych poétov $v$ perevode. Moskau 1967 (Mastera poètiXeskogo perevoda vyp. 7). S. 32.

2 Sie locken uns ins Dasein,/Sie führen die Schwäche zu Verbrechen,/ Und nachner strafen sie mit Qualen:/Es gibt auf der Erde kein Vergehen ohne Rache!

3 Vgl. A. v. GRONICKA, The Russian Image of Goethe, a.a.0., S. 158159. 


\subsubsection{Zusamenfassung}

Im Mittelpunkt des Interesses steht bei Žukovskijwie auch bei Tjutter Goethes Liebes- und Naturlyrik. Jedoch abgesehen von dem berühmten Lied Mignons "Kennst du das Land" haben die beiden russischen Dichter aus diesem Themenkreis unterschiedliche Vorlagen gewählt.

Während sich Žukovskij an bekannten Gedichten wie "An den Mond", "Schäfers Klagelied" und "Neue Liebe, neues Leben" versucht, übersetzt TjutZev das weniger verbreitete "Nachtgedanken" sowie die einem Drama entnommenen verse "Freudvoll und leidvoll".

Vielfältig sind die von Zukovskij gewählten Vorlagen der gedanklich orientierten Lyrik Goethes. Sowohl formal wie auch inhaltich bieten die übersetzungen ein breites Spektrum der Goetheschen Weltschau.

Gedichte der klassischen Zeit des deutschen Dichters sowie der späten Schaffensperiode greift Zukovskij nicht auf. Die Wiedergaben aus dem Themenkreis "Künstler und Weltanschauung" entstammen sämtlich Goethes erster Lebenshälfte.

"Die Freuden" ist ein Jugendgedicht des deutschen Dichters, noch im Stil der Anakreontik verfaBt, "Der Wandrer" sowie "Der Adler und die Taube" entstammen der Zeit des Sturm und Drang, "Meine Göttin" verfaßte Goethe in seinen weimarer Lebens Jahren.

Bei dem von Tjutčev übersetzten "Hegire" aus dem "WestÖstlichen Divan" handelt es sich demgegenüber um die Selbstaussage des alternden Goethe. Jedoch im Gegensatz zur eigentlichen Alterslyrik stellt sich der deutsche 
Dichter mit seinem "West-óstlichen Divan" bewuBt und gewollt in eine dichterische Tradition, seine Begegnung mit Hafis ist das letzte wirklich produktive Zusammentreffen Goethes mit fremder Dichtung.

Seine Alterslyrik entwickelt Goethe demgegeniuber nahezu ausschlieblich aus sich selbst heraus, verbindungen zur Lyrik seiner dichtenden Zeitgenossen, wie sie in seiner Jugendlyrik noch vorhanden sind, oder zu historischen Vorbildern des Altertums, wie Goethe sie vor allem in seiner klassischen zeit pflegt, bestehen kaum mehr.

In "Hegire" thematisiert Goethe seine dichterische Weltauffassung, bereits in diesem Einleitungsgedicht des "West-Östlichen Divan" entfaltet er einen geistigen Raum von enormer weite. Inn kann nur gestalten, wer bereits auf ein langes reiches Leben mit einer fülle von Erfahrungen zurückblicken kann.

Es ist bemerkenswert, daß TJutčev diese Verse eines Alternden, zu denen selost die meisten deutschen Leser nur schwer Zugang finden konnten, bereits als Fünfundzwanzigjähriger ins Russische ubersetzt. Dabei gelingt es dem noch Jugendlichen Dichter, die geistige Weite des originals dem russischen Leser zu erhalten.

Aus dem Themenkreis "Schicksal und Einsamkeit" haben Žukovskij und Tjutčev je zwei Gedichte libersetzt, als eine Vorlage wurde dabei von beiden Dichtern Goethes "Wer nie sein Brot mit Tränen aß" gewählt.

Tjutčevs zweiter übertragung liegt ebenfalls ein Lied aus "Wilhelm Meister" zugrunde, und zwar "Wer sich der Einsamkeit ergibt". Während Tjutčev letzteres frei übersetzt das zugrundeliegende Thema weitgehend unab- 
hängig von der Vorlage ausgestaltet, gehört seine übersetzung von "Wer nie sein Brot mit Tränen $a \beta$ " zu den genauesten und insgesamt gelungensten Goethe-wiedergaben des russischen Dichters. Tjutłev hält sich stilistisch, formal und auch inhaltlich exakt an die vorlage.

Zukovskijs wiedergabe von "Trost in Tränen" ist insofern eine beachtenswerte Leistung, als er - obwohl sich das Thema des deutschen Gedichts geradezu dafür anzubieten scheint - nicht in übertriebene sentimentalität abgleitet. Trotz der stärkeren emotionalen Färbung der übersetzung gelingt es dem russischen Dichter, die straffe Dialogführung und die sprachlichen Kontraste wiederzugeben. 


\subsection{BESONDERE GATTUNGEN}

2.2.1. Balladen

\subsubsection{Die Ballade als Gattungsbegriff}

Die Wurzeln des Begriffs der Ballade, wie er in Deutschland um 1770 heimisch wurde, liegen in England, wo das Wort zum ersten Mal auch eine stofflich-thematische Bedeutung gewinnt. Es verkörpert meist ein volkstülichepisches Lied, in dem ungewöhnliche Ereignisse in knapper Form dargestellt werden. 1

Der Aufstieg der deutschen Kunstballade ist unmittelbar verknüpft mit dem sich allgemein abzeichnenden $A D-$ stieg der Volksballade. Diese bleibt jedoch - besonders seit Herder - als stilistisches vorbild von großer Bedeutung. So wird in Bürgers "Lenore" (1773) - mit ihr wird häufig der Beginn der Geschichte der deutschen Kunstballade festgelegt ${ }^{2}$ - eine volksballadische Vorlage ("Totenritt") in die damalige Gegenwart gerückt.

Es stellt sich die grundlegende Frage nach dem Gattungscharakter der Ballade, also danach, welche wesensmerkmale eine Dichtung eindeutig als Ballade ausweisen.

Nach Rudolf Wildbolz ist für die gattungsmäßige Bestimmung der Ballade "ihre wesentliche Teilhabe an den drei Grundmöglichkeiten der Dichtung: der lyrischen, epischen und dramatischen" entscheidend. Diese drei

1 Vgl. R. WILDBOLZ, Art. Kunstballade. In: RL. Bd. 1. S. 902-909. Hier S. 902.

2 Zur Problematik einer genauen Festlegung der Anfänge der neueren Kunstballade in Deutschland vgl. H. LAUFHUTTE, Die deutsche Kunstballade. Grundlegung einer Gattungsgeschichte. Heidelberg 1979 (Beiträge zur neueren Literaturgeschichte Folge 3, Bd. 43). S. 15-19. 
Möglichkeiten erscheinen in der "eigentülich synthetischen Form der Ballade" vereinigt. 1

Auf dieses Merkmal hat bereits Goethe hingewiesen:

Das Geheimnisvolle der Ballade entspringt aus der Vortragsweise. Der Sänger nämlich hat seinen prägnanten Gegenstand, seine Figuren, deren Taten und Bewegung so tief im Sinne, daB er nicht weiB, wie er inn ans Tageslicht fördern will. Er bedient sich daher aller drei Grundarten der Poesie; ... er kann lyrisch, episch, dramatisch beginnen und, nach Belieben die Formen wechselnd, fortfahren, zum Ende hineilen oder es weit hinausschieben. Der Refrain, das Wiederkehren ebendesselben Schlubklanges, gibt dieser Dichtart den entscheidenden lyrischen Charakter. ... Übrigens liebe sich an einer Auswahl solcher Gedichte die ganze Poetik gar wohl vortragen, weil hier die Elemente noch nicht getrennt, sondern wie in einem lebendigen Ur-Ei zusammen sind ..." 2

Episch ist die Ballade meist der Darbietungsform nach, indem hier erzählt wird, lyrisch ist sie, wenn stimmungsgehalte uberwiegen und liedhafte bzw. musikalische Elemente durchbrechen, und dramatisch durch die Hinordnung auf einen Konflikt und seine meist tragische Lösung. Die Ballade ist knapp gehalten, das Geschehen dicht gedrängt. Der Höhepunkt, und damit das Ende, kommt oft uberraschend. Die Eindringlichkeit der Schilderung wird durch die Sparsamkeit der Ausdrucksmittel hervorgerufen. 3

In der deutschen Dichtung haben sich nach Thema und Grundhaltung verschiedene Balladentypen herauskristallisiert, wobei jedoch Mischungen aller Art auftreten und daher eine systematische Einteilung kaum möglich ist. Zwei Hauptrichtungen - in deren Umkreis wiederum mannigfaltige Spielarten auftreten - heben sich besonders hervor: die mysteriöse Ballade sowie die Heldenballade.

1 Vgl. R. WILDBOLZ, a.a.0., S. $902-903$.

2 Zitiert nach: E. STAIGER, Goethe. 3 Bde. Zürich - Freiburg i. Br. 1952-59. Hier Bd. 2. S. 304-305.

3 Vgl. R. WILDEOLZ, a.a.0., S. 903; F.W. NELNANN, a.a.0., S. 6-7.

4 Vgl. R. WILDOOZ, a.a.0., S. 903. 
In der russischen Literatur werden die vielfältigen Spielarten der Ballade mit unterschiedlichsten Begriffen bezeichnet. Gedichte von zweifelsohne balladenhafter Art tragen die Bezeichnungen "Romanze" ("romanc"), "Legende" ("legenda"), "Mär" ("skazka"), "Lied" ("pesn"" oder "pesnja"), "Chronik" ("byl"") und daruber hinaus auch "poéma" und "duma". Oer besondere Name bezeichnet dabei meist auch eine bestimmte spielart des ubergreifenden Gattungsbegriffs "Ballade".

Aus der Verwendung der Bezeichnung "ballada" im Russischen läbt sich die Existenz eines Genrebewubtseins im engeren sinne nicht entnehmen. So stellen die ersten Dichtungen, die als "Balladen" veröffentlicht werden, zumeist typische Romanzen dar, und folglich fallen zu Anfang der russischen Kunstballade die romanzenhaften Züge besonders stark ins Gewicht. 2

Im Gegensatz zur deutschen Kunstballade wurzelt die russische Balladendichtung nicht unmittelbar in der russischen Volksdichtung. Bei der russischen Kunstballade handelt es sich demgegenuber um eine Lehngattung, deren Entstehung und Entwicklung sich unter dem Einflub der Wiederbelebung der Volksdichtung, vor allem des Volksliedes, in Deutschland vollzieht. 3

1 Vgl. F.w. NEUMAN, a.a.0., S. 2-3; G. sahulz, a.a.0., S. 33.

2 Zur genawen Differenzierung der Begriffe "Romanze" und "Ballade" vgl. G. soulz, a.a.0., S. 34-37.

3 Diese wiederbelebung der deutschen Volksdichtung murde von Thomas Percys Samlung "Reliques of Ancient English Poetry" und der durch sie eingeleitete "ballad-revival" in England ausgelöst. Vgl. hierzu HA I, S. 506; R. WILBOLZ, a.a.D., S. 803. 
In Rubland beginnt sich dieser EinfluB um die Wende vom 18. zum 19. Jahrhundert geltend zu machen. Zuerst ruft er Nachahmungen fremder Dichtungen hervor, später beginnen jedoch auch Werke zu entstehen, die ihre Grundlagen in der eigenen Volksdichtung haben. 1

2.2.1.2. Zukovakije Übertragungen Goethescher Balladen 2.2.1.2.1. Žukovskijs Bedeutung für die Entwicklung der Balladendichtung in RuBland

Ihren ersten Höhepunkt erreicht die Verbreitung balladischer Dichtung in RuBland zu der Zeit, als ihre Entwicklung maBgeblich durch Žukovskij geprägt wird. Nie wieder gewinnt die Ballade einen derartigen Einflub auf die literarische Gesamtentwicklung wie in diesen Jahren.

In den Augen seiner Zeitgenossen gilt Žukovskij vorwiegend als Verfasser von Balladen, Konstantin $N$. Batjuskov bezeichnet inn in einem seiner verse als "balladnik" schlechthin:

Прости, балладник моя,

Белева мирныя житель!

да будет Феб с тобоя,

наш давния покровитель! 2

1 Die drei wesentlichen Wurzeln der russischen Kunstballade liegen nach Gisela Schulz in der westeuropäischen Romanzendichtung, der Oseianischen Dichtung sowie in der Volkedichtung begründet. Vgl. G. SorvLZ, a.a.0., S. 34-41.

2 Abgedruckt in: K.N. BATJǔKKOV, Opyty $v$ stichach $i$ proze. Hrsg. I.M. Semenko. Moskau 1977. S. 275. 
Bei Zukovskijs Balladendichtung handelt es sich uberwiegend um übersetzungen oder Nachdichtungen entsprechender vorlagen aus der deutschen, englischen und französischen Literatur.

Von den insgesamt zweiundvierzig Schöpfungen dieser Gattung k können lediglich fünf als originale werke Žukovskijs gelten. Für Belinskij sind es "Svetlana" (1808-1812), "Alina i Al'sim" (1814), "Achill" (18121814), "Éolova arfa" (1814) sowie "Uznik" (1819).2

Inwieweit es sich bei den beiden erstgenannten Balladen um Originalschöpfungen bzw. um Nachdichtungen handelt, bleibt wohl letztlich eine Ermessensfrage. Auf jeden Fall kann - trotz der deutlich spürbaren Umprägung und persönlichen Gestaltung Žukovskijs - eine gewisse Beziehung "Svetlanas" zu Bürgers "Lenore" und "Alina und Al'sims" zu F.-A. Paradis de Moncrifs "Les constantes

1 Einschließlich der Wiedergaben von Schillers "Der Handschuh", "Der Kampf mit dem Drachen" und "Der Gang nach dem Eisenharmer", die in der vierbändigen Zukovokij-Ausgabe unter "Poemy i povesti" eingegrdnet sind.

Vgl. ZUKOVSKIJ II, S. 282-283, 296-300, 301-305.

2 Vgl. V.G. BELINSKIJ, Sočinenija Aleksandra Puškina. Aufsatz Nr. 2, a.a.0., S. 170-206.

3 François-Augustin Paradis de Moncrif (1687-1770), französischer schriftsteller. Näheres vgl. DICTIONAIRE des Auteurs francais. Paris 1961 (Collection Seghers). S. 275. 
amours d'Alix et d'Alexis" nicht übersehen werden. 1

Bei der überwiegenden Zahl handelt es sich jedoch eindeutig um übersetzungen. Dies macht deutlich, das Zukovskij seine Balladen nicht auf den Erwartungshorizont der Volksdichtung hin konzipiert hat; der Rückgriff auf diese Genreform muB ganz unter dem Aspekt der von inm vertretenen Kunst- und Stilauffassung gesehen werden.

Unzulänglich bleibt folglich das Urteil derjenigen zeitgenobsischen Kritiker und späteren Literaturwissenschaftler, die folkloristische Dichtung als ein Ideal ansehen, dem es in jeder Beziehung nachzueifern gilt und folglich an Žukovskijs Balladen ausschlieblich der Volksdichtung entnommene Maßstäbe anlegen. 2

$\overline{1 \mathrm{Vgl}}$. ŽKKovsKIJ II, S. 453 und 457.

Weitergehende Gruppierungen von Zukovekijs Balladen sind ebenfalls problematisch. Irina $M$. Semenko und V. Ja. Kaplinskij ordnen die Balladen nach inrem jeweiligen thematischen Hintergrund ein: Semenko unterecheidet "russische" Balladen von "antiken" und "mittelalterlichen", Kaplinekij gliedert Zukovskijs Balladen in religiöse, historische und in Liebesballaden. - Dengegenuber orientiert sich Gisela Schulz in ihren Ausfuhrungen stärker an den verschiedenen Balladentypen. Sie unterscheidet Balladen des Sturm und Drang, Liebes- und Schauerballadon von historischen, naturmagischen, religiösen und Ideenballaden. Vgl. V. Ja. KAPLINSKIJ, Zukovskij, kak perevodZik ballad. In: ZuNP 1 (1915). S. 1-25; I.M. SEMENKO, a.a.0., S. 165-224; G. SOAUL, a.a.0., S. $86-140$.

Eine eindeutige Zwordnung bestimmter Balladen ist jedoch bei allen drei Entwürfen nicht immer sinnvoll und möglich. Besonders bei Kaplinskij und Semenko kormt es zu unverständlichen Zwordnungen. So rechnet I.M. Semenko Goethes "Fischer" und "Erlkönig" zu den "mittelalterlichen" Balladen. Vgl. I.M. SEVENKO, a.a.O., S. 195.

2 Vgl. G. sanlz, a.a.o., s. 21. 
Zukovskij aber wollte und konnte nicht dichten wie das Volk. Er strebte lediglich - wie es die Nachdichtungen von Bürgers "Lenore" deutlich zeigen - nach einer uberbrückung des Abstandes zwischen volksdichtung und Bildungsliteratur. Seine Balladen sind, auch wenn sie nicht aus Volksballaden heraus entstanden sind, doch selbst als Volksballaden konzipiert. ${ }^{1}$

Žukovskij nutzt das volkstümliche Genre der Ballade, um Menschen aus dem "einfachen" Volk zu beschreiben, Menschen, deren Gefühlsleben in Rubland gerade erst durch Karamzin entdeckt worden war. 2

Žukovskijs erstes dichterisches Vorbild für seine Balladenschöpfungen ist Gottfried August Bürger, der "Begründer der ernsten Ballade" ${ }^{3}$ in Deutschland.

Der russische Dichter bewundert Bürgers Balladen besonders, weil sie den engen Rahmen kanonisierter Poesie sprengen und ihrem Gehalt wie auch ihrer sprachlichen Gestalt nach stark volkstümliche Züge aufweisen. In der volkstümlich-einfachen Erzählform sieht er seine eigenen sprachlichen und dichterischen Intentionen verwirklicht,

1 Die U.a. von Marcelle Ehrhard vorgebrachte Kritik, Žukovskij sei es weder in "Ljudinila" noch in den "Dvenadcat" spjašcich dev" gelungen, den volkstimlichen Ton zu treffen, weil er sich nicht mit der "bäwerlichen Seele" ("l'âme paysanne") habe identifizieren können, trifft somit nicht den Kern des Problems. Vgl. M. EHAWRD, a.a.O., S. 225; G. sorulz, a.a.O., S. 113-114.

2 Beruhmt murde der Satz "Ibo i krest'janki ljubit" umejut" aus der Novelle "Bednaja Liza". Abgedruckt in: N.M. KARANZIN, Izbrannye sočinenija $v$ dvuch tomach. Moskau-Leningrad 1964. Hier Bd. 1. S. $605-621$. Vgl. G. satulz, a.a.0., S. 59.

3 Vgl. den Titel der Darstellung von Valentin Beyer: V. BEYER, Die Begründung der ernsten Ballade durch G.A. Bürger. Straßburg 1905 (Quellen und Forschungen 97 ). 
Zukovskij schätzt Bürger als "einfachen Erzähler". 1

Der erste Versuch des russischen Dichters in der Gattung der Ballade stammt aus dem Jahre 1804. Zu dieser zeit arbeitet er an der übersetzung von Bürgers Pagenballade "Lenardo und Blandine".

Zunächst glaubt Žukovskij wohl, in dieser Ballade eine Vorlage gefunden zu haben, die seinen eigenen Intentionen entgegenzukommen scheint. In "Lenardo und Blandine" erzählt Bürger im volkstümlichen Ton der Romanze die Geschichte einer Liebe, die keine gesellschaftlichen Rangunterschiede kennt, jedoch aufgrund engstirniger vorurteile der Umgebung zum Scheitern verurteilt ist und ein tragisches Ende nimmt.

Žukovskij bricht seine fast wörtliche übersetzung "Blandina vzdychala, Rinal'do vzdychal" jedoch nach der funften strophe ab. Vermutlich ist inm klar geworden, daB Burger in dieser mit "Rohheiten wie Schlüpfrigkeiten überladenen Pagenballade" 2 vom Sentimentalen ins Geschmacklose abzugleiten droht. 3

Seine eigentliche Balladendichtung beginnt Žukovskij mit der Bearbeitung von Bürgers "Lenore" (1774).

In der grundsätzlichen Tendenz stimmen Žukovskijs Nachdichtungen "Ljudmila" und "Svetlana" mit der deutschen vorlage uberein, in nicht unwesentlichen Einzelheiten läbt der russische Dichter Jedoch eine spezifische

1 Folglich würdigt Žukovskij besonders die Darstellung des Numinosen in der Balladendichtung Bürgers. Eine weitergehende Darstellung der Vorstellung des russischen Dichters von der Bedeutung des Numinosen als genrepragendes Kriterium der Ballade vgl. G. SatulZ, a.a.0., S. $86-89$, S. 113.

2 F.W. NELMAN, a.a.0., S. 54.

3 Vgl. ebd.; G. SCHulz, a.a.o., s. 88. 
poetische Intention erkennen. So verlegt er die Handlung von "Ljudmila" in das RuBland der Livländischen Kriege, russifiziert somit den nistorischen Hintergrund. 1

Explizit wird Žukovskijs Intention dadurch, daß er seine Nachdichtung zwar als "Podražanie Bjurgervoj 'Lenore". ausweist, inr aber gleichzeitig den programmatischen Untertitel "Russkaja ballada" verleint. 2 Žukovskijs Ballade wird diesem selbst gestellten Anspruch gerecht. Er verwandelt Bürgers Lenore in eine "Heldin der russischen Literatur". 3

Nach Karamzins "Raisa" (1791) war mit "Ljudmila" das Musterbeispiel einer russischen Ballade geschaffen, ein Beispiel, das nicht zuletzt aufgrund der popularitat, die es erlangte, ganz entscheidenden Einflub auf die Entwicklung der Balladendichtung in RuBland nahm.

Die Balladen des Sturm und Drang, repräsentiert durch G.A. Bürger, verweisen ŽukovskiJ auf den Typ der reinen Liebesballade. Hier ergeben sich für inn neve Möglichkeiten, volkstüliche stilmomente in die Kunstdichtung zu integrieren. Von besonderer Bedeutung für Žukovskij ist dabei die Begegnung mit den Liebesballaden Ludwig Unlands, die - entstanden unter dem EinfluB des "Knaben wunderhorn" - den schlichten Ton der Volksdichtung bewahren.

In der zweiten Periode seiner Balladendichtung verlagert Žukovskij das Schwergewicht auf die sowohl in der Ballade des Sturm und Drang wie auch in der Liebes-

1 Bürgers Ballade spielt dengegenuber in der dem Siebenjährigen Krieg folgenden Zeit.

2 Vgl. ŽUKOVSKIJ II, S. 451; I.M. SEMENKO, a.a.O., S. 17-18; G. Sorvlz, a.a.0., S. 90.

3 G. SaluLZ, a.a.O., S. 91. Kennzeichnenderweise ordnet I.M. Sermenko "Ljuomila" und "Svetlana" den "russischen" Balladen zu. Vgl. I.M. SEMENKO, a.a.O., S. 165. 
ballade thematisch bereits angelegte Schaverballade. Im Mittelpunkt des Interesses stehen nun die Balladen Robert Southeys.

Diese lassen Zuukovskij erkennen, wie das Numinose, dessen Bedeutung inm schon bei Bürger klar geworden ist, voll zur Geltung gebracht werden kann. Die schaurigen Fabeln dieser Balladen dienen nicht nur der Motivierung des volkstümlichen Erzählstils, sondern sollen auch den stil als solchen aufdecken und dem Leser kenntlich machen. 1

Auf die von Southey dominierte Periode folgt Žukovskijs Hinwendung $z u$ den historischen Balladen Uhlands. Bereits ein Jahr nach Erscheinen der ersten deutschen Gesamtausgabe von Uhlands Gedichten im Jahre 1815 arbeitet Žukovskij an der übersetzung der kurzen liedhaften Balladen "Die Rache" ("Mß̌̌enie"), "Harald" ("Garal"d") und "Die drei Lieder" ("Tri pesni").

Diese schnelle Rezeption weist auf eine besondere verwandtschaft beider Dichter in der kunstlerischen Vorstellung nin. 2

1 Die Wirksankeit dieses Verfahrens zeigt sich deutlich am Boispiel von Zukovskijs "Ballada, $v$ kotoroj opisyvaetsja, kak odna staruăka echala na černom kone vơvoem i kto sidel vperedi". Vgl. nierzu G. Saviz, a.a.0., S. 115-117.

2 Nach Gisela Schulz kommen diese Balladen Žukovskijs eigenen Bestrebungen in doppelter Hinsicht entgegen. Sie sind "poetisch in ihrem Verhältnis zur Vergangenheit, ohne dabei das Geschehen mit jenem sagenhaften 'poetischen Hauch' zu Uberziehen, der für den sentimentalistisch-romantischen Historiemus so charakteristisch ist" und gleichzeitig sind sie "lyrisch in inrer Gestaltung der volkstimlichen Naivität, onne dabei in das Ausmalen des Sentimental-Gefühlvollen oder Magisch-Stimmungsvollen zu verfallen." G. SOHUZ, a.a.O., S. 117. 
Noch einmal beschäftigt sich Žukovskij in den Jahren 1831 und 1832 intensiver mit der Balladendichtung Uhlands. In diesen Jahren übersetzt er neben der Liebesballade "Durand" ("Alonzo") und der Schaverballade "Junker Rechenberger" ("Rycar" Rollon") die beiden liberwiegend religiös geprägten Balladen "Graf Eberhards WeiBdorn" ("Staryj rycar"") und "Der Waller" ("Bratoubijca"). Ebenfalls aus dieser Zeit stammen Žukovskijs übersetzungen der nistorischen Balladen "Roland Schildträger" ("Roland oruženosec") und "König Karls Meerfahrt" ("Plavanie Karla velikogo").

Vorbereitet durch die frühe Beschäftigung mit Uhland wendet sich Žukovskij im Jahre 1818 den naturmagisshen Balladen Goethes zu.

Im Gegensatz zu seinen bis dahin wiedergegebenen Balladen, die entweder auf eine Nachahmung oder Nachschöpfung der Volksdichtung zielen, ist demgegenüber in den Balladen vom "Fischer" und "Erlkönig" die Umsetzung von Volksdichtung in Kunstdichtung beabsichtigt."

Die beiden naturmagischen Balladen Goethes, die sowohl im Visuellen als auch im Akustischen nach Anschaulichkeit streben, ermöglichen es Žukovskij, seine ausgeprägten lyrischen Fähigkeiten zur Geltung zu bringen. 2

über Uhland und Goethe führt Žukovskijs Weg schließlich auch zur Balladendichtung Schillers, zu der er zunächst keinen Zugang hatte finden können. Nach anfänglich vorsichtigen Versuchen - bereits 1809 übersetzt der russische Dichter das Rollengedicht "Kassandra",

1 Vgl. W. KAYSER, a.a.0., S. 109-120, bes. S. 119-120. Zur genauen Differenzierung von Unlands und Goethes Balladenschaffen vgl. G. SONLZ, a.a.0., S. 123-125.

2 Vgl. ebd. S. 125. 
und es folgen bis 1818 drei weitere übertragungen ${ }^{1}$ - beginnt sich Žukovskij ab dem Jahre 1825 intensiv mit Schillers Balladendichtung auseinanderzusetzen.

Deutlich im Gegensatz zur naiven volksballade und zur numinosen Kunstballade, bei denen die Macht des Irrationalen uberwiegt, ist Schillers Balladendichtung bewubt als künstlerische verkörperung von Ideen geschaffen und stimmt somit nach Art und Sinn weitgehend mit dem Typ von Goethes Ideenballade uberein.

Im Mittelpunkt steht nicht der passiv getriebene Mensch, seinem Schicksal bedingungslos ausgeliefert, sondern der aktiv handelnde "Held", dessen wille und" Selbstuberwindung den Vorrang des Ideellen und willensmäßigen über das individuelle Schicksal verkörpert. Schiller verwendet die Gattung der Ballade zur Darstellung der sittlichen welt, z.B. des Kampfes des edlen Menschen mit den Naturgewalten. 2

Im Gegensatz zu Goethe finden sich bei Schiller zahlreiche antike Balladenmotive, die auch von Zukovskij aufgegriffen werden. Neben seinen frühen wiedergaben von "Kassandra" und den "Kranichen des Ibykus" libersetzt Žukovskij "Das Siegesfest" ("Toržestro pobeditelej", 1828), "Der Ring des Polykrates" ("Polikratov persten"." 1831), die "Klage der Ceres" ("Žaloba Cerery", 1831) sowie "Das Eleusische Fest" ("Élevzinskij prazdnik, 1833). 3

1 "Die Kraniche des Ibykus"/"Ivikovy Žurav11" (1813), "Der Graf von Habsburg"/"Graf Gabsburgskij" (1818) und "Ritter Toggenburg"/ "Rycar' Togenburg" (18'18).

2 Vgl. R. WILDOOLZ, a.a.0., S. 905.

3 Näheres zu Žukovskijs "antiker" Balladendichtung vgl. auch V.G. EELINSKIJ, Sočinenija Aleksandra Pǔ̌kina. Aufsatz Nr. 2, a.a.0., S. 200-207. 
Aber auch Schillers Ideenballaden mit mittelalterlichem Hintergrund finden Zukovskijs Beachtung. So übersetzt der russische Dichter bereits 1818 die Balladen vom "Grafen von Habsburg" ("Graf Gabsburgskij") und "Ritter Toggenburg" ("Rycar" Togenburg"), später fügt er die wiedergaben von "Der Taucher" ("Kubok", 18251831), "Der Handschuh" ("PerCatka", 1831), "Der Gang nach dem Eisenhammer" ("Sud boß̌ij", 1831) und "Der Kampf mit dem Drachen" ("Sraǩenie s zmeem", 1831) hinzu.

Da Schillers Balladendichtung Žukovskij nur in geringem AusmaB die Möglichkeit bietet, bestimmte Sprach- und stilformen zu realisieren, wendet sich der russische Dichter von diesen eindeutig von architektonischer Klarheit und dem Übergewicht rationaler Ideen bestimmten Balladendichtung ${ }^{1}$ wieder mehr solchen Balladen zu, die weniger an den Verstand als an das Gefunl appellieren.

So folgt auf die Orientierung an der Ideenballade die für Zukovskijs späte Schaffensperiode signifikante Hinwendung zur spezifisch religibsen Ballade. ${ }^{2}$

Allein im Jahre 1831 übersetzt Žukovskij drei Balladen dieser Art: "God's Judgement on a Wicked Bishop" ("Sud božij nad episkopom") und "Queen Orraca and the Five Martyrs" ("Koroleva Uraka i pjat" mučenikov") von Southey, sowie Walter Scotts "Gray Brothers" ("Pokajanie"). Es folgen die bereits erwähnten wiedergaben von unlands "Graf Eberhards WeiBdorn" ("Staryj rycar"", 1832) und "Der Waller" ("Bratoubijca", 1832).

1 Vgl. R. WILEOUz, a.a.0., S. 905.

2 Zur Problematik einer eindeutigen Definierung dieses Balladentyps vgl. G. Satulz, a.a.O., S. 135-136. 
Ihren Höhepunkt erreicht die Verbreitung der russischen Ballade - einschlieblich der von fremdsprachiger Dichtung entlehnten - zwischen 1830 und 1840 .

Nach einem beträchtlichen Absinken des Umfangs wie auch des Niveaus balladischer Dichtung in dem folgenden Jahrzehnt, bedingt durch das Ableben derjenigen Dichter, die neben Zukovskij bedeutenden Anteil an balladischer Dichtung in RuBland hatten, 1 gewinnt die Ballade erst in den füfziger Jahren wieder neuen Zuwachs.

Das Gesamtbild ist jedoch uneinheitlich; es wird bestimmt durch das Nebeneinander von traditionsgebundener und neuartiger Balladendichtung. ${ }^{2}$ Bestimmte Balladentypen, wie z.B. die Liebesballade, ziehen in dieser Zeit verstärktes Interesse auf sich.

Vor allem bei der historisch orientierten Heldenballade werden gegenüber dem Bestand der Pǔkinzeit Ansätze zu Neuem sichtbar. Während in den vierziger Jahren kaum geschichtliche Balladen entstanden sind, nimmt diese Untergattung seit der Mitte des folgenden Jahrzehnts an Bedeutung und Umfang ständig zu. Die Zahl der Übersetzungen ist gering, Originalballaden stehen nun im Mittelpunkt. Die Vergangenheit rückt immer mehr in das Zentrum des dichterischen Interesses, die Auseinandersetzung mit der eigenen Geschichte wird als ein Stück nationaler selbsterfahrung begriffen.

1 Neben Aleksandr S. Pušk in (gest. 1837) auch Michail Ju. Lenmontov (gest. 1841), Ivan I. Kozlov (gest. 1840), Aleksej V. Kol'cov (gest. 1842), Aleksandr I. Polezaev (gest. 1838) und Nikolaj M. Jazykov (gest. 1847). Zwar ragt die Lebenszeit Zukovskijs (gest. 1852) und Pavel A. Katenins (gest. 1853) noch ins sechste Jahrzehnt des 19. Jahrhunderts hinein, beide stehen gegen Ende ihres Lebens länst außerhalb der literarischen Entwicklung. Vgl. F.W. NELMAN, a.a.0., S. 168.

2 Vgl. F.W. NELMANN, a.a.O., S. 283. 
Klassische Balladenstoffe, wie das westeuropäische Mittelalter oder die griechisch-römische welt verlieren an Bedeutung. Letztlich isoliert bleiben Schiller-übersetzungen wie Mejs "Graf Ebergard Grejner", 1857 ("Graf Eberhard Greiner") oder TJutלevs "Pomniki", 1850/51 ("Das Siegesfest"). Neben dem Hauptstrom der Entwicklung liegen ebenso Balladen aus fremdländischen stoffkreisen wie Z.B. Karolina K. Pavlovas "Nočleg Vitikinda" (1858) oder Majkovs "Savonarola" (1851).

Das erwachte historische Selbstbewubtsein in RuBland führt demgegenüber zu einer immer bedeutender werdenden Konzentrierung auf die eigene nationale vergangenheit.

Der weg zur selbständigen Nationalballade führt dabei sowohl uber das Heldenlied und die Byline der volksdichtung ${ }^{1}$ als auch iber das geschichtliche Lied.

In letzterem werden bedeutsame historische Ereignisse der Vergangenheit thematisiert, $2 . B$. der polnischlitauische Krieg in Aleksej Tolstojs "Noč. pered pristupom" (um 1840), die siegreiche Schlacht Aleksandr Nevskijs im Jahre 1240 gegen die Schweden in Mejs "Aleksandr Nevskij" (1861), oder die oramatische Auseinandersetzung zwischen Peter dem GroBen und seinem Sohn Aleksej in K.K. Slučevskijs "O careviče Aleksee" (veroffentlicht 1881). 2

1 So faßt Lev A. Mej in die überwiegend epische form der Byline vor allem Inhalte aus der mittleren und neueren russischen Geschichte; 2.B. in "Spasitel"" (1857), "Pesnja pro knjaginju UI'janu Andreevnu Vjazemskuju" (zwischen 1857 und 1858) und "Pesnja pro Dojarina Evpatija Kolovrata" (1859). Ausflihrliche Erläuterungen zum historischen Hintergrund der beiden zuletzt genannten Bylinen vgl. L.A. MEJ, Izbrannye proizvedenija. Hrsg. K.K. Buchme Jer. B8P. Leningrad 1972. S. 181-182 und 208-211.

2 Vgl. F.W. NEUMAN, a.a.0., S. 224. 
Auf dieser Grundlage entwickelt sich ein spätes wiederaufblinen der russischen Ballade in den sechziger und siebziger Jahren.

Wie seinerzeit die Hochblute der Balladendichtung in RuBland uberwiegend an den Namen eines einzigen Dichters geknüpft ist - an den Žukovskijs -, so ist inr zweites Aufleben ebenfalls an die Begabung eines einzelnen Dichters gebunden - an die Aleksej K. Tolstojs. ${ }^{1}$ Er ist es, der die nationalgeschichtliche Ballade in inrer reinen Form begründet.

Tolstojs bevorzugter stoffkreis entstammt der russischen und slavischen Geschichte, ein häufig wiederkehrendes Thema seiner Balladen ist 2.B. die urkundich bestens belegte Epoche Ivan Groznyjs. 2 Erst später wendet er sich auch solchen historischen Begebenheiten zu, die weniger gut durch die Forschung ausgeleuchtet waren, wie z.B. die Zeit der Kiever Rus'. 3

Neben A.K. Tolstoj als dem wesentlichen Schöpfer der russischen Ballade steht Nikolaj A. Nekrasov, dessen "realistische Balladen" ebenfalls ihren festen Platz in der Entwicklungsgeschichte der russischen Ballade haben. 4

1 Vgl. zu Tolstojs Balladendichtung: I. JAMPOL'SKIJ, A.K. Tolstoj. In: A.K. Tolstoj, Stichotvorenija. Car' Fedor Ioannovič. Hrsg. I. Jampol'skij. MBP. Leningrad 1952. S. 5-82. Hier S. 38-46.

2 Diese Zeit bildet den Hintergrund z.B. für "Vasilij Šibanov" (um 1840, Erstoruck 1858), "Starickij voevoda" (Erstoruck 1858) und "Knjaz' Michajlo Repnin".

3 Vgl. hierzu die Balladen "Pesnja o Garal'de i Jaroslavne" und "Tri poboisca", beide 1869. Den Stoff dieser Balladen bilden die Schicksale von Kiever Fürsten und Fürstenkindern des 11. Jahrhunderts in ihren persönlichen und politischen Beziehungen zu West- und Nordeuropa. Vgl. F.W. NEUMANN, a.a.O., S. 251;

I. JAMPQL'SKIJ, a.a.0., S. 42-43.

4 Vgl. D. TSCHIŽEWSKIJ, Literaturgeschichte, a.a.0., so. 2. S. 112 . 
Nekrasov thematisiert in seiner Balladendichtung die Unzulänglichkeit der bestehenden sozialen Ordnung ${ }^{1}$ sowie Menschenschicksale am Rande der Gesellschaft. ${ }^{2}$ In seinem späten Balladenschaffen wird die soziale frage auf eine höhere Ebene gehoben, sie erhält einen im weitesten Sinne religiösen Unterbau. Beispielnaft für diese Entwicklung ist Nekrasovs Ballade "O duuch velikich grešnikach" aus oem Jahre 1876.

wie sehr die russische Balladendichtung der sechziger und siebziger Jahre von den wenigen balladischen Dichterbegabungen abhängt, zeigt die völlige verödung dieser Gattung nach dem Tode Tolstojs und Nekrasovs.

Tolstoj, der auf der von Žukovskij geschaffenen Grundlage die vollendung der russischen Balladendichtung verkörpert, bleibt ohne Nachfolger.

Eine Breitenwirkung, wie etwa die übersetzungsballaden Žukovskijs erlangten, ist der eigentlich russischen Ballade nicht beschieden. Nur sehr wenige Balladen Pułkins und Lermontovs, daneben vielleicht noch Tolstojs "Sibanov" werden wirklich volkstülich. 3

Eine breite und tiefe Verwurzelung in der nationalen Geistes- und Literaturgeschichte konnte die russische Ballade - im Gegensatz zur Ballade in Deutschland - jedoch trotz der herausragenden Leistung einiger Dichter bis neute nicht erlangen.

1 Z.B. in "Ogorodnik" (1846), "Izvozčik" (1848) und "Sekret" (1846).

2 Z.B. in "Blagodarenie Gospodu Bogu" (1863) und "Železnaja doroga" (1864). Beide Balladen behandeln das Schicksal politisch Verbannter.

3 Vgl. F.W. NEUMANN, a.a.o., S. 286. 


\subsection{Zur Auswahl der übersetzten Goethe-8alladen}

Auf die 1816 beginnende Orientierung Žukovskijs an der Balladendichtung Uhlands folgt seine Wendung zu Goethe: im Jahre 1818 Ubersetzt er Goethes "Der Fischer" ("Rybak") und "Erlkönig" ("Lesnoj car""). Beide Übersetzungen erscheinen noch im gleichen Jahr in der Reihe "Für Wenige. Dlja nemnogich".

Die beiden von Žukovskij übersetzten Balladen Goethes gelten als die bezeichnendsten Beispiele für den "naturmagischen" Balladentypus," der unter dem EinfluB der deutschen Volksballade entstanden ist. Die Ausbildung der naturmagischen Ballade ist an den Namen Goethes geknüpft; dies ist seine eigene schöpferische Leistung. ${ }^{2}$

Im Gegensatz zur Dichtung des 18. Jahrhunderts, die ein Naturgefunl nur in Richtung auf das Ästhetische und das Religiöse hin entwickelt hatte, tritt die Natur in diesen Balladen in ganz anderer Art zu den Menschen in Beziehung, lockend, bezaubernd, beglückend und tötend. Paul Ludwig Kämpchen kennzeichnet das wesen der naturmagischen Ballade folgendermaBen:

"Dieser Typ laBt das Numinose in der Natur Erscheinung werden. Sie wird zur offenbarung eines übermenschlichen. Mit ihren ungeheuren und of geheimen Kräften gewinnt sie Gewalt über den Menschen. Natur lebt in diesen Balladen als geheimnisvolle Macht, die auf den Menschen EinfluB ausübt." 4

1 Der Begriff "natumagische Ballade" murde von P.L. Kämpchen geprägt, der "naturmagische", "religiöse" und "totenmagische" Balladen als Untergruppen der "numinosen Ballade" unterscheidet. Vgl. P.L. KÄMPOEN, Die numinose Ballade. Bonn 1930 (Mnemosyne 4); W. KAYSER, a.a.0., S. 116-120.

2 Vgl. HA I, S. 563; W. KAYSER, a.a.0., S. 116.

3 Vgl. HA I, S. 563-564.

4 P.L. KÄMPOEN, a.a.0., S. 35. 
Den Sinn für diese magischen Kräfte haben der einfache Mensch (der Fischer) und vor allem das Kind (im "Erlkönig"). Innen gegenüber steht der verstandesbetonte Mensch, im "Erlkönig" ist es der Vater. Das Ende dieser Ballade gibt dem Kind recht, aber es hat den vater nicht überzeugen können. 1

In den naturmagischen Balladen verdichtet sich die Feindseligkeit der Natur zur drohenden Gestalt, die den Menschen ergreift: ${ }^{2}$ die lockende, verderbende Macht des wassers wird zur Nixe, die Macht des um die Bäume geisternden Nebels zum Erlkönig. Dabei tritt das Geschehen an sich zurück. Der Tod des Fischers und des Knaben wird in den Schlubzeilen lakonisch mitgeteilt: "Und ward nicht mehr gesehn", "In seinen Armen das Kind war tot."

Weiterhin ist das Geschehen überzeitlich und überindividuell. "Ein Fischer" und "der Vater mit seinem Kind", diese Gestalten sind so unbestimmt wie nur möglich gehalten. Ihren Charakter lernen wir nicht kennen. ${ }^{3}$

Den AnstoB zur Übersetzung der deutschen Balladen hatte Žukovskij von seinem freund Batjuškov erhalten. In einem Brief vom Januar 1818 ermuntert dieser ŽukovskiJ zur Behandlung naturmagischer Stoffe: "Locke Dir eine Wassernymphe oder ähnliches aus der seele." 4

1 Gisela schulz formuliert es folgendermaßen: "In den Balladen herrscht die Gläubigkeit des in der Natur stehenden, von ihr erfaßten und von ihr getragenen einfachen Menschen." G. Saulz, a.a.o., S. 124 .

2 Vgl. W. HINCK, Die deutsche Ballade von Burger bis Brecht. Göttingen 1972. S. 77.

3 Vgl. W. KAYSER, a.a.0., S. 116-117; H. PRANG, Formgeschichte der Dichtkunst. Stuttgart-Berlin-Köln-Mainz 1968. S. 174.

4 K.N. BATJušKov, Sǒ̌inenija. Hrsg. P. Batjuškov. 3. Bde. St. Petersburg 1885-1887. Hier Bd. 3. S. 489. Zitiert nach: F.W. NELMAN, a.a.0., S. 68 . 


\subsubsection{3. "Der Fischer"}

In der Ballade "Der Fischer" (HA I, S. 153-154) gestaltet Goethe ein volkstüliches Motiv. Nixen und wasserfrauen, die zeitweise in menschliche Lebensbereiche eintreten, gibt es in Märchen und Volksliedern. 1

Goethes Fischer ist ein einfacher Mann, der still am ufer sitzt. Žukovskij stellt sich diesen Mann ganz anders vor:

Задумчив, над рекон

Сидит рыбак; душа полна

Прохлапноп тнинноя. 2

(ŽUKOVSKIJ II, S. 135-136)

Aus dem "feuchten weib", das sich aus dem wasser erhebt, macht Žukovskij eine "schöne Frau" ("krasavica") mit "feuchtem Haupt" ("vlažnaja glava").

Die Volkstumlichkeit der Gestalten ist in der russischen Nachdichtung verloren gegangen. 3 Ehrhard drückt

1 Vgl. M. ENNEMOSER, Goethes magische Balladen. Diss. Minster 1939. S. 62. Bezeichnend ist, daß "Der Fischer" zum ersten Mal in "Volko- und andere Lieder, in Musik gesetzt von S. v. Seckendorff", Weimar 1779, gedruckt murde. Vgl. MA I, S. 565.

2 Nachdenklich iber dem Flub/Sitzt ein Fischer; die Seele ist voll/ Von (angenehm) kühler Stille.

3 Nachdem Žukovskijs Ballade 1820 in der Zeitschrift "Syn Otečestva" gedruckt worden war, murde sie von O.M. Somov, dem führenden Theoretiker der Romantik, heftig kritisiert. Er veröffentlichte 1821 im "Nevskij Zritel"" einen mit "Zitel" Galernoj gavani" unterzeichneten "Brief an Marlinskij", in dem er Zukovskijs Stil auf das heftigste attackierte. $V_{g l}$. ZuKOVSKIJ II, S. 461 .

Zur neuartigen Bildtechnik Žukovskijs in" "Rybak", in dem ungewöhnliche und ungewohnte Verbindungen verschiedener Vorstellungsbereiche zum ersten Mal wirklich als Technik zur Geltung kamen, vgl. G. SOHUL, a.a.0., S. 61-64. 
es pointiert aus:

"Le pecheur de Joukovski est un homme moins simple que celui de Goethe et qui reve au lieu de pecher ...". 1

So berechtigt diese Kritik auf der einen Seite erscheint, so energisch muB sie doch unter einem anderen Aspekt zurückgewiesen werden.

"Das Wasser rauscht", das Wasser schwoll" - diese wenigen worte in ihrem gleichmäßigen Rhythmus, der wie das ineinandergeschlungene Auf und $A D$ der wellen klingt, sind auftaktgebend für die Gesamtbewegung des Gedichts. Diese Bewegung und die den magischen Ton tragenden Stellen werden durch den Vokal ' $a$ ' veranschaulicht. Das ' $a$ ' hat im ganzen Gedicht nicht so sehr den Ausdruckswert drängender Energie, als vielmehr den Charakter magischer Eindringlichkeit. Er tritt sparsam auf, näufig nur an prägenden Stellen:

Das Wasser rauscht', das Wasser schwoll

Ein Fischer sạ daran,

Sah nach dem Angel ruhevoll,

Kühl bis ans Herz hinan

Die Wiederholung verleint dem ' $a$ ' eine besondere wirkung. Das dreimalige ' $a$ ' in der dritten zeile weckt den Eindruck statischer Ruhe, die aber bereits magisch durchdrungen ist durch die tiefe Hingabe des Fischers an die Beschäftigung mit dem feuchten Element. 2

Žukovskijs Können zeigt sich darin, daB es inm gelingt, die lautliche Gestalt der vorlage zu erhalten:

1 M. EHPAPD, a.a.0., S. 303, Die gleichen Vormirfe finden sich auch in den Ammerkungen zu Zukovskijs Gedichten von I.M. Semenko. Vgl. KLUKOVSKIJ II, S. 461.

2 Vgl. M. ENNEMOSER, a.a.O., S. 58. 


\section{Бежит волна,, шумит волна̨! \\ Задумчив, над рекоя \\ Сидит рыбак; душа полна \\ Прохладноя тиинноя. 1}

Auch in den letzten beiden zeilen der ersten strophe kommt es Goethe offensichtlich darauf an, mit lautlichen Korrespondenzen zu arbeiten: ${ }^{2}$

Aus dem bewegten wasser rauscht

Ein feuchtes weib hervor

In direkter lautlicher übereinstimmung lauten die Zeilen bei Žukovskij:

\section{И влахнон всплыла главор \\ Красавица из них. ${ }^{3}$}

Die wiederholte Lautkombination VerschluBlaut und Liquida (pl, gl, $k r$ ) bzw. Liquida und ' $a$ ' $(1 a, r a)$ und Reibelaut mit ' $a$ ' (av, as) beschwört den magischen Ton des Ganzen.

Auch an anderen Stellen wird deutlich, wie sehr sich Žukovskij um lautliche Entsprechungen bemüht. Das bedeutsame ' $a$ ' in Goethes letzter Zeile

und ward nicht mehr gesehn

findet sich auch bei Žukovskij:

и след навек пропал ${ }^{4}$

Hier unterstreicht das ' $a$ ' gleichsam die Unwiderruflichkeit des Geschehens, setzt das SchluBzeichen unter die magischen Ereignisse.

1 Die Welle läuft, die Welle rauscht!/Nachdenklich über dem Fluß/ Sitztein Fischer; die Seele ist voll/Von (angenehm) kühler Stille.

2 vgl. G. sarviz, a.a.o., S. 126.

3 Und mit feuchtem Haupt tauchte/Eine schöne Frau aus ihnen [den Wellen] auf.

4 Und die Spur verschwand für immer. 
In den beiden mittleren, lyrischen strophen ${ }^{1}$ steht bei Goethe sowohl das weiche, gedehnte ' 0 ' (wie in "wohlig" und "Mond") als auch das kurze ' 0 ' (wie in "locken") ganz im Dienst der Lockungen der faszinierenden Nixe.

\author{
Sie sang zu ihm, sie sprach zu ihm: \\ "Was lockst du meine Brut \\ Mit Menschenwitz und Menschenlist \\ Hinauf in Todesglut? \\ Ach wübtest du, wie's Fischlein ist \\ So wohlig auf dem Grund, \\ Du stiegst herunter, wie du bist, \\ Und wurdest erst gesund. \\ Labt sich die liebe Sonne nicht, \\ Der Mond sich nicht im Meer? \\ Kehrt wellenatmend ihr Gesicht \\ Nicht doppelt schöner her? \\ Lockt dich der tiefe Himmel nicht, \\ Das feuchtverklärte Blau? \\ Lockt dich dein eigen Angesicht \\ Nicht her in ew'gen Tau?"
}

$1 \mathrm{ZU}$ den lyrischen Elementen in dieser Ballade bemerkt Maria Ennemoser: "Zwar läßt sich ... nicht abstreiten, daß eine gewisse, wenn auch geringe Handlungsbewegung besteht: Ein Fischer angelt, ein Wasserweib taucht empor und spricht und singt zu imm - und zieht inn zu guter Letzt hinunter. Aber diese Handlung ist so gering an sich und so stark überwachsen von rein Lyrischem, daß ... kein Zweifel an der hauptsächlich lyrischen Neigung dieser Ballade bestehen kann. ... Allerdings muß 'Lyrik' hier weit uber bloße ruhende Stimmungemalerei verstanden werden, so daß die Wandlung in Fischer als innerseelischer vorgang ... mit einbegriffen werden kann." M. ENNEMOSER, a.a.O., S. 53. 
Im Deutschen ist das kurze ' $O$ ' gegenüber dem langen viel aktiver, Symbol der lockend auf den Fischer gerichteten Aktivität. 1

Die Vokale ' $i{ }^{\prime}(\ddot{u}), e^{\prime}(\ddot{a})$ und 'ö', sowie die Diphtonge 'ei' und 'eu' geben den beiden Gesangsstrophen, besonders der zweiten, die bezaubernde Musikalität. Die dunkleren Laute 'au" (in "Blau" und "Tau") und " $u$ " (in "gesund" und "Grund") wecken sehnsüchtige Regungen im Fischer.

Žukovskij gibt den Klang dieser beiden strophen faszinierend genau wieder. Auch in der russischen übersetzung stehen die hellen, lockenden vokale ' $i$ ', ' $y$ ', ' $e$ ' und der Diphtong 'oj' dem dunklen, verführerischen ' 0 ', ' $a$ ' und ' $u$ ' gegenüber:

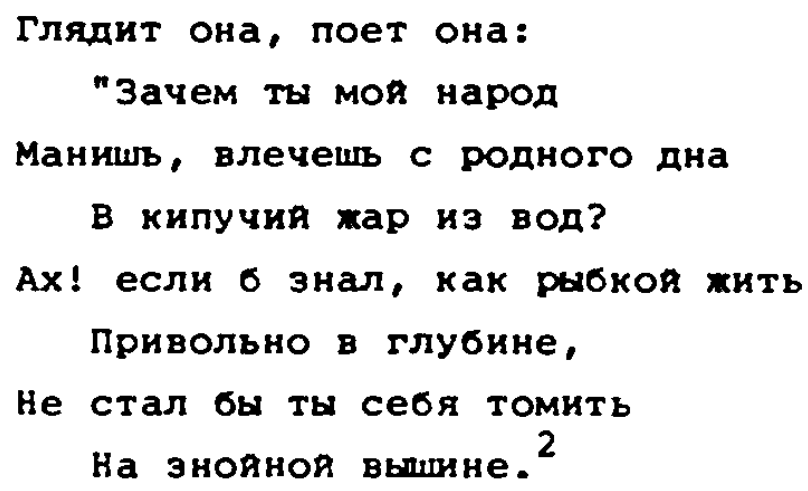

1 Es ist zu beachten, daß die betonten russischen Vokale gegenüber den deutschen langen und kurzen Vokalen eine mittlere Länge haben.

2 Sie blickt, sie singt:/"warum lockst du mein Volk,/Ziehst es von dem ursprünglichen Grund weg/Aus dem wasser [Plural] in die brodelnde Hitze?/Ach! Wenn du wißtest, wie es sich als Fischlein lebt,/Frei in der Tiefe,/Bräuchtest du dich nicht zu quälen/Auf der glühendheißen Höhe. 


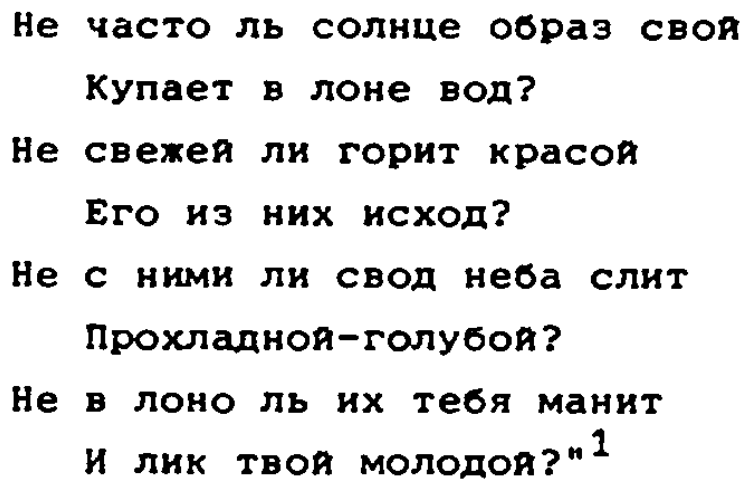

Die Besonderheit der Goetheschen Ballade besteht darin, daß nicht nur der Klang der worte deren Sinngehalt unterstreicht, wie etwa bei "rauschen" und "schwellen", sondern daß der Klang in Verbindung mit dem Rhythmus eine musikalische Symbolfunktion erhält. So sind die eigentlichen Träger der magischen stimmung die dipodischen Verse. Sie symbolisieren als rhythmisches Leitmotiv das Auf und $A b$ des Wassers:

Das wasser rauscht', das Wasser schwoll

oder

Und wie er sitzt, und wie er lauscht

Gerade in diesen versen wird die Anschaulichkeit noch durch das Absetzen des Atems in der Versmitte gesteigert.

1 Badet nicht die Sonne oft inre Umrisse/Im SchoB des Wassers [Plural] ?/Glüht nicht von frischer Schönheit/Ihr Auftauchen aus inm?/FlieBt nicht mit inm [dem Wasser] das Himmelsgewbibe/ Das kühlend-blawe, zusammen?/Lockt dich in seinen SchoB/Nicht dein Junges Antlitz?" 
Die dipodische Anordnung der Hebungen bestimmt in starkem MaBe das metrische Bild der ersten strophe des Nixengesanges und bewirkt nicht zuletzt die Gewalt der Betörung, die aus dem Gesang auf den Fischer wirkt:

Sie sang zu ihm, sie sprach zu ihm

Mit Menschenwitz und Menschenlist

Ach wibtest du, wie's Fischlein ist

Die vorletzte, einprägsame Zeile des Gedichtes

Halb zog sie ihn, halb sank er hin

stellt das allmähliche Absinken des Fischers rhythmisch dar.

Žukovskij gelingt es in seiner übersetzung, neben der lautlichen auch die rhythmische Gestalt der vorlage zu erhalten. In den russischen versen findet sich die gleiche dipodische Anordnung wie bei Goethe:

Бежит волна, шумит волна

Сидит он час, сидит другоя

Глядит она, поет она

Манишь, влечешь с родного дна

Ах! если б знал, как рыбкоя жить

К нему она, он к нея бежит

Störend wirkt jedoch bei Žukovskij die Diskrepanz zwischen Inhalt und Form. Im Gegensatz zu Goethe, bei dem die Nixe "aus dem bewegten Wasser rauscht" und diese Wellenbewegung durch die dipodischen verse rhythmisch untermalt wird, verstummt in der russischen version das Rauschen der Wellen mit dem Auftauchen der Nymphe:

Вдруг шум в волнах притих...

и влажною всплыла главоя

Красавица из них. 1

1 Plötzlich verstumte das Rauschen in den wellen .... Und mit feuchtem Haupt tauchte/Eine schöne Frau aus innen auf. 
Trotz einiger Schwächen bei der wiedergabe - so werden die beiden Komposita "Menschnwitz" und "Menschenlist" nicht übersetzt - ist es Žukovskij beispielhaft gelungen. die lautliche und rhythmische Gestalt der deutschen verse ins Russische zu ubertragen.

\subsubsection{4. "Erlkönig"}

Der "Erlkönig" (HA I, S. 154-155) entstand im Jahre 1782 und wurde in Goethes Singspiel "Die Fischerin" eingefügt. Stoffliche Anregung gab Herders Übersetzung einer dänischen Volksballade mit dem deutschen Titel "Erlkönigs Tochter". Bei dieser übersetzung ist jedoch aus dem dänischen "Ellerkonge" (deutsch: "Elfenkönig") irrtümlich ein Erlkönig geworden. 1

Žukorskij gab seiner Nachdichtung den Titel "Lesnoj Car"" (ŽUKOVSKIJ II, S. 140-141). So wurde bei der Übertragung aus dem Dänischen über das Deutsche ins Russische aus dem Elfenkönig endgültig ein "Waldkönig", eine Gestalt, die dazu angetan ist, die an Bäume gebundenen naturmagischen Kräfte zu verkörpern.

Wie im "Fischer", so bestimmt auch im "Erlkönig" die reine Gewalt einer ins Numinose erhöhten stimmung den Charakter des Gedichtes. Jedoch sind der Erlkönig und seine Töchter nicht zu leiblichen Gestalten verdichtet, sondern werden eher im Imaginären belassen. Im "Erlkönig" wirkt die Magie nicht als süße Verlockung, die den Verzauberten in einem Zustand unendicher Beglückung mit sich fortnimmt; hier zeigt sich das gravenhafte wesen

1 Ein Vergleich des "Erlkönigs" mit der dänischen Volksballade verdeutlicht den naturmagischen Charakter der Goetheschen Ballade. Bei der dänischen Vorlage handelt es sich eher un ein Märchen, in dem zwar ein gespenstisches Ereignis im Mittelpunkt steht, aber dieses eindeutig märchenhaft gestaltet ist.

Vgl. M. ENNEMOSER, a.a.O., S. 96. 
einer Magie, die vor der Anwendung brutaler Gewalt nicht zurückschreckt ("Und bist du nicht willig, so brauch" ich Gewalt").

Eine faszinierende wirkung auf den Knaben ist ausgeschlossen, da von vornherein gegen die Lockungen der Magie eine Abwehrstellung besteht, die ihn die Versprechungen des Erlkönigs als tiefbeängstigend erleben läBt. Das Faszinosum wird hier nicht als beglückend empfunden, sondern als Gefahr und Bedrohung, die mit allen verfügbaren Kräften gebannt werden soll. 1

Auch im "Erlkönig" unterstreicht der Rhythmus symbolhaft die Bedeutung der Aussage: das Locken der Töchter des Erlkönigs wird zunächst durch Jamben ausgedrückt.

Du liebes Kind, komm, geh mit mir

Sobald jedoch die Rede vom Tanz ist, gehen die Jamben in Daktylen über.

Und wiegen und tanzen und singen dich ein

Diese Daktylen bestimmen den besonderen rhythmischen Stimmungscharakter der deutschen Ballade.

Das Metrum des "Erlkönigs" ist wesentlich unterschieden vom streng alternierenden Versmaß des "Fischers". Hier haben wir Daktylen und Jamben, die einander in unregelmäßigem Wechsel folgen. Dies erinnert an das Volkslied, das auch Takte ungleicher Silbenzahl nebeneinander aufweist. ${ }^{2}$

Žukovskij hat in der russischen Fassung durchgehend Amphibrachen verwendet; jeweils im vierten versfuB ist die letzte Senkung nicht mehr realisiert:

1 Vgl. M. ENNEMOSER, a.a.0., S. 65-77.

2 Maria Ennemoser weist darauf hin, daß dieses Versmaß von Herder stamt. Vgl. M. ENNEMOSER, a.a.O., S. 88. 
"Дитя, что ко мне ты так робко прильнул?" -

"Родимыя, лесноя царь в глаза мне сверкнул:

Он в темноя короне, с густоя бородоя". -

"О нет, то белеет туман над водоя". 1

Die Regelmäßigkeit des Metrums nat zur folge, daß bei Žukovskij die Anzahl der Silben pro zeile - es sind immer elf - unverändert bleibt. ${ }^{2}$ Das starre Beibehalten ein und desselben Metrums macht es Yukovskij unmöglich, die unterschiedlichen sinngehalte und stimmungen rhythmisch differenziert zu untermalen. Da jedoch bei den deutschen versen eine deutliche Tendenz zu dreisilbigen versmaßen zu erkennen ist, paBt sich der Amphibrachus insgesamt bemerkenswert gut dem eher volkstülichen Metrum des Originals an. 3

Das Tempo der deutschen Verse wird in Žukovskijs wiedergabe nicht verfälscht.

Wer reitet 80 spät durch Nacht und wind?

Es ist der Vater mit seinem Kind

Der das Galoppieren des Pferdes nachahmende Rhythmus ist auch in der russischen Übersetzung deutlich zu hören: ${ }^{4}$

Кто скачет, кто мчится под хладною мглоя?

Ездок эапоздалыя, с ним сын молодоя. 5

1 "(Mein) Kind, was hast du dich so furchtsam an mich geschmiegt?"/"Vater, der Waldkönig funkelt mir in die Augen:/Er ist in einer dunklen Krone, mit dichtem Bart." $/ " O$ noin, es schimmert der Nebel über dem Wasser."

2 Bei Goethe sind es neun, acht oder zehn Silben pro Zeile.

3 Vgl. M. EHPHAPD, a.a.O., S. 399.

4 André $v$. Gronickas Kritik an Žukovskijs Übertragung der ersten Zeilen ist einseitig: "The great fidelity of Zhukovski's Russian version of the "Erlkönig" ... is nevertheless disrupted at certain critical points. Thus the epic opening lines of the original are changed to a dramatic staccato introduction." A. v. GRONICKA, The Russian Image of Goethe, a.a.0., S. 52.

5 Wer reitet, wer jagt unter dem kalten Nebel?/Ein verspäteter Reiter, mit inm der junge Sohn. 
Mit unvergleichlicher Meisterschaft gibt Zukovskij die lockende Leichtigkeit der Zeile

Und wiegen und tanzen und singen dich ein

wieder:

играя, летая, тебя усыплять 1

Der lautlichen und dramatischen Gestaltung der russischen verse mißt Žukovskij auch hier ${ }^{2}$ besondere Bedeutung zu. Die wortgetreve übersetzung steht dabei eher im Hintergrund.

So beanstandet Neumann, $d a B$ auch bei der wiedergabe des "Erlkönigs" Žukovskijs Tendenz zur Verallgemeinerung der Ausdrucksweise und zur Abschwächung der Ausdruckskraft offenbar werde. Als Beispiel führt er an, daB Zukovskij statt vom "Schweif" des Erlkönigs von einem "dichten Bart" ("gustaja boroda") spreche. ${ }^{3}$ Neumann hat bei seiner Kritik Jedoch ubersenen, daB es Zukovskij offensichtlich auf die lautliche Untermalung der entsprechenden verse ankam. 4

"Он в темноя короне, с густоя бородоя". -

"О нет, то белеет туман над водоя".

1 Spielend, fliegend, dich einzuschläfern.

2 Vgl. seine Wiedergabe von "Der Fischer", bei uns Kapitel III, 2.2.1.2.3.

3 Vgl. F.W. NEUMAN, a.a.O., S. 68; auch Ehrhard weist auf diesen Unterschied hin: vgl. M. EHRHARD, a.a.0., S. 302.

4 Vgl. G. SOHUL, a.a.0., S. 126.

5 "Er ist in einer dunklen Krone, mit dichtem Bart."-/" 0 nein, es schimmert der Nebel über dem Wasser." 
Ehrhard kritisiert, daß Zukovskij bei der übersetzung des "Erlkönigs" das zweifache "Mein Vater, mein Vater" in der sechsten strophe nicht beibehalten habe, wo sich doch in diesem Anruf die fieberhafte Angst des Kindes ausdrücke. Weiterhin habe es Zukovskij nicht verstanden, das verhängnisvolle wort "tot", auf das Goethe seine Ballade enden läßt, entsprechend hervorzuheben und dem SchluB 80 die Eindringlichkeit der Goetheschen Verse zu verleihen. 1

Dem ist jedoch entgegenzuhalten, daß Žukovskij die Antworten des Vaters durchgehend mit "O net" beginnen läßt und dadurch dem Dialog zwischen vater und Sohn eine gesteigerte Dramatik verleint. ${ }^{2}$

Abgeschwächt hat Žukovskij die Darstellung der konkreten Bedrohung des Kindes durch den Erlkönig. Goethes siebte Strophe:

"Ich liebe dich, mich reizt deine schöne Gestalt; und bist du nicht willig, so brauch" ich Gewalt."Mein Vater, mein vater, Jetzt faßt er mich an!

Erlkönig hat mir ein Leids getan! -

übersetzt Žukovskij mit:

"Дитя, я пленился твоен красотоя:

неволея иль волея, а будешь ты моя". -

"Родимы, лесноя царь нас хочет догнать;

Уж вот он: мне душно, мне тяжко дышать". 3

1 Vgl. M. EHPHARO, a.a.0., S. 303.

2 A. v. Gronicka zur Wiedergabe der Dialogführung: "Znukovski completely fails to bring off the tense realiem of coethe's dialogue between father and son." A. V. GRONICKA, The Russian Image of Goethe, a.a.O., S. 52. Diese Kritik ist nicht berechtigt und wird von Gronicka nicht belegt.

3 "(Mein) Kind, ich murde von deiner Schönheit hingerissen:/0b du willst oder nicht, aber du wirst mein sein."-/Vater, der Waldkönig will uns einholen;/Ach, da ist er: ich kann nur schwer atmen. 
Von bemerkenswerter Prägnanz und Expressivität ist die wiedergabe der zweiten zeile. Die Alliteration in dem deutschen vers formt Žukovskij vortrefflich nach.

Während bei Goethe in der letzten Strophe nur noch das bestätigt wird, was sich der Leser bereits am Ende der siebten strophe denken konnte, nämlich dab der Knabe stirbt, löst sich die Spannung bei Zukovskij erst in der letzten strophe.

Bedingt durch das mehrfache wiederholen von "ezdok" und "mladenec" und das völlige Fehlen von Konjunktionen erhöht der Leser das Lesetempo, wie auch der Vater schneller reitet.

Und auch die graphische Kennzeichnung, die fortfihrenden Punkte am Ende der vorletzten zeile, tragen dazu bei, das die Spannung bis zum Schlub erhalten bleibt.

Die Assonanz von "mertvyJ mladenec", die beim Sprechen eine Pause zwischen den Wortenerfordert, führt zu einer Verlangsamung des Tempos im letzten Vers; alle Anstrengungen des Vaters, das Kind zu retten, sind vergeblich. ${ }^{1}$

Ездок оробелы не скачет, летит;

младенец тоскует, младенец кричит;

Ездок погоняет, ездок доскакал...

В руках его мертвыя младенец лежал. 2

1 Vgl. G. sarulz, a.a.0., s. 126.

2 Der Reiter, von Angst erfüllt, reitet nicht, er fliegt;/Das Kind sehnt sich, das Kind schreit;/Der Reiter treibt zur Eile an, der Reiter erreichte ....In seinen Armen lag das tote Kind. 
Die jeweils zusammengehörigen Formeln "Nacht und Wind" ("Wer reitet so spät durch Nacht und Wind") und "Muihe und Not" ("Erreicht den Hof mit Mühe und Not") haben im deutschen den Wert von Komposita, d.h. einer Zweigliedrigkeit mit wechselseitiger Bedeutungsdurchdringung. 1

Žukovskij gibt diese Wortverbindungen durch Parallelismen in der Verbkonstruktion wieder. Das subjekt bleibt jeweils unverändert:

Кто скаччет, кто мч부요 под хладною мглоя

Ездок погоняет, ездок доскакал

Die in der ersten Zeile der deutschen Ballade dominierenden Vokale ' $a$ ' und ' $i$ ' ("Nacht und Wind") prägen auch den Klang der russischen Wiedergabe. Diese Einheit von ' $a$ ' und ' $i$ ' weckt beim Zuhörer eine lebhafte Spannung. Das lange, gedehnte ' $O$ ' zusammen mit langem ' $u$ ' Orückt Trauer aus:

Erreicht den Hof mit Mühe und Not

Žukovskij untermalt die SchluBverse mit den dunklen vokalen ' $a$ ' und ' 0 '.

Es ist inm gelungen, sowohl die Gedankenfiguren als auch die Lautschicht der deutschen Verse angemessen ins Russische zu übertragen.

Die Lockungen des Erlkönigs gibt Žukovskij durch die Klangfolge ' $i-a^{\prime}$ und die hellen vokale ' $i$ ', ' $y^{\prime}$, ' $e^{\prime}$ und ' $\dot{e}$ ' wieder. Das dunkle, sanfte ' $u$ ' und das geheimnisvolle ' $O^{\prime}$ vertiefen die Lockungen in magisch betörender weise. ${ }^{3}$

1 Vgl. M. ENNEMOSER, a.a.0., S. 86.

2 Vgl. M. ENNEMOSER, a.a.0., S. 81.

3 Vgl. die Lockungen der Nixe in "Der Fischer", bei uns Kapitel III, 2.2.1.2.3. 
"Дитя, оглянися; младенец, ко мне;

Веселото много в moеn стороне:

Цветы бирізовы, жемчужны струи;

из золота слиты чертоги мон". 1

Žukovskij hat sich bei der Lautgestaltung dieser strophe eng an die deutsche Vorlage gehalten; nur die Nachbildung der figura etymologica in der zweiten Zeile ist Zukovskij nicht gelungen.

"Du liebes Kind, komm, geh mit mir!

Gar schöne Spiele spiel' ich mit dir;

Manch' bunte Blumen sind an dem Strand;

Meine Mutter hat manch" gülden Gewand."

Trotz seiner im allgemeinen kritischen Einstellung zu Žukovskijs übertragung des "Erlkönigs" lobt Ehrhard überschwenglich die lautliche Gestaltung der russischen verse:

\begin{abstract}
"Surtout, quelle musique caressante dans les phrases enjoleuses du roi de la forêt! Cette musique, obtenue par le choix savant des sons, par la disposition de la phrase, les coupes des mots et des pieds à l'intérieur du vers, atteint a la valeur mélodique des vers de Goethe et l'on ne saurait faire plus bel éloge."2
\end{abstract}

Einen bemerkenswerten Vergleich zwischen Goethes Original und der Nachdichtung Žukovskijs zient die russische Lyrikerin Marina Cretaeva in einem Aufsatz mit dem Titel "Dva Lesnych Carja", den sie im Jahre 1933, also während der Zeit ihrer Pariser Emigration, ver-

1 "(Mein) Kind, sieh dich um, (mein) kleines Kind, (korm) zu mir;/ Es gibt viel Fröhliches in meinem Land:/Türkisfarbene Blumen, Strahlen wie Perlen;/Aus Gold gegossen sind meine Paläste."

M. EHTLRD, a.a.0., S. 303. 
fast nat. 1

Wort für Wort, Zeile für zeile vergleicht sie - ausschlieblich nach inhaltlichen Kriterien - die beiden Dichtungen miteinander. Obwohl inr Goethes Ballade eindeutig näher steht und sie gleich zu Anfang ihrer Gegenuberstellung versucht, dem russischen Leser deren inhaltiche Aussage exakt zu erschlieBen, gent Marina Cretaeva weiter: sie wirdigt die Dichtkunst Kukovskijs und dessen Treue zu sich selbst.

Das Ergebnis ihrer Analyse nimmt Marina Cvetaeva in der Überschrift vorweg: beide Dichtungen sind gleichwertig. Aber vollkommen verschieden. Es gibt somit nicht nur zwei unterschiedliche Gedichte, sondern auch zwei unterschiedliche Erlkönige.

Bei Žukovskij sehen wir einen erhabenen Greis mit einer dunklen Krone und einem dichten Bart vor uns. Von seiner Machtfülle fühlen wir uns trotz allem nicht sehr stark bedroht. So zittert der knabe in Zukovskijs Version bereits vor dem Erscheinen des Erlkönigs und dies fürt Marina Cretaeva zu dem Gedanken, daß hier die Gestalt des Erlkönigs selbst eine Fieberphantasie des Knaben ist.

Ganz anders bei Goethe: bei inm zittert der Knabe vor der Realität des Erlkönigs, seine Furcht wird erst durch dessen Auftauchen ausgelöst. Goethes Knabe kann sich gar nicht vorstellen, daß der Vater den Erlkönig nicht sieht:

Siehst, Vater, du den Erlkönig nicht?

Die fordernde, ja fast hypnotisierende Frage suggeriert dem Vater dessen reale Existenz.

1 M. CVETAEVA, Ova Lesnych Carja. In: Masterstvo perevoda 3. Moskau 1964. S. 283-291. Marina Cvetaeva kannte aus eigener Erfahrung die Schwierigkeiten eines Ubersetzers. In den dreißiger Jahren übersetzte sie vorwiegend russische Werke ins Französische. 
Bel Goethe hat der Erlkönig kein fest umrissenes Äußeres, kein bestimmtes Alter. Genau genommen besteht er lediglich aus Schweif und Krone. 1 Das wesen ist das eines Dämons, seine Verführungen sind konkreter, für den Knaben verlockender

Gar schöne Spiele spiel' ich mit dir

als das vage

веселого много в моея стороне ${ }^{2}$

Ebenso ist die Mutter des Erlkönigs, in ein goldenes Gewand gehüllt, für ein kind anziehender als kalte, goldene Paläste. Die bei Žukovskij in der vierten strophe vom Knaben aufgezählten Versprechen

он золото, перлы и радость сулит ${ }^{3}$

sind weit weniger beunruhigend als das Verschweigen der eigentlichen Verlockungen:

Mein Vater, mein Vater, und hörest du nicht,

was Erlenkönig mir leise verspricht? -

Entsprechend sind auch die Erwiderungen der Väter. Ruhig bei Žukovskij:

"О нет, моя младенец, осльшался тн:

то ветер, проснувшись, колыхнул листы". 4

und erschrocken bei Goethe:

Sei ruhig, bleibe ruhig, mein Kind!

In dürren Blättern säuselt der Wind. -

1 Der Schweif von Goethes Erlkönig realisiert sich als "Nebelstreif", ebenso treffend entspricht dem Bart in Zukovskijs Version der "Nebel über dem Wasser".

2 Es gibt viel Fröhliches in meinem Land.

3 Er verspricht Gold, Perlen und Freude.

4 'o nein, mein kleines Kind, ou hast dich verhört:/Es ist der aufgekormene Wind, er schaukelte die Blätter." 
Mit jedem wort bekämpft der Vater seine eigene Angst.

Ähnlich sind die Unterschiede in der sechsten Strophe. Bei Zukovskij erzählt der Knabe das Geschehen nach:

"Родимыя, леснов царь созвал дочерея:

мне, вику, кивают из темных ветвея". 1

Bei Goethe ist die Erscheinung real:

Mein Vater, mein Vater, und siehst du nicht dort

Erlkönigs Töchter am düstern Ort? -

Die unterschiedichen Antworten entsprechen den Fragen; erhaben bei Zukovskij:

"О нет, все споковно в ночноя глубине:

то ветлы седые стоят в стороне". 2

und herzklopfend bei Goethe:

Mein Sohn, mein Sohn, ich seh' es genau;

Es scheinen die alten weiden so grau. -

Dies ist die Antwort eines Menschen, der flehentlich den anderen beschwört, inm zu vertraven, damit er sich selbst vertrauen kann. Die Genauigkeit, mit der der verängstigte Vater die weiden beschreibt, überzeugt uns im Gegenteil immer mehr von der tatsächlichen Existenz der unheimlichen Erscheinung.

Zu guter Letzt die ultimative Drohung des Erlkönigs:

"Ich liebe dich, mich reizt deine schöne Gestalt;

Und bist du nicht willig, so brauch" ich Gewalt."

Demgegenuber ist Žukovskijs Walokönig eher passiv:

"дитя, я пленился твоея красотоя:

неволея иль волея, а будешь ты моп". 3

1 "(Mein) Vater, der Waldkönig hat die Töchter gerufen:/Ich sehe, sie nicken mir aus dunklen Zweigen zu."

2 "O nein, alles ist runig in der nächtlichen Tiefe:/Es stehen graue Silberweiden an der Seite (des Weges)."

3 "(Mein) Kind, ich murde von Deiner Schönheit hingerissen:/00 du willst oder nicht, aber du wirst mein sein." 
Zwischen dem drohenden Ausruf des Erlkönigs - "so brauch" ich Gewalt" - und dem Aufschrei des Kindes "jetzt faBt er mich an" - liegt bei Goethe nur der zweimalige Anruf "Mein Vater, mein Vater"; bei Žukovskij dagegen erscheint die Drohung des Erlkönigs zunächst nur als Absicht:

Родимыя, лесноя царь нас хочет догнать 1

Marina Cretaeva zieht folgende Schlüsse aus ihrer Gegenüberstellung:

1. Bei Goethes "Erlkönig" und Žukovskijs "Lesnoj Car"" handelt es sich um zwei Variationen auf ein und dasselbe Thema, um zwei Sichtweisen einer Erscheinung.

2. Goethe konnte den Erlkönig sehen, und wir mit ihm. Kukovskij dagegen konnte ihn nicht erkennen, und wir ebenfalls nicht.

3. In der russischen Fassung stirbt der knabe vor Angst, bei Goethe wird er vom Erlkönig getötet.2

4. Der Erlkönig Žukovskijs ist, alles in allem, positiver dargestellt als der Goethes: zu dem Knaben ist er besser - dieser füht sich lediglich beklommen -, zu dem Vater ist er besser - der Tod des Knaben ist zwar traurig, aber trotz alledem natürlich -, auch seine Erscheinung ist angenehmer - ein Greis mit dichtem Bart.

1 (Mein) Vater, der Waldkönig will uns einholen.

2 Es bleibt fraglich, ob aus Goethes "Erlkönig" tatsächlich die Todesursache des Knaben eindeutig geklärt werden kann. 


\subsubsection{TjutCevs Übertragungen Goethescher Balladen}

\subsection{Tjutלev als Übersetzer Goethescher Balladen}

Tjutłev, der im Gegensatz zu Zukovskij keine eigenen Balladen verfaßt hat, übersetzte insgesamt drei GoetheBalladen, 1 und zwar alle im Jahre 1830. Gemeinsam ist den von Tjutčev wiedergegebenen Balladen der historische, vermutlich mittelalterliche, Hintergrund. 2

"Geistesgruß" und "Der König in Thule" gehören zu Goethes frühen Balladen, beide sind im Jahre 1774, also in der Zeit des Sturm und Drang, entstanden. 3

Inspiriert wurde Goethe durch seine Begegnung mit dem deutschen volksliedgut. Im Jahre 1771 unternahm er auf Anregung Herders ${ }^{4}$ eine Reise durch das ElsaB und sammelte Lieder, die er dort hörte. Jedoch im Gegensatz zu Herder, der für seine "Volkslieder" nur aus Drucken sammelte und

1 Es sind: "GeistesgruB"/Privetstvie ducha" - "Der König in Thule"/ "Zavetnyj kubok" - "Der Sänger"/"Pevec".

2 Der Name Thule ("Der König in Thule") war Goethe durch Vergil und Seneca bekannt, bei denen er das fernste nördliche Reich, eine Insel, bezeichnet. Vgl. HA I, S. 511.

3 Die Ballade vom König in Thule steht auch in 1. Teil des Faust, in der "Abend" überschriebenen Szene. Entstarden ist die Ballade jedoch unabhängig vom Faust-Plan. Goethe legte sie Gretchen in den Mund, weil er sie ihre Gefühle - ihrem einfachen Wesen entsprechend - in einem volkstimlichen Lied aussprechen lassen wollte. Vgl. E. BEUTLER, "Der König in Thule" und die Dichtungen von der Lorelay. In: Ders., Essays un Goethe. Bd. 2. Wiesbaden 1948. S. 307-369. Hiers S. 312-315.

4 Hefele weist auf die außerordentliche Bedeutung Herders bei der Entstehung des Volksliedes hin: "Herder hatte Goethe die Augen geöffnet für das Naturhafte in der Dichtung ... Er hat inn das volkslied kennen und schätzen lernen als die letzte und höchste Bliute aller Dichtungen - das Volkslied, ein Begriff, den Herder erst eigentlich geschaffen hat ..." H. HEFELE, a.a.O., S. 28. 
sich nicht scheute, das Gefundene anschließend umzudichten, notierte Goethe nur, was wirklich im Volk gesungen wurde. 1

Es ist kein Zufall, daß fast alle zwölf Lieder, die er aufzeichnete, Balladen sind. So z.B. das Lied vom Pfalzgrafen, vom eifersüchtigen Knaben und vom Herrn von Falckenstein. 2 Als echte Volksballaden zeichnet diese Lieder die epische Erzählweise, ihre Länge und die stark bewegte Handlung aus. 3 Dieses besondere Interesse Goethes an Balladen war nicht nur durch englisches vorbild begründet, sondern entsprach auch seiner persönlichen Neigung zu dieser zeit. 4

Goethe knüpfte in seinem eigenen Balladenschaffen an die alten Traditionen der Volksballade an; dies verraten sowohl der schlichte stil als auch die volkstumliche Motivwahl. 5 wie in der volksballade tritt in

1 Vgl. HA I, S. 507.

2 Vgl. W. KAYSER, a.a.O., S. 110. Abgedruckt sind sämtliche Lieder bei H. FISOAER-LAMBERG (Hrsg.), Der junge Goethe. 5 Bde und 1 Registerband. Berlin 1963-74. Hier Bd. 2. S. 34-53.

$3 \mathrm{Vgl.} \mathrm{St.} \mathrm{STEFFENSEN,} \mathrm{"Dor} \mathrm{König} \mathrm{in} \mathrm{Thule".} \mathrm{Bemerkungen} \mathrm{zu} \mathrm{den}$ Elementen des Goetheschen Gedichts. In: Orbis litterarum 15 (1960). S. 36-43. Hier S. 36 .

41765 war in Schottland eine Sarmlung alter Volksballaden erschienen, zusamengestellt von Thomas Percy, die auch in Deutschland schnell bekannt murde. Vgl. HA I, S. 506-507.

5 Aus "Dichtung und Wahrheit" können wir entnehmen, daß coethe seine frühen Balladen nicht etwa aufschrieb, sondern an vertraute Personen muindlich mitteilte: "In Gefolg von diesem Seelen- und Geistesverein, wo alles, was in einem jeden lebte, zur Sprache $\mathrm{kam}$, erbot ich mich, meine neuesten und liebsten Balladen zu rezitieren. "Der König in Thule" und "Es war eine Buhle frech genug" taten gute Wirkung ..." HA $X, S$. 34. Vgl. M. KOMEEREL, a.a.0., S. 327 . 
Goethes Schöpfungen dieser Gattung der Dichter nicht hervor. Er äußert keine Anteilnahme am Geschehen, hält sich ganz im Hintergrund. 1

Gleichzeitig stellen Goethes Balladen des Sturm und Drang jedoch auch eine weiterentwicklung der traditionellen Volksballade dar. Statt einer Aneinanderreihung mehrerer Motive, statt Sprunghaftem und Andeutendem, finden wir bei Goethe nur eine einzige, symbolische situation hervorgehoben. Durch das Fehlen der in der volksballade ublichen Abschweifungen sind Goethes Balladen insgesamt kurzer, in sich geschlossener. 2

Die Ballade "Der Sänger" stammt aus dem Jahre 1783. Dies ist die zeit, in der Goethe der Balladendichtung, 2.B. im "Erlkönig" und im "fischer", neue Themenbereiche eröffnete. "Der Sänger" weist demgegenüber bereits auf die klassischen schöpfungen des sogenannten "Balladenjahres" 1797 hinaus. Im Zusammenwirken mit Schiller schaffte Goethe den neven Typus der Ideenballade.

Ihre Hauptmerkmale

- im Mittelpunkt des Geschehens steht der aktiv handelnde Mensch im Konfliktfeld diesseitiger Menschlichkeit ${ }^{3}$

- es herrscht eine rational formulierbare Idee 4

lassen sich bereits im "Sänger" erkennen. So kann man, trotz seiner Entstehung lange vor Goethes eigentlich klassischer Zeit, den "Sänger" als die erste klassische Ideenballade des deutschen Dichters bezeichnen. 5

1 Vgl. W. KAYSER, a.a.o., S. 112.

2 Vgl. HA I, S. 508; W. KAYSER, a.a.O., S. 112.

3 Dengegenuber steht der passiv getriebene Mensch der naturmagischen Ballade. Er ist geprägt durch das Erlebnis des "ganz anderen".

4 Beide Merkmale nach R. WILOBOLZ, a.a.0., S. 904-905. Vgl. I. BRAAK, a.a.0., S. 128.

5 Vgl. ebd., J. KLEIN, a.a.0., S. 341. 


\subsubsection{2. "GeistesgruB" und "Der König in Thule"}

Sowohl von ihrer Entstehung - beide Balladen schuf Goethe vermutlich im Abstand weniger Tage während seiner Rheinreise - als auch vom beherrschenden Motiv her, sind diese Gedichte eng miteinander verknüpft. Das Bild des mittelalterlichen Herrschers auf der Zinne des Schlosses bestimmt sie beide. Zechen und Wagemut als Männertugenden gehören ebenso dazu wie lebenslange Treue. 1

Beutler vermutet in dem Gedicht "Geistesgrub" 2 eine
vorstufe zum "König in Thule". 3 Im ersteren ist das Bild
vom kernig-biederen Ritter noch stecken geblieben, Goethes
romantisches Stimmungsbild - angesichts der Burgruine
"Lahneck" improvisierend diktiert - verfliegt sofort
wieder.

1 Vgl. W. ROSS, Johann Wolfgang Goethe. Es war ein König in Thule. In: Wege zum Gedicht. Bd. 2. Minchen - Zürich 1964. S. 147-153. Hier S. 150.

2 Den Titel "Geistesgruß" erhielt die Ballade erst 1789, als Goethe sie in seine "Schriften" aufnahm. Vgl. MA I, S. 512.

3 Vgl. E. BEUTLER, Der König in Thule, a.a.o., S. 312-315. Wie Steffen Steffensen in seinem Aufsatz über den König in Thule nachweist, tauchen in beiden Balladen ossianische Elemente auf. Typisch ossianisch sind die Vorstellungen vom Geist des verstorbenen Helden ("GeistesgruG") und vom trinkenden nordischen Helden ("Der König in Thule"). Während Jedoch im "GeistesgruB" das mittelalterliche deutsche Rittermilieu den Hintergrund bildet, vermischen sich im König von Thule nordisch-ossianische und gotischmittelalterliche Elemente ("Die Ritter un inn her,/Auf hohem Vatersaale") miteinander. Das Rittermilieu im "GeistesgruB" hat wahrscheinlich auf den König in Thule eingewirkt. Vgl. St. STEFFENSEN, a.a.0., S. 39-42; J. KLEIN, a.a.0., S. 317; E. BEUTLER, Der König in Thule, a.a.o., s. 312. 
Tjutלev gibt die Stimmung dieser, ursprünglich an ein bestimmtes Erlebnis gebundenen Verse, uberraschend genau wieder, teilweise übersetzt er wörtlich.

"Sieh, diese Senne war so stark,

Dies Herz so fest und wild,

Die Knochen voll von Rittermark,

Der Becher angefullt."

(HA I, S. 81)

In Tjut Xevs übersetzung lautet diese zweite Strophe:

"кипела кровь и в сея груди,

Кулак был из свинца,

и богатьрскня мозг в кости,

и кубок до кониа!" 1

(TJUTČEV II, S. 60)

Auch formal entspricht die übersetzung der vorlage: Jambische Verse mit abwechselnd vier und drei Hebungen und stumpfem versschluB. Bei Goethe wird jedoch das alternierende VersmaB verschiedentlich durch Betonung der Anfangssilbe einer zeile unterbrochen. Dies fürt zu einer Abschwächung der folgenden Hebung, der Versbeginn wirkt daktylisch. Die Betonung des Eingangswortes "hoch" läßt uns den Blick gleichsam nach oben richten.

Hoch auf dem alten Turme steht

Des Helden edler Geist,

Der, wie das Schiff voruber geht,

Es wohl zu fahren heibt.

Tjutčev beachtet in seiner Wiedergabe solche Abweichungen vom Metrum nicht. Bemerkenswert jedoch auch hier die grobe inhaltiche Genauigkeit seiner verse.

1 "Es kochte das Blut auch in dieser Brust,/Die Faust war aus Blei,/ Und Heldemark in den Knochen,/Und der Becher bis zum Rand Igefiullt)!" 
На староя башне, у реки,

Дух рынаря стонт

И, лишь завидит челноки,

Приветом их дарит. ${ }^{1}$

Während im "GeistesgruB" noch befremdend wirkendes Ritterpathos überwiegt, entfaltet sich im "König von Thule" (HA I, S. 80-81) ein umfassendes Bild, geprägt vom Erlebnis unvergänglicher Liebe und Treve. ${ }^{2}$ Eine neve, tiefere Dimension des Lebens steht dem schlichten Kämpfertum des Ritters gegenüber. 3

"Getreu bis an das Grab" - diese Zeile begleitet gewissermaßen das Geschehen. Es handelt sich jedoch nicht um eine Treve im bürgerlichen Sinn. Die Treve, die den König mit seiner Geliebten verbindet, gründet auf einem freiwilligen Versprechen, das einer Bestätigung durch die Gesellschaft nicht bedarf.

$$
\begin{aligned}
& \text { Es war ein König in Thule } \\
& \text { Gar treu bis an das Grab, } \\
& \text { Dem sterbend seine Buhle } \\
& \text { Einen goldnen Becher gab. }
\end{aligned}
$$

Der Reim wechselt regelmäßig zwischen weiblich und männlich, das Versmaß ist, wenn man einige Elisionen und Kontraktionen in Kauf nimmt $(z . B$. in der ersten strophe Kön'g statt König, ein' statt einenl ziemlich regelmäßig jambisch.

1 Auf dem alten Turm, am Fluß,/Steht der Geist des Ritters/Und kaum erblickt er von weitem die Boote/wirdigt er sie eines Grußes.

2 Johann Klein bezeichnet daher den "König in Thule", und nicht "GeistesgruB", als Goethes "erste wirkliche Ballade". Vgl. J. KLEIN, a.a.0., S. 330; M. KOMMERELL, a.a.0.. S. 327.

3 Vgl. E. BEUTLER, Der König in Thule, a.a.0., S. 312, 319. 
Jamben und Kreuzreime auch bei Tjutčevs "Zavetnyj kubok" (TJUTCEV II, S. 100-101), wobei er in der ersten Gedichtzeile die - bei deutlicher Artikulierung auch im Original vorhandene - zusätzliche Senkung beibenält.

Был царь, как мало их ныне, -

По смерть он верен оьл:

От мнлов, при кончине,

Он кубок получил. 1

Zwei bezeichnende Abweichungen vom jambischen VersmaB führen zu einer merklichen verzögerung des Tempos in der zweiten und sechsten Strophe des Originals. "Die Augen gingen inm über" 2 und "Die Augen täten ihm sinken", diese beiden parallel laufenden Verse, die bildich die Trauer des Königs über den Tod der Geliebten und schlieblich den eigenen Tod darstellen, leiten das Ende je einer Strophengruppe ${ }^{3}$ ein.

In seiner wiedergabe dieser ausdruckstarken Bilder greift Tjutčev auf die eher blasse formel vom "pochenden Herzen" zurück: "V nem serdce sil'no bilos."4 und "Zabilos" retivoe" 5 .

1 Es war ein König, wie es heute wenige gibt,-/8is zum Tod war er treu:/Von der Geliebten bei (ihrem) Tod,/Erhielt er einen Becher.

2 Das heiBt die Augen flossen über (von Tränen). Diese wendung hat Goethe aus der wtherbibel ubernormen, in der "Jesus wointe" (Joh. 11,35) ibbersetzt ist mit "Und Jesu gingen die Augen über". Vgl. HA I, S. 511.

3 Die erste Gruppe umfaßt die Strophen eins und zwei (Tod der Buhle) und die zweite die Strophen drei bis sechs (Tod des Königs und Opferung des Bechers).

4 In itm schlug das Herz stark.

5 Das Herz [folkl.] fing an zu schlagen. 
Sowohl das Motiv dieser Ballade - Liebe uber die Grenzen des standes hinweg - als auch ihr stil verraten starke Einflüsse von der Volksballade her. ${ }^{1}$ Ein typisch volkstumlicher Zug sind die plastisch-anschaulichen Eingangs- und Ausgangssituationen: anfangs gibt sie inm den Becher, am SchluB wirft er inn ins Meer. Das Volkslied verwendet gern prägnante symbolische situationen, die die Phantasie des Hörers lebendig weroen lassen. 2

VolksmäBig auch der schlichte Beginn "Es war ein König ..." und die fast nur Hauptsätze aneinanderreihende

1 Steffen Steffensen weist auf die besonders enge Beziehung zwischen dem "König in Thule" und der von Goethe im Elsaß notierten Volksballade "Das Lied vom eifersichtigen Knaben" hin. In beiden Balladen komt der Dingsymbolik eine besondere Bedeutung zu. Dem Becher als Symbol der Liebe und Treue bei Goethe entspricht in der Volksballade der Ring, den der Knabe seiner Geliebten schenkt. Gemeinsam ist den Balladen weiterhin ihre relative Kürze, die daraus resultiert, daß beide Male nur eine Situation und deren knapp angedeutete Vorgeschichte beschrieben wird. Die Vermutung liegt also nahe, daß Goethes "König in Thule" in Anlehnung an "Das Lied vom eifersiichtigen Knaben" entstanden ist, auch wenn das Motiv der Volksballade von Goethe ungestaltet murde. Während "Das Lied vom eifersiuchtigen Knaben" von Treulosigkeit und ihren tragischen Folgen handelt, steht im "König von Thule" unvergängliche Liebe und Treue im Mittelpunkt des Erzählten. Vgl. St. STEFFENSEN, a.a.0., S. 37-38.

2 Immer wieder tauchen symbolische Gesten und situationen auch in der Kunstballade auf, Z.B. in Goethes "Sänger" und C.F. Meyers "Der gleitende Purpur". Vgl. St. STEFFENSEN, a.a.O., S. 39. 
Syntax. Das wort "Buhle" und die Umschreibungen mit "tät" und "kam" sowie die Elisionen sind den Volksballaden entnommen. 1

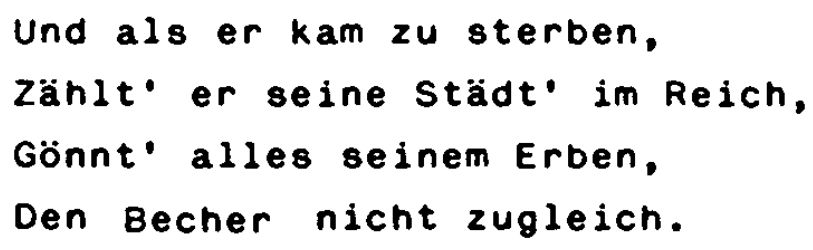

Der bewuBten Archaisierung und wendung ins volksliedhafte in wortwahl und Satzbau entspricht der gleichmäßige syntaktische Bau: Abgesehen von der ersten und der letzten Strophe (Vorgeschichte und Erinnerung), in denen sich eine syntaktische Einheit in die nächste Versreine fortsetzt (Enjambement), endet mit dem Versschluß auch eine Einheit, Verse und Satzglieder entsprechen sich.

Demgegenüber bedient sich Tjuttev verschiedentlich der Versiberschreitung. So auch bei der wiedergabe der dritten strophe:

Когда х сея мир покинуть

Пришел его черед,

Он делит все наследство, -

но кубка не дает. 2

Tjutčev verwandelt die von Goethe bewuBt schlicht gehaltene, volkstümliche Sprache ("Und als er kam zu sterben") in eine poetisch-gehobene Ausdrucksweise ("Als aber diese welt zu verlassen/An ihn die Reihe kam").

1 Vgl. W. KAYSER, a.a.0., S. 112; HA I, S. 508.

2 Als aber diese Welt zu verlassen/An inn die Reihe kam,/Teilt er das ganze Erbe,-/Aber den Becher übergibt er nicht. 
Nur wenige Zuge der deutschen Ballade wirken dieser grundlegend volkstülichen stiltendenz entgegen. So nebt sich in der sechsten strophe das wort "Lebensglut" heraus; in einer Volksballade könnte man es nicht finden.

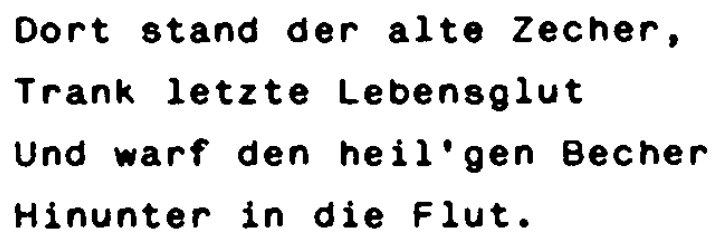

Tjuťevs übersetzung dieser Verse ist nur lose mit der Vorlage verbunden. Dem ungewöhnlichen Kompositum "Lebensglut" - diese ist es, die der König aus dem geweinten Becher trinkt - entspricht in der russischen fassung die ebenso ungewöhnliche Metapher "ognevaja vlaga".

В последния раз упился

Он влаго огневоя,

Над бездноя наклонился

и в море - кубок своя... 1

An die Stelle einer knappen Beschreibung der Geschehnisse im alten Volksliedstil tritt in der AbschluBstrophe das genau beobachtete Detail.

Er sah ihn stürzen, trinken

Und sinken tief ins Meer.

Die Augen täten inm sinken;

Trank nie einen Tropfen mehr.

Diese Verse mit ihrer kunstvollen verschränkung - der Becher trinkt den Tod, wie der König inn trinkt, und die Augen sinken inm, wie der Becher gesunken ist -2 lauten bei Tjutčev:

1 Zum letzten Mal berauschte er sich/Am feurigen Naß/Er beugte sich über den Abgrund/Und im Meer - ist sein Becher ...

2 Vgl. W. ROSS, a.a.0., S. 152; J. KLEIN, a.a.0., S. 318. 
На дно пал кубок морское, -

Он пал, пропал из глаз,

Забилось ретивое, -

Царь пил в последния раз!.. 1

Dies ist weniger eine übersetzung als eine selbständige Bearbeitung der deutschen Verse. Die symbolische Pointe der Schlubzeilen - der Becher, aus dem der König und seine Buhle getrunken haben, trinkt selber wie ein wesen aus dem Meer, in dem er schlieblich untergeht - ist in der russischen fassung verlorengegangen. Lediglich die auf den ersten Blick durchaus trinkliedhaft wirkende schlubzeile mit ihrer Alliteration "Irank nie einen Tropfen mehr" findet im Russischen eine Entsprechung: "Car" pil $v$ posiednij raz". 2

Insgesamt ist Tjutčevs Übersetzung des "Königs in Thule" sowohl in der Wort-, wie auch in der Bildwahl sehr frei. 3 Gemeinsam ist beiden Fassungen das wesen des Erzänlten.

Im Mittelpunkt steht die Liebe und Treue zwischen zwei Menschen. Zum symbol inrer inneren verbundenheit wird der Becher, den der König von seiner sterbenden

1 Auf den Meeresgrund sank der Becher,-/Er sank, entschwand aus den Augen, /Das Herz [folkl.] fing an zu schlagen,/Der König trank zum letzten Mal! ...

2 Der König trank zum letzten Mal.

3 So taucht in Tjutčevs Ubersetzung - im Gegensatz zu denen Fets und Brjusovs - das Wort "Thule" weder in der überschrift noch in Gedicht selbst auf.

4 Durch das Adjektiv "heilig", dem in der russischen Fassung "zavetnyj" - in seiner alten Bedeutung von "geweiht" - entspricht, erhält das Wort "Becher" bei Goethe wie auch bei Tjutčev einen fast religiösen Klang. Daß Tjutčev jedoch "golden" - dieses Epitheton steht für alles Edle und Kostbare - wegläßt, mindert die Anschaulichkeit der russischen wiedergabe. 
Geliebten als Vermächtnis erhält. 1 Jeder Trunk aus diesem Becher bedeutet somit eine sichtbare Erneverung des Trevebundes. Und als auch der König sterben muß, wirft er das Symbol seiner Liebe, das von keinem anderen Menschen entweint werden soll, mit einer feierlichen, ja fast sakralen Geste hinab ins Meer.

Das Urerlebnis der Treve war Goethes eigenes Problem und auch Tjutčev war persönlich davon betroffen. 2 Trotz der Entrückung des Geschehens ins Märchenhafte, in die welt ierner Vergangenheit, die so kaum wahr ist, beruht die außerordentliche wirkung der Ballade darauf, daß wir den wert der Treue für den Menschen als eine höhere Wahrheit unmittelbar begreifen. ${ }^{3}$ Diese zentrale Mitteilung war es wohl, die Tjutčev an der Ballade vom "König in Thule" fasziniert hat.

1 Wie Carl Roos in seiner Interpretation der Ballade gezeigt hat, wird diese Symbolik bei Goethe noch dadurch hervorgehoben, daß "Buhle" mit "Becher" und "trinken" mit "treu" alliteriert. C. ROOS, Faustproblemer. Kobenhavn 1941. S. 13. Zitiert nach St. STEFFENSEN, a.a.0., S. 36-37.

2 Interessant ist in diesem Zusammenhang, daß Goethe, als er den "König in Thule" verfaßte, und TjutZev, als er die Ballade Ubersetzte, etwa gleich alt waren. Goethe war fast 25 und Tjutčev 27 Jahre alt.

3 Vgl. W. ROSS, a.a.0., S. 150. 


\subsubsection{3. "Der Sänger"}

Von dieser Ballade, die vermutlich 1783 in Weimar entstanden ist, existieren verschiedene Fassungen. Ursprünglich stand sie in "wilhelm Meisters theatralischer Sendung"1, eine abgeänderte Fassung mit der überschrift "Der Sänger" befindet sich - losgelöst vom Roman - in den "Gedichten" ("Ausgabe letzter Hand" 1815 und 1827) in der Gruppe "Balladen". Diese Fassung liegt TJuttevs übersetzung ("Pevec") zugrunde.

Im Gegensatz zu den anderen Gedichten aus "wilhelm Meister", die von den singenden Gestalten nicht gänzlich zu trennen sind, kann "Der sänger" auch für sich bestehen, er mus nicht als Rollenlyrik verstanden werden.

Die Ballade vermittelt den Eindruck einer dramatisch geprägten szene, die sich nicht nur durch Gebärden veranschaulichen läßt, sondern sich wie ein Spiel aus Handlungen und Gesprächen zwischen den agierenden Personen aufbaut. Im lebendigen Gegenliber von Sänger und Zuhörern entwickelt sich ein kleines Drama im stil der Ballade. Der dramatisierende Charakter ermöglicht es dem Leser oder Zuhörer, innerlich mitzuspielen. Die rein epischen Elemente fuhren andererseits dazu, daß eine gewisse Distanz den dramatischen Vorgängen gegenüber gewahrt bleibt. 2

1 Da dieser Roman 1783 geschrieben murde, kann man von einer gleichzeitigen Entstehung der Ballade ausgehen. Vgl. HA I, S. 566.

2 Vgl. E. KEPAOFF, Kleine deutsche Stilistik. Bern und Minchen 1962. S. 66-67. 
Im Mittelpunkt steht der Sänger. Er preist die prächtige höfische Ungebung sowie die Tapferkeit und Schönheit der Menschen. Gleichzeitig verkündet er Rang und Würde des Dichters als eines Menschen, der dem König durchaus ebenbürtig ist. In fünf von sechs strophen huldigt Goethe dem Sänger, in vieren läßt er ihn mit wörtlicher Rede hervortreten.

Die Einleitungsstrophe zeigt sich, im Gegensatz zu der breit ausgefuhrten Szene, die dem Sänger gilt, in äuBerster verdichtung. Wenige zeilen genügen, um uns in die historische Umgebung einzuführen.

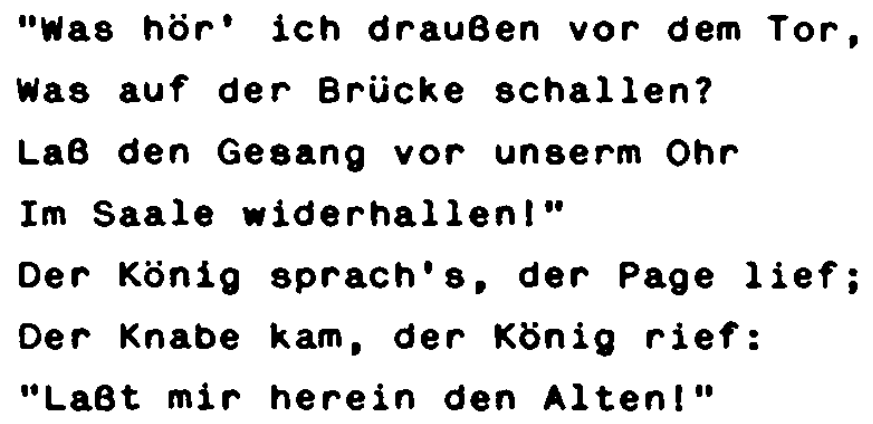

(HA I, S. 155-156)

Die Strophenform ist von Luthers "Aus tiefer Not schrei ich zu dir" übernommen. Das Charakteristische dieser als "Lutherstrophe" in die Poetik eingegangenen form liegt in ihrer deutlichen Zweiteilung: einem vierzeiligen Aufgesang im Kreuzreim abab und einem oreizeiligen Abgesang, der sich aus einem männlich endenden Reimpaar (zeile fünf und sechs) und einem reimlosen Schlubvers zusammensetzt. 1

1 Vgl. H.J. FRANK, Handbuch der deutschen Strophenformen. Minchen 1980. S. 543; W. HINCK, Goethes Ballade "Der untreue Knabe". Zur Geschichte der siebenzeiligen Strophe in mittelalterlicher und neuerer deutscher Lyrik. In: Euphorion 56 (1962). S. 25-47. Hier S. 43. 
Tjuťev ahmt diese Form genau nach:

"что там за звуки пред крыльцом,

За гласы пред вратамн?..

В высоком тереме моем

Раздаяся песнь пред нами!.."

Король сказал, и паж бежит,

Вернулся паж, король гласит:

"Скорея впустите старนа!.." 1

(TJUTČEV II, S. 98-99)

Wie bei der Vorlage bestent die russische strophe aus jambischen vierhebern mit männlicher und Dreihebern mit weiblicher Kadenz.

Während die ersten fünf Zeilen einer strophe häufig mit einem SatzschluB oder einer Pause enden, sind von Zeile sechs zu zeile sieben die sätze meist herübergezogen, so daB am strophenschlub ein langer satz steht.

"Die goldne Kette gib mir nicht,

Die Kette gib den Rittern,

Vor deren kühnem Angesicht

Der Feinde Lanzen splittern!

Gib sie dem Kanzler, den du hast,

Und lab ihn noch die goldne Last

Zu andern Lasten tragen!"

Durch das Enjambement erhält die Strophe ihre Abrundung und zugleich einen festlich-stimmungsvollen Ton.

Auch bei Tjutčev endet die vierte strophe mit einem die sechste und siebente zeile umfassenden Satz:

1 "Was für Laute gibt es dort vor dem Aufgang, /Was für Stimmen vor den Toren? ..../In meinem Gemach/Ertöne das Lied vor uns! ..."/Der König sprach, und der Page läuft,/Der Page kam zurück, der König ruft:/"Laßt den Alten schneller herein! ..." 


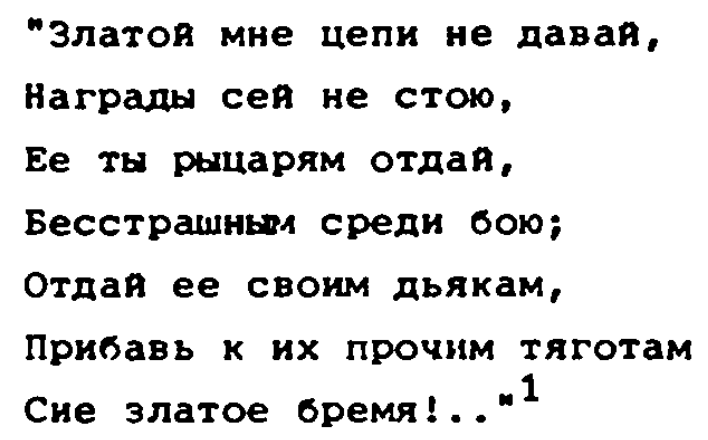

Mit knapper Beschreibung einiger Detalls, auBen Brücke und Tor, innen ein Festsaal, ruft Goethe beim Leser Assoziationen an das Mittelalter hervor. Tjuttev verstärkt diesen Eindruck durch eine bewubte Archaisierung der Sprache.

Er meidet den Gebrauch der modernen Polnoglasie-Formen, so heist es "zlatoj" statt "zolotoj", "pred" statt "pered", "vrata" statt "vorota", und "glas" statt "golos". In die Vergangenheit weisen ebenso verben wie "glasit" (in der Bedeutung von "rufen"), "molvit", "Cajat", und Substantive wie "mzda" und "oti".

Goethes altertümlich wirkende Umschreibung "Der Sänger orückt die Augen ein" 2 ubersetzt Tjutčev sinngemäs richtig mit der im modernen Russisch ebenfalls ungebräuchlichen Wendung "SedoJ pevec glaza smežil". 3

Die mittelalterliche Atmosphäre wiro in Tjutčevs übersetzung unterstrichen durch die verwendung des neute nur noch in bestimmten Ausorucken verwendeten Demonstrativpronomens "sej".

In Goethes Gedicht lassen sich verschiedene figurationen erkennen. Am auffäligsten ist die wiederholung,

1 "Gib mir nicht die goldene Kette,/Dieser Auszeichnung bin ich nicht wirdig,/Gib du sie den Rittern zurick,/(Die) furchtlos inmitten des Kampfes (sind);/Gib sie deinen Beamten,/Füge zu ihren übrigen Lasten/Diese goldene Bürde hinzu! ..."

2 Vgl. DEUTSOAES WÖRTERBUCH, a.a.O., Bd. 3. Sp. 164.

3 Der ergraute Sänger schloß die Augen. 
die auch als Variation vorliegt. Ein wort oder sein sinn treten dabei zweimal auf, wobei beide Male beim Leser die gleiche Assoziation hervorgerufen wird.

Tjuť̌ev bemüht sich in seiner Übersetzung um eine Nachbildung dieser schlichten poetischen form.

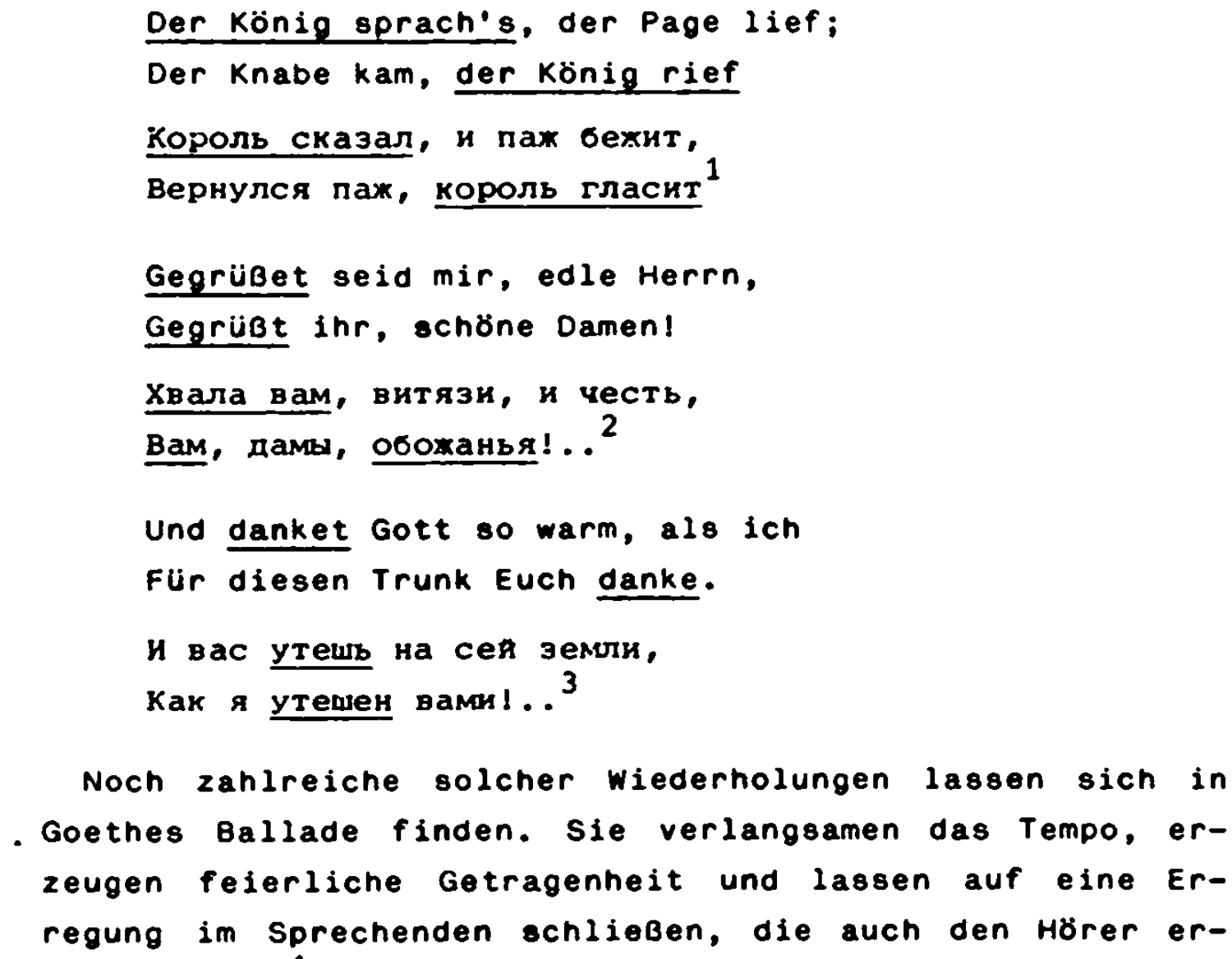

1 Der König sprach, und der Page läuft,/Der Page kan zurück, der König ruft.

2 Lob ihnen, Helden, und Ehre,/Ihnen meinen Damen - Verehrung.

3 Und tröste euch auf dieser Erde/wie ich von ouch getröstet murdel ...

4 Vgl. E. KERADFF, a.a.0., S. 69. 
Verschiedentich gelingt es TjutCer jedoch nicht, eine formal angemessene wiedergabe zu liefern. Den metaphorischen Ausdruck "Welch reicher Himmell stern bei Stern!", der die höfische Atmosphäre bezeichnen soll, übersetzt Tjuť̌ev schlicht mit "Kak zvezdy $v$ nebe perecest.". 1 Und das Polyptoton in der Rede des Sängers

Und lab ihn noch die goldne Last

Zu andern Lasten tragen!

findet keine Entsprechung in der russischen Fassung.

Прибавь к их прочим тяготам

Сие златое оремя!..2

Die auch in der funften Strophe mehrmals auftretenden wiederholungen bestimmter Begriffe werden von Tjutčv nicht beachtet.

"Ich singe, wie der Vogel singt,

Der in den Zweigen wohnet;

Das Lied, das aus der Kehle dringt,

Ist Lohn, der reichlich lohnet.

Doch darf ich bitten, bitt ich eins:

LaB mir den besten Becher Weins

In purem Golde reichen!"

Inhaltlich genau, aber formal nicht adäquat lauten diese Zeilen bei TJutčev:

1 Wie die Sterne in Himel auf zuzählen.

2 Füge zu ihren übrigen Lasten/Diese goldene Bürde hinzu! ... 
на божье воле я пог,

Как птичка в поднебесье,

Не чая мзды за песнь свою -

мне песнь сама возмездье!..

Просил бы милости одноя,

Вели мне кубок золотоя

Вином наполнить светлым!

Die wiederholung im deutschen Gedicht bewirkt, daß vorstellungen und Gedanken fester zusammengeschlossen werden, räumlich Getrenntes miteinander verbunden, zerstreutes geordnet wird. ${ }^{2}$ Durch die häufig formal ungenaue wiedergabe drohen Aufbau und struktur der Ballade im Russischen verlorenzugenen.

Besonders plastisch wird Goethes Ballade durch den symmetrischen Aufbau. Die Symmetrie dient in erster Linie der Gestaltung des Gehaltes, besonders ausgeprägt ist sie daher in der Parataxe. Bei dieser Figuration bildet eine Erscheinung das Gegenstuick zur anderen. Gewisse Elemente sind gemeinsam, andere unterschiedich. Die Symmetrie besteht im logischen, syntaktischen, im bildichen oder im rhythmischen Bereich. Manchmal umgreift sie sogar ganze strophen. 3

So spiegeln die beiden ersten Zeilen des Gedichtes die beiden folgenden formal und inhaltlich wider. Formal steht einer rhetorischen frage mit zwei adverbialen Bestimmungen des Ortes drauben (vor dem Tor, auf der Brücke) ein Imperativ mit zwei adverbialen Bestimmungen des Ortes arinnen (vor unserem Ohr, im Saale) gegenuber. Inhaltilich geht es um den Gesang vor dem Tor und um seinen widerhall im Saale. 4

1 Ich singe in göttlicher freiheit, Nie ein Vögelchen in der Höhe,/ Nicht hoffend auf Auszeichnung für mein Lied -/Ist mir das Lied selbst Lohn genug .../ICh möchte nur um eine Gabe bitten,/Befiehl mir einen goldenen Becher/Mit klarem wein zu füllen!

2 Vgl. E. KERWOFF, a.a.O., S. 69.

3 Vgl. ebd. S. 69-71.

4 Vgl. E. KERWHOFF, a.a.0., S. 70. 
"Was hör" ich drauBen vor dem Tor,

Was auf der Brücke schallen?

LaB den Gesang vor unserm Ohr

Im Saale widerhallen!

Die russische wiedergabe ist sowohl formal wie inhaltlich exakt.

"что там за звуки пред крыльцом,

3 ал гласы пред вратами?..

В высоком тереме моем

Раздаяся песнь пред нами!..." 1

Auch hier handelt 88 sich um eine rhetorische frage mit zwei adverbialen Bestimmungen des Ortes drauben lpred kryi'com; pred vratamil und um einen Imperativ mit $2 w e i$ adverbialen Bestimmungen des Ortes drinnen (v vysokom tereme moem, pred namil.

Während Goethe die räumliche spaltung durch die Infinitive "schalien" - "widerhallen", die Jeweils am Schlub eines Satzes stehen, unterstreicht, enden in der russischen version die beiden satze mit den entgegengesetzten Ortsbestimmungen "pred vratami" und "pred nami". Die Symmetrie erhalt eine antithetische Funktion.

Der zentrale Gegenstand der ersten vier verse des Goetheschen Gedichtes ist der Gesang, im ersten Zeilenpaar hervorgehoben durch die wiederholung des fragepronomens "was" und im zweiten Zeilenpaar durch die Nennung des Begriffs selbst. 2

Auch in der russischen Fassung ist das Lied des Sängers gegenständlicher Angelpunkt der ersten beiden Sätze.

1 "Was für Laute gibt es dort vor dem Aufgang, Nas für Stimmen vor den Toren? ....IIn meinem Gemach/Ertöne das Lied vor mir! ..."

2 Vgl. E. KERAHDFF, a.a.O., S. 70. 
Tjutter benutzt drei verschiedene Bezeichnungen: "zvuki", "glasy" und "pesn"", wobei die Begriffe - und somit auch die Vorstellung des Königs vom Gehörten - immer exakter werden. Die drei Bezeichnungen rufen, obgleich bedeutungsmäbig nicht identisch, beim Hörer ähnliche Assoziationen hervor.

Ebenfalls symmetrisch aufgebaut sind die zeilen fünf und sechs der deutschen Ballade.

Der König sprąch's, der Page lief;

Der Knabe kâm, der König rief

In beiden Zeilen wechseln Aktion und Reaktion (sprach's lief; kam - rief) einander ab. Semantisch zeichnet sich dies auch im Gehen und Kommen des Pagen in der zweiten Hälfte von zeile fünf und der ersten Hälfte von zeile sechs ab.

Entsprechend aufgebaut sind die russischen Verse:

Король сказал, и паж бехйт,

Вернулся паш, король гласйт ${ }^{1}$

Die symmetrie reicht bis in die klangliche Gestaltung der Verse. Wie im Original stehen sich in beiden zeilen ein weites offenes [a] und ein enges, geschlossenes [i] bzw. [y]gegenüber. ${ }^{2}$ Um diese lautliche Entsprechung zu erreichen, stellt Tjutčev in der ersten Hälfte der zweiten zeile subjekt und Prädikat um und wechselt die Tempora der Verben.

Der symmetrische Aufbau der strophe im dargestellten Sachverhalt, in der Klanggestalt und auch im Satzbau verursacht den bewegten Rhythmus der Verse. So enthalten die zellen fünf und sechs sowohl vom Rhythmus als auch

1 Der König sprach, und der Page läuft/Der Page kam zurïck, der König ruft.

2 Vgl. E. KERWOFF, a.a.0., S. 71. 
von der Bedeutung her ein Ansteigen der Spannung, die dann in der Schlubzeile gelöst wird: Der König bittet den Sänger hinein.

Tjutter hat das rhythmische Auf und $A b$, das sich durch die ganze Ballade zieht, gespürt und verstanden, diese Bewegung in seiner wiedergabe zu erhalten.

Im Zentrum der Ballade stehen Goethes überlegungen zum Selostverständnis des Künstlers. Die Rede des Sängers, die den ganzen zweiten Teil des Gedichts umfaßt, beginnt mit der unumwundenen Ablehnung des ehrenden Geschenks. Nur dadurch kann er sich seine Unabhängigkeit vom König bewahren. Dem Nein zur goldenen Kette folgt das Bekenntnis des Sängers zur Kunst. Er vergleicht seine künstlerische freiheit mit der freiheit eines vogels. Wie der vogel nur um des Gesanges selbst willen singt, so ist auch der höchste Lohn des Dichters allein das Lied selbst.

Die Gabe, um die er den König bittet, hat keinen materiellen wert: einen Schluck besten weins, gereicht in einem goldenen Becher. Nur eine solche symbolische Gabe ist inm und seiner Kunst angemessen. 1 sie kennzeichnet den Sänger als dem König ebenbürtig. Zwei stolze Menschen stehen sich gegenüber. 2

Goethe sieht die Rolle des Dichters in dieser Ballade unter zwei Aspekten. Auf der einen seite nimmt der Sänger teil am geselligen Leben und rünmt die Schönneit der Welt. Die menschliche Gesellschaft ist schön und er -

1 Vgl. "Der König in Thule". Auch in dieser von Tjutčov übersetzten Ballade kormt einem goldenen Becher Symbolbedeutung zu.

2 Vgl. W. GReNDWN, Joham Wolfgang Goethe. Der Sänger. In: Wege zum Gedicht. Bd. 2. Minchen-Zürich 1964. S. 169-175. Hier S. 170 171. 
der Künstler - macht sie durch seine Dichtung noch schöner. Seine Kunst will den Menschen vorgetragen werden und bedarf, wenn auch nicht materieller Gaben, so doch der Anerkennung und Zustimmung.

Auf der anderen seite bleibt der Dichter allein, er bleibt araußen. Trotz seines geselligen wesens schliebt er sich doch nur vorübergehend anderen Menschen an. So wahrt er seine Unabhängigkeit, ohne die seine Kunst nicht gedeihen könnte. 1

Eine solche Künstlerexistenz, unabhängig von der Gesellschaft, geprägt vom Spannungsverhältnis zwischen Einsamkeit und geselliger Umgebung, verkörpert beispielnaft TjutČevs Leben.

Bereits Tjutčevs erster Biograph Ivan Aksakov weist darauf hin, wie genau die Zeilen

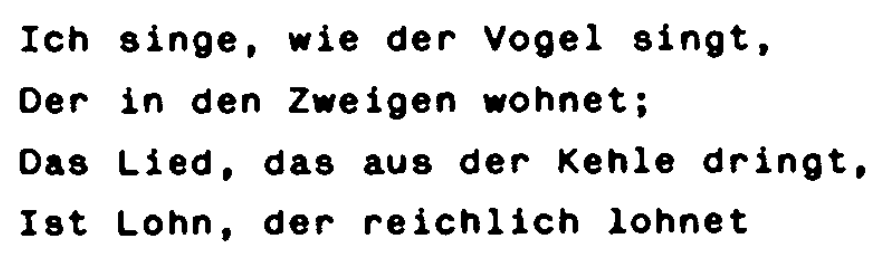

die Einstellung des russischen Dichters zu seinem Tun widerspiegeln.2

Dichten war für Tjutčev niemals Broterwerb. Der Verbffentlichung - und sogar der Bewahrung - seiner Werke stand er eher gleichgültig gegenüber. Er schrieb - für sich und für seine freunde - aus Freude am Dichten selbst.

1 Vgl. M. KOMERELL, a.a.0.. S. 156.

2 Vgl. I.S. AKSAKOV, a.a.0., Sp. 104-105. 


\subsubsection{Spruch und Epigramm}

\subsubsection{Lyrische Kleinformen in der deutschen und russi- schen Literatur}

Die Entwicklung oer Kurzlyrik in RuBland ist eng verknüpt mit der Wirkungsgeschichte des antiken Epigramms in westeuropa, besonders in Deutschland.

Das Epigramm, ursprünglich eine Grab- oder Weihinschrift, faßt in sich mannigfaltige Formen und strukturen und ist somit auch von wesentlicher Bedeutung für das dichterische wesen der verschiedenen lyrischen Kurzgedichte, wie z.B. das kleine Lied, das Briefgedicht und den Spruch.

Im alten Griechenland standen kleine Gedichte in hohem Ansehen. Zunächst existierten sie nur als Aufschriften auf Standbildern und Grabmälern, wo sie dem Beschaver in knapper Form die Bedeutung des Gegenstandes erläutern sollten, entwickelten sich mit der zeit aber unabhängig vom Denkmal und dienten auch der würdigung von hervorragenden Persönlichkeiten, Büchern und Taten.

Schlieblich wird das Epigramm zum lyrischen Kurzgedicht, meist im elegischen Versmaß, in dem Gedanken, Anekdoten, Empfindungen - und später auch Satirisches pointiert formuliert werden können.

In der berühmten "Griechischen Anthologie" "Anthologia Graeca"), einer spätantiken Sammlung von Gedichten aus mehr als zwölf Jahrhunderten, sind der Nachwelt etwa 3700 Epigramme verschiedenster Art erhalten geblieben. 1

1 Näheres zu dieser Samlung und inrer Geschichte, der Geschichte der Epigrammatik sowie einen Überblick uber den modernen Forschungsstand vgl. $H$. BECKBY, Einfürung in die Griechische Anthologie. In: Anthologia Graeca. Griechisch-Deutsch. Hrsg. Hermann Beckby. 4 Bde. Miinchen 1957-58. Hier Bd. 1. S. 9-99. 
Aufgegriffen wird die griechische Tradition epigrammatischer Dichtung in der römischen Antike. Besonders Martial, Catull und Ausonius widmen sich dem Epigramm, wobei sie die Möglichkeiten dieser Gattung auf recht unterschiedliche weise nutzen. 1

In der lateinischen Dichtung des Mittelalters führt das Epigramm eine Randexistenz, in der deutschen Dichtung dieser zeit fehlt es völlig.

Neue Bedeutung gewinnt das Epigramm erst wieder in der Renaissance, in lateinischer sprache pflegen es Humanisten wie Sabäus, Euricius, Cordus und Grudius, in die deutsche Dichtung führt es schlieblich Martin Opitz ein.

Lessing, der neben Abraham Gotthelf Kästner den Höhepunkt der deutschen Aufklärungsepigrammatik verkörpert, beschäftigt sich auch als Theoretiker ausführlich mit dieser Gattung.

In seiner 1771 entstandenen Schrift "Zerstreute Anmerkungen über das Epigramm und einige der vornehmsten Epigrammatisten" 2 deutet Lessing das wesen dieser Gattung überwiegend unter formalen Gesichtspunkten. Die in der ursprünglichen Bedeutung des Begriffs implizierte Zweigeteiltheit von Gegenstand und Aufschrift uberträgt Lessing auf die Struktur des Epigramms selbst.

Wie die Aufschrift zunächst unzertrennlich mit dem Gegenstand, den sie zierte, verbunden war, so sollen sich diese beiden Komponenten auch in einem vom Gegenstand losgelösten Epigramm finden lassen. Die so ent-

1 Während sich Catulls Epigramm besonders durch die Urmittelbarkeit des Erlebnisses hervortut, gelten seit Martial formales Können, Witz und Satire als genreprägendes wesen des Epigramms. Vgl. A. SCHULE, a.a.0., S. 18.

2 Abgedruckt in: G.E. LESSING, Werke. 8 Bde. Minchen 1970-1979. Hier Bd. 5. S. 420-529. 
stehenden aufeinanderfolgenden Teile bezeichnet Lessing mit den Begriffen "Erwartung" und "AufschluB", wobei ersterer für das Denkmal und zweiterer für die Aufschrift stent. 1

Lessings einseitige Orientierung an der ratio - im Mittelpunkt seiner Betrachtungen steht immer das scharfe, das satirische Epigramm - weckt widerspruch. Friedrich Gottlieb Klopstock läßt auch das betrachtende Epigramm gelten:

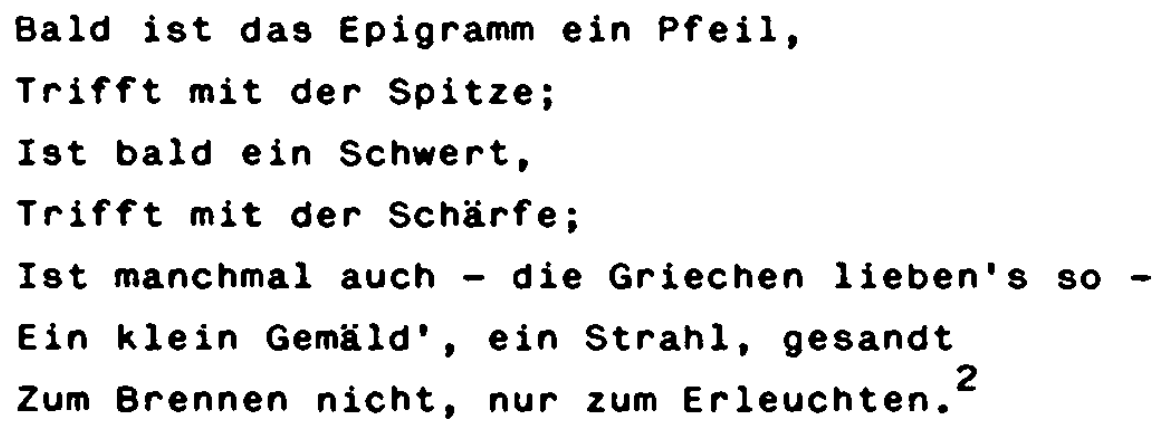

Auch Johann Gottfried Herder wendet sich von Lessing ab. Seine Definition des Epigramms ist sehr viel weiter gefaBt, er verwischt die Grenze zwischen Epigramm und Sinnspruch. Statt Kürze und Pointe verlangt er die Einheit des Gesichtspunkts, unter dem der Gegenstand betrachtet werden soll.

Er verlegt somit das Schwergewicht vom "AufschluB", Herder spricht von "Befriedigung", auf die "Erwartung", bei Herder "Darstellung" oder "Exposition".

1 Vgl. G.E. LESSING, a.a.O., Bd. 5. S. $424-427$.

2 Abgedruckt in: F.G. KLOPSTOCK, Ausgewählte Werke. Hrsg. Karl August Schleiden. Minchen 1962. S. 180. Vgl. A. SOHULE, a.a.O., S. 19. 
"Auch hier bleibt ... die Exposition das Hauptwerk und die Pointe ist nur der goldene Lichtstrahl, der das object erhellet und ordnet, der seine Theile sondert und sie aufs schönste wieder zu Einem Ganzen verbindet." 1

Herders außerordentliches Verdienst ist es, als erster Dichter deutsche Epigramme in antiken Versmaßen geschaffen zu haben. Waren die Epigramme der Aufklärungsdichtung noch durchweg in den alten madrigalischen Reimversen verfaBt, die dem Epigramm als Gattung - witzig, pointiert, rational - sehr entgegenkamen, so verhilft Herder dem Epigramm "griechischer Art" zum Durchbruch und bürgert das Distichon als Strophenform ein.

Seine 1780 begonnenen Nachdichtungen aus der "Anthologia Graeca", die er fünf Jahre später unter dem Titel "Blumen aus der griechischen Anthologie gesammlet" ${ }^{2}$ veröffentlicht, regen Goethe zu umfangreichem epigrammatischem Schaffen an.

Im Gegensatz zu Herder, der überwiegend griechische Epigramme - meist über das Lateinische - ins Deutsche ubersetzt, dichtet Goethe auch eigene Epigramme in antiken versmaßen. Abgesehen von den "Xenien", die Lessings vorstellung von einem Epigramm nahe kommen, wandelt Goethe dabei uberwiegend in Herders Bahnen.

So strebt Goethe nicht immer nach pointierter Kürze, sondern er malt aus, entwickelt eine plastische Bildkraft. Seine Epigramme haben im Gegensatz zur Aufklärungsepigrammatik etwas Stilles und Nachdenkliches

1 J.G. HERDER, Sämntliche Werke. Hrsg. Bernhard Suphan. 33 Bde. Berlin 1877-1909. Hier Bd. 15. S. 356. Weitere Amerkungen Herders zum griechischen Epigram und zur Anthologie der Griechen ebd. S. 205-221 und S. 337-392. Vgl. hierzu auch Herders Ausführungen über Lessings Armerkungen über das Epigram J.G. HEROER, a.a.O.., Bd. 5. S. 338-345.

2 J.G. HEROER, a.a.0., Bd. 26. 
an sich. Konzipiert sind sie ursprünglich tatsächlich als "Inschriften" für Steine.

Goethes Gedanken über das Leben, die liebe und die Kunst finden sich jedoch nicht nur in seinen antikisierenden Epigrammen, sondern auch in den gereimten Kurzgedichten, die häufig zwischen der epigrammatischen Dichtung plaziert sind.

Beide Formen sind ihrer Sinngebung nach tatsächlich nicht weit voneinander entfernt. Eine gewisse Bewubtheit des Sprechens, ein ordnendes Verfahren ist sowohl dem eher auf die Gesellschaft ausgerichteten wesen des Epigramms als auch dem mehr stimmungshaften Kurzgedicht eigen. 1

Die Einsicht in diese strukturelle Verwandtschaft beider Gattungen führt direkt zur Kurzlyrik Tjutčevs.

Der russische Dichter war mit Goethes "kleinen" Gedichten bestens vertraut, neben dem Epigramm "Sakontala" ("will ich die Blumen des frühen, die Früchte des späteren Jahres") ubersetzte er verschiedene Kurzgedichte, wie 2.B. "Nachtgedanken" und zwei Harfnerlieder aus

1 Als Beleg für die Parallelität beider Gattungen stellt Almut Schulze Goethes Gedicht "Wandrers Nachtlied" Herders Übertragung eines anonymen griechischen Epigrams mit dem Titel "Die schöne Fichte" gegenüber. Vgl. A. SOHLZE, a.a.0., S. 21.

Unseren Ausführungen zum Wesen und zur Entwicklung lyrischer Kleinformen, besonders des Epigramm, liegen folgende Werke zugrunde: J. WIEGAND, Art. Epigram. In: RL. Bd. 1. S. 374-379; E. BEUTLER, Vom griechischen Epigram im 18. Jahrhundert. Leipzig 1909 (Probefahrten 15); A. SOHULE, a.a.O., S. 17-23; HA I, S. 620-621. Auf weiterführende Literatur wird besonders in dem Artikel des Reallexikons der deutschen Literaturgeschichte verwiesen. 
"wilhelm Meister". - Direkte Impulse erhielt TjutČev weiterhin von Heine, der in seinem "Buch der Lieder" ebenfalls Kleinformen der Lyrik entwickelte. 1

Tjuť̌ev, der lyrischen Kleinformen zeit seines Lebens besondere Aufmerksamkeit widmet - Pigarev bezeichnet inn als "Meister des Vierzeilers" ${ }^{2}$-, verschmilzt in seiner eigenen Dichtung Epigramm (antikes Versmaß) und Kurzgedicht (Reimverse) zu einer Einheit. Dabei läßt er die metrischen Unterschiede unberücksichtigt, das elegische Versmaß als ein signifikantes Merkmal des Epigramms fällt weg. 3

Tjutčevs Epigramme und Sprüche müssen nicht zuletzt vor dem Hintergrund der in Munchen lebendigen Salonkultur gesehen werden. Auf zahlreichen abendlichen Gastlichkeiten profiliert sich der russische Dichter als amisanter Unterhalter und scharfer Beobachter.

Seine Sprüche und Epigramme weisen dabei eine vielzahl von Themen und Haltungen auf. Neben scharfen Stellungnahmen zu politischen, gesellschaftlichen und literarischen Ereignissen, 4 formuliert Tjutčev vor allem widmungen und scherze, sowie Grüße an Freunde

1 Vgl. A. SCAULZE, a.a.0., s. 22.

2 K. PIGAREV, Tjutčev, a.a.0., S. 297.

3 Vgl. A. SOHLZE, a.a.0., S. 20-21.

4 Z.B. in dem fünfzeiler auf den 1855 verstorbenen Zaren Nikolaus I: "Ne bogu ty služil i ne Rossii". 
und Bekannte in knapper Form. ${ }^{1}$

Empfindungen, die seine eigene Person betreffen, wie Einsamkeit, Trauer und Todesahnung faBt Tjuttev in eine Reihe von Sprüchen. Hier gibt er das Charakteristikum des satirisch-kritischen Epigramms - die Zweigeteiltneit - auf. 2

Unmittelbare Anregungen für seine Kurzlyrik ernält Tjuťev jedoch nicht nur von der antiken Kleindichtung und den von Goethe und Heine geschaffenen Lied- und Spruchformen, sondern der russische Dichter kann auch an eine russische Tradition epigrammatischer Dichtung sowie an die Arbeiten verschiedener russischer Literaturtheoretiker uber das griechische Epigramm anknüpfen.

1 Zum fünften Todestag Žukovskijs 1857 war der zehnte Band der gesammelten Werke des Dichters in St. Petersburg erschienen. Tjutčev, der U.a. neben P.A. Pletnev und P.A. Vjazemskij an der Herausgabe dieser Ausgabe beteiligt war, schenkte seiner Tochter Dar' ja nach ihrer eigenen Aussage den gerade fertiggestellten Band mit folgendem Vierzeiler auf dem Titelblatt, der von TjutCevs Achtung vor Yukovskij zeugt:

Prekrasnyj den' ego na Zapade išez, Polneba obchvativ bessmertnoju zare ju,

A on iz glubiny polunotnych nebes -

On sam gljadit na nas proročeskoj zvezdoju.

TJUTCEV II, S. 142. Vgl. ebd. S. 369; A. SOHULZE, a.a.O., S. 83.

2 Aus dem Jahre 1867 starmen folgende Verse:

Kak ni tjažel poslednij Cas -

Ta nepon jatnaja dl ja nas

Istoma smertnogo stradan' ja, -

No dlja duši esce strašnej

Sledit' kak vymirajut $v$ nej

Vse lučsie vospominan' ja ...

TJUTČCEV I, S. 211; Vgl. A. SOHULZE, a.a.O., S. 83. 
Bereits Gavriil R. DerYavin lieferte verschiedene Übersetzungen von Epigrammen der "Anthologia Graeca", eine größere Verbreitung erlangt das lyrische Kurzgedicht in RuBland Jedoch erst durch Schöpfungen Denis Vasileevil Davydovs und V.A. Zukovskijs.

Bereits im Jahre 1800 verfaBt Žukovskij das Alexandrinerepigramm "K Platonu", es folgen - abgesehen von seinen wiedergaben aus Goethe und Herder ${ }^{2}$ - verschiedene schöpfungen, in denen er die spruchdichtung, wie Goethe sie entwickelt hat, aufnimmt. ${ }^{3}$

Noch einmal wendet sich Žukorskij im Jahre 1837 epigrammatischer Dichtung zu. Es entsteht ein Zyklus von acht Epigrammen, 4 niedergeschrieben in einem versalbum, das für eine befreundete Dichterin bestimmt ist. 5

1 2.B. "Spjaß̌cij Érot" (1795), "Gorjučij kljuX̌" (1797), "Okovy" (1809). Erläuterungen $z u$ den drei genannten übersetzungen DerŽavins aus der Griechischen Anthologie sowie die Wiedergabe der griechischen Vorlagen vgl. G.R. DERZAVIN, Sočinenija. Hrsg. Ja. Grot. 8 Bde. St. Peteraburg 1864-1866. Hier Bd. 1. S. 679681 ; Bd. 2. S. 128-130; Bd. 3. S. 6-7.

2 Im Jahre 1829 ibersetzte Žukovskij Herders Epigramm "Zeiten hinab und Zeiten hinab, tönt ewig Homerus", dem er den Titel "Homerus" gibt. Veröffentlicht wird diese übersetzung postum im Jahre 1884. Vgl. ZuKOVSKIJ I, S. 464.

3 2.B. in "K Portretu Gete" (1819), "Vospominanie" (1821) und "K ravnodus̆noj krasavice" (1831).

4 "Roza", "Lavr", "Nadgrobie Junoše", "Golos mladenca iz groba", "Mladost" i starost"", "Fidij", "Sud'ba" und "Zavistnik".

5 Vgl. ŽUKOVSKIJ I, S. 467. 
Sowohl als Literaturtheoretiker wie auch als Dichter widmet sich Konstantin Nikolaevit Batjułkov dem Epigramm.

In dem 1820 zusammen mit S.S. Uvarov veröffentlichten werk "O GreXeskoj antologii"1 finden sich neben übersetzungen Batjuškovs aus der Griechischen Anthologie auch ein hinführender Aufsatz, der dem russischen Leser inhaltliche und formale Besonderheiten der griechischen Epigrammatik nahe bringen soll.2

Die Verfasser legen besonderen Wert auf die unterschiediche Bedeutung des Begriffs "Epigramm" im modernen und im griechischen Sprachgebrauch:

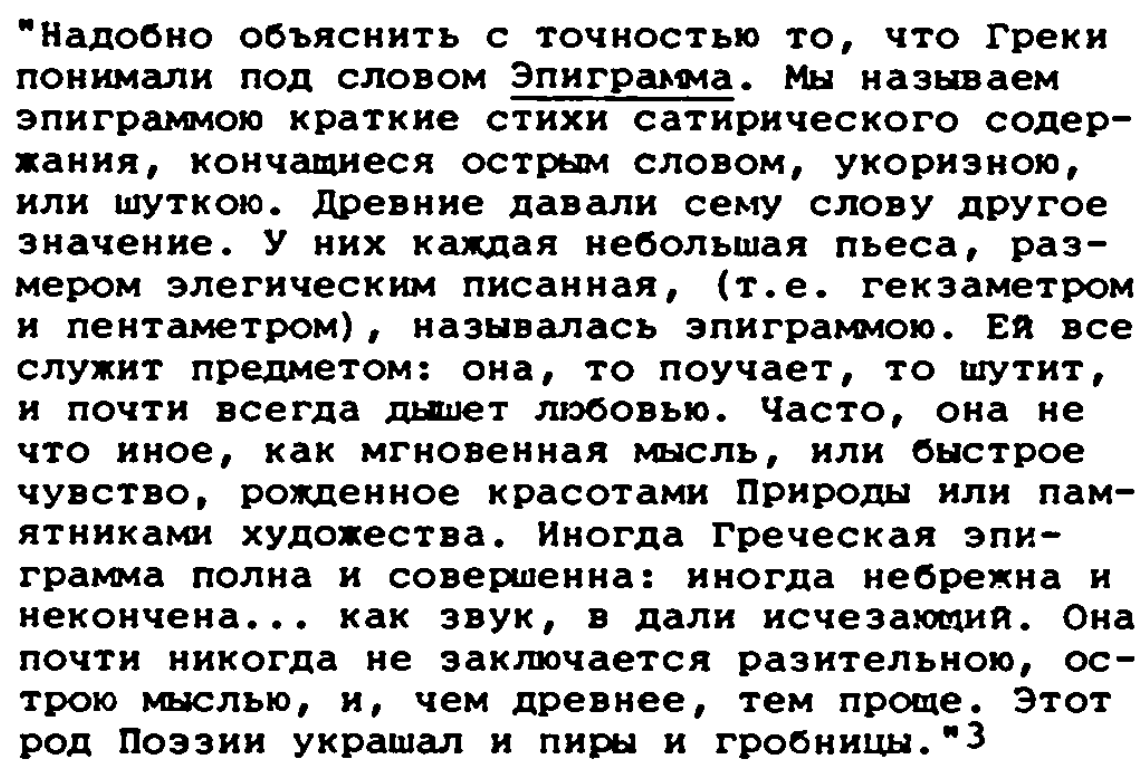

1 K.N. BATJǓKKOV, S.S. UVAROV, O GCě̌eskoJ antologii. St. Petersburg 1820. Abgedruckt in: K.N. BATJUSKKOV, SoŽinenija. Hrsg. Aleksandr Smirdin. 2 Bde. St. Petersburg 1850. Hier Bd. 2. S. 267-294.

2 Batjuškovs Wiedergaben stammen aus der Zeit zwischen 1817 und 1818. Sie sollen als Illustration zu den vermutlich von Uvarov und Batjuăkov gemeinsam verfaßten Ausführungen iuber die Griechische Anthologie dienen. Da Batjuß̌kov jedoch selbst kein Griechisch konnte, stützen sich seine Wiedergaben auf Ubersetzungen Uvarovs ins Französische, die ebenfalls in dem 1820 veröffentlichten Bändchen abgedruckt sind. Vgl. K.N. BATJǔKKOV, Opyty $v$ stichach i proze, a.a.0., S. 573.

3 K.N. Batjuškov, Sočinenija. Hrsg. A. Smirdin, a.a.0., Bd. 2. S. 269-270. (Unterstrichene Stellen im Original kursiv gedruckt). 
Einen ersten Widerhall finden die überlegungen Batjułkovs und Uvarovs zum wesen des antiken und modernen Epigramms bereits im Jahre 1821 in dem von Nikolaj Ostolopov herausgegebenen "wörterbuch der Dichtkunst". 1 Ostolopov zitiert verschiedene Abschnitte aus dem Band "O Gręeskoj antologii" und gibt u.a. vier übersetzungen Batjułkovs wieder.

Ausführlich behandelt werden in Ostolopovs Lexikon das griechische Epigramm und die "Anthologia Graeca" sowie im AnschluB daran die lateinische Epigrammatik, für die Je zwei Epigramme von Martial und Ausonius und eine Übersetzung aus Ausonius, angefertigt von G. Vostokov, als Beispiele dienen sollen.

Schlieblich bemüh sich Ostolopov auch um eine Bestimmung des zeitgenössischen Epigramms. Als wesentliches Strukturmerkmal erkennt Ostolopov dabei die Zweigeteiltheit: Darstellung und Auflobsung stehen einander gegenuiber.

1 N.F. OSTOLOPOV (Hrsg.), Slovar' drevnej i novoj poézii. 3 Bde. St. Petersburg 1821. ND München 1971 (Slavische Propyläen 113). Hier Bd. 1. Art. "Epigramma", S. 386-389. 
Weiterhin heibt es zum Wesen des modernen Epigramms:

\begin{abstract}
"Следуюине примеры, взятье иэ раэных писателея, лучше покажут существо Епиграммы. Из них мохно увидеть, что иногда предлохение и развязка Епиграммы состоят просто в разсказе, иногда предложение эаклочается в вопросе, а развязка в ответе, которые автор делает, говоря сам с собо1, или вводит лице постороннее; иногда же предложение былает в разсказе, а развязка в обрамении к тому лицу, которое слухит предметом насмешки и проч." 1
\end{abstract}

Als Beispiele führt 0stolopor im folgenden Epigramme von Ivan Ivanovic Dmitriev, Nikolaj Michajlovit Karamzin, Vasilij L'vovič Puß̌kin, Petr Andreevit Vjazemskij, Aleksandr Efimovit Izmajlov und anderen an. 2

Im AnschluB an seine Übersetzungen aus der Griechischen Anthologie dichtet Batjułkov auch eigene Epigramme, die er unter die Überschrift "Nachahmungen der Alten" ("Podražanija drevnim") stellt. 3

Weitere kleine Gedichte schafft Batjuskov, indem er aus bestimmten Abschnitten ausländischer Dichtungen selbständige neve Schöpfungen formt. Nach dieser vorgehensweise entstehen der Achtzeiler "Est' naslaždenie i V dikosti lesov" (1819), nach versen aus Byrons "Childe Harold" 4 und "Podražanie Ariostu" (1821), in dem er eine stanze von acht zeilen zu einem sechszeiler umformt. 5

1 N.F. OSTOLOPOV, a.a.O., Bd. 1. S. 396. (Unterstrichene Stellen im Original kursiv gedruckt). Vgl. A. SCAULZE, a.a.0., S. 26.

2 Vgl. A. SONLZE, a.a.0., S. 25-26.

3 Diese Epigrame stamen aus dem Jahre 1821, veröffentlicht wurden sie zum ersten Mal 1883 in der Zeitschrift "Rus"". Vgl. K.N. BATJUSKOV, Opyty $v$ stichach i proze, a.a.0., S. 576.

4 Vgl. K.N. BATJư̌KoV, Opyty $v$ stichach i proze, a.a.0., S. 574575.

5 Vgl. ebd. S. 575. 
Neben Anton Antonovit Del'vig, der bereits während seiner Lyzeumszeit epigrammatische Vierzeiler schreibt - seine "Aufschriften" regen später sogar Pułkin zu Variationen an ${ }^{1}$ - und Fedor Nikolaevit Glinka - er verfabt mit "Grečeskie devicy $k$ Junožam (Iz antologii)" ein Epigramm, das offensichtlich auf einer vorlage aus der "Anthologia Graeca" basiert, 2 wendet sich auch Aleksandr SergeeviC Pußkin dieser Gattung zu.

So entstehen in den Jahren 1820 und 1821 zahlreiche "Epigramme nach dem Geschmack der Alten" ("Ėpigrammy vo vkuse drevnich"): "Nereida", "Redeet oblakov letulaja grjada", "Krasavica pered zerkalom", "Muza", "Dioneja" und "Primety". Veröffentlicht wurden sie 1826 in einer Sammlung von Gedichten Pułkins unter der überschrift "Nachahmungen der Alten" ("Podražanija drevnim"). 3

Auch später nimmt sich Puškin epigrammatischer Dichtung an. Im Jahre 1832 verbffentlicht er in "Severnye cvety" unter dem Titel "Anfologiteskie èpigrammy" insgesamt vier Epigramme im elegischen VersmaB, 4 etwa zur gleichen zeit übersetzt er Epigramme nach französischer Vorlage.

1 So vgl. 2.8. Del'vigs 'Nadpis' na statuju florentinskogo Merkurija" mit Puškins "Na statuju igrajuß̌ego $v$ svajku" und "Na statuju igrajuscego $v$ babki".

2 Und zwar auf einem achtzeiligen Epigram Agathias. Vgl. A. SOLIZE, a.a.O., S. 31; F.N. GINKA, Izbrannye proizvedenija. Hrsg. V.G. Bazanov. B8P. Leningrad 1957. S. 462.

3 Vgl. A.S. PǓ́KIN, a.a.O., Bd. 2. S. 405.

4 Und zwar "Carskosel'skaja statuja", "Otrok", "Rifma" und "Trud". Vgl. A.S. PUSKIN, a.a.0.., Bd. 3. S. 506. 
Beliebt ist bei Puskin auch das nicht antikisierende Kurzgedicht, wie seine zahlreichen "Porträts" und AlbumVerse belegen.

Inspirieren läßt sich der russische Dichter nach eigenen Aussagen auch von der orientalischen Kurzlyrik, die er während seines Aufenthaltes im Süden kennenlernt. Unter diesem EinfluB entstehen 1824 "Vinograd" und "O deva-roza, Ja $v$ okovach", das nach einem türkischen Lied gedichtet ist, 1 sowie 1825 "V krovi gorit ogon" želan'ja" und "Vertograd moej sestry", zu denen inn verse aus dem "Hohen Lied" inspiriert haben."

Den Hauptbestandteil lyrischer Kurzgedichte bilden Jedoch Pułkins Liebesgedichte, wie 2.8 . der 1828 entstandene Achtzeiler "Ja vas ljubil: ljubov' ěce, byt" možet".

Petr AleksandroviC Pletnev, Professor der Literaturwissenschaft an der Petersburger Universität, widmet sich sowohl als Dichter wie auch als wissenschaftler der pflege der kleinen lyrischen form und ist damit neben Pułkin zu den bedeutendsten vorläufern F.I. TjutCevs zu zählen.

In dem 1828 erschienenen Band "Opyt Russkoj Antologii" sind zahlreiche antikisierend-epigrammatische Gedichte Pletnevs gesammelt, 2.B. "Sirota" (1820), "Al'bom" (1824) und "Rassudok i strast"" (1826).3

1 Vgl. A.S. PUĽKIN, a.a.O., Bd. 2. S. 425.

2 Vgl. ebd. S. 436.

3 P.A. PLETNEV, Opyt Russkoj Antologii. Hrsg. Michail Luk'janovič Jakovlev. St. Petersburg 1828. 
Als typisch für die damals herrschende vorstellung von einem Epigramm betrachtet Almut Schulze das 1826 entstandene Gedicht "More":

Воспомннание, один друг верныя мне, Разнообразит дни в печальноя стороне. Безцветноя пеленоя покрылись неба своды и мертвы красоты окованноя природы, А взор моя в этот миг, пленяясь и горя, объемлет с жадностью привольные моря, А слух моя ловит гул и плеск волны мятехноя, Музыку вечную обители прибрежноя. ${ }^{1}$

Das alexandrinische Versmaß, der zweigliedrige Aufbau mit einer steigerung im zweiten Teil sowie der trotz aller Pathetik und romantischen Metaphern an die Gegenständichkeit gebundene Aufschwung der seele lassen diesen Achtzeiler zum Paradigma eines russischen Epigramms werden. 2

Seine theoretischen überlegungen legt pletnev in seinem 1822 in den "Trudy Vol'nogo Obł̌estva ljubitelej rossijskoj slovesnosti" veröffentlichten Aufsatz "Dva antologiteskie stichotvorenija" ${ }^{3}$ nieder.

Ausgangspunkt seiner Darlegung ist dabei die Bestimmung des griechischen Epigramms, wie sie von Batjuskov und Uvarov vorgenommen worden war. Als neven Begriff führt Pletnev im folgenden den Terminus "AnthologieGedicht" ein, mit dem nach seiner Auffassung nur solche epigrammatischen Schöpfungen bezeichnet werden düren, die sich durch besondere gedankliche und formale vollendung hervortun.

1 Abgedruckt in: P.A. PLETNEV, Sočinenija i perepiska. Hrsg. Ja. Grot. 3 Bde. St. Petersburg 1885. Hier Bd. 3. S. 291. Vgl. A. SONLZE, a.a.0., S. 33.

2 Vgl. A. SCAvLZE, a.a.0., s. 33.

3 Abgedruckt in: P.A. PLETNEV, Sočinenija i perepiska, a.a.O., Bd. 1. S. 53-61. 
Als gelungenes Beispiel für ein klassisch-zeitloses Anthologie-Gedicht führt Pletnev Pußkins "Muza" I"V mladenčestre moem ona menja ljubila"l an, Petr $A$. vjazemskijs "K uedinennoj krasavice", die zweite von inm ausgewählte "Blume" der russischen Poesie, erinnert Pletnev eher an die Gegenwart. 1

Bemerkenswert ist Pletnevs Darstellung des unterschiedlichen Schaffensvorgangs bei der Dichtung eines schönen Poems und eines Anthologie-Gedichts. Sind bei ersterem fortwährende Arbeit und auBerordentliche Geduld vonnöten, so fordert das Anthologie-Gedicht die Inspiration des Augenblicks sowie einen glücklichen Kunstgriff.
"Странно было бы утверждать, что для сочинения прекрасноя поэм и антологического стихотворе- ния потребно равное усилие гения. Разность ви- дима: одна требует обширного взгляда на пред- мет, безчисленных сообрахения, продолхительного труда и редкого терпения, другое минутного вдох- новения и счастливого приема; но ни то, ни дру- гое не будет совершенньм, если за них примется не гения." 2

In jedem fall bedarf es jedoch zur schaffung eines vollkommenen Kunstwerks nach Pletnevs überzeugung der genialen Begabung des Dichters.

1 Vgl.: P.A. PleTnEV, Sočinenija i perepiska, a.a.o., Bd. 1. S. 60 .

2 Ebd. S. 55. 


\subsubsection{Ubersetzungen Žukovskijs}

\subsubsection{1. "Ländliches Glück"}

Im Jahre 1821 übersetzt Zukovskij das sechszeilige Epigramm "Ländliches Glück", dem er den Titel "Obety" gibt.

Das deutsche Original gehört zu einer ganzen Reihe von Epigrammen Goethes, die ursprünglich als wirkliche "Inschriften" konzipiert waren, und zwar für steine im Park von Weimar.

Goethe schreibt seine Verse in Distichen. Von der Italienischen Reise bis zum Beginn des neuen Jahrhunderts treten in Goethes Lyrik die antiken Versformen in den vordergrund. Regelmäßig wechseln sich Hexameter und Pentameter ab:

Seid, o Geister des Hains, o seid, ihr Nymphen des Flusses,

Eurer Entfernten gedenk, eurer Nahen zur Lust! Weihend feierten sie im stillen die ländlichen Feste; wir. dem gebahnten Pfad folgend, beschleichen das Glück. Amor wohne mit uns, es macht der himmlische knabe Gegenwärtige lieb, und die Entfernten euch nah. (GOETHES GEDICHTE I, S. 258)

1 Diese übersetzung murde zum ersten Mal veröffentlicht im "Noskgvakij telegraf", 1827, Teil 16.

Vgl. ZuKOVSKIJ I, S. 462.

2 Uber antikisierende Langstrophen bei Goethe ausführlich vgl. HA I, S. 567-575. 
Typisch für den deutschen Pentameter ist dabei die unveränderliche Diärese zwischen den mittleren beiden Hebungen:

Eurer Entfernten gedenk, // eurer Nahen zur Lust wir, dem gebahnten Pfad // folgend, beschleichen das Glück Gegenwärtige lieb, // und die Entfernten euch nah

In seiner übersetzung bemüht sich Žukovskij um Nachformung der zwei- und dreisilbigen Takte; auch die russischen Verse weisen jeweils sechs Hebungen auf. Dennoch genügen sie nicht den strengen Regeln der von Goethe angewandten antiken Strophenform: die zweite und vierte Zeile weisen in der Mitte keine Diärese auf; dem verkürzten dritten versfuß folgt eine unbetonte silbe.

Nur in der sechsten Zeile gelingt es Žukovskij, die Versform des Originals exakt wiederzugeben; sogar die für einen Pentameter ungewöhnliche Verkurzung des ersten Taktes um eine silbe formt Žukovskij genau nach:

Gegenwärtige lieb, und die Entfernten euch nah

Хизни прелесть она, близко далекое с нея

Die graphische Darstellung beider Verse ist gleich:

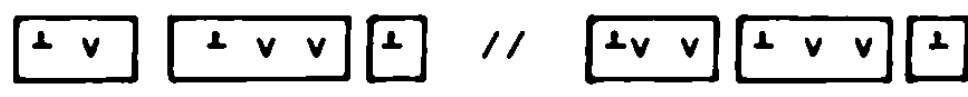

In der ersten zeile der russischen übersetzung ist der dritte versfuB verkürzt, beide senkungen fehlen. 1 Nur der katalektische versschlub weist darauf hin, das es sich um einen Hexameter handeln soll:

1 Bein Hexameter soll jeder der sechs Takte nach der ersten betonten Silbe ein oder zwei Sekungen aufweisen. Nur der letzte Takt ist immer zweisilbig. Vgl. I. BRAak, a.a.0., S. 94. 
Будьте, о духи лесов, будьте, О нимфы потока

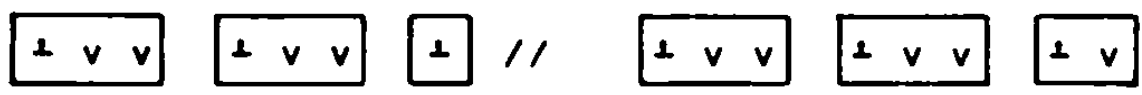

Inhaltlich hält sich Zukovskij in seiner übersetzung eng an das Original. Er verwandelt lediglich Goethes "himmlischen Knaben Amor" in die "Liebe, die Göttin der reinen Freude". Nach der vorstellung des russischen Dichters hat die Liebe wohl eher ein weibliches wesen.

Будьте, О духи лесов, будьте, о нимфы потока, Верны далеким от вас, доступны олизким друзьям! Нет их, некогда эдесь беспечною жизнию жияших; Мы, сменя их, им вслед смиренно ко счастью идем. С нами, Любовь, обитап, богння радости чнстоя! Жизни прелесть она, близко далекое с нея! 1

(ŽUKovsKIJ I, S. 362)

1 Seid, o Geister der Wälder, seid, o Nymphen des Stromes/Treu den von euch entfernten, offen den nahen Freunden!/Sie sind nicht mehr (hier), die sich hier einst dem sorglosen Leben hingaben; /Wir lösen sie $a b$ und gehen ihnen demitig zum Glücke nach./Liebe wohne mit uns, Göttin der reinen Freude!/Sie ist der Zauber des Lebens, mit inr ist das Entfernte nah. 
2.2.2.2.2. Übersetzungen aus dem "Tasso" und den "Zahmen xenien"

Im Jahre 1829 beschäftigt sich Zukovskij intensiv mit Goethes Spruchdichtung. Er übersetzt orei zeilen aus dem "Tasso", die er neben einer Wiedergabe aus dem Englischen unter die Überschrift "Pamjatniki" stellt."

Offensichtlich fühlt sich Zukovskij durch die Aussage dieser Verse besonders angesprochen.

Die Stätte, die ein guter Mensch betrat, Ist eingeweint; nach hundert Jahren klingt

Sein Wort und seine Tat dem Enkel wieder.

(HA V, S. 75)

Vielleicht hat Žukovskij, als er im August 1833 noch einmal Goethes Haus in Weimar besuchte, genau dies empfunden.

Das formgebende Grundmuster der deutschen Verse ist der alternierende Fünftakter. Auch bei Zuukovskij wechseln Hebungen und Senkungen regelmäBig, die Zahl der Hebungen pro Zeile ist jedoch nicht einheitlich.

То место, где был добрыя, свято.

для самых поздных внуков там звучит

Его благое слово и живет

Его благое дело. 2

1 Losgelöst vom Gesamtdrama haben diese drei Zeilen einen eindeutig sentenzhaften Charakter. Die Einordnung unter dem Gliederungspunkt "Spruch und Epigram" scheint dadurch gerechtfertigt.

2 Abgedruckt in: V.A. ŽuKOVSKIJ, Sočinenija $v$ stichach i proze. Hrsg. A.P. Efremov Izd. 10-e St. Petersburg 1901. S. 257. Jene Stätte, wo ein guter (Mensch) war, ist geweint./(Selbst) den aller spätesten Enkeln erklingt dort/Sein gutes Wort und lebt/ Seine gute Tat. 
Ebenfalls im Jahre 1829 übersetzt Žukovskij noch zwei vierzeiler aus Goethes "Zahmen Xenien": ${ }^{1}$ "wär nicht das Auge sonnenhaft" und "Liegt dir Gestern klar und offen". Er gibt beiden Übersetzungen den gemeinsamen Titel "Mysli".

Den Gedanken vom göttlichen Wesenszug im Menschen, der dem erstgenannten Spruchgedicht zugrunde liegt, ${ }^{2}$ gibt Zukovskij genau wieder.

1 Der Name "Xenien" (Martial hatte einem Buch seiner Sammlung von Epigrammen den Namen "Xenia" gegeben. "Xenia" ist das griechische Wort für Kleine Geschenke, die ein Gastgeber nach der Mahlzeit an seine Gäste verteilt. Sowohl Martial als in Anspielung an ith Schiller und Goethe haben das wort als ironisch gebraucht) weckt boim Leser Assoziationen an die von Schiller und Goethe gemeinsam zusammengestellte Sammlung von meist polemischen Epigramen. Im Gegensatz hierzu bezeichnet Goethe seine für die "Ausgabe letzter Hand" (1827) zusammengefaßten Spriuche als "Zamme Xenien". Vgl. HA I, S. 625 und 686 .

2 Vgl. hierzu Goethes Einleitung zur "Farbenlehre", Didaktischer Teil:

"Hierbei erinnern wir uns der alten ionischen Schule, welche mit so großer Bedeutsankeit immer wiederholte: nur von Gleichem werde Gleiches erkannt, wie auch der Worte eines alten Mystikers [gemeint ist Plotin], die wir in den deutschen Reimen folgendermaßen ausdrücken möchten:

Wär nicht das Auge sonnenhaft, Wie könnten wir das Licht erblicken?

Lebt nicht in uns des Gottes eigne Kraft, wie könnt uns Göttliches entzücken?"

(HA XIII, S. 324) 
Wär nicht das Auge sonnenhaft,

Die Sonne könnt' es nie erblicken;

Läg' nicht in uns des Gottes eigne Kraft,

wie könnt' uns Göttliches entzücken?

(HA I, S. 367)

Diese Verse lauten im Russischen:

Будь несолнечен наш глаз -

Кто бы солнцем любовался?

Не живи дух Божия в нас -

Кто $о$ божественным пленялся? ${ }^{1}$

Goethe formuliert in diesem vierzeiler seine vom neuplatonischen Weltbild beeinflubte Weltanschauung. Im Alter wächst seine Neigung zu knapper form, zu belehrendeinprägsamer Sprechweise.

Dies belegt auch die folgende von Žukovskij übersetzte Spruchdichtung:

Liegt dir Gestern klar und offen, wirkst du heute kräftig frei,

Kannst auch auf ein Morgen hoffen,

Das nicht minder glücklich sei.

(HA I, S. 308)

Auch hier wird die enge Verwandtschaft zwischen Spruchdichtung und Lyrik deutlich, beide formen berühren einander, gehen gleichsam ineinander über.

1 Abgedruckt in: V.A. ŽUKOVSKIJ, Sočinenija $v$ stichach i proze, a.a.0., S. 257.

Ist unser Auge nicht sonnenhaft,/Wer würde sich an der Sonne ergötzen?/Ist nicht der göttliche Geist in uns lebendig,/Wer wirde sich vorn Göttlichen bezaubern lassen? 
Formal handelt es sich um viertaktige Reimstrophen. Bereits seit der Jahrhundertwende hatte Goethe keine Epigramme in antikisierenden Distichen mehr verfaßt. In seinen Altersjahren kehrt er zu den schlichten Vierhebern, die er besonders in der Zeit seines sturm und Drang geschätzt hatte, zurück. 1

Žukovskij hält sich formal eng an die Goethesche Vorlage. Inhaltlich betont er jedoch wesentlich stärker den moralischen Aspekt der Aussage:

Чнст душоя ты был вчера

ныне деяствуеш прекрасно -

И от завтра жди добра:

Бывшим будуиее ясно. 2

1 Vgl. HA I, S. 683-686.

2 Abgedruckt in: V.A. ŽuKovSKIJ, sočinenija $v$ stichach i proze, a.a.O., S. 257 .

Du warst gestern rein an deiner Seele,/Gegenwärtig handelst du vortrefflich -/Und vom Morgen erwarte Gutes:/Durch das Gewesene ist die Zukunft klar. 


\subsubsection{3. "Sakontala" in Übersetzung TJutČevs}

Tjuť̌ev beginnt seine Tätigkeit als Goethe-Übersetzer mit der Wiedergabe des Vierzeilers "Sakontala".

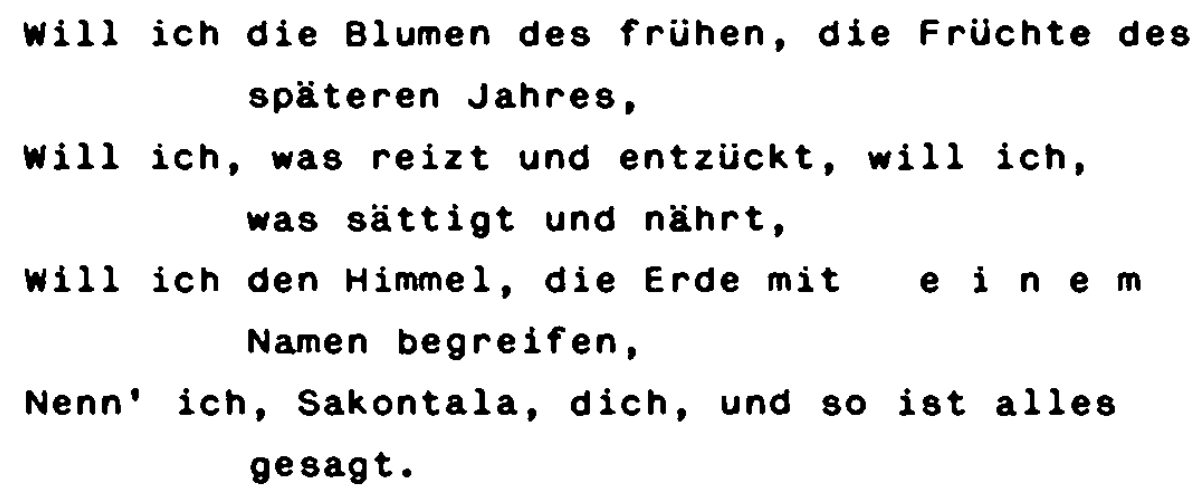

(HA I, S. 206)

Ausgelöst wurden diese Zeilen durch Goethes Bekanntschaft mit der deutschen übersetzung des in Sanskrit abgefaBten Dramas "Sakontala" 1 des altindischen Dichters Kalidasa (4. Jahrhundert). Von diesem "anmutigen, glühenden, pflanzenhaft-zarten und zugleich tiefen Werk" war Goethe auBerordentlich fasziniert. Bis ins hohe Alter hat er es in seinen Schriften gepriesen. ${ }^{2}$

"Sakuntala" gehörte zu jenen literarischen Schöpfungen, die Goethes Bild vom Osten erweiterten, und, einem Mosaikstein gleich, seine Kenntnis der orientalischen Kultur vervolikommneten. Diesem Drama ist Goethes Epigramm gewidmet.

1 Die heutige Wissenschaft schreibt "Sakuntala". Die erste deutsche übersetzung dieses Dramas, angefertigt von G. Forster, erschien 1791. Vgl. HA I, S. 622 .

2 vgl. ebd. 
Tjutčevs übersetzung ist nur lose mit der Vorlage verbunden. Die vier Zeilen des Originals sind auf vierzehn Zeilen ausgeweitet, in denen allerdings, genau wie bei Goethe, nur ein Satz entfaltet wird.

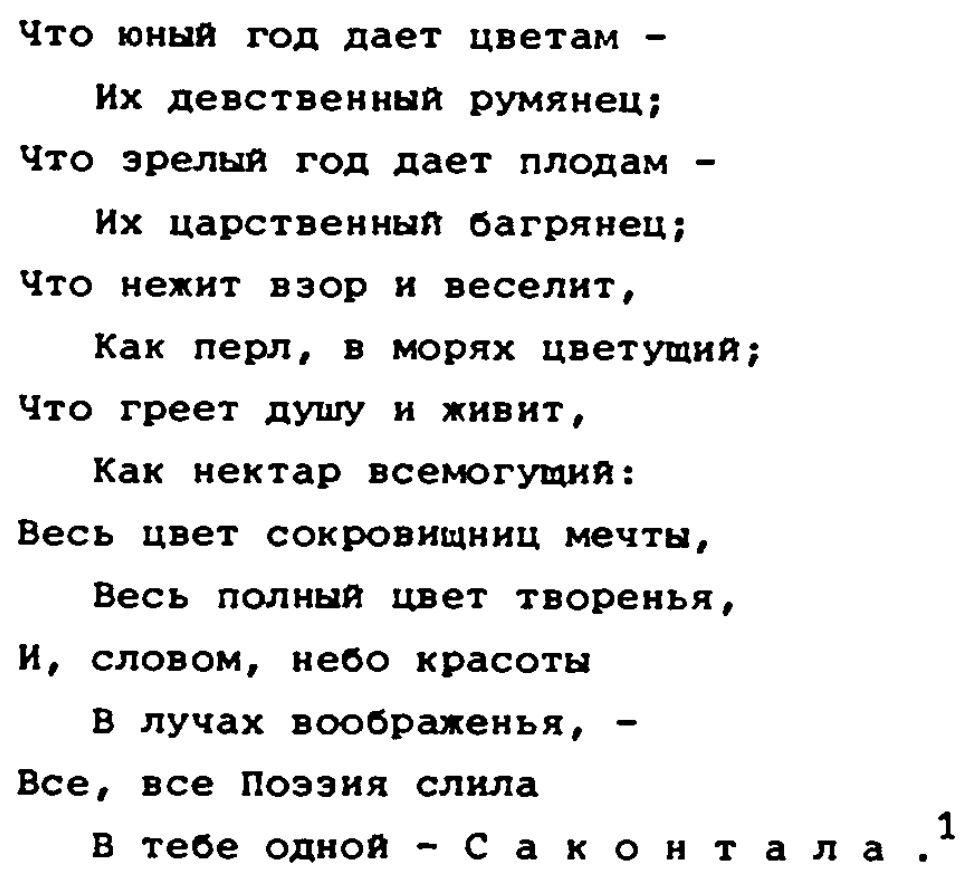

Die freie Ausgestaltung des Themas, das Einfügen eigener Metaphern und Vergleiche und nicht zuletzt die völlige Umgestaltung der Form erinnern in der Art der übersetzung deutlich an die frühen Goethe-übersetzungen Žukovskijs.

1 Was gibt das junge Jahr den Blumen -/Ihre jungfräuliche Röte;/Was gibt das reife Jahr den Früchten -/Ihre majestätische purpurrote Farbe; /was schmeichelt dem Blick und erheitert, Wie eine Perle, die in den Meeren blüht;/Was wärmt die Seele und belebt,/Wie allmächtiger Nektar:/Die ganze Blüte der Schatzkammer des Traums,/Die ganze volle Blüte der Schöpfung,/Und, mit einem Wort, den Himmel der Schönheit/In den Lichtstranlen der Phantasie, -/Alles, alles vereinigt die Poesie/In dir allein, Sakontala. (Gesperrt geschriebene Stelle in Original kursiv gedruckt). 
So zählt $K$. Pigarev mit gutem Grund diese wiedergabe Tjutčevs zu den "Variationen über ein fremdes Thema". Zu dieser Gruppe rechnet der Literaturwissenschaftler solche literarischen Schöpfungen, die eigentlich nicht mehr als übertragungen oder Nachdichtungen im strengsten sinne anzusehen sind, da das "Original" lediglich die Anregung lieferte. ${ }^{1}$

TjutČvs persönliche Gestaltung oer Verse, in denen sich die in der Vorlage zum Ausdruck kommende Begeisterung für Kalidasas Drama lebendig widerspiegelt, läßt vermuten, das auch dem russischen Dichter die altindische "Sakuntala" bekannt war und dab er die künstlerische Bedeutung dieses werks ebenso hoch einschätzte wie Goethe.

Mit der grundlegenden wandlung der Form - aus Goethes in Distichen abgefabtem Epigramm wurde ein Gedicht in der Form des Shakespearschen Sonetts - verrät Tjuťev "artistischen Ehrgeiz". 2

Der russische Dichter erbrachte einen Beweis dafür, daß er auch strenge, den Künstler bindende Formen des Künstlergedichts beherrscht. ${ }^{3}$

1 Vgl. K. PIGAREV, Tjutčev - perevoočik Gete, a.a.0., S. 86, 91. 2 Vgl. A. SOAULZE, a.a.0., S. 13, Arm. 19.

3 Allerdings muB in der letzten Zeile des Gedichts das Schlüseelwort "Sakontala" zur Einhaltung des Jambischen Versmaßes und des männlichen Reims auf der Schlubsilbe betont werden. Die richtige Betonung liegt jedoch auf der zweiten Silbe: Sakóntala. 


\subsubsection{Zusamenfassung}

Die Darstellung der überragenden Bedeutung Žukovskijs für die Entwicklung der Balladendichtung in RuBland hat gezeigt, daß wir bei dem russischen Dichter eine stringente Entwicklung des Balladeninteresses und -verständnisses verfolgen können.

Durch seine vielfältigen Schöpfungen und Nachdichtungen leitet Žukovskij eine bis dahin nicht gekannte Verbreitung balladischer Dichtung in RuBland ein. Neben der stofflichen Bereicherung und Erweiterung der russischen Literatur ist vor allem die Einbürgerung dieser neuen Gattung in RuBland überwiegend sein Werk.

Žukovskijs übertragungen der beiden berühmtesten naturmagischen Balladen Goethes zeichnen sich vor allem durch die meisterhafte lautliche Gestaltung aus. Hier hat der russische Dichter sein musikalisches Feingefühl und sein sensibles Gespür für Töne und Klänge unter Beweis gestellt.

Im Gegensatz zu Žukovskij, in dessen Dichtung die Ballade eine wesentliche Rolle spielt, kommt dieser Gattung bei Tjutčev nur geringe Bedeutung zu. Die von inm ubersetzten Goetheschen Vorlagen sind onne Zweifel nach thematischen Gesichtspunkten ausgewählt. Die Aussage der Balladen war es, die Tjutčev faszinierte.

Žukovskij und Tjutčev haben sich beide, wenn auch auf unterschiediche Art und Weise, um die Einbürgerung epigrammatischer Dichtung in der russischen Literatur verdient gemacht. 
TjutXev ist seit seiner Jugend mit der in der europäischen Dichtungsgeschichte verfolgten Weiterführung der antiken Tradition der lyrischen Kleinformen vertraut und entwickelt diese in entscheidendem Maße weiter.

Angeregt durch die struktur der in der deutschen Literatur verbreiteten Epigramm- und Kleindichtung verbindet er beide formen zu einer Einheit. Das nach antiker Verslehre ubliche elegische VersmaB des Epigramms nimmt Tjuť̌ev dabei weder in seiner eigenständigen noch in der von inm übersetzten lyrischen Dichtung auf.

Unter diesem Gesichtspunkt ist die Übersetzung des Goetheschen Epigramms "Sakontala" als durchaus kennzeichnend für TJutłev zu betrachten.

Das epische, in Distichen abgefaßte Epigramm verwandelt der russische Dichter in ein Gedicht in der form eines Shakespearschen Sonetts. Statt der Verbindung von Hexametern und Pentametern nun ein Reimgedicht von vierzehn meist jambischen Versen, die in drei Quartette mit Kreuzreim und ein abschließendes Reimpaar eingeteilt sind.

Trotz der antiken strophenform der vorlage bleibt TjutZev den zeit seines Lebens bevorzugten Reimversen mit alternierendem versmab treu.

Demgegenüber versucht Zuukovskij - er hat auch eigene Distichen-Epigramme verfast ${ }^{1}$ - bei seiner Übersetzung

1 Z.B. "Lavr" und "Nadgrobie junoše". Letzteres lautet folgendermaßen:

Plaval, kak vse vy, i ja po volnam nenadežnyja žizni.

Imja moe Anonim. Skoro moj končilsja put'.

Burja vnezapu vosstala; chotel ja protivit'sja bure, Junyj, bessil'nyj plovec; volny umčali menja.

(ŽuKovsKIJ I, S. 392). 
von Goethes sechszeiligem Epigramm "Ländliches Glück", dem russischen Leser auch die formalen Besonderheiten des Originals zu vermitteln. Wenn auch nicht immer mit Erfolg, so bemuint er sich doch offensichtich um eine Nachbildung der antikisierenden Langzeilen im Russischen.

Als weitere Vorlagen für Übersetzungen von Kleinformen wählt ŽukovskiJ aus der Formvielfalt Goethescher Dichtung gleichsam beispielhaft verse unterschiedlicher formaler Gestaltung aus.

Neben dem Distichen-Epigramm "Ländliches Glück" iubersetzt er die in Blankversen abgefabten zeilen aus dem "Tasso" sowie die beiden in viertaktigen Reimstrophen gehaltenen Vierzeiler aus den "Zahmen Xenien".

Diese breitgestreute Auswahl weist nicht nur auf die unterschiedlichen formalen Möglichkeiten dichterischer Kleinformen hin, sondern macht auch die enge Verwandtschaft dieser formen untereinander deutlich.

Diese Erkenntnis ermöglichte TJutčev die Aufwertung lyrischer Kurzdichtung in der russischen Literatur. Nicht zuletzt durch inn wurde auf diesem Gebiet eine vielfältige Dichtung in RuBland angeregt. Erwähnt seien nur A.A. Fet und die russischen symbolisten. 


\section{AUS DRAMATISCHEN WERKEN}

\subsection{TJutčevs Übersetzungen aus dem "Faust"}

Aus dem ersten Teil des "Faust" übersetzte Tjuť̌ev insgesamt füf Fragmente: ${ }^{1}$ den Anfang des "Prologs im Himmel" ("Die Sonne tönt nach alter Weise"/"Zvučit, Kak drevle, pred toboju"), und den Dialog Fausts mit dem Erdgeist aus der szene "Nacht" ("wer ruft mir?"/"Kto zval menja?"). Hinzu kommen die Monologe fausts aus der Szene "Nacht" ("was sucht ihr, mächtig und gelind"/ "Čego vy ot menja chotite"), aus "Vor dem Tor" ("Doch $I a B$ uns dieser stunde schönes Gut"/"Začem gubit" $v$ unynii pustom") und aus der szene "Wald und Höhle" ("Erhabner Geist, du gabst mir, gabst mir alles"/ "Deržavnyj duch! ty dal mne, dal mne vse").

Die Auswahl der übersetzten Stücke ermöglichte dem russischen Leser überraschend vielfältige Einblicke in Goethes Drama.

Klangfulle und Pathos zeichnet den hymnisch klingenden Lobgesang der drei Erzengel aus. Mit inrem Gesang preisen sie Gott, den Schöpfer und die Unvergänglichkeit seines Werkes.

Die ausgewählten Partien aus Fausts Gespräch mit dem Erdgeist und aus dem Selbstmordmonolog in der Osterszene gestalten den Umschlag in Fausts Stimmung von deprimierter Niedergeschlagenheit zu neuem Schaffensdrang.

1 Die Übersetzungen stammen alle vermutlich aus den Jahren 1829 30. 
In den verbleibenden Monologen Fausts stehen romantisch anmutende Naturbeschreibungen im Mittelpunkt. ${ }^{1}$

Doch laB uns dieser stunde schönes Gut

Durch solchen Trübsinn nicht verkümmern!

Betrachte, wie in Abendsonneglut

Die grünumgebnen Hütten schimmern.

Sie rückt und weicht, der Tag ist überlebt,

Dort eilt sie hin und fördert neues Leben.

o dab kein flügel mich vom soden hebt,

Ihr nach und immer nach zu streben!

(HA III, S. 39-40, Z. 1068-1075)

Auch in den russischen versen die gefülsstarke und gleichzeitig gehaltene Sprache:

Зачем губить в уныния пустом

Сего часа олагое достоянье?

Смотри, как хижины с их зеленью кругом

Осыпало вечернее сиянье.

День пережит, - и к небесам иньм,

Светило дня несет животворенье.

О, где крыло, чтоб взвиться вслед за ним,

Прильнуть к его лучам, следнть его теченье? ${ }^{2}$

(TJUTČEV II, S. 91, IV. Z, 1-8)

1 Vor Tjutčev waren diese beiden Ausschnitte bereits von $D$. Venevitinov, einem bedeutenden Geist der russischen Romantik, ubertragen worden. Jedoch formal wie auch inhaltlich bedeuten Tjutčevs Varianten der beiden Faust-Monologe eine deutliche Verbesserung gegenuber Venevitinovs elegisch wirkender übersetzung. Vgl. K. PIGAREV, Tjutčev - perevodčik Gete, a.a.O., S. 108-109.

2 Wozu zerstören in grundloser Schwermut/Dieser Stunde vortreffliches Gut?/Schau, wie die Hütten mit inrem Grün ringsum/Der abendliche Glanz bedeckte./Der Tag ist überlebt, - zu anderen Himmeln/ Trägt das Gestirn des Tages [d.h. die Sonne] neues Leben./O, wo ist ein Flügel, um hinter inm aufzusteigen,/Sich seinen Strahlen anzuschließen, seinem Lauf zu folgen? 
Besonders gelungen ist Tjutčevs Beschreibung eines Unwetters aus Fausts in Blankversen abgefaßtem Monolog, der mit dem Satz "Erhabner Geist, du gabst mir, gabst mir alles, warum ich bat" anhebt.

Und wenn der Sturm im Walde braust und knarrt,

Die Riesenfichte stürzend Nachbaräste

Und Nachbarstämme quetschend niederstreift, Und ihrem Fall dumpf hohl der Hügel donnert,

Dann führst du mich zur sichern Höhle, zeigst

Mich dann mir selbst, und meiner eignen srust

Geheime tiefe wunder öffnen sich.

$$
\text { (HA III, S. 103, Z. 3228-3234) }
$$

Bei Tjutčev lauten diese Verse:

Когда ж в бору скрыпит и свимет буря,

Ель-великан дерев соседних с треском

Круинт в паденье ветви, глухо гул

Встает окрест и, зыилясь, стонет холм.

Т७ в мирную ведеш меня пемеру,

и самого меня являешь ты

Очам дуим моен - и мир ее,

чудесныя мир, разоблачаешь мне! ${ }^{1}$

(TJUTČEV II, S. 93, V. Z. 13-20)

1 Wenn aber im Nadelwald der Sturm knarrt und pfeift,/Die Riesenfichte mit Knistern der benachbarten Bäume/Im Fall die Zweige zerschmettert, sich dumpf das Getöse/Ringsumher erhebt und schwankend der Hügel stöhnt/Führst du mich in eine friedliche Höhle,/Und du offenbarst gerade mich/Den Augen meiner Seele - und ihr Reich,/ Das underbare Reich, enthüllst du mir! 
Neben Partien aus dem "Faust" übersetzt Tjutčev noch das Lied Klärchens aus dem dritten Aufzug des "Egmont". Da dieses Lied jedoch auch als selbständige lyrische Einheit betrachtet werden kann, haben wir es in dem Kapitel "Liebes- und Naturlyrik" besprochen.

Žukovskijs Wiedergabe aus dem "Tasso" wurde - wegen des sentenzhaften Charakters dieser orei verse - unter dem Gliederungspunkt "Spruch und Epigramm" eingeordnet. 
IV. SCHLUSSBETRACHTUNG

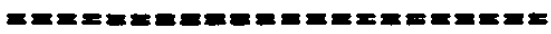

Ein rückschavender Blick auf die Analyse der Goetheübersetzungen Kukovskijs und Tjuťevs ermöglicht eine kritische Betrachtung der geleisteten übersetzerarbeit und der inr zugrundeliegenden Prinzipien sowie die zusammenfassende Beantwortung der eingangs gesteliten Frage nach dem persönlichen Anteil des übersetzers am übersetzten Werk.

Bei der überwiegenden Zahl der angefertigten übersetzungen ist das Bemuihen beider Dichter um adäquate wiedergabe der äuberen Form zu erkennen. Eine offensichtliche Ausnahme bilden lediglich TjutČevs Wiedergaben von "Sakontala", hier ändert der russische Dichter in voller Absicht die Strophenform des Originals sowie Yukovskijs wiedergaben von "Meine Göttin" und "Die Freuden", die sowohl vom metrischen Schema und der Zeileneinteilung als auch von der Aussage her nur sehr lose Bezüge zum Original aufweisen.

Bemerkenswert ist die formale vielfalt der von Žukovskij gewählten Vorlagen. Neben den ublichen metrisch gebundenen Reimgedichten mit gleichmäBiger Zeileneinteilung übersetzt der russische Dichter auch Schöpfungen wie "Der Wandrer" - diese besteht aus wechselreden in freien Rhythmen, verbunden mit einer freien strophik - und "Schäfers Klagelied", dessen ungewöhnliches Metrum Žukovskij durchaus gelungen mit einem freien versmaß wiedergibt.

Weiterhin reizen Žukovskij auch gebundene strophenformen wie die romanische Stanze oder das antike Distichon; diese gehen schlieblich auch in seine eigenständige Dichtung ein. 
Offensichtliche Schwierigkeiten bereitet Zukovskij jedoch das umfassende inhaltiche Erfassen einiger Goethescher Vorlagen.

Es kommt zu einem regelrechten MiBverstehen der zentraIen Aussage. So hat der russische Dichter die in der Versfabel "Der Adler und die Taube" angesprochene Problematik vom Wesen des Genies in der Spannung zwischen bürgerlicher Idylle und tragischem schicksal nicht verstanden.

Weiterhin geht bei einigen übersetzungen die emotionale und gedankliche spannweite des originals verloren oder Žukovskij verkehrt die grundlegende Idee - möglicherweise beabsichtigt - in ihr genaues Gegenteil. Letzteres ist besonders kraB der Fall bei der wiedergabe vor. "Neue Liebe, neues Leben". Statt des aktiven Widerstandes gegen die Fesseln der Liebe wird die Aussage der russischen Verse durch bereitwillige Hingabe an die Geliebte bestimmt.

Tjutčevs übersetzungen entsprechen demgegenüber in ihrer Mehrzahl relativ genau der Grundidee der Goetheschen Vorlage. Auch wenn das Hauptinteresse des russischen Dichters nicht immer einer inhaltich exakten wiedergabe gilt, wie z.B. bei seiner übertragung von "Kennst du das Land" - hier geht es Tjutčev offensichtlich zumindest gleichrangig um eine gelungene Nachformung des Metrums und des Rhythmus der deutschen Verse -, so kommt es doch nicht zu einem MiBverstehen oder einer Umkehrung der zentralen Aussage des Originals.

Die Spannweite bei Tjutčev reicht dabei von einer eher freien Übernahme des Grundgedankens bis zu einer inhaltlich und auch formal exakten übersetzung, wie sie der russische Dichter von "Wer nie sein Brot mit Tränen aB" liefert. 
Auch die Auswahl der von Zukovskij übersetzten GoetheGedichte ist charakteristisch für das Temperament und das Wesen des russischen Dichters.

Neben den berühmten Balladen "Erlkönig" und "Der Fischer" sind es vor allem Gedichte der Erinnerung und der Melancholie wie "An den Mond" und "Trost in Tränen", die - wie Aleksandr $N$. Veselovskij zu Recht bemerkt an sich genommen ein recht einseitiges Bild von Goethes schaffen ergeben müssen. 1

Typisch für Žukovskij sind auch die Abweichungen, mit denen er die Goethe-Gedichte ins Russische überträgt. In seinem Bemuihen, den russischen Lesern Goethe nahezubringen, arbeitet er Themen frei aus, dehnt sie in die Länge. Dadurch wirken seine übersetzungen häufig naiv und überdeutlich; trotzdem werden wesentliche Aspekte der Aussage übersehen.

Žukovskij neigt zur Anhäufung sentimentaler Details, die Motive seiner Abschweifungen entstammen häufig dem Inventar der Empfindsamkeit und der Frühromantik. Leicht läBt der russische Dichter einen Hauch gezierter Lieblichkeit oder sentimentaler Hoffnungslosigkeit einflieben, der dem Wesen des Originals fremo ist. Die sinnliche Bildhaftigkeit Goethes wird häufig durch ätherische, verschwommen-gefühlvolle Ausschmückungen ersetzt. Wenig Verständnis zeigt Žukovskij für Goethes knappen, expressiven stil.

1 Vgl. A.N. VESELOVSKIJ, a.a.O., S. 305; R. JACOOITSOH, a.a.0., S. 374 . 
Den aktiven, vorwärtsstrebenden Geist des deutschen Dichters gibt Zukovskij - vielleicht unbewuBt - in der passiven Grundhaltung der Verträumtheit und der Erinnerung wieder. ${ }^{1}$ Das Vage, Unbestimmte, Vergangenheitsbezogene, der Mangel an Objektivität in Zukovskijs Lyrik ist dem Geist Goethes jedoch fremd, geradezu entgegenge$\operatorname{setzt} .^{2}$

Erklären läßt sich diese Gegensätzlichkeit dadurch, das in den Jahren, In denen sich Žukovskijs künstlerische Persönlichkeit bildete, von allen Werken Goethes lediglich der "Werther" auf ihn einwirkte.

1 Eine parodistische Darstellung der russischen sentimentalen Lyrik gibt uns Puß̌kin in der Gestalt des Lenakij in "Evgenij Onegin". Von Lenskij heißt es:

On 8 liroj stranstvoval na svete;

Pod nebom Sillera i Gote

Ich poettičeskim ognem

Duba vosplamenilas' $v$ nem.

Es folgt eine Charakteristik der Lyrik Lenskijs, die sich an der Flame Schillers und Goethes entfacht hat:

on pel razluku i pocal',

I ne čto i tu'mannu dal'

Abgedruckt in: A.S. PUSKIN, a.a.0., Bd. 5. S. 40. (Gesperrt geschriebene Stellen in Original kursiv gedruckt).

2 Genau darauf mist Goethe selbst in seiner Kritik an Zukovskijs Abechiedsgedicht hin; vgl. bei uns Kapitel II, 2.2.1.2. "Zukovskijs Besuche bei Goethe". 
Seine Jugendlyrik entstand unabhängig von derjenigen Goethes - er kannte sie vermutlich nicht einmal - unter dem EinfluB des Sentimentalismus. Grundzüge dieser Richtung - Schwelgen in Erinnerung, sanfte Träumerei, leise Melancholie - sind auch noch in den späteren Jahren in Žukovskijs Lyrik lebendig.

Folglich berunt die offensichtlich enge verbindung Žukovskijs zu den von inm übersetzten Goethe-Gedichten häufig auf einem MiBverständnis oder zumindest auf einem fiktiven Bild des russischen Dichters vom Wesen der deutschen Vorlage. Seine Übertragungen entsprechen demnach eher der eigenen dichterischen Persönlichkeit als derjenigen Goethes.

Anders als bei Žukovskij läßt sich der Einfluß von Tjutčevs eigenständiger künstlerischer Përsönlichkeit lediglich in der Auswahl der übersetzten Gedichte erkennen, nicht aber in der übersetzung selbst. Signifikante Änderungen der Sprache und des Stils oder der zugrundeliegenden dichterischen Haltung sind nicht zu beobachten.

Die festgestellten stilistischen Schwächen in TJutčevs übersetzungen können somit nur im Kontext des einzelnen Gedichts, des bestimmten sprachlichen Problems, gesehen werden, eine einheitliche Tendenz zeigen sie nicht auf. Verallgemeinerungen sind daher nicht möglich.

Die kritische Untersuchung der übersetzungen hat deutlich gemacht, daß weder bei Žukovskij noch bei TJutčev der Schwerpunkt der jeweiligen übersetzerischen Tätigkeit immer gleich gelagert ist. 
So kann das Hauptaugenmerk des Dichters der formalen struktur, der sprachlichen Gestalt wie auch der inhaltlichen Aussage des Originals gelten. Einige Übersetzungen sind - als Ausdruck der besonderen übersetzer-Persönlichkeit - nur lose mit der Goetheschen Vorlage verbunden, andere dagegen spiegeln ein beinahe exaktes Bild des Originals wider.

Ein bestimmtes, durchgängig angewandtes übersetzerPrinzip läßt sich weder bei den wiedergaben Žukovskijs noch denen Tjuttevs erkennen. Anders als bei professionellen Übersetzern. die meist auf der Grundlage einer selbstentwickelten oder von Sprachwissenschaftlern ubernommenen linguistischen Theorie arbeiten, steht bei Zukovskij und Tjuť̌ev nicht die handwerkliche Tätigkeit des Übersetzens im Vordergrund, sondern das schöpferische Moment des Nachdichtens.

Wie die Analyse der angefertigten übersetzungen gezeigt hat, können die Ursachen fur die besondere Beschaffenheit einer solchen schöpferischen Ubersetzung nur dann ermittelt werden, wenn auch der Anteil des Dichters am libersetzten Werk berücksichtigt wird. Nur so ist ein umfassendes Verständnis und eine tiefgreifende würdigung der Bedeutung seiner Übersetzung möglich. 


\section{LITERATURVERZEICHNIS}

A. Werkausgaben, Briefe, Tagebücher

Žukovskij, V.A. Iz neizdannych stichotvoreniJ N.M. Jazykova i V.A. Žukovskogo. Hrsg. I.A. Bytkov. St. Petersburg 1911. Im Text zitiert: Iz neizdannych stichotvorenij.

Neizdannye pis'ma Kukovskogo K A.P. Elaginoj i A.P. Zontag. St. Petersburg 1912 .

Dnevniki V.A. Zukovskogo. Hrsg. I.A. Bytkov. St. Petersburg 1903. Im Text zitiert: Dnevniki.

Pis'ma V.A. Žukovskogok I.A. Turgenevu. In: RA 1895 Beil. S, 160. Im Text zitiert: Pis'ma V.A. Zukovskogo $k$ A.I. Turgenevu.

Pis'ma V.A. Žukovskogo $k$ vel. $k n$. Aleksandre Feodorovne iz pervogo ego zagranižnogo putešestvija v 1821 g. Hrsg. I.A. ByCkov. In: Rueskaja Starina $5(1902)$. S. 357.

Pis'mo Žukovskogo $k$ Gete. In: RA 1870. Sp. 1817-1819. Im Text zitiert: Pis'mo k Gete.

Polnoe sobranie sočinenij $v$ 12-ti tomach. Hrsg. A.S. Archangel'skij. St. Petersburg 1902.

Sobranie sotinenij v Ketyrech tomach. Moskau-beningrad 1959. Im Text $z i-$ tiert: ZUKOVSKIJ.

Sočinenija $v$ stichach i proze. Hrsg. A.P. Efremov. Izd. 10-e. St. Petersburg 1901.

Sočinenija $v$ 6-ti tomach. Hrsg. P.A. Efremov. Izd. 7-e. St. Petersburg 1878 .

Stichotvorenija. Hrsg. C.S. Vol'pe. 2 Bde. BBP. Leningrad 1939-1940. 
Tjutčev, fedor Ivanovic

Goethe, Johann wolfgang von

\section{B. Weitere Literatur}

Aksakov, Ivan
Sergeevit
Alekseev, M.P.

Atkins, Stuart

Bach, Rudolf

Batjuškov, Konstantin Nikolaevič

Batjuškov / S.S. Uvarov
Lirika. Hrsg. K. Pigarev, 2 Bde. Moskau 1965. Im Text zitiert: TJUTČEV.

Goethes Werke in 14 Bänden. Hamburger Ausgabe. Hrsg. E. Trunz. 12., neubearbeitete Auflage. München 1981. Im Text zitiert: HA.

Goethes Gedichte in zeitlicher Folge. Hrsg. H. Nikolai. 2 Bde. Wiesbaden 1978. Im Text zitiert: GOETHES GEDICHTE .

Goethes Werke, hrsg. im Auftrag der Großnerzogin Sophie von Sachsen. I. Abt., [Goethes Werke im engeren Sinne] . Bd. 6. Weimar 1888.

III. Abt., Goethes Tagebiucher. Bd. 11. Weimar 1900.

IV. Abt., Goethes Briefe. Bd. 35 u. Bd. 43. Weimar 1908.

Fedor Ivanovit Tjutčev. Biografičeskij oterk. Moskau 1874.

Nochmals über Tjutčev und Goethe. In: Germanoslavica 2 (1932-33). S. 64-69.

Zum besseren Verständnis einiger Gedichte des "West-östlichen Divan". In: Euphorion $59(1965)$. S. 178206.

Deutsche Romantik. Ein geistesgeschichtlicher Umriß. Hamburg 1948.

Opyty $v$ stichach i proze. Hrsg. I.M. Semenko. Moskau 1977. Im Text zitiert: Opyty $v$ stichach i proze.

Sočinenija. Hrsg. P. Batjuškov. 3 Bde. St. Petersburg 1885-1887.

Sočinenija. Hrsg. A. Smirdin. 2 Bde. St. Petersburg 1850. Im Text zitiert: Sočinenija. Hrsg. A. Smirdin.

o grečeskoj antologii. St. Petersburg 1820 . 
Beckby, Hermann

Belinskij, Vissarion Grigor'evit

Bem, A.

Bessarab, Majja Jakovlevna -

Beutler, Ernst

Beyer, Valentin

Birkfellner, Gerhard

Blagoj, D.

Bočeva, Milka

Boissereé, Sulpiz
Einführung in die Griechische Anthologie. In: Anthologia Graeca. Griechisch-Deutsch. Hrsg. H. Beckby. 4 Bde. München 1957-1958. Hier Bd. 1. S. 9-99.

Sotinenija Aleksandra Puškina. In: Ders.. Polnoe sobranie sotinenij $\checkmark$ 13-ti tomach. Moskau 1953-1958. Hier Bd. 7. S. 99-597.

Rezension der 1. Aufl. von 1937 zu: V.M. Zirmunskij. Gete v russkoj literature. Leningrad 1981. In: Zfslph 16 (1939). S. 430-434.

v.A. Žukovskij. Moskau 1975.

"Der König in Thule" und die Dichtungen von der Lorelay. In: Ders., Essays um Goethe. Bd. 2. Wiesbaden 1948. S. 307-369. Im Text zitiert: Der König in Thule.

Vom griechischen Epigramm im 18. Jahrhundert. Leipzig 1909 (Probefahrten 15).

Vorwort. In: J.W. Goethe, West-östlicher Divan. Wiesbaden 1948. S. IX-XIV. Im Text zitiert: Vorwort.

Die Begründung der ernsten Ballade durch G.A. Bürger. Strabburg 1905 (Quelien und Forschungen 97).

Rezension zu: W. Pohl, Russische Faust-übersetzungen. Meisenheim am Glan 1962. In: Wiener Slavistisches Jahrbuch. Bd. 11 (1964). S. 208-211.

Citatel' Tjutčeva - Lev Tolstoj. In: Uranija. TjutZevskij Al'manach 1803-1928. Leningrad 1928. S. 224256 .

Poezija TjutCeva i tradicija romantizma. In: Slavjanska Filologija $13(1973)$. S. 121-134.

Briefwechsel/Tagebücher. 2 Bde. Stuttgart 1862. ND Göttingen 1970. 
Braak, Ivo

Brandt, Roman F.

Brjusov, Valerij Jakovlevit

Busch, Wolfgang

Byčkov, I.A.

Čulkov, Georgij Ivanovic

Cretaeva, Marina

Čy̌̌evśkyj, Dmitrij

Deržavin, Gavriil Romanovič
Poetik in Stichworten. Kiel 1974.

Materialy dlja issledovanija "Fedor Ivanovit Tjutter i ego poezija". In: Izvestija otd. russk. jaz. i slovesn. Imp. Akad. Nauk. St. Petersburg 1911. Bd. 16. 2. Buch, S. 136-232; 3. Buch, S. 1-65.

F.I. Tjutčev. Kritiko-biografiCeskij očerk. In: F.I. Tjutčev. Polnoe sobranie sotinenij. Hrsg. P.V. Bytkov Izd. 7-e. St. Petersburg 1912. S. VII-XLII.

Rezension zu: H. Eichstädt, Žukovskij als übersetzer. Drei Studien zu übersetzungen V.A. Zukovskijs aus dem Deutschen und Französischen. Minchen 1970 (FS Bd. 29). In: ZfsIPh 37 (1974). S. 198-201.

Rezension zu: I.M. Semenko, Žizn' 1 poezija Zukovskogo. Moskau 1975. In: ZfslPh $41(1980)$. S. 230-234.

Iz neizdannych stichotvorenij N.M. Jazykoya i V.A. Zukovskogo. Siehe unter Zukovskij.

Neizdannye pis'ma Žukovskogo $k$ A.P. Elaginoj i A.P. Zontag. Siehe unter Zukovskij.

Stichotvorenija, prislannye iz Germanii. $K$ voprcsu ob otnosenii Puzkina $k$ Tjuţevu. In: Zven'ja 2 (1933). S. 255-267.

Dva Lesnych Carja. In: Masterstvo perevoda 3. Moskau 1964. S. 283291.

Stichi zarubežnych poètov $v$ perevode. Moskau 1967 (Mastera poétiCeskogo perevoda vyp. 7 ).

Siehe unter Tschižewskij, Dmitrij

Solinenija. Hrsg. Ja. Grot. 8 Bde. St. Petersburg 1864-1866. 
Deutsche Dichtung

Deutsches Wörterbuch

\section{Dictionnaire \\ Du Feu, Veronica}

Durylin, $s$.

Ehrhard, Marcelle

Eichstädt, Hildegard

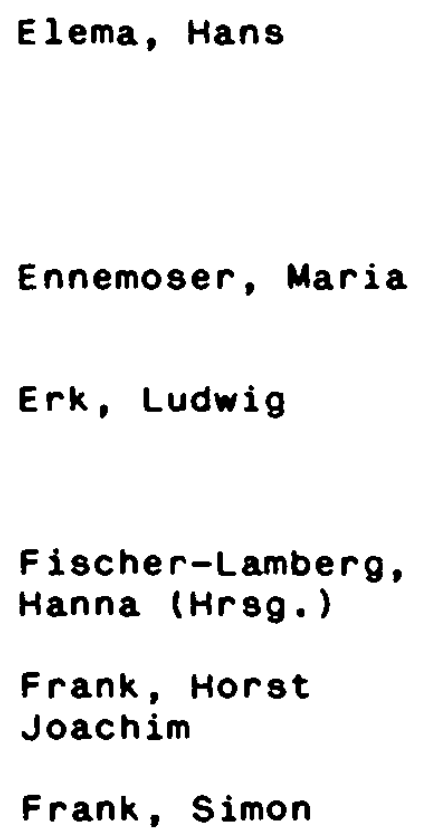

in russischer Übertragung. Hrsg. M. Hellmann. Weimar 1948 .

Von Jacob Grimm und wilhelm Grimm. 16 Bde. und 1 Quellenverzeichnis. Leipzig 1854-1971.

des Auteurs français. Paris 1961 (Collection Seghers).

Tiutcheff, premier symboliste russe. In: Langue et Littérature. Actes du VIIIe Congrès de la Fédération Internationale des Langues et Littératures Modernes. Paris 1961.

Zukovskij i Gete. In: Literaturnoe Nasledstvo 4-6. Moskau 1932. S. 324-373.

V.A. Joukovski et le préromantisme russe. Paris 1938.

Žukovskij als Ubersetzer. Drei stugien zu Übersetzungen $V$.A. Zukovskijs aus dem Deutschen und Französischen. München 1970 (FS 29).

Zur Interpretation von Goethes "An den Mond". In: Ders., Imaginäres Zentrum. Studien zur deutschen Literatur. Assen (Niederlande) 1968. S. 124-145.

Goethes magische Balladen. Diss. Munster 1939.

Deutscher Liederhort. Neubearb. u. fortges. von F.M. Böhme. Bd. 2. Leipzig 1893.

Der Junge Goethe. 5 Bde. und 1 Registerband. Berlin 1963-1974.

Handbuch der deutschen Strophenformen. München 1980.

Das kosmische Gefühl in Tjutčevs Dichtung. In: ZfslPh $3(1926)$. S. 20-58. 
Friedenthal, Richard

Gerhardt, Dietrich

Gižickij, Adrian

Glinka, Fedor NikolaeviC

Gorlin, M.

Grenzmann, wilhelm

Gronicka, André von

Gudzij, N.K.
Goethe. Sein Leben und sein Werk. Frankfurt a.M. - Berlin - Wien 1978.

Aus deutschen Erinnerungen an Zukovskij. In: Orbis scriptus. 0 . TschiYewskij zum 70.Geburtstag. München 1966. S. 245-313.

Eigene und ubersetzte deutsche Gedichte Zukovskijs. In: Gorski Vijenac. A Garland of Essays offered to Professor Elizabeth Mary Hill. Cambridge 1970. S. 118-154.

Faust und die Folgen. V.A. Zukovskijs Aufsatz "Zwei Szenen aus Faust". In: Mnemozina. Studia litteraria Russica in honorem Veevolod Setchkarev. Hrsg. J.Th. Baer und N.W. Ingham. München 1974 (Centrifuga 15). S. 130-152.

V.A. Zukovskij i rannie nemeckie romantiki. In: RLit 22 (1979) $\mathrm{Nr}$. 1. S. 120-128.

Izbrannye proizvedenija. Hrsg. V.G. Bazanov. BBP. Leningrad 1957.

Goethe in RuBland. In: ZfslPh 9 (1932), S. 335-357; ZfslPh 10 $(1933)$, S. 310-334.

Johann Wolfgang Goethe. Der Sänger. In: Wege zum Gedicht. Bd. 2. München - Zürich 1964. S. 169-175.

Fedor Iwanowitsch Tiutschew und Goethe. In: Literatur und Geistesgeschichte. Festgabe für Heinz Otto Burger. Hrsg. R. Grimm und C. wiedermann. Berlin 1968. S. 422432. Im Text zitiert: Tiutschew und Goethe.

The Russian Image of Goethe. Goethe in the Russian Literature of the First Half of the Nineteenth Century. Philadelphia 1968. Im Text zitiert: The Russian Image of Goethe.

Tjutčev v poètičeskoj kul'ture russkogo simvolizma. In: Izvestija po russkomu jazyku i slovesnosti Bd. 3. Buch 2. Leningrad 1930. S. 465549 . 
Gutman, D.S.

Hammer-Purgstall, Josef von

Hefele, Hermann

Herder, Johann Gottfried

Heusler, Andreas

Hinck, Walter

Holzheid, Sieglinde

Ihekweazu, Edith

Ivanov, Vjačeslav

(Iwanow, W.)
Jagoditsch, Rudolf
Turgenev i Gete. $K$ voprosu ob ocenke Turgenevym mirovozzrenija i tvortestva Gete. In: Učen. zap. Elabužskogo ped. in-ta. Bd. 5 (1959). S. 149-183.

Der Diwan von Mohammed Schemseddin-Hafis. Aus dem Persischen zum erstenmal ganz übersetzt von josef von Hammer. 2 Bde. Stuttgart und Tübingen 1812-1813.

Geschichte und Gestalt. Leipzig 1940.

Sämmtliche Werke. Hrsg. Bernhard Suphan. 33 Bde. Berlin 1877-1909.

Goethes Verskunst. In: Kleine Schriften. Bd. 1. Berlin 1943. ND Berlin 1969. S. 462-482.

Die deutsche Ballade von Bürger bis Brecht. Gbttingen 1972.

Goethes Ballade "Der untreue Knabe". Zur Geschichte der siebenzelligen Strophe in mittelalterlicher und neverer deutscher Lyrik. In: Euphorion $56(1962)$. S. 25-47.

Rezension zu: H. Eichstäd, Zukovskij als Übersetzer. Drei Studien zu übersetzungen $V$.A. Zukovskijs aus dem Deutschen und Franzobischen. München 1970 (FS Bd. 29). In: WdSI $1(1972)$. S. 244247.

Goethes West-östlicher Divan. Untersuchungen zur Struktur des lyrischen Zyklus. Hamburg 1971.

Iskusstvo i Simvolizm. In: Ders., Borozdy i Meži. Moskau 1916. ND Ilkley, Yorks. 1971. Im Text zitiert: Iskusstvo i Simvolizm.

Zwei russische Gedichte auf Goethes Tod. In: Corona $4(1934)$. S. 697703.

Goethe und seine russischen Zeitgenossen. In: Germanoslavica 1 (19311932 ). S. 347-381. 
Jampol'skij, I.

Jones, Malcolm V.

Kämpchen, Paul

Ludwig

Kaiser, Bruno

Kaplinskij, V.Ja.

Karamzin, Nikolaj

Michajlovit

Kayser, Wolfgang

Kazanovið, E.P.

Kerkhoff, Emmy

Klein, Johannes

Klemperer, Victor

Klopstock, Friedrich Gottlieb

Kobilinski-Ellis, Leo
A.K. Tolstoj. In: A.K. Tolstoj, Stichotvorenija. Car' Fedor Ioannovit. Hrsg. I. Jampol'skij. MBP. Leningrad 1952. S. 5-82.

Rezension zu: H. Eichstädt,
Zukovskij als übersetzer. Drei
Studien zu übersetzungen V.A.
Zukovskijs aus dem Deutschen und
Französischen. München 1970 (FS
Bd. 29). In: SEER 121 (1972). S.
$637-638$.

Die numinose Ballade. Bonn 1930 (Mnemosyne 4).

Über Beziehungen der deutschen und russischen Literatur. Berlin 1948.

Žukoyskij, kak perevodčik ballad. In: ŽMNP 1 (1915). S. 1-25.

Izbrannye solinenija $v$ dvuch tomach. Moskau - Leningrad 1964.

Geschichte der deutschen Ballade. Berlin 1936.

Iz mjunchenskich vstreč F.I. TjutČeva (1840-e gg). In: Uranija. TjutCevskij Al'manach 1803-1928. Leningrad 1928. S. 125-171.

Kleine deutsche stilistik. Bern und München 1962.

Geschichte der deutschen Lyrik. Von Luther bis zum Ausgang des Zweiten Weltkrieges. Wiesbaden 1957.

Romantik und französische Romantik. In: Idealistische Neuphilologie, Festschrift für Karl Vossler. Heidelberg 1922. ND in H. Prang (Hrsg.), Begriffsbestimmung der Romantik. Darmstadt 1968 (wege der Forschung 8d. 150). S. 48-72.

Ausgewählte Werke. Hrsg. Karl August Schleiden. München 1962.

W.A. Joukowski. Seine Persönlichkeit, sein Leben und sein Werk. Paderborn 1933. 
Koller, Werner

Kommere 11, Max

Kopelew, Lew

Kratkij slovar'

Küenzlen, Karin

Kulę̌r, V.I.

Laufhüte, Helmut

Lehmann, Jürgen

Lessing, Gotthold Ephraim

Lettenbaver, Wilhelm

Levik, Vil'gel'm

Leví, Jǐrí
Einführung in die übersetzungswissenschaft. Heidelberg 1983 (UTB $819)$.

Gedanken uber Gedichte. Frankfurt a.M. 1943.

Faust in Rubland. In: Ders., Zwei Epochen deutsch-russischer Kulturbeziehungen. Frankfurt a.M. 1973. S. 47-93.

literaturovedteskich terminov. Hrsg. L.I. Timofeev und S.V. Turaev. Moskau 1978.

Deutsche übersetzer und deutsche Übersetzungen Lermontovscher Gedichte von 1841 bis zur Gegenwart: Angaben über das Leben und das literarische wirken der übersetzer und Versuch einer kritischen Beurteilung ihrer übertragungen. Diss. Tübingen 1980 .

Literaturnye svjazi Rossii i zapadnoJ Evropy $v$ XIX veke. Moskau 1965.

Die deutsche Kunstballade. Grundlegung einer Gattungsgeschichte. Heidelberg 1979 (Beiträge zur neveren Literaturgeschichte folge 3 , Bd. 43).

Rezension zu: I.M. Semenko, Žizn' i poezija Zukovskogo. Moskau 1975. In: Krit Litt 1976/4. S. 291-293.

Werke. 8 Bde. München 1970-1979.

Der russische Dichter Fjodor Tjutschev und München. In: Monachium. Hrsg. A.W. Ziegler. München 1958. S. 199-211.

Izbrannye perevody. Bd. 1. Moskau 1977 .

Umění překladu. Prag 1963. Deutsche Übersetzung von Walter Schamschula: Die literarische übersetzung. Theorie einer Kunstgattung. Frankfurt a.M. 1969. 
Lohner, Edgar

Mathesius, Vilém

McMillin, Arnold B.

Me J, Lev Aleksandrovit

Meyer, Hermann

Moðul'skij, K.

Muiller, Friedrich von

Neumann, Friedrich Wilhelm

Ostolopor, Nikolaj F. (Hrsg.)

Petersen, Julius
Einleitung. In: Ders. (Hrsg.), Interpretationen zum West-Östlichen Divan Goethes. Darmstadt 1973 (Wege der Forschung Bd. 288). S. VII-XVII.

- problémech Zeského prekladatelství. In: PFenled 11 (1913).

Rezension zu: B. Zelinsky, Russische Romantik. Köln - Wien 1975 (Slavistische Forschungen Bd. 15). In: SEER 55 (1977). Nr. 2. S. 237-240.

Izbrannye proizvedenija. Hrsg. K.K. Buchmejer. BBP. Leningrad 1972.

Mignons Italienlied und das Wesen der Verseinlagen im "Wilhelm Meister". Versuch einer gegenständlichen Polemik. In: Euphorion 46 (1952). S. 149-169.

Rezension zu: L. Kobilinski-Ellis, W.A. Joukowski. Seine Persönlichkeit, sein Leben und sein Werk. Paderborn 1933. In: Put' 45 (1934). S. 79-80.

Briefe des Kanzlers Friedrich von Muiller an Wasily Andrejewitsch Joukovsky. Hrsg. A.v. Schorn. In: Deutsche Rundschau 120 (1904). Nr. 3. S. 277-287.

Goethes Unterhaltungen mit dem Kanzler Friedrich von Muller. Hrsg. C.A.H. Burkhardt. Stuttgart 1870. Im Text zitiert: Kanzler v. Mulller.

Geschichte der russischen Ballade. Königsberg (Pr.) - Berlin 1937 (Schriften der Albertus-Universität Bd. 15).

Slovar drevnej i novoj poezil. 3 Bde. St. Petersburg 1821. ND Muinchen 1971 (Slavische Propyläen 113).

Die Wesensbestimmung der deutschen Romantik. Eine Einführung in die moderne Literaturwissenschaft. Leipzig 1926. 
Pigarev, Kirill

Pletnev, Petr Aleksandrovit

Pogodin, A.

Pohl, Wilma

Pokrovskij, vladimir Ivanovit (Hrsg.)

Polevoj, Nikolaj Aleksandrovic

Prang, Helmut (Hrsg.)

Pumpjanskij, L.V.
Čto perevodil Tjutčev. ( $K$ voprosu - trorčestre TjutZeva - perevodŻika). In: Zven'ja 3-4 (1934). S. 245-262. Im Text zitiert: Cto perevodil Tjuťev.

F.I. TjutZev i ego vremja. Moskau 1978. Im Text zitiert als: TjutKev.

Tjutter - perevodZik Gete. In: Uranija. Tjuttevskij Al'manach 18031928. Leningrad 1928. S. 85-113. Im Text zitiert: Tjuttev perevodtik Gete.

Opyt Russkoj Antologii. Hrsg. Michail Luk'janovit Jakovlev. St. Petersburg 1828.

Solinenija i perepiska. Hrsg. Ja. Grot. 3 Bde. St. Petersburg 1885. Im Text zitiert: Sočinenija i perepiska.

Goethe in RuBland. In: Germanoslavica $1(1931-32)$. S. 333-347.

Russische Faust-Übersetzungen. Meisenheim am Glan 1962. Zugl. Dis8. Munster (Slavisch-Baltisches Seminar der Westfälischen Wilhelms-Universität Munster. Veröffentlichung $\mathrm{Nr}$. 5).

Vasilij Andreevit Zukovskij. Ego Zizn' i sotinenija. Sbornik istoriko-literaturnych statej. Moskau 1912.

OČerki russkoj literatury. Bd. 1. St. Petersburg 1839.

Begriffobestimmung der Romantik. Darmstadt 1968 (Wege der Forschung Bd. 150). Im Text zitiert: Romantik.

Formgeschichte der Dichtkunst. Stuttgart - Berlin - Köln - Mainz 1968.

Poèzija Tjutčeva. In: Uranija. Tjutčevskij Al'manch 1803-1928. Leningrad 1928. S. 9-57. 
Puškin, Aleksandr Sergeevit

Rehm, Walther

Reissner, Eberhard

Reutern, Gerhardt von

Richter, Peter

Roos, Carl

Ross, Werner

Russische Lyrik

Russkie pisatelio perevode

Rychner, Max

S., v.

Šatalov, S.E.

Schenk, Hans Georg
Polnoe sobranie sotinenij $v$ desjati tomach. Moskau - Leningrad 1949.

Der Todesgedanke in der deutschen Dichtung vom Mittelalter bis zur Romantik. Darmstadt 1967.

Zukovskij und Gray. In: ZfSl 17 (1972) 4. S. 504-514.

Ein Lebensbild, dargestellt von seinen Kindern. St. Petersburg 1894.

Rezension zu: H. Eichstädt, Zukovskij als übersetzer. Drei Ştudien zu übersetzungen $V$.A. Zukovskijs aus dem Deutschen und Französischen. München 1970 (FS Bd. 29). In: Krit Litt 1972/1. S. 76-77.

Faustproblemer. Kobenhavn 1941.

Johann Wolfgang Goethe. Es war ein König in Thule. In: Wege zum Gedicht. Bd. 2. München - Zürich 1964. s. 147-153.

Von den Anfängen bis zur Gegenwart. Deutsch/Russisch. Hrsg. Kay Borowsky und Ludolf Muller. Stuttgart 1983.

Hrsg. Ju, Levin und A.V. Fedorov. Leningrad 1960.

Antworten. Aufsätze zur Literatur. zurich 1961.

Rezension der 1. Aufl. yon 1904 zU: A.N. YeselovskiJ, V.A. Zukovskif. Poézija čuvstva i "serdečnogo voobraženija". Petrograd 1918. In: Vesy 1/10 (1904). S. 71-72.

Romantizm Žukovskogo. In: Istorija romantizma $v$ russkol literature. Vozniknovenie i utverždenie romantizma $v$ russkoj literature (17901825). Moskau 1979. S. 110-144.

Geist der europäischen Romantik. Ein kulturhistorischer Versuch. Frankfurt a.M. 1970. 
Schneider, Hildegard

Schulz, Gisela

Schulze, Almut

Seidlitz, Carl von

Semenko, Irina Michajlovna

Ševyrev, Stepan P.

Silz, Walter

Staiger, Emil

Steffensen, steffen

Stelliferovskij, P.

Storz, Gerhard

Strich, Fritz

Suchanek, LucJan
Der frühe Bal'mont. Untersuchungen zu seiner Metaphorik. Muinchen 1970 (FS Bd. 16).

Zur Balladen- und Märchendichtung v.A. Zukovskijs. Diss. Konstanz 1972.

Tjuttevs Kurzlyrik. Traditionszusammenhänge und Interpretationen. München 1968 (FS Bd. 25).

Wasily Andrejewitsch Jouk offsky. Ein russisches Dichterleben. Mitau 1870 .

Žizn' I poèzija Zukkovskogo. Moskau 1975.

- značenii Žukovskogo $v$ russkoj zizni i poèzii. Moskau 1853.

Goethe: 'Der Wandrer'. In: Stoffe, Formen und Strukturen. Hans Heinrich Borcherdt 2 um 75 . Geburtstag. Mlinchen 1962. S. 139-150.

Goethe. 3 Bde. Zürich - Freiburg i. Br. 1952-1959.

"Der König in Thule". Bemerkungen zu den Elementen des Goetheschen Gedichts. In: Orbis litterarum 15 $(1960)$. S. 36-43.

"Ego stichor plenitel'naja sladost" ..." Rezension zu M.Ja. Bessarab, V.A. Zukorskij. Moskau 1975 und I.M. Semenko, Žizn' i poèzija Zukovskogo. Moskau 1975. In: VL 1977/1. S. 284-289.

Goethe-Vigilien. Stuttgart 1953.

Goethe und die Weltliteratur. Bern 1957.

Rezension zu: I.M. Semenko, Žizn' i poèzija Žukovskogo. Moskau 1975. In: Sl Or Nr. 3 (1976). S. 411-413. 
Tolstoj, LeV

Nikolaevič

Tschǐ̌ewskij,

Dmitri

(Čževikyj, D.)

(̄̌xyževíky\}, D.)

Veselovakij, Aleksandr NikolaeviC

Vol'pe, Cezar's.

Weitz, Hans-J. (Hrsg.)

Wellek, René

Wiegand, Julius

Wildbolz, Rudolf

Zajcev, Boris K.

Zamotin, I.I.
Polnoe sobranie sočinenij v 90 tomach. Moskau 1934-1953.

Rezension zu: K. Pigarev, Tjutčev - perevodik Gete. In: ZfslPh 7 $(1930)$. S. 459-467.

Russische Literaturgeschichte des 19. Jahrhunderts. 2 Bde. Munchen 1977 und 1967. Im Text zitiert: Literaturgeschichte.

Tjutčev und die deutsche Romantik. In: ZfslPh 4 (1927). S. 299-323.

V.A. Zukovskij. Poézija Zuvstra i "serdečnogo voobraženija". Petrograd 1918.

V.A. Žukovekij. In: Istorija russkoj literatury. Bd. 5. Moskau - Leningrad 1941. S. 355-391. Im Text zitiert: Istorija.

V.A. Žukovskij. In: V.A. Žukorskij, Stichotvorenija. Hrsg. C.S. Vol'pe. 2 Bde. BBP. Leningrad 1939-1940. Hier Bd. 1. S. V-XLVIII.

Johann Wolfgang Goethe, West-östlicher Divan. Mit Essays zum "Divan" von Hugo von Hofmannsthal, Oskar Loerke und Karl Krolow. Mit Erlauterungen versehen von Hans-J. Weitz. Frankfurt a.M. 1974.

Konfrontationen. Vergleichende studien zur Romantik. Frankfurt a.M. 1964.

Art. Epigramm. In: RL Bd. $1 . S$. 374-379.

Art. Kunstballade. In: RL Bd. 1. S. 902-909.

Žukovskij. Paris 1951.

Romantizm dvadcatych godov XIX stoletija $v$ russkoj literature. 2 Bde. 2. Aufl. Petersburg - Moskau 19111913. 
Zelinsky, 8odo

Russische Romantik. Köln - wien 1975 (Slavistische Forschungen Bd. 15).

Ziegengeist, Gerhard

Varnhagen von Ense und V.A. Zukovskij. In: ZfSI 4 (1959). S. 1-14.

Žirmunskij, V.M.

Gete $v$ russkoj literature. Leningrad 1981. Im Text zitiert: Literatura.

Gete $v$ russkoj poèzil. In: Literaturnoe Nasledstvo 4-6. Moskau 1932. S. 505-650. Im Text zitiert: Poézija.

Sravnitel'noe literaturovedenie. Leningrad 1979. Im Text zitiert: Literaturovedenie. 


\section{SLAVISTISCHE BEITRAGE}

150. Deppermann, M.: Andrej Belyjs ästhetische Theorie des schöpferischen BewuBtseins. Symbolisierung und Krise der Kultur un die Jahrhundertwende. 1982. X, $256 \mathrm{~S}$.

151. Meichel, J.: Zur Entfremdungs- und Identitatsproblematik in der Sowjetprosa der 60er und 70er Jahre. Eine literatursoziologische Untersuchung. 1981. $217 \mathrm{~s}$.

152. Davydov, S.: "Teksty-Matres̄ki" Vladimira Nabokova. 1982. VI, 252 S.

153. Wallrafen, C.: Maksimilian Volos̄in als Künstler und Kritiker. 1982. IV, $273 \mathrm{~S}$.

154. Dienes, L.: Russian Literature in Exile: The Life and Work of Gajto Gazdanov. 1982. XII, 224 S., 7 Abb.

155. Bulgarien 1300. Referate der Sektion "Sprache und Literatur" des Symposiums "Bulgarien in Geschichte und Gegenwart", Hamburg 9.-17. Mai 1981. Herausgegeben von Peter Hill. 1982. $97 \mathrm{~S}$.

156. Bock, I.: Die Analyse der Handlungsstrukturen von Erzăhlwerken am Beispiel von N.V. Gogol's "Die Nase" und "Der Mantel". 1982. VIII, $168 \mathrm{~s}$.

157. Pihler, M.: Die, Progressive' Form des englischen Verbs und ihre Ubersetzungsmoglichkeiten im Slowenischen. 1982. $170 \mathrm{~s}$.

158. Sesterhenn, R.: Das Bogostroitel'stvo bei Gor'kij und Lunačarskij bis 1909. Zur ideologischen und literarischen Vorgeschichte der Parteischule von Capri. 1982. VIII, $366 \mathrm{~S}$.

159. Kunstmann, H.: Vorlaufige Untersuchungen uber den bairischen Bulgarenmord von $631 / 632$. Der Tatbestand. Nachklänge im Nibelungenlied. 1982. $104 \mathrm{~S}$.

160. Slavistische Linguistik 1981. Referate des VII. Konstanzer Slavistischen Arbeitstreffens Mainz 30.9.-2.10.1981. Herausgegeben von Wolfgang Girke. 1982. $264 \mathrm{~S}$.

161. Stobbe, P.: Utopisches Denken bei V. Chlebnikov. 1982. VIII, $157 \mathrm{~S}$.

162. Neureiter, F.: Weibrussische Anthologie. Ein Lesebuch zur weibrussischen Literatur (mit deutschen Ubersetzungen). 1983. $230 \mathrm{~s}$.

163. Witte, G.: Die sowjetische Kolchos- und Dorfprosa der funfziger Jahre. Zur Evolution einer literarischen Unterreihe. 1983. X, 292 S.

164. Timroth, W.v.: Russische und sowjetische Soziolinguistik und tabuisierte Varietăten des Russischen. 1983. VIII, $194 \mathrm{~s}$.

165. Christians, D.: Die Sprachrubrik in der Literaturnaja gazeta von 1964 bis 1978. Dokumentation und Auswertung. 1983. 266 S.

166. Koschmal, W.: Das poetische System der Dramen I.S. Turgenevs. Studien zu einer pragmatischen Dramenanalyse. 1983. X, $453 \mathrm{~S}$. 
167. Hofmann, T.: Das Bauerntum in der sowjetrussischen Prosa der 20er Jahre. Konzeptionen, Konflikte und Figuren. 1983. $434 \mathrm{~S}$.

168. Morsbach, P.: Isaak Babel' auf der sowjetischen Bühne. 1983. $\mathrm{X}, 255 \mathrm{~S}$.

169. Tutschke, G.: Die glagolitische Druckerei von Rijeka und ihr historiographisches Werk Knizice od zitié rimskih arhierëov i cesarov. 1983. $373 \mathrm{~S}$.

170. Lam, A.: Mainzer Vorlesungen uber die polnische Literatur seit 1918. 1983. IV, $280 \mathrm{~S}$.

171. Pratt, S.: The Semantics of Chaos in Tjutčev. 1983. VIII, $149 \mathrm{~S}$.

172. Slavistische Linguistik 1982. Referate des VIII. Konstanzer Slavistischen Arbeitstreffens Kiel 28.9. - 1.10.1982. Herausgegeben von Hans Robert Mehlig. 1983. $262 \mathrm{~S}$.

173. Dingley, J.: The Peripheral Plural Endings of Nouns in Petrine Sermons. 1983. VIII, $388 \mathrm{~S}$.

174. Hoelscher-Obermaler, H.-P.: Das lyrische Werk Antoni Langes. Untersuchungen zur Dichtungssprache eines , jungpolnischen' Autors. 1983. $127 \mathrm{~s}$.

175. Bojit, V., w. Oschlies: Lehrbuch der mazedonischen Sprache. $1984.185 \mathrm{~S}$.

176. Roedel-Kappl, C.: Analogie und Sprachwandel im Vergleich zweier verwandter Sprachen: Russisch und Polnisch. 1984. $\mathrm{X}, 246 \mathrm{~s}$.

177. Kattein, R.: Die Pronominalsysteme der slavischen Sprachen. 1984. IV, 142 S.

178. Wust, H.: Tradition und Innovation in der sowjetrussischen Dorfprosa der sechilger und siebziger Jahre. zu Funktion, Darstellung und Gehalt des dörflichen Helden bei Vasilij Sukšin und Valentin Rasputin. 1984. VIII, $249 \mathrm{~S}$.

179. Vogl, J.: Das Frühwerk Valentin P. Kataevs. 1984. VIII, $197 \mathrm{~S}$.

180. Aspekte der Slavistik. Festschrift für Josef Schrenk. Herausgegeben von Wolfgang Girke und Helmut Jachnow. 1984. $270 \mathrm{~s}$.

181. Slavistische Linguistik 1983. Referate des IX. Konstanzer Slavistischen Arbeitstreffens München 27. mit 29.9.1983. Herausgegeben von Peter Rehder. 1984. $282 \mathrm{~S}$.

182. Penzkofer, G.: Der Bedeutungsaufbau in den späten Erzählungen Cechovs. "Offenes" und "geschlossenes" Erzählen. 1984. $367 \mathrm{~s}$.

183. Kammer, G.: Probleme bei der Ubersetzung von phraseologischen Einheiten aus dem Russischen ins Deutsche (anhand von Werken V.F. Panovas). 1985. VIII, 223, XXV S.

184. Slavistische Linguistik 1984. Referate des $X$. Konstanzer Slavistischen Arbeitstreffens Konstanz 11. mit 14.9.1984. Herausgegeben von Werner Lehfeldt. 1985. $359 \mathrm{~S}$.

185. Kahlenborn, $U_{.}:$Goethes Lyrik in russischer Ubersetzung. V.A. Zukovskij und F.I. Tjutčev als bedeutendste Goethe-Ubersetzer der russischen Romantik. 1985. XIV, $309 \mathrm{~S}$. 